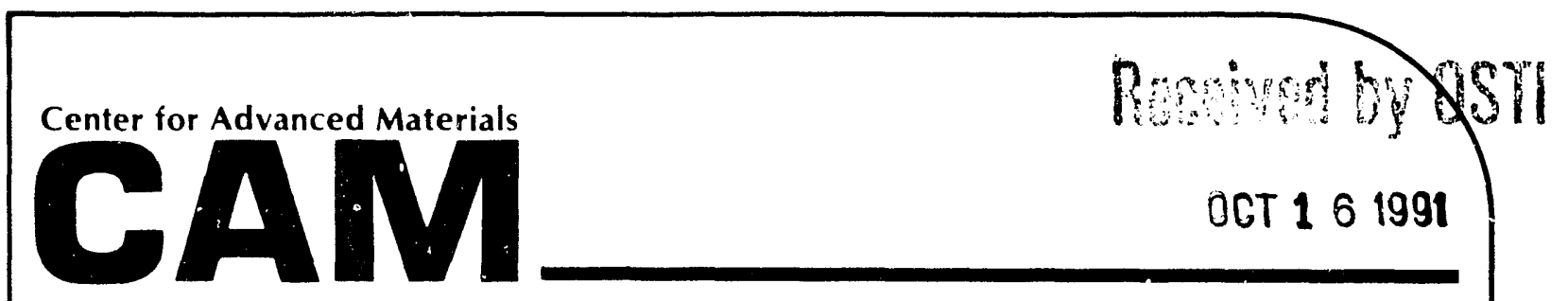

Design, Microstructure, and High-Temperature Behavior of Silicon Nitride Sintered with Rare-Earth Oxides

M.K. Cinibulk

(Ph.D. Thesis)

August 1991

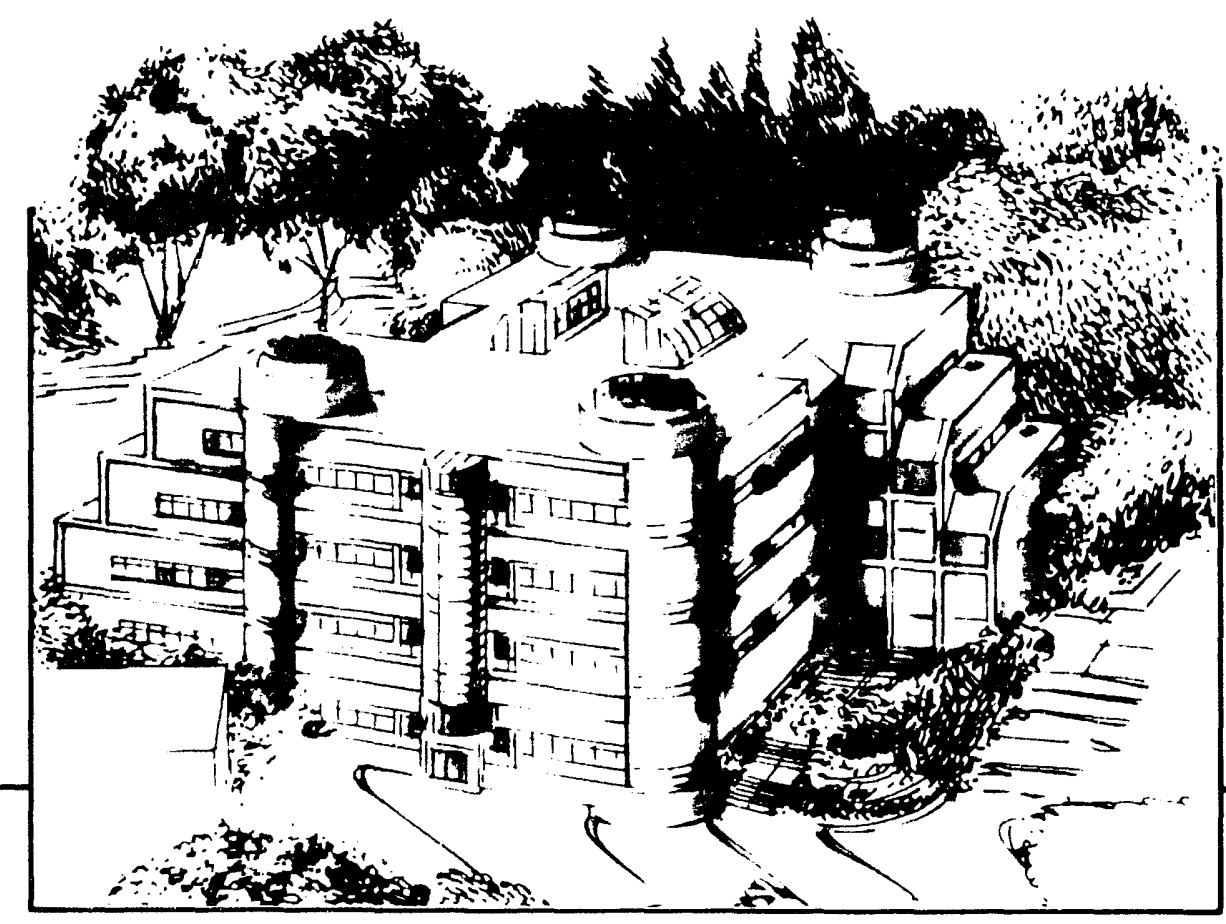

Materials and Chemical Sciences Division

Lawrence Berkeley Laboratory - University of California

ONE CYCLOTRON ROAD, BERKELEY, CA 94720 •(415) 486-4755 


\section{DISCLAIMER}

This document was prepared as an account of work sponsored by the United States Government. Neither the United States Government nor any agency thereof, nor The Regents of the University of California, nor any of their employees, makes any warranty, express or implied, or assumes any legal 'sability or responsibility for the accuracy, completeness, or usefuliess of any information, apparatus, product, or process disclosed, or represents that its use would not infringe privately owned rights. Reference herein to any specific commercial product, process, or service by its trade name, trademark, manufacturer, or otherwise, does not necessarily constitute or imply its endorsement, recommendation, or favoring by the United States Government or any agency thereof, or The Regents of the University of California. The views and opinions of authors expressed herein do not necessarily state or reflect those of the United States Government or any agency thereof or The Regents of the University of California and shall not be used for advertising or product endorsement purposes.

Lawrence Berkeley Laboratory is an equal opportunity employer. 


\title{
DESIGN, MICROSTRUCTURE, AND HIGH-TEMPERATURE BEHAVIOR OF SILICON NITRIDE SINTERED WITH
}

\section{RARE-EARTH OXIDES}

\author{
Michael K. Cinibulk \\ Ph.D. Dissertation \\ Materials Science and Engineering \\ University of California at Berkeley
}

August 1991

Initially supported by the National Science Foundation under Contract No. DMR 831317239. Additional support was provided by the Director, Office of Energy Research, Office of Basic Energy Sciences, Materials Sciences Division of the U.S. Department of Energy under Contract No. DE-AC03-76SF00098. Additioral facilities were provided by SRI Intermational. 
Design, Microstructure, and High-Temperature Behavior of

Silicun Nitride Sintered with Rare-Earth Oxides

by

Michael Klaus Cinibulk

\begin{abstract}
The processing-microstructure-property relations of silicon nitride ceramics sintered with rare-earth oxide additives have been investigated with the aim of improving their hightemperature behavior. The additions of the oxides of $\mathrm{Y}, \mathrm{Sm}, \mathrm{Gd}, \mathrm{Dy}, \mathrm{Er}$, or $\mathrm{Yb}$ were compositionaily controlled to tailor the intergranular phase. The resulting microstructure consisted of $\beta-\mathrm{Si}_{3} \mathrm{~N}_{4}$ grains and a crystalline secondary phase of $\mathrm{RE}_{2} \mathrm{Si}_{2} \mathrm{O}_{7}$, with a thin residual amorphous phase present at grain boundaries.

The lanthanide oxides were found to be as effective as $\mathrm{Y}_{2} \mathrm{O}_{3}$ in densifying $\mathrm{Si}_{3} \mathrm{~N}_{4}$, resulting in identical microstructures. The crystallization behavior of all six disilicates was similar, characterized by a limited nucleation and rapid growth mechanism resulting in large single crystals. Complete crystallization of the intergranular phase was obtained with the exception of a residual amorphous, observed at interfaces and believed to be rich in impurities, the cause of incomplete devirrification.

The low resistance to oxidation of these materials was attributed to the minimization of amorphous phases via devirrification to disilicates, compatible with $\mathrm{SiO}_{2}$, the oxidation product of $\mathrm{Si}_{3} \mathrm{~N}_{4}$. During oxidation $\mathrm{RE}_{2} \mathrm{Si}_{2} \mathrm{O}_{7}$ grew out of the surface silicate in preferred orientations that were dictated by crystal structure.
\end{abstract}


The strength retention of these materials at $1300^{\circ} \mathrm{C}$ was found to be between $80 \%$ and $91 \%$ of room-temperature strength, due to crystallization of the secundary phase and a residual but refractory amorphous grain-boundary phase. The creep behavior was found to be strongly dependent on residual amorphous phase viscosity as well as on the oxidation behavior, as evidenced by the nonsteady-state creep rates of all materials. As oxidation proceeds there is a purifying effect on the residual amorphous phase due to impurity diffusion to the surface, resulting in higher viscosity glasses and destabilized glasses that may further devitrify. All of the rare-earth oxide sintered materials, with the exception of $\mathrm{Sm}_{2} \mathrm{Si}_{2} \mathrm{O}_{7}-\mathrm{Si}_{3} \mathrm{~N}_{4}$, had lower creep strains than the $\mathrm{Y}_{2} \mathrm{Si}_{2} \mathrm{O}_{7}-\mathrm{Si}_{3} \mathrm{~N}_{4}$ material.

Deformation was found to proceed by grain-boundary cavitation. Cavities nucleate at the thin amorphous films between $\mathrm{RE}_{2} \mathrm{Si}_{2} \mathrm{O}_{7}-\mathrm{Si}_{3} \mathrm{~N}_{4}$ and $\mathrm{Si}_{3} \mathrm{~N}_{4}-\mathrm{Si}_{3} \mathrm{~N}_{4}$ grains. A diffusive mass transport mechanism results in cavity growth and loss of $\mathrm{RE}_{2} \mathrm{Si}_{2} \mathrm{O}_{7}$.

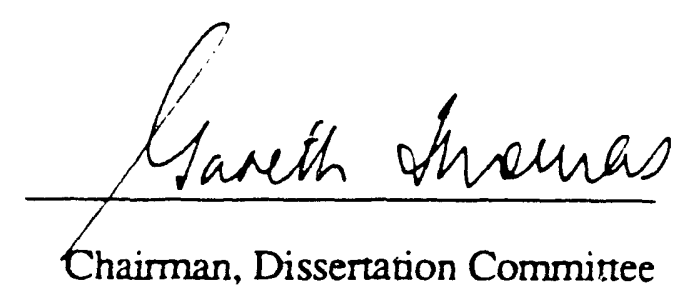




\section{ACKNOWLEDGMENTS}

I thank Prof. Gareth Thomas for the support and encouragement that I received during my stay at Berkeley. Thanks to Profs. Lut De Jonghe and Iain Finnie for reviewing the draft. Thanks to Prof. Alan Searcy for help in determining oxidation mechanisms. Thanks to Ron Wilson for assistance with SEM and microanalysis. I also thank the members of our research group for valued scientific advice and technical assistance.

The support of SRI International, where ali processing and mechanical evaluation of these materials was performed is appreciated. Special thanks to Dr. Sylvia Johnson for taking an active interest in this work. Thanks to all the staff of the Materials Research Laboratory. I especially thank George Craig for machining all test specimens.

I thank Dr. John Porter of The Science Center, Rockwell International for sharing the designs of his high-temperature creep appararus.

Finally I thank my family for their support and encouragement.

This work was initially supported by the National Science Foundation under Contract No. DMR 83-1317239. Additional support was provided by the Director, Office of Energy Research, Office of Basic Energy Sciences, Materials Sciences Division of the U.S. Department of Energy under Contract No. DE-AC03-76SF00098. Additional facilities were provided by SRI Liternational. 


\section{CONTENTS}

I. INTRODUCTION

A. SILICON NITRIDE CERAMICS 1

B. PROCESSING SILICON NITRIDE 3

C. THE $\mathrm{Si}_{3} \mathrm{~N}_{4}-\mathrm{SiO}_{2}-\mathrm{RE}_{2} \mathrm{O}_{3}$ SYSTEM

D. SUMMARY OF PRIOR WORK

E. PURPOSE AND OBJECTIVES OF THIS RESEARCH 8

II. EXPERIMENTAL PROCEDURES 10

A. MATERIAL FABRICATION 10

1. Microstructural Design 10

2. Silicon Nitride Processing 11

B. CHARACTERIZATION TECHNIQUES 14

1. X-ray Diffraction 14

2. Light Microscopy 14

3. Scanning Electron Microscopy 15

4. Transmission Electron Microscopy 15

C. HIGH-TEMPERATURE BEHAVIOR EVALUATION 16

1. Oxidation Behavior 16

2. Flexural Strength 17

3. Time-Dependent Creep 18

III. RESULTS 20

A. SILICON NITRIDE PROCESSING 20

B. MICROSTRUCTURAL CHARACTERIZATION 21

1. X-ray Diffraction of Bulk Materials 21 
2. Transmission Electron Microscopy of Bulk Microstructures 22

a. General Morphology 22

b. Secondary-Phase Characterization 22

C. HIGH-TEMPERATURE BEHAVIOR 27

1. Oxidation Behavior $\quad 27$

a. Oxidation Kinetics $\quad 27$

b. Microstructure of Oxidized Surfaces 29

2. Fracture Behavior 31

a. Flexural Strength 31

b. Fractography 33

3. Time-Dependent Deformation Behavior 34

a. Flexural Creep $\quad 34$

b. Microstructures Following Creep $\quad 36$

IV. DISCUSSION 39

A. MICROSTRUCTURAL EVOLUTION DURING PROCESSING 39

1. Crystallization of the Intergranular Phase 39

2. Crystallization of $\mathrm{RE}_{2} \mathrm{Si}_{2} \mathrm{O}_{7}$ as a Secondary Phase 41

B. MICROSTRUCTURAL EVOLUTION DURING OXIDATION 42

1. Mechanism of Silicon Nitride Oxidation 42

2. Morphology of Oxidized Surfaces 46

C. INFLUENCE OF MICROSTRUCTURE ON MECHANICAL BEHAVIOR 49

1. Dependence of Strength on Inhomogeneities 49

2. Mechanism of Time-Dependent Creep 51

3. Oxidation Effects on Creep Behavior 53

D. ALTERNATTVE SECONDARY PHASES 55

V. CONCLUSIONS 58 
APPENDIX

Analysis of Stresses and Strains in Flexural Creep

REFERENCES

67

TABLES

75

FIGURES

85 


\section{INTRODUCTION}

\section{A. SILICON NITRIDE CERAMICS}

Silicon nitride ceramics are currently being considered for use as structural components in high-temperature oxidizing environments. The covalent nature of the silicon-nitrogen bond is responsible for the attractive thermal, chemical, and mechanical properties of silicon nitride, shown in Table $\mathrm{I}^{1-3}$ The combination of low thermal expansion $\left(-3 \times 10^{-6{ }^{\circ}} \mathrm{C}^{-1}\right)$ with moderate thermal conductivity $\left(20-50 \mathrm{~W} / \mathrm{m} \cdot{ }^{\circ} \mathrm{C}\right)$ and high fracture toughness (4-11 $\mathrm{MPa}$ ) provide silicon nitride with excellent thermal shock resistance. This high resistance to thermal shock, along with high strength, high fracture toughness, and high resistance to chemical attack makes silicon nitride a suitable material for components operating under extreme conditions. In the automotive industry, for example, sintered $\mathrm{Si}_{3} \mathrm{~N}_{4}$ is a leading candidate material for mocing metallic components in conventional internal combustion engines ${ }^{4}$ as well as for components comprising the hottest sections in advanced gas turbine engines ${ }^{5}$ where high-temperature resistance and/or wear resistance is critical. In these applications, the thermomechanical response of the ceramic to external forces depends on the microstructure, in particular on the refractoriness and chemical activity of the phases that make up the ceramic. Most high-temperature structural ceramics consist of highly refractory grains bonded by a less refractory vitreous phase. Therefore, the high-temperature behavior depends primarily on the composition, amount, and distribution of the intergranular phase within the ceramic structure.

Although it is the covalent nature of the silicon-nitrogen bond that is responsible for the high strength, hardness, and chemical stability of $\mathrm{Si}_{3} \mathrm{~N}_{4}$, this strong bonding also is responsible for the difficulties that are encountered during processing. The low selfdiffusivity of $\mathrm{Si}_{3} \mathrm{~N}_{4}{ }^{6}$ does not allow densification by classical solid-state sintering to 
proceed to completion. Since appreciable shrinkage of a powder compact can occur only when matter is transported to the surfaces of pores by bulk and grain-boundary diffusion, during the solid-state sintering of $\mathrm{Si}_{3} \mathrm{~N}_{4}$ there is little mass transport, and hence densification, by these mechanisms occuring at the firing temperature. However, during firing, surface diffusion and/or vapor-phase transfer (evaporation/condensation) cause the formation and growth of interparticle necking and particle coarsening. Therefore the lower activation energy non-densifying processes of evaporation/condensation and surface diffusion dominate bulk and grain-boundary diffusion, reducing the specific surface area and permitting little shrinkage to occur as a result of particle rearrangement.

Processing to obtain high density $\mathrm{Si}_{3} \mathrm{~N}_{4}$ requires the use of sintering aids to provide a medium for liquid-phase sintering. These sintering aids react with the everpresent oxide layer on the surface of $\mathrm{Si}_{3} \mathrm{~N}_{4}$ particles to form a eutectic liquid phase in which solutionreprecipitation of the $\mathrm{Si}_{3} \mathrm{~N}_{4}$ particles occurs. ${ }^{7,8}$ The resulting microstructure typically consists of $\beta-\mathrm{Si}_{3} \mathrm{~N}_{4}$ grains surrounded by a solidified liquid (amorphous) phase ${ }^{9-12}$, as shown in Fig. 1. It is this amorphous phase that can soften at temperatures above $-1000^{\circ} \mathrm{C}$ (Fig. 1), leadir.g to subcritical growth of inherent flaws in the material due to stressenhanced grain-boundary sliding at the crack tip. The rate of grain-boundary sliding at a given temperature is inversely related to the viscosity of the amorphous grain-boundary phase. The presence of impurities are also known to degrade both room-temperature strength by the formation of inclusions resulting in stress-concentrations, and hightemperature properties by reducing the viscosity of the intergranular amorphous phase. ${ }^{13}$ Attempts to improve the high-temperature strength of these materials by increasing the softening point and viscosity of the amorphous grain-boundary phase led to the substitution of $\mathrm{Y}_{2} \mathrm{O}_{3}$ or $\mathrm{Y}_{2} \mathrm{O}_{3}$ and $\mathrm{Al}_{2} \mathrm{O}_{3}$ for $\mathrm{MgO}$ as the most widely used sintering additives over the past ten years. ${ }^{14-21}$ Further improvements in high-temperature strength were realized by crystallizing the grain-boundary phase, with the aim of eliminating the softening point entirely. $22-28$ 


\section{B. PROCESSING SILICON NITRIDE}

To overcome the difficulties of sintering silicon nitride imposed by low solid-state sintering kinetics complete densification is achieved by sintering in the presence of a liquid. Sintering additives are used which form a liquid phase at the sintering temperature, providing an diffusion path for enhanced mass transport. The liquid-phase sintering of $\mathrm{Si}_{3} \mathrm{~N}_{4}$ can be described by Kingery's model ${ }^{7}$ as a solution-reprecipitation process. ${ }^{8}$ The first stage involves the reaction of the sintering additives with the oxide layer on the $\mathrm{Si}_{3} \mathrm{~N}_{4}$ particles to form a viscous liquid phase, in which impurities are incorporated. The second stage of densification proceeds by particle rearrangement induced by the capillary forces in the presence of the newly formed liquid. The third stage then involves a solutionreprecipitation mechanism where the $\alpha-\mathrm{Si}_{3} \mathrm{~N}_{4}$ particles dissolve into the liquid-phase, due to high solubility of material at the points of particle contact caused by high capillary pressures between particles and chemical potential differences between large and small particles, and reprecipitate out as $\beta-\mathrm{Si}_{3} \mathrm{~N}_{4}$. The densification rate of this stage is controlled by the diffusion of $\mathrm{Si}_{3} \mathrm{~N}_{4}$ through the liquid phase, which is ten times faster than selfdiffusion in $\mathrm{Si}_{3} \mathrm{~N}_{4}{ }^{6}$ This process results in a microstructure of a discontinuous matrix phase of $\beta-\mathrm{Si}_{3} \mathrm{~N}_{4}$ surrounded by a secondary phase composed of the liquid phase and incorporating additional silicon, nitrogen, oxygen, and any impurities originally present in the $\alpha-\mathrm{Si}_{3} \mathrm{~N}_{4}$ powder due the solution-reprecipitation process.

The morphology of the resulting microstructure depends greatly on the composition and viscosity of the liquid phase. Submicrometer $\mathrm{Si}_{3} \mathrm{~N}_{4}$ powders with a high fraction of the $\alpha$-phase are desirable since this phase is thermodynamically unstable and will transform into the stable $\beta$-phase at temperatures $21400^{\circ} \mathrm{C}$. This instability causes an enhancement of $\alpha-\mathrm{Si}_{3} \mathrm{~N}_{4}$ dissolution and therefore accelerates the densification process. If the starting powder contains a large number of $\beta$-particles, the fine particles dissolve due to their higher chemical potential. The dissolved $\mathrm{Si}_{3} \mathrm{~N}_{4}$ continuously precipitate on the coarser original $\beta$ - 
$\mathrm{Si}_{3} \mathrm{~N}_{4}$ particles under nearly equilibrium conditions in such a way as to minimize their surface energy, leading to large equiaxed $\beta-\mathrm{Si}_{3} \mathrm{~N}_{4}$ grains. ${ }^{29}$ If the starting powder contains a minimal concentration of $\beta-S_{3} N_{4}$ particles, a high superstaturation of $\mathrm{Si}_{3} \mathrm{~N}_{4}$ in the liquid phase is created, $r$ sulting in spontaneous nucleation and growth of elongated $\beta-\mathrm{Si}_{3} \mathrm{~N}_{4}$ grains far from thermodynamic equilibrium. Such a microstructure of fine columnar grains with high aspect ratios is desirable for ceramics with high strength and fracture toughness.

For an additive to be effective at sintering $\mathrm{Si}_{3} \mathrm{~N}_{4}$ it must meet certain thermudynamical requirements. ${ }^{30-32} \mathrm{Si}_{3} \mathrm{~N}_{4}$ must be soluble in the resulting liquid phase formed by reaction with the surface oxide present on the $\mathrm{Si}_{3} \mathrm{~N}_{4}$ particles, unless particle rearrangement provides complete densification which is generally not the case. Second, the liquid phase must wet the $\beta-\mathrm{Si}_{3} \mathrm{~N}_{4}$ grains (dihedral angle $\phi<120^{\circ}$ ), with complete wetting preferred $\left(\phi=0^{\circ}\right) . \mathrm{Si}_{3} \mathrm{~N}_{4}$ must be more thermodynamically stable than the nitride of the additive metal, while the oxide of the additive metal must be more stable than $\mathrm{SiO}$ and $\mathrm{SiO}_{2}$, the oxidation products of $\mathrm{Si}_{3} \mathrm{~N}_{4}$. The last two requirements must be met to avoid reactions between the additives and $\mathrm{Si}_{3} \mathrm{~N}_{4}$ such that $\mathrm{Si}_{3} \mathrm{~N}_{4}$ is not oxidized. Finally, the melting temperature of the pure additive should be greater than the sintering temperature.

The temperature at which liquid-phase sintering occurs is determined in part by the additives used. Most oxide sintering aids require temperatures of $1650-1900^{\circ} \mathrm{C}$ to obtain complete densification in the absence of applied stress; however, at temperatures above $1500^{\circ} \mathrm{C}$ under $0.1 \mathrm{MPa}$ (15 psig) $\mathrm{N}_{2} \mathrm{Si}_{3} \mathrm{~N}_{4}$ begins to decompose. 33 Three reactions have been proposed $33-35$ to account for the decomposition of $\mathrm{Si}_{3} \mathrm{~N}_{4}$ to volatile species:
1. Direct decomposition:
$\mathrm{Si}_{3} \mathrm{~N}_{4}(\mathrm{~s})=3 \mathrm{Si}(\mathrm{g})+2 \mathrm{~N}_{2}(\mathrm{~g})$
2. Active oxidation:
$\mathrm{Si}_{3} \mathrm{~N}_{4}(\mathrm{~s})+3 / 2 \mathrm{O}_{2}(\mathrm{~g})=3 \mathrm{SiO}_{(\mathrm{g})}+2 \mathrm{~N}_{2}(\mathrm{~g})$
3. Reaction with $\mathrm{SiO}_{2}$ :$$
\mathrm{Si}_{3} \mathrm{~N}_{4}(\mathrm{~s})+3 \mathrm{SiO}_{2}(\mathrm{~s})=6 \mathrm{SiO}_{(\mathrm{g})}+2 \mathrm{~N}_{2}(\mathrm{~g})
$$ 
At temperatures below about $1850^{\circ} \mathrm{C}$ the decomposition of $\mathrm{Si}_{3} \mathrm{~N}_{4}$ by the reaction with $\mathrm{SiO}_{2}$ dominates. To minimize $\mathrm{Si}_{3} \mathrm{~N}_{4}$ decomposition during sintering high nitrogen partial pressures are usually employed along with packing the compact in a protective bed of loose $\mathrm{Si}_{3} \mathrm{~N}_{4}$ powder, which will partially decompose by reaction (3), thereby providing an $\mathrm{SiO}$ partial pressure to maintain equilibrium.

To achieve optimum high-temperature silicon nitride materials, the ideal sintering additive should form a liquid at the sintering temperature to allow for densification and should then form a crystalline phase during a post-sintering heat treatment. The resulting amorphous phase should devitrify without a large volumetric change so as to minimize initiation of residual stresses in the final material. The crystalline phase should have a coefficient of thermal expansion close to that of $\mathrm{Si}_{3} \mathrm{~N}_{4}$ (see Table I), and should have good mechanical properties at both room temperatures and at elevated temperatures such that the strength of the ceramic is enhanced by crystallization.

\section{THE $\mathrm{Si}_{3} \mathrm{~N}_{4}-\mathrm{SiO}_{2}-\mathrm{RE}_{2} \mathrm{O}_{3}$ SYSTEM}

Phase relations in the $\mathrm{Si}_{3} \mathrm{~N}_{4}-\mathrm{SiO}_{2}-\mathrm{RE}_{2} \mathrm{O}_{3}$ system are generally not well known for the majority of the lanthanide oxides (here, RE refers to $Y$, as well as the elements collectively known as lanthanides, $\mathrm{La} \rightarrow \mathrm{Lu}$ ), however, they are assumed to be similar to those in the $\mathrm{Si}_{3} \mathrm{~N}_{4}-\mathrm{SiO}_{2}-\mathrm{Y}_{2} \mathrm{O}_{3}$ system. The lanthanide ions all have similar electronic configurations and ionic radii, with $\mathrm{RE}^{3+}$ being the common oxidation state, and therefore the chemistry of the group is very similar as well. This is because the $4 f^{n}$ electrons do not participate directly in chemical bonding; they are shielded from the effects of adjacent charge fields by the $5 s^{2} 5 p^{6}$ electrons. ${ }^{36}$ In rare-earth aluminosilicate glasses it was shown that ytrium behaves similarly to the lanthanides in forming melts. ${ }^{37}$ The physical properties of these glasses such as glass transformation and softening temperatures, and thermal expansion coefficient varied linearly with ionic radius for the rare-earth ions; this trend was 
attributed to the field strength of the rare-earth ion (field strength varies with the reciprocal of cationic radius).

Ito and Johnson 38 and Felsche ${ }^{36}$ have shown that phases in the $\mathrm{RE}_{2} \mathrm{O}_{3}-\mathrm{SiO}_{2}$ system and the $\mathrm{Y}_{2} \mathrm{O}_{3}-\mathrm{SiO}_{2}$ system are isostructural, forming silicates having the general formulae $\mathrm{RE}_{2} \mathrm{SiO}_{5}$ and $\mathrm{RE}_{2} \mathrm{Si}_{2} \mathrm{O}_{7}$. The formation of isostructural silicon lanthanide oxynitrides has also been demonstrated. ${ }^{39}$ The phases found in the $\mathrm{Si}_{3} \mathrm{~N}_{4}-\mathrm{SiO}_{2}-\mathrm{Y}_{2} \mathrm{O}_{3}$ system will be discussed since what is known implies analogous phases exist in the other $\mathrm{Si}_{3} \mathrm{~N}_{4}-\mathrm{SiO}_{2}-\mathrm{RE}_{2} \mathrm{O}_{3}$ systems as well. However, recently it has been suggested that the $\mathrm{Yb}_{2} \mathrm{O}_{3}$-containing system has phase relations slightly different from those of the $\mathrm{Y}_{2} \mathrm{O}_{3}$ containing system with respect to the formation of certain quaternary phases. 40

An isothermal section of the phase diagram of the $\mathrm{Si}_{3} \mathrm{~N}_{4}-\mathrm{SiO}_{2}-\mathrm{Y}_{2} \mathrm{O}_{3}$ system is shown in Fig. 2. Of the possible silicates and oxynitrides that can form as secondary phases in $\mathrm{Si}_{3} \mathrm{~N}_{4}$ ceramics, $\mathrm{Y}_{2} \mathrm{Si}_{2} \mathrm{O}_{7}$ is the phase that is most resistant to oxidation. ${ }^{41,42}$ Ytrium disilicate is the only $\mathrm{Y}$-containing phase in equilibrium with $\mathrm{SiO}_{2}$ (up to the eutectic temperature of $1660^{\circ} \mathrm{C}$ ), the oxidation product of $\mathrm{Si}_{3} \mathrm{~N}_{4}$, and is therefore the preferred secondary phase for $\mathrm{Si}_{3} \mathrm{~N}_{4}$ ceramics which will be exposed to high-temperature oxidizing environments. Under high-temperature oxidizing conditions the other silicates and oxynitrides when present as secondary phases react to form $\mathrm{Y}_{2} \mathrm{Si}_{2} \mathrm{O}_{7}, \mathrm{SiO}_{2}$, and $\mathrm{N}_{2}$; these reactions are accompanied by volumetric changes leading to stresses and eventually cracking and failure of the ceramic.

In designing $\mathrm{Si}_{3} \mathrm{~N}_{4}$ ceramics with improved high-temperature behavior a secondary phase of $\mathrm{RE}_{2} \mathrm{Si}_{2} \mathrm{O}_{7}$ is necessary. In addition to yttrium disilicate, the disilicates of the lanthanides should also prove to be effective for the formation of refractory $\mathrm{Si}_{3} \mathrm{~N}_{4}$ ceramics. The binary $\mathrm{RE}_{2} \mathrm{O}_{3}-\mathrm{SiO}_{2}$ (in this study, $\mathrm{RE}=\mathrm{Y}, \mathrm{Sm}, \mathrm{Gd}, \mathrm{Dy}, \mathrm{Er}$, and $\mathrm{Yb}$ ) phase diagrams are given in Fig. 3 showing the high melting temperature of the $\mathrm{RE}_{2} \mathrm{Si}_{2} \mathrm{O}_{7}$ phases, which are tabulated along with the lowest eutectic temperatures in Table II. The lowest eutectic temperature for each system is between $1640^{\circ} \mathrm{C}$ and $1680^{\circ} \mathrm{C}$, well above the 
$1400^{\circ} \mathrm{C}$ operating temperature to which $\mathrm{Si}_{3} \mathrm{~N}_{4}$ ceramics will be exposed. The rare-earth disilicates can exist in one to five crystallographic forms. $36,37,44$ The polymorphism of the disilicates from $900^{\circ} \mathrm{C}$ to $1800^{\circ} \mathrm{C}$ is shown in Fig. 4. The increase in the number of polymorphs for the disilicates of $\mathrm{Sm}, \mathrm{Eu}, \mathrm{Ho}$, and $\mathrm{Er}$ has been attributed to the rather unstable electron configurations of these compounds together with the possible critical size of the cations. ${ }^{36}$ Felsche ${ }^{36}$ has also attributed the large number of polymorphs of $\mathrm{Y}_{2} \mathrm{Si}_{2} \mathrm{O}_{7}$ to special hybridized orbitals of $s$ - and $d$-electrons with regard to the charge field of the $\mathrm{Si}_{2} \mathrm{O}_{7}^{6-}$ anion, allowing for different geometric arrangements of the isolated silicate double te trahedra around the rare-earth atom.

\section{SUMMARY OF PRIOR WORK}

Bulk glasses compositionally similar to the amorphous phases found in $\mathrm{Si}_{3} \mathrm{~N}_{4}$ ceramics were extensively investigated at Berkeley $45-50$ and elsewhere $51-54$ to gain insight into the crystallization behavior of these grain-boundary phases and also as possible glassceramics themselves. At Berkeley, the work of Dinger et al. ${ }^{48,49}$ led to the formation of a homogeneous Y-Si-Al-O-N glass that could be fully crystallized. They found that in the crystallization of these glasses, devitrification proceeds by the formation of $\mathrm{Y}_{2} \mathrm{Si}_{2} \mathrm{O}_{7}$ and the quaternary oxynitrides until the $\mathrm{Al}$ concentration at the silicate (or oxynitride)-melt interface had reached a critical level, at which point $\mathrm{YSi}_{2} \mathrm{AlO}_{4} \mathrm{~N}_{2}$ begins to form. It was also shown that although $\mathrm{Al}_{2} \mathrm{O}_{3}$ in low concentrations is a popular sintering additive in commercial $\mathrm{Si}_{3} \mathrm{~N}_{4}$ materials because it forms a low-melting eutectic liquid with $\mathrm{SiO}_{2}$ which facilitates densification, it also promotes intergranular glas sy phase retention and inhibits grain-boundary phase devitrification. $20,21,27,41,42,55$

As an outcome of this study, a YSiAION glass was used as the sintering aid for $\mathrm{Si}_{3} \mathrm{~N}_{4}$ and heat treatments were then performed to crystallize the grain-boundary phase. ${ }^{56-}$ 58 Although a $70 \%$ retention of room-temperature strength at $1300^{\circ} \mathrm{C}$ was obtained, the 
grain-boundary phase did not crystallize completely, leaving an Al-rich amorphous film surrounding $\beta-\mathrm{Si}_{3} \mathrm{~N}_{4}$ primary and secondary silicate and oxynitride phases. 57,58 Although a small amount of $\mathrm{Al}$ and $\mathrm{O}$ were found to have dissolved in $\mathrm{Si}_{3} \mathrm{~N}_{4}$ forming a "sialon"1 solid solution, Al was also present in an intergranular amorphous phase. Crystallization of phases present at the multiple-grain junctions was found to be complete, with the exception of the Al-rich film, for heat treatments of $>8 \mathrm{hr}$ at $1350-1450^{\circ} \mathrm{C}$. The crystalline secondary phases formed were found to be dependent on annealing temperature. At the higher temperature of $1450^{\circ} \mathrm{C}$, the quaternary phases $\mathrm{YSiO}_{2} \mathrm{~N}$ and $\mathrm{Y}_{4} \mathrm{Si}_{2} \mathrm{O}_{7} \mathrm{~N}_{2}$ crystallized, while at $1350^{\circ} \mathrm{C}$ the only secondary phase present was $\beta-\mathrm{Y}_{2} \mathrm{Si}_{2} \mathrm{O}_{7}$; this is consistent with YSiAION glass crystallization in bulk at these temperatures. 50

\section{E. PURPOSE AND OBJECTIVES OF THIS RESEARCH}

This investigation sought to produce silicon nitride ceramics with improved hightemperature behavior by tailoring a microstructure specifically designed for high temperatures, through compositional and process control. To improve high-temperature properties it is essential to eliminate $\mathrm{Al}_{2} \mathrm{O}_{3}$, which has become a popular sintering additive, and form more refractory and thermodynamically stable secondary phases. The formation of single-phase $\mathrm{Si}_{3} \mathrm{~N}_{4}$ ceramics by incorporating $\mathrm{Al}$ and $\mathrm{O}$ into the $\beta-\mathrm{Si}_{3} \mathrm{~N}_{4}$ crystal structure to form a substitutional solid solution (sialon) having the formula $\mathrm{Si}_{6-\mathrm{x}} \mathrm{Al}_{\mathrm{x}} \mathrm{O}_{\mathrm{x}} \mathrm{N}_{8-\mathrm{x}}, \mathrm{x} \leq 4.2$, was first suggested by Jack ${ }^{1}$ as a means of eliminating Al from the grain-boundaries. However, the low chemical activity of $\mathrm{Al}$ can lead to transformation kinetics which are slow enough to preclude complete substitution within reasonable processing times. Incomplete substitution results in a low viscosity aluminosilicate phase which may remain amorphous following processing, as $\mathrm{Al}_{2} \mathrm{O}_{3}$ is known to reduce the tendency of binary

silicate melts to devitrify. 59 Clearly the incorporation of $\mathrm{Al}_{2} \mathrm{O}_{3}$ during processing of $\mathrm{Si}_{3} \mathrm{~N}_{4}$ ceramics as a sintering aid or as an impurity must be avoided. 
In this study, ceramics were designed to consist of a discontinuous matrix phase of $\beta-\mathrm{Si}_{3} \mathrm{~N}_{4}$ grains with a crystalline secondary phase of a rare-earth disilicate. In addition to $\mathrm{Y}_{2} \mathrm{O}_{3}$, a number of rare-earth oxides were considered as sintering additives in this investigation. Limited work has been published on the use of rare-earth oxides as sintering additives for $\mathrm{Si}_{3} \mathrm{~N}_{4} \cdot{ }^{15,60-65}$ These studies have focused primarily on sintering feasibility and behavior and room-temperature strength of the ceramics with the lighter lanthanide oxides (oxides of $\mathrm{La}, \mathrm{Ce}, \mathrm{Nd}$, and $\mathrm{Sm}$ ). These oxides were found to be nearly as effective as $\mathrm{Y}_{2} \mathrm{O}_{3}$ in densifying $\mathrm{Si}_{3} \mathrm{~N}_{4}$, producing materials having slightly lower room-temperature strengths and slightly higher strengths at $1370^{\circ} \mathrm{C} .63$

In the present investigation grain-boundary phase crystallization and hightemperature behavior of $\mathrm{Si}_{3} \mathrm{~N}_{4}$ sintered with $\mathrm{Y}_{2} \mathrm{O}_{3}$ and the heavier lanthanide oxides (oxides of $\mathrm{Sm} \rightarrow \mathrm{Yb}$ ) were studied. As discussed in Section I.C. these oxides all have eutectic temperatures with $\mathrm{SiO}_{2}$ of $1640-1680^{\circ} \mathrm{C}$, about the same as that of $\mathrm{Y}_{2} \mathrm{O}_{3}-\mathrm{SiO}_{2}$ $\left(1660^{\circ} \mathrm{C}\right)$ indicating they should form highly refractory intergranular pnases. The crystallization behavior of these compounds is also expected to be similar to those of the $\mathrm{Si}_{3} \mathrm{~N}_{4}-\mathrm{SiO}_{2}-\mathrm{Y}_{2} \mathrm{O}_{3}$ system. Although complete crystallization of the intergranular phase is ideal it has been proposed based on thermodynamical considerations ${ }^{66}$ (and also generally observed) that a thin residual amorphous film, will always exist at grain boundaries. Therefore, the use of the higher melting point rare-earth oxides as sintering aids, would also provide a highly refractory amorphous phase should complete devitrification not be achieved. 


\section{EXPERIMENTAL PROCEDURES}

\section{A. MATERIAL FABRICATION}

\section{Microstructural Design}

The main objective of this study was to design a microstructure for $\mathrm{Si}_{3} \mathrm{~N}_{4}$ ceramics specifically to obtain improved high-temperature properties; these include oxidation resistance, strength, and creep resistance. In liquid-phase sintered materials the presence of a less refractory intergranular phase is usually responsible for the degradation of properties at high temperatures. Therefore, the most effective means of tailoring these ceramics for high temperatures is to specify a highly refractory and oxidation resistant intergranular phase composition.

A microstructure was designed to consist of a discontinuous matrix phase of $\beta$ $\mathrm{Si}_{3} \mathrm{~N}_{4}$ with a secondary phase of $\mathrm{RE}_{2} \mathrm{Si}_{2} \mathrm{O}_{7}$. As discussed in Section I.C., in the $\mathrm{Si}_{3} \mathrm{~N}_{4}$ $\mathrm{SiO}_{2}-\mathrm{Y}_{2} \mathrm{O}_{3}$ system, $\mathrm{Y}_{2} \mathrm{Si}_{2} \mathrm{O}_{7}$ is considered to be the preferred secondary phase for obtaining ceramics with maximum oxidation resistance, since it is the only $Y$-containing phase in equilibrium with $\mathrm{SiO}_{2}$, the oxidation product of $\mathrm{Si}_{3} \mathrm{~N}_{4}$. Pure $\mathrm{Si}_{3} \mathrm{~N}_{4}$ oxidizes in the presence of high oxygen partial-pressures according to the following reartion:

$$
\mathrm{Si}_{3} \mathrm{~N}_{4}(\mathrm{~s})+3 \mathrm{O}_{2}(\mathrm{~g})=3 \mathrm{SiO}_{2}(\mathrm{~s})+2 \mathrm{~N}_{2}(\mathrm{~g})
$$

where a protective oxide layer forms on the surface and limits the rate of oxidation. In sintered $\mathrm{Si}_{3} \mathrm{~N}_{4}$, which usually contains an amorphous intergranular phase, overall oxidation is enhanced by the oxidation of $\mathrm{Si}_{3} \mathrm{~N}_{4}$ dissolved in a surface silicate phase. It was first proposed by Singhal67, then verified by Cubicciotti et al.68,69 that the ratelimiting step in the oxidation of $\mathrm{MgO}$-hot-pressed $\mathrm{Si}_{3} \mathrm{~N}_{4}$ is the diffusion of $\mathrm{Mg}^{2+}$ and 
impurity cations from the bulk to the surface oxide interface rather than the diffusion of oxygen through the oxide layer to the interface. The oxidation of $\mathrm{Si}_{3} \mathrm{~N}_{4}$ was shown to be enhanced by dissolution in magnesium silicate at the surface. Other studies then found that the same mechanism applied to the oxidation of selected rare-earth-oxide-sintered $\mathrm{Si}_{3} \mathrm{~N}_{4} .{ }^{70}$ 72

It is therefore important to stay compositionally as close to the $\mathrm{Si}_{3} \mathrm{~N}_{4}-\mathrm{Y}_{2} \mathrm{Si}_{2} \mathrm{C}$, ieline as possible. Materials with an overall composition in the upper left portion of the $\mathrm{Si}_{3} \mathrm{~N}_{4}-\mathrm{Si}_{2} \mathrm{ON}_{2}-\mathrm{Y}_{2} \mathrm{Si}_{2} \mathrm{O}_{7}$ compatibility triangle (Fig. 2) contain significant fractions of $\mathrm{Si}_{2} \mathrm{ON}_{2}$, a more oxidation resistant but lower strength phase than $\mathrm{Si}_{3} \mathrm{~N}_{4} \cdot{ }^{73,74}$ If the composition crosses the $\mathrm{Si}_{3} \mathrm{~N}_{4}-\mathrm{Y}_{2} \mathrm{Si}_{2} \mathrm{O}_{7}$ tie-line into the $\mathrm{Si}_{3} \mathrm{~N}_{4}-\mathrm{Y}_{2} \mathrm{Si}_{2} \mathrm{O}_{7}-\mathrm{Y}_{10} \mathrm{Si}_{7} \mathrm{O}_{23} \mathrm{~N}_{4}$ compatibility triangle, the apatite $\left(\mathrm{Y}_{10} \mathrm{Si}_{7} \mathrm{O}_{23} \mathrm{~N}_{4}\right)$ phase can exist which is not in equilibrium with $\mathrm{SiO}_{2}$ and hence increased oxidation results. ${ }^{42}$ Compositions were therefore carefully controlled to result in a final product lying directly on the $\mathrm{Si}_{3} \mathrm{~N}_{4}$ $\mathrm{RE}_{2} \mathrm{Si}_{2} \mathrm{O}_{7}$ tie-line.

\section{Silicon Nitride Processing}

SN E-10 (Ube Industries, Tokyo, Japan) $\mathrm{Si}_{3} \mathrm{~N}_{4}$ powder, obtained directly from the manufacturer, was selected for use in this research primarily because of its high purity, high specific surface area, and high $\alpha / \beta$ content, shown in Table III. Major impurities common to silicon nitride powders include oxygen as well as magnesium, aluminum, calcium, and iron. The oxide sintering additives were obtained either directly from the manufacturer, as for the case of $\mathrm{Y}_{2} \mathrm{O}_{3}(99.9 \%, 1 \mu \mathrm{m}$, Hermann C. Starck Co., Berlin, Germany) or from suppliers for the case of $\mathrm{SiO}_{2}(99.9 \%$, $<45 \mu \mathrm{m}$, Alfa Products Inc., Danvers, MA) and the rare-earth oxides $(99.99 \%,<45 \mu \mathrm{m}$, Aesar Group, JohnsonMatthey Inc., Seabrook, NH). The rare-earth oxides selected to be examined as sintering additives were the heavier and more refractory lanthanide oxides: $\mathrm{Sm}_{2} \mathrm{O}_{3}, \mathrm{Gd}_{2} \mathrm{O}_{3}, \mathrm{Dy}_{2} \mathrm{O}_{3}$, 
$\mathrm{Er}_{2} \mathrm{O}_{3}$, and $\mathrm{Yb}_{2} \mathrm{O}_{3}$. The oxides of those lanthanides that were not included in this study lying between samarium and lutetium were omitted because of their prohibitively high cost and limited availability. The $\mathrm{Si}_{3} \mathrm{~N}_{4}$ and $\mathrm{SiO}_{2}$ powders were chemically analyzed since their reported purity was lower than that of the rare-earth oxide powders and impurities were likely to be present. Semi-quantitative chemical analyses (Metallurgical Laboratories Inc., San Francisco, CA) obtained by emission spectroscopy of trace impurities of the $\mathrm{Si}_{3} \mathrm{~N}_{4}$ and $\mathrm{SiO}_{2}$ powders are given in Table IV.

All $\mathrm{Si}_{3} \mathrm{~N}_{4}$ compositions were prepared with a 2:1 molar ratio of $\mathrm{SiO}_{2}: \mathrm{RE}_{2} \mathrm{O}_{3}$ (taking into account oxide present on the surface of $\mathrm{Si}_{3} \mathrm{~N}_{4}$ particles), placing the composition directly on the $\mathrm{Si}_{3} \mathrm{~N}_{4}-\mathrm{RE}_{2} \mathrm{Si}_{2} \mathrm{O}_{7}$ tie line. Materials were processed to obtain a 12.3 vol\% grain-boundary phase for all compositions since high-temperature properties are directly related to the amount of grain-boundary phase present; this volume fraction is equivalent to a $15 \mathrm{wt} \% \mathrm{Y}_{2} \mathrm{Si}_{2} \mathrm{O}_{7}-\mathrm{Si}_{3} \mathrm{~N}_{4}$ material, which could be sintered to $>99 \%$ theoretical density. 75 Prior to mixing with the $\mathrm{Si}_{3} \mathrm{~N}_{4}$ powder, the oxide additives were all pre-milled in polyamide milling containers in a planetary ball mill with hot-pressed $\mathrm{Si}_{3} \mathrm{~N}_{4}$ milling media in anhydrous methanol to reduce them to submicrometer size to improve homogeneity when mixing with the $0.3 \mu \mathrm{m} \mathrm{Si} 3 \mathrm{~N}_{4}$ powder. Compositions were then prepared by milling 50-75 $\mathrm{g}$ of the powders in the polyamide milling containers for $24 \mathrm{hr}$ using hot. oressed $\mathrm{Si}_{3} \mathrm{~N}_{4}$ milling media in anhydrous methanol. Following milling the slurry was heated to allow the majority of the methanol to evaporate. With the powder still wet with methanol, drying was completed in a vacuum oven at $65^{\circ} \mathrm{C}$.

The dried cakes of powder were gently crushed in a carborundum mortar and pestle and passed through a 100 mesh $(150 \mu \mathrm{m})$ sieve to remove any large agglomerates. The powders were then uniaxially consolidated using a hardened-steel die. Thin blocks $6 \mathrm{~cm}$ in length, $0.6 \mathrm{~cm}$ in thickness and $\sim 2 \mathrm{~cm}$ in width were lightly die-pressed under $\sim 25 \mathrm{MPa}$ (3700 psi). The blocks were then immediately sealed in latex balloons and evacuated, followed by isostatic pressing at $>450 \mathrm{MPa}(65,000 \mathrm{psi})$ to improve the green density of 
the body and minimize density gradients which may have been introduced during uniaxial pressing. Organic binders and lubricants were not necessary since simple shapes and shape-forming techniques were used, and thus residual contamination from incomplete binder burn-out was avoided.

Up to four green bodies were placed in a graphite crucible that had been coated with a boron nitride wash to minimize carbon contamination of the samples. The bodies were loosely packed in a protective bed of $30 \mathrm{wt} \% \mathrm{BN}-\mathrm{Si}_{3} \mathrm{~N}_{4}$ powder to provide a local SiO partial pressure to minimize $\mathrm{Si}_{3} \mathrm{~N}_{4}$ decomposition. The loaded crucible was then covered with a graphite lid and placed in a moderate-pressure graphite-element resistance furnace (Centorr Associates, Suncook, NH), as shown in Fig. 5. The temperature of the furnace was controlled by a programmable temperature controller (MicRIcon 823, Research Inc., Minneapolis, $\mathrm{MN}$ ) capable of maintaining the temperature to $\pm 1^{\circ} \mathrm{C}$. The temperature could be controlled with either a W-Re thermocouple entering through the bottom of the hot zone or by an optical pyrometer focused directly on the graphite crucible through a hole in the heating element.

Bases on results obtained processing $\mathrm{Si}_{3} \mathrm{~N}_{4}$ in the Y-Si-O-N and Y-Si-Al-O-N systems, 58,75 the following sintering/heat-treating schedule was chosen:

1. The samples were heated to $1000^{\circ} \mathrm{C}$ at $10^{\circ} \mathrm{C} / \mathrm{min}$ under a $50-200 \mathrm{~m}$ Torr vacuum, depending on the amount of out-gassing occuring during heating.

2. At $1000^{\circ} \mathrm{C}$ the furnace was pressurized to $0.1 \mathrm{MPa}(0 \mathrm{psig})$.

3. The samples were then heated to $1600^{\circ} \mathrm{C}$ at $15^{\circ} \mathrm{C} / \mathrm{min}$ and the furnace was pressurized to $1.8 \mathrm{MPa}$ (250 psig).

4. The samples were then heated to the final sintering temperature of $1850^{\circ} \mathrm{C}$, and maintained at $1850^{\circ} \mathrm{C}$ for $4 \mathrm{hr}$.

5. Following densification, the samples were cooled at a rate of $10^{\circ} \mathrm{C} / \mathrm{min}$ to $1400^{\circ} \mathrm{C}$ and held at $1400^{\circ} \mathrm{C}$ for $24 \mathrm{hr}$ to induce crystallization. 
6. The samples were then cooled at $10^{\circ} \mathrm{C} / \mathrm{min}$ to $1000^{\circ} \mathrm{C}$ and then finally cooled to room temperature at the maximum rate allowed by the furnace $\left(50-60^{\circ} \mathrm{C} / \mathrm{min}\right)$.

Theoretical densities were calculated by assuming a fully crystalline grain-boundary phase of the appropriate $\mathrm{RE}_{2} \mathrm{Si}_{2} \mathrm{O}_{7}$ and using the rule of mixtures. Actual densities were determined by the Archimedes method of weighing the sample in air and then in ethanol, which was used as the immersion liquid.

\section{B. CHARACTERIZATION TECHNIQUES}

\section{X-ray Diffraction}

$\mathrm{X}$-ray diffraction was used to identify major secondary crystalline phases present in the bulk ceramics as well as the oxidized surfaces of those materials used in the oxidation studies. For those materials undergoing bulk characterization, samples were cut with a high-speed diamond saw to reveal flat internal sections and ground using a 320 grit diamond wheel. The surfaces of the oxidized materials were simply scanned as oxidized. In both cases the surfaces were scanned in bulk form using an $\mathrm{x}$-ray diffractometer (D500 Kristalloflex, Siemens AG, Munich, Germany) with $\mathrm{Cu} \mathrm{K}_{\alpha}$ radiation (1.54 $\AA$ ) operating at $40 \mathrm{kV}$ with a filament current of $20 \mathrm{~mA}$ over angles $15^{\circ}<2 \theta<55^{\circ}$ at $0.05^{\circ}$ intervals using a count integration time of $1 \mathrm{~s} / \mathrm{step}$. Diffraction patterns were interpreted by comparison with calculated and empirically determined patterns obtained from the literature. $36,38,44,76$

\section{Light Microscopy}

Each of the $\mathrm{Si}_{3} \mathrm{~N}_{4}$ ceramics processed were examined by reflected light microscopy using a metallograph (ICM 405, Carl Zeiss Inc., Oberkochen, Germany). Bulk 
microstructural features were examined including sample porosity, homogeneity, and evidence of secondary-phase segregation. Samples were sliced using a high-speed diamond saw, mounted for handling, and polished to $1 \mu \mathrm{m}$ finish using successively finer diamond pastes.

\section{Scanning Electron Microscopy}

Scanning electron microscopy (SEM) was used to characterize the oxidized surfaces of those ceramics used in the oxidation studies and to identify fracture origins on the fracture surfaces of those samples tested for flexural strength. A scanning electron microscope (JSM-35CF, Japan Electron Optic Co. Ltd., Tokyo, Japan) equipped with an energy-dispersive x-ray spectrometer (TN-5500, Noran Instruments Inc., Middleton, WI) was used in this study. The windowless detector allowed for the detection of elements with atomic number $\geq 5$. Secondary electron imaging was used to obtain topographical information while backscattered electron imaging provided enhanced contrast due to compositional differences with the instrument operating at $10-20 \mathrm{kV}$. A $20 \mathrm{kV}$ electron beam was used for energy-dispersive $x$-ray spectroscopy..

Specimens were prepared by sectioning using a low-speed diamond saw. A thin layer of carbon was then evaporated onto the specimen to minimize charging under the electron beam.

\section{Transmission Electron Microscopy}

Selected $\mathrm{Si}_{3} \mathrm{~N}_{4}$ specimens were examined in a transmission electron microscope (EM 400T, Philips Gloeilampenfabrieken NV, Eindhoven, The Netherlands) operated at $120 \mathrm{kV}$ and equipped with an energy-dispersive $\mathrm{x}$-ray spectrometer (Microanalyst-8000, Kevex Instruments Inc., San Carlos, CA) incorporating a SuperQuantum ${ }^{\mathrm{TM}}$ ultra-thin 
window detector for detection of elements with atomic number $\geq 5$. Electron diffraction was used to identify secondary crystalline and amorphous phases. Dark-field imaging using both diffracted electrons and incoherently scattered electrons was used to image crystalline and amorphous phases, respectively.

Specimens for transmission electron microscopy (TEM) were prepared from samples sliced $\sim 250 \mu \mathrm{m}$ thick with a low-speed diamond saw. These slices were then hand ground to 50-100 $\mu \mathrm{m}$ using $\mathrm{SiC}$ abrasive paper and water as a lubricant. Self-supporting discs $3 \mathrm{~mm}$ in diameter were then cut using an ultrasonic disc cutter employing $45 \mu \mathrm{m} \mathrm{SiC}$ powder as the abrasive medium. A central section 0-5 $\mu \mathrm{m}$ thick was obtained using a dimple grinder and $6 \mu \mathrm{m}$ diamond paste. Final thinning to electron transparency was achieved by ion milling after cooling with liquid nitrogen. Specimens were first milled using $6 \mathrm{keV}$ argon ions at an incidence of $15^{\circ}$ until a small perforation was obtained. The final milling was accomplished using $5 \mathrm{keV}$ argon ions at progressively shallower angles from $15^{\circ}$ to $10^{\circ}$. A thin layer $(-15 \mathrm{~nm})$ of carbon was then evaporated onto both sides of the specimen to minimize charging under the electron beam. Following creep, samples for examination of cavitation resulting from creep deformation were cut from the bend bars normal to and as close as possible to the tensile surface, shown in Fig. 6, for subsequent preparation as described above.

\section{HIGH-TEMPERATURE BEHAVIOR EVALUATION}

\section{Oxidation Behavior}

The oxidation behavior of these materials was evaluated by measuring the weightgain associated with the oxidation of $\mathrm{Si}_{3} \mathrm{~N}_{4}$ to $\mathrm{SiO}_{2}$. Oxidation studies were conducted at $1400^{\circ} \mathrm{C}$ over a period of $-200 \mathrm{hr}$ in laboratory air, i.e., water vapor was present in the atmosphere. Samples $3 \mathrm{~mm} \times 4 \mathrm{~mm} \times 45 \mathrm{~mm}$ were cut from the sintered blocks. The 
surfaces were ground with a 320 grit diamond wheel, then polished to a $15 \mu \mathrm{m}$ finish. Prior to oxidation, the samples' surfaces were ultrasonically cleaned in acetone followed by a cleaning in ethanol. The specimens, on platinum wire supports in an alumina tray, were placed in a high-temperature box furnace (CM Inc., Bloomfield, NJ) at $400^{\circ} \mathrm{C}$ and heated to $1400^{\circ} \mathrm{C}$ within $15 \mathrm{~min}$. The temperature was controlled by a temperature controller (Eurotherm International Corp., England) capable of maintaining the set-point temperature to $\pm 2{ }^{\circ} \mathrm{C}$. The furnace was cooled to $400^{\circ} \mathrm{C}$ and the specimens removed at $12-48 \mathrm{hr}$ intervals for weighing on an analytical balance (E. Mettler Inc., Zürich, Switzerland) having microgram resolution to determine weight change as a function of time. Oxidized surfaces were characterized by light microscopy, SEM, and $x$-ray diffraction.

\section{Flexural Strength}

Flexural strength tests were conducted at room temperature and at $1300^{\circ} \mathrm{C}$ to determine the effects of the various additives on fast fracture of these $\mathrm{Si}_{3} \mathrm{~N}_{4}$ ceramics. Four-point flexure testing was conducted in accordance with standards and specifications set by the U.S. Army Materials Technology Laboratory. ${ }^{77}$ Test specimens $3 \mathrm{~mm} \mathrm{x} 4 \mathrm{~mm} x$ $45 \mathrm{~mm}$ were cut and machined from the sintered samples. The specimens were tested asground (using a 320 grit diamond wheel) with edges chamfered to climinate machining flaws that could act as initiation sites for fracture. The four-point test fixture consisted of $4.5 \mathrm{~mm}$ hardened steel cylindrical loading points, with a $40 \mathrm{~mm}$ outer support span and a $20 \mathrm{~mm}$ inner load span. Tests were conducted in laboratory air with a cross-head speed of $0.5 \mathrm{~mm} / \mathrm{min}$ using a universal testing instrument (1122, Instron Corp., Canton, MA).

For the flexure tests conducted at $1300^{\circ} \mathrm{C}$, a modified high-temperature box furnace (CM Inc., Bloomfield, NJ), shown in Fig. 7, with a temperature controller (Eurotherm International Corp., England) capable of maintaining the set-point temperature to $\pm 2^{\circ} \mathrm{C}$ was used. A silicon carbide fixture having the same dimensions as that used at room 
temperature was used at $1300^{\circ} \mathrm{C}$. SiC was used for the support tube and loading rod. The specimens were first loaded into the $\mathrm{SiC}$ fixture and then the assembly was placed in position in the furnace, which was supported between the testing frame. The specirnens entered the furnace at $-500^{\circ} \mathrm{C}$ and were heated to $1300^{\circ} \mathrm{C}$ in $15 \mathrm{~min}$. The system was then allowed to thermally equilibrate for an additional $15 \mathrm{~min}$ prior to commercing the test.

A minimum of six specimens were tested to obtain a single datum. The applied load was recorded as a function of time using a strip-chart recorder from which a stressstrain curve, as well as the modulus of rupture, could be obtained. The modulus of rupture was obtained from the following formula: 77

$$
\sigma_{\mathrm{f}}=\frac{3 \mathrm{P}(\mathrm{L}-\mathrm{a})}{2 \mathrm{bh}^{2}}
$$

where $P$ is the load, $L$ is the support span and $a$ is the load span, $b$ is the specimen width, and $h$ is the specimen height. The strength data were analyzed assuming a Weibull statistical distribution function. ${ }^{78,79}$ Fracture surfaces were examined by SEM.

\section{Time-Dependent Creep}

To determine the long-term effects of the various additives on the high-temperature behavior of $\mathrm{Si}_{3} \mathrm{~N}_{4}$, time-dependent creep deformation tests were required. Creep testing was carried out at $1400^{\circ} \mathrm{C}$ in four-point bending mode. adopting the specifications used for fast fracture tests. The SiC test fixture and furnace used for flexural strength determination were also modified for creep testing (Fig. 7). Static loads ranging from $30 \mathrm{MPa}$ to 170 N.Pa were applied to the specimen and the load-point displacement continuously meacured by an external linear variable differential transducer (LVDT). This displacement was plotted on a strip-chart recorder as a function of time. 
The method of Hollenberg et al. 80 was used to analyze the data to determine maximum outer fiber stresses and strains. This analysis simplifies the analytical work substantially and allows solutions to be presented in closed forms. More complex and exact analyses $81-83$ for creep in bending have been proposed, however for this investigation the use of the simplified analysis for calculating stress and strain values allowed comparative creep behavior to be investigated for small deflections $(<0.02$ outer fiber strain), assuming equal behavior in tension and compression. Also, work reforted in the literature has been obtained primarily using the analysis of Hollenberg et al., allowing for r.ore direct comparison of results obtained in this present study with those published in the literature. The maximum stress in bending, which is in the outer fiber, is then calculated using the following modified elastic equation: 80

$$
\sigma_{\max }=\left[3(L-a) P / B h^{2}\right][(2 n+1) / 3 n]
$$

where $\mathrm{L}$ is the outer support span, $\mathrm{a}$ is the inner load span, and $\mathrm{n}$ is the stress exponent. The strain in the outer fiber was computed using the relation between the strain and the load-point deflection:

$$
\varepsilon_{\max }=[2 h(n+2)][(L-a)(L+a(n+1))] y_{L}
$$

where $y_{L}$ is the load point displacement. Appendix I reviews the analysis leading to these equations of stresses and strains in four-point flexural creep tests in detail. 


\section{RESULTS}

\section{A. SILICON NITRIDE PROCESSING}

Silicon nitride ceramics containing 12.3 vol\% $\mathrm{RE}_{2} \mathrm{Si}_{2} \mathrm{O}_{7}$ secondary phase were prepared. The compositions of the materials investigated are given in Table V. All compositions contained approximately $18 \mathrm{~mol} \%$ sintering additives with the weight fraction of additives ranging from $15 \mathrm{wt} \%$ for the $\mathrm{Y}_{2} \mathrm{Si}_{2} \mathrm{O}_{7}-\mathrm{Si}_{3} \mathrm{~N}_{4}$ composition and increasing with increasing molecular weight $\mathrm{RE}_{2} \mathrm{Si}_{2} \mathrm{O}_{7}-\mathrm{Si}_{3} \mathrm{~N}_{4}$ compositions to $\sim 20 \mathrm{wt} \%$ for the $\mathrm{Yb}_{2} \mathrm{Si}_{2} \mathrm{O}_{7}$ $\mathrm{Si}_{3} \mathrm{~N}_{4}$ composition. The powders were consolidated into rectangular blocks weighing about $11 \mathrm{~g}$ by uniaxial die pressing followed by isostatic pressing to $~ 58 \%$ of theoretical density. All ceramics appeared smooth and uniform with no evidence of warping or cracking following cunsolidation into the final green state.

The samples were then fully densified followed immediately by a heat treatment to crystallize the secondary phase. Again, the samples appeared smooth and uniform with no sign of warpage of nonuniform densification occuring. Most of the sintered samples were dark gray in colct with the $\mathrm{Sm}_{2} \mathrm{O}_{3}$-sintered $\mathrm{Si}_{3} \mathrm{~N}_{4}$ having a violet-gray coloring and the $\mathrm{Er}_{2} \mathrm{O}_{3}$-sintered $\mathrm{Si}_{3} \mathrm{~N}_{4}$ having a slightly reddish-gray coloring ( $\mathrm{Er}_{2} \mathrm{O}_{3}$ powder is pink). The compositions lost $3.5-6 \%$ in weight depending on the specific composition following sintering, which can be attributed to loss of adsorbed water as well as partial decomposition of $\mathrm{Si}_{3} \mathrm{~N}_{4}$ and reduction of $\mathrm{SiO}_{2}$ to $\mathrm{SiO}$. The final densities attained by the compositions as a result of sintering are summarized in Truble VI. Sintered densities ranged from $97.8 \%$ for the $\mathrm{Sm}_{2} \mathrm{O}_{3}$-sintered $\mathrm{Si}_{3} \mathrm{~N}_{4}$ to $99.8 \%$ of theoretical density for the $\mathrm{Gd}_{2} \mathrm{O}_{3}$-sintered $\mathrm{Si}_{3} \mathrm{~N}_{4}$. Fig. 8 shows the porosity levels present in each of the six compositions which qualitatively agree with the values obtained by density measurements using the Archimedes method, summarized in Table VI. 


\section{B. MICROSTRUCTURAL CHARACTERIZATION}

\section{X-ray Diffraction of Bulk Material}

Fig. 9 presents the $x$-ray diffraction patterns of the six compositions, obtained by scanning the bulk samples after heat treating and sectioning. All patterns consisted of well defined peaks with no evidence of incoherent scattering of $x$-rays that would indicate the presence of a high amorphous phase content. Table VII contains the identification of crystalline phases indexed from the patterns in Fig. 9. Only the $\beta$-phase of $\mathrm{Si}_{3} \mathrm{~N}_{4}$ was detected with certainty in these compositions along with the possibility of trace amounts of $\mathrm{Si}_{2} \mathrm{ON}_{2}$, indicating the final compositions laid slightly within the $\mathrm{Si}_{3} \mathrm{~N}_{4}-\mathrm{Si}_{2} \mathrm{ON}_{2}-\mathrm{RE}_{2} \mathrm{Si}_{2} \mathrm{O}_{7}$ compatibility triangle. This slight deviation from the $\mathrm{Si}_{3} \mathrm{~N}_{4}-\mathrm{RE}_{2} \mathrm{Si}_{2} \mathrm{O}_{7}$ tie-line can be atributed to greater amounts of impurity oxide present on the $\mathrm{Si}_{3} \mathrm{~N}_{4}$ powders than specified by the manufacturer resulting from the continuous oxidation of $\mathrm{Si}_{3} \mathrm{~N}_{4}$ during handling, as well as additional oxidation of $\mathrm{Si}_{3} \mathrm{~N}_{4}$ occuring during processing to the green state, which caused a slight compositional shift toward $\mathrm{SiO}_{2}$.

The rare-earth disilicates in most of the compositions were crystallized at $1400^{\circ} \mathrm{C}$ in the forms predicted and experimentally determined by previous investigators. $36,38,44$ The $\mathrm{Y}_{2} \mathrm{O}_{3-}, \mathrm{Sm}_{2} \mathrm{O}_{3}-, \mathrm{Er}_{2} \mathrm{O}_{3-}$, and $\mathrm{Yb}_{2} \mathrm{O}_{3}$-sintered $\mathrm{Si}_{3} \mathrm{~N}_{4}$ ceramics contained secondary phases of $\beta-\mathrm{Y}_{2} \mathrm{Si}_{2} \mathrm{O}_{7}, A-\mathrm{Sm}_{2} \mathrm{Si}_{2} \mathrm{O}_{7}, \beta-\mathrm{Er}_{2} \mathrm{Si}_{2} \mathrm{O}_{7}$, and $\beta-\mathrm{Yb}_{2} \mathrm{Si}_{2} \mathrm{O}_{7}$, respectively, as expected (the use of capital letters to denote the various polymorphs of the rare-earth disilicates was used by Felsche ${ }^{36}$, while the use of Greek letters was adopted by Ito and Johnson 38 for the polymorphs of $\mathrm{Y}_{2} \mathrm{Si}_{2} \mathrm{O}_{7}$. The latter convention has been chosen here for all rare-earth disilicates where applicable as detailed in Fig. 4). $\mathrm{Gd}_{2} \mathrm{Si}_{2} \mathrm{O}_{7}$ and $\mathrm{Dy}_{2} \mathrm{Si}_{2} \mathrm{O}_{7}$ crystallized in the $\delta$-phase, with lesser amounts of $\alpha-\mathrm{Dy}_{2} \mathrm{Si}_{2} \mathrm{O}_{7}$ also detected, whereas the $\alpha$-phase had been reported as the stable polymorph for both at $1400^{\circ} \mathrm{C} .36,38$ 


\section{Transmission Electron Microscopy of Bulk Microstructures}

\section{a. General Morphology}

The microstructure of these sintered silicon nitride ceramics consisted of fine $\beta$ $\mathrm{Si}_{3} \mathrm{~N}_{4}$ grains as a discontinuous matrix phase with a secondary crystalline phase of $\mathrm{RE}_{2} \mathrm{Si}_{2} \mathrm{O}_{7}$. Fig. 10 presents a set of low-magnification transmission electron micrograph showing the general morphologies of the six compositions, with the $\beta-\mathrm{Si}_{3} \mathrm{~N}_{4}$ grains in bright contrast and the rare-earth disilicate phase in much darker contrast due to the high atomic scattering factor and greater electron absorption of the higher average atomic number secondary phases. The general morphologies of the microstructures of the six compositions were very similar. The $\beta-\mathrm{Si}_{3} \mathrm{~N}_{4}$ grains typically ranged on the order of about $0.2-0.8 \mu \mathrm{m}$ in diameter in the basal plane, while in the $c$-direction size varied considerably from 1 to $>5 \mu \mathrm{m}$ in length. All compositions showed a small fraction of abnormal graingrowth with grains on the order of a few micrometers in diameter in the basal plane. The secondary phase was observed at multiple-grain junctions as well as along two-grain boundaries. The average grain-junction pocket size varied between $0.2 \mu \mathrm{m}$ and $0.5 \mu \mathrm{m}$ depending on secondary phase composition. Some secondary pockets were as large as $\sim 1$ $\mu \mathrm{m}$ in diameter, although these were rarely observed.

\section{b. Secondary-Phase Characterization}

Electron diffraction confirmed the presence of crystalline secondary phases of the type $\mathrm{RE}_{2} \mathrm{Si}_{2} \mathrm{O}_{7}$ in the polymorphic forms as indexed from the $\mathrm{x}$-ray diffraction patterns for each of the six compositions. Figs. 11 and 12 shows the microstructure of the $\mathrm{Y}_{2} \mathrm{Si}_{2} \mathrm{O}_{7}$ $\mathrm{Si}_{3} \mathrm{~N}_{4}$ composition. The secondary phase in the bright-field image of Fig. 11 is oriented exactly on the $\left[\begin{array}{lll}1 & 3 & 2\end{array}\right]$ zone axis and is therefore scattering electrons away from the 
transmitted beam, leaving this phase extremely dark. The dark-field image obtained by using one of the diffracted electron beams reveals the crystalline $\beta-\mathrm{Y}_{2} \mathrm{Si}_{2} \mathrm{O}_{7}$ phase in bright contrast. A single crystal of $\mathrm{RE}_{2} \mathrm{Si}_{2} \mathrm{O}_{7}$ in a single orientation extending over several square micrometers, shown especially in Fig. 11, was frequently observed in all six compositions, indicating a similar limited-nucleation/rapid-growth mechanism of the secondary rare-earth di. ilicate phase. Such crystallization behavior has been reported in $\mathrm{Si}_{3} \mathrm{~N}_{4}$ ceramics containing secondary phases of $\mathrm{Y}_{2} \mathrm{Si}_{2} \mathrm{O}_{7}, 28,57,58$ and $\mathrm{YSiO}_{2} \mathrm{~N}$ and $\mathrm{Y}_{4} \mathrm{Si}_{2} \mathrm{O}_{7} \mathrm{~N}_{2}$ 57,58 as well as $\mathrm{Y}_{3} \mathrm{Al}_{5} \mathrm{O}_{12} \cdot{ }^{26} \beta-\mathrm{Y}_{2} \mathrm{Si}_{2} \mathrm{O}_{7}$ was the only polymorph characterized by electron diffraction in the $\mathrm{Y}_{2} \mathrm{Si}_{2} \mathrm{O}_{7}-\mathrm{Si}_{3} \mathrm{~N}_{4}$ material. Of those multi-grain junctions analyzed by TEM all appeared to have completely crystallized. Imaging of amorphous films in these ceramics was extremely difficult due to the low intensity of electrons diffusely scattered by the minimal volume fraction of amorphous phase. The existence of a thin residual amorphous film was only detected at the interfaces of $\mathrm{Y}_{2} \mathrm{Si}_{2} \mathrm{O}_{7}$ and $\mathrm{Si}_{3} \mathrm{~N}_{4}$ grains and at $\mathrm{Si}_{3} \mathrm{~N}_{4}-\mathrm{Si}_{3} \mathrm{~N}_{4}$ grains by diffuse dark-field imaging as shown in Figs. 13 and 14. The slight blurring of the darkfield image in Fig. 14 is due to specimen drift occuring during the extended time (>60 s) required to adequately expose the film under these low intensity conditions.

The microstructures of the other $\mathrm{RE}_{2} \mathrm{Si}_{2} \mathrm{O}_{7}-\mathrm{Si}_{3} \mathrm{~N}_{4}$ ceramics were very similar to those of the $\mathrm{Y}_{2} \mathrm{Si}_{2} \mathrm{O}_{7}-\mathrm{Si}_{3} \mathrm{~N}_{4}$ material. However, due to the presence of the rare-earth elements in the secondary phases, resulting in high electron scattering and absorption, extremely clark contrast of this phase was obtained in all orientations, as shown in Fig.10. Obtaining diffraction patterns with a convergent beam and obtaining crystalline images in bright contrast in dark field was therefore complicated and limited to only the thinnest portions of the specimen where adequate electron transparency existed.

The darker intergranular phases were otherwise identical to those of the $\mathrm{Y}_{2} \mathrm{Si}_{2} \mathrm{O}_{7}$ $\mathrm{Si}_{3} \mathrm{~N}_{4}$ material, with complete crystallization of secondary phases at multiple-grain junctions observed in all but the $\mathrm{Yb}_{2} \mathrm{Si}_{2} \mathrm{O}_{7}-\mathrm{Si}_{3} \mathrm{~N}_{4}$ material. Figs. 15-24 show brightfield/dark-field images, along with diffraction patterns of the disilicate phase, of the 
$\mathrm{Sm}_{2} \mathrm{Si}_{2} \mathrm{O}_{7}-\mathrm{Si}_{3} \mathrm{~N}_{4}, \mathrm{Gd}_{2} \mathrm{Si}_{2} \mathrm{O}_{7}-\mathrm{Si}_{3} \mathrm{~N}_{4}, \mathrm{Dy}_{2} \mathrm{Si}_{2} \mathrm{O}_{7}-\mathrm{Si}_{3} \mathrm{~N}_{4}, \mathrm{Er}_{2} \mathrm{Si}_{2} \mathrm{O}_{7}-\mathrm{Si}_{3} \mathrm{~N}_{4}$, and $\mathrm{Yb}_{2} \mathrm{Si}_{2} \mathrm{O}_{7}-$ $\mathrm{Si}_{3} \mathrm{~N}_{4}$ compositions indicating similar crystallization and growth mechanisms operating for each material. Also observed were multiple-grain junctions where the secondary phase crystallized into two or more orientations. Fig. 16 is an example of a completely crystalline multiple-grain junction of at least two $\mathrm{A}-\mathrm{Sm}_{2} \mathrm{Si}_{2} \mathrm{O}_{7}$ grains in differing orientations as evidenced by the highlighted contrast of only a portion of the secondary phase in dark-field imaging. The streaks in the set of spots are the result of planar faults (twins or stacking faults) in the highlighted $\mathrm{A}-\mathrm{Sm}_{2} \mathrm{Si}_{2} \mathrm{O}_{7}$ phase, which is tetragonal and oriented in the $\left[\begin{array}{lll}1 & 1 & 0\end{array}\right]$ direction. Twinning of the higher symmetry polymorphs (tetragonal and orthorhombic vs. monoclinic) of yttrium disilicate in $\mathrm{Si}_{3} \mathrm{~N}_{4}$ ceramics has been identified as a means of accommodating strain resulting during secondary phase devitrification. $48,49,84$

One composition, $\mathrm{Yb}_{2} \mathrm{Si}_{2} \mathrm{O}_{7}-\mathrm{Si}_{3} \mathrm{~N}_{4}$ contained a small amount of residual amorphous phase at the multiple-grain junctions in an isolated area of the TEM specimen. Figs. 25 and 26 are bright-field/dark-field pairs of TEM images of regions in the $\mathrm{Yb}_{2} \mathrm{Si}_{2} \mathrm{O}_{7}-\mathrm{Si}_{3} \mathrm{~N}_{4}$ composition containing residual amorphous pockets between $\beta-\mathrm{Yb}_{2} \mathrm{Si}_{2} \mathrm{O}_{7}$ and $\mathrm{B}-\mathrm{Si}_{3} \mathrm{~N}_{4}$ phases at multiple-grain junctions. The dark-field image in Fig. 25 was obtained using diffracted electrons ([ $\left[\begin{array}{lll}1 & 1 & 2\end{array}\right]$ diffraction pattem shown in upper right) from $\beta-\mathrm{Yb}_{2} \mathrm{Si}_{2} \mathrm{O}_{7}$, therefore that phase is in bright contrast (where thin enough to permit electron transmission) while the amorphous region labeled $A$ remains in the same contrast as in bright-field. The lower diffraction pattern is of region $A$, verifying that it is amorphous. The dark-field image in Fig. 26 was obtained by using the electrons diffusely scattered by the amorphous phase, therefore the amorphous phase is imaged in bright contrast as indicated. Some of the crystalline secondary phase appears in bright contrast as well which is probably due to a surface layer of material which has undergone a crystalline to amorphous phase transformation during ion milling. The crystalline nature of the bulk of this pocket was confirmed by electron diffraction. The partially crystallized multiple-grain junctions were observed in only a small region of the specimen, while the other regions 
consisted of fully crystalline $\beta-\mathrm{Yb}_{2} \mathrm{Si}_{2} \mathrm{O}_{7}$ as the secondary phase. The amorphous phase appeared in somewhat brighter contrast than $\mathrm{\beta}-\mathrm{Yb}_{2} \mathrm{Si}_{2} \mathrm{O}_{7}$ and contained gas bubbles characteristic of radiation damage, from either ion milling during specimen preparation or the electron beam in situ. $8,45,85$

Energy-dispersive $x$-ray spectroscopy of this amorphous phase indicated a much higher concentration of silicon than that detected in $\mathrm{B}-\mathrm{Yb}_{2} \mathrm{Si}_{2} \mathrm{O}_{7}$, which is primarily why the glass is slightly more transparent. Fig. 27 compares two EDS spectra, one of $\beta$ $\mathrm{Yb}_{2} \mathrm{Si}_{2} \mathrm{O}_{7}$ and one of the amorphous phase, which illustrates the difference in Si content of the two phases, as well as the presence of some $\mathbf{N}$ in the glass. Impurities commonly expected to reside in the amorphous grain-boundary phases of $\mathrm{Si}_{3} \mathrm{~N}_{4}$ ceramics, such as $\mathrm{Mg}, \mathrm{Al}, \mathrm{Ca}$, and $\mathrm{Fe}$, were not detected in appreciable concentrations (within the limits of uncertainty) in the amorphous $\mathrm{Yb}-\mathrm{Si}-\mathrm{O}-\mathrm{N}$ phase. The detection of small amounts of $\mathrm{Al}$, however, is also complicated by the presence of $\mathrm{Yb}$ since the location of the $\mathrm{Yb} \mathrm{M}_{\alpha}$ peak obscures the $\mathrm{Al} \mathrm{K} \mathrm{K}_{\alpha}$ peak. The presence of $\mathrm{Ar}, \mathrm{Mo}$, and $\mathrm{Cu}$ in all specimens is an artifact of specimen preparation. Initial dimpling with a $\mathrm{Cu}$ wheel and diamond abrasive paste, and ion milling with Ar ions which also results in the redeposition of Mo from the specimen support plates at low angles of incidence account for these artifacts.

The existence of residual amorphous phases at the multiple-grain junctions in the $\mathrm{Yb}_{2} \mathrm{Si}_{2} \mathrm{O}_{7}-\mathrm{Si}_{3} \mathrm{~N}_{4}$ composition is probably a result of a heterogeneous distribution of sintering aids caused by inadequate mixing during milling and subsequent sintering. The observation of this amorphous phase in only an isolated region of the specimen rather than in random or even distribution throughout the microstructure, and the presence of excess silicon but not impurity transition metals in this phase implies that this region where the two secondary phases ( $\beta-\mathrm{Yb}_{2} \mathrm{Si}_{2} \mathrm{O}_{7}$ and $\mathrm{Yb}-\mathrm{Si}-\mathrm{O}-\mathrm{N}$ glass) exist resulted from the presence of excess $\mathrm{SiO}_{2}$, possibly in the form of inclusions of large $\mathrm{SiO}_{2}$ particles that were not reduced during milling. 
The microanalysis of the other compositions by energy-dispersive $x$-ray spectroscopy also focused on the detection of impurities in both crystalline and amorphous phases. Quantification of the spectra obtained from these phases was attempted only with the theoretical $\mathrm{k}$-factors provided with the EDS software, resulting in a semi-quantitative analysis at best. Quantifications based on these $\mathbf{k}$-factors with no corrections due to sample composition and thickness when analyzing elements of greatly differing atomic number are suspect. The preferential absorption of characteristic $x$-rays produced by the atoms of the lighter elements results in detectable concentrations of the rare-earth elements much higher than expected based on phase stoichiometry; for example, the quantification of the spectra obtained of $\beta-\mathrm{Yb}_{2} \mathrm{Si}_{2} \mathrm{O}_{7}$ given in Fig. 27 indicated the presence of 64.6 at.\% $\mathrm{Yb}$ and 35.4 at.\% $\mathrm{Si}$, rather than equal atomic fractions as dictated by stoichiometry. For accurate quantification experimental $\mathrm{k}$-factors needed to be determined from standards. 86 Qualitative and semi-quantitative analyses were adequate to characterize these materials since crystalline phases were simultaneously characterized by electron diffraction, and amorphous phases were usually too small in size or found to be superimposed upon other phases to preclude contributions of these neighboring phases. All EDS was performed on the thinnest regions containing the phases of interest to minimize preferential absorption of $\mathrm{X}$-rays emitted from the lighter elements.

Analysis of the $\beta-\mathrm{Si}_{3} \mathrm{~N}_{4}$ grains in all materials detected the presence of only $\mathrm{Si}, \mathrm{N}$, and $O$ (present as a surface-oxide impurity), as shown in Fig. 28, supporting the theory that the rare-earths do not exist as substitutional impurities in $\mathrm{Si}_{3} \mathrm{~N}_{4}{ }^{1}$ due to their larger ionic radii $(-0.86-0.96 \AA)^{36}$. However, iron-rich particles were observed to reside within $\mathrm{Si}_{3} \mathrm{~N}_{4}$ grains and also at the grain boundaries. Fig. 29 contains bright-field images of Ferich inclusions in two different areas within the $\mathrm{Yb}_{2} \mathrm{Si}_{2} \mathrm{O}_{7}-\mathrm{Si}_{3} \mathrm{~N}_{4}$ material. Iron has been previously reported to have been detected exclusively as small crystalline particles in oxynitride glasses 47,49 and in the glassy grain-boundary phases of silicon nitride ceramics. ${ }^{12}$ These particles have been cited as nucleation centers for $\beta-\mathrm{Si}_{3} \mathrm{~N}_{4}$ as well as for 
secondary-phase crystals. ${ }^{48,51}$ Fig. 30 shows the EDS spectra obtained from the inclusion at the center of the $\mathrm{Si}_{3} \mathrm{~N}_{4}$ grain in the $\mathrm{Yb}_{2} \mathrm{Si}_{2} \mathrm{O}_{7}-\mathrm{Si}_{3} \mathrm{~N}_{4}$ material, imaged in Fig. 29. In addition to $\mathrm{Fe}$, impurities of $\mathrm{Cr}$ and $\mathrm{Ti}$ were detected to compose these particles, as well as Si and $\mathrm{Yb}$.

Microanalysis of the secondary phase rare-earth disilicates in all materials revealed only the presence of $\mathrm{Si}, \mathrm{O}$, and the appropriate rare-earth atom. Fig. 31 contains the EDS spectra of the rare-earth disilicate phases in each of the six compositions, with the absence of peaks attributable to any impurities. Microanalysis of the amorphous phases at the grain boundaries was attempted, however, due to the thin width and improbability of obtaining a grain-boundary in an edge-on orientation at the fixed angle of specimen tilt required for $x$ ray acquisition no compositional variations were detectable between grains and grainboundaries.

\section{HIGH-TEMPERATURE BEHAVIOR}

\section{Oxidation Behavior}

\section{a. Oxidation Kinetics}

Samples of the six materials were heated at $1400^{\circ} \mathrm{C}$ for $192 \mathrm{hr}$ in laboratory air. Fig. 32 is a plot of weight gain per unit surface area as a function of time at $1400^{\circ} \mathrm{C}$. All materials had specific weight gains on the order of $0.25-0.35 \mathrm{mg} / \mathrm{cm}^{2}$ after $192 \mathrm{hr}$ with the exception of the $\mathrm{Sm}_{2} \mathrm{Si}_{2} \mathrm{O}_{7}-\mathrm{Si}_{3} \mathrm{~N}_{4}$ material which had a weight gain of $0.64 \mathrm{mg} / \mathrm{cm}^{2}$ after the same time at temperature. The oxidation of sintered silicon nitride has been shown to obey a parabolic-type of rate law such that

$$
w^{2}=k t
$$


were $W$ is the weight gain per unit surface area, $\mathbf{k}$ is the parabolic oxidation rate constant, and $t$ is exposure time. ${ }^{67}$ Plotting these data parabolically results in straight lines for all curves but those for the $\mathrm{Sm}_{2} \mathrm{Si}_{2} \mathrm{O}_{7}-\mathrm{Si}_{3} \mathrm{~N}_{4}$ and $\mathrm{Dy}_{2} \mathrm{Si}_{2} \mathrm{O}_{7}-\mathrm{Si}_{3} \mathrm{~N}_{4}$ materials, as shown in Fig. 33. The $\mathrm{Dy}_{2} \mathrm{Si}_{2} \mathrm{O}_{7}-\mathrm{Si}_{3} \mathrm{~N}_{4}$ material deviates only slightly while $\mathrm{Sm}_{2} \mathrm{Si}_{2} \mathrm{O}_{7}-\mathrm{Si}_{3} \mathrm{~N}_{4}$ departs significantly from linearity when plotted parabolically. The oxidation resistance of these materials can be correlated reasonably well with the refractoriness of the $\mathrm{RE}_{2} \mathrm{O}_{3}-\mathrm{SiO}_{2}$ system, i.e. inversely related to the lowest eutectic temperature in each system (see Table II and Fig. 3). The $\mathrm{Y}_{2} \mathrm{Si}_{2} \mathrm{O}_{7}-\mathrm{Si}_{3} \mathrm{~N}_{4}$ material fell in the middle of the group with respect to oxidation resistance while the $\mathrm{E}_{2} \mathrm{Si}_{2} \mathrm{O}_{7}-\mathrm{Si}_{3} \mathrm{~N}_{4}$ material displayed the best resistance toward oxidation.

Parabolic oxidation rate constants were obtained from the slopes of the lines that best fit the data. Table VIII contains the rate constants for the six compositions investigated, as well as the total specific weight gain after $192 \mathrm{hr}$. The rate constants are nearly an order of magnitude lower than the lowest $1400^{\circ} \mathrm{C}$ rate constant for sintered $\mathrm{Si}_{3} \mathrm{~N}_{4}$ reported to date in the literature. 87 The parabolic oxidation behavior of these ceramics indicates a diffusional process as the rate-limiting step in the oxidation mechanism, associated with the migration of additive $\left(\mathrm{RE}^{3+}\right)$ and impurity cations along residual amorphous grain-boundary phases to the surface oxide interface. The high oxidation resistance of these materials can be attributed to the presence of a minimal amount of amorphous grain-boundary phase, but with high viscosity due to the presence of refractory $\mathrm{RE}^{3+}$, and the presence of thermodynamically stable crystalline secondary phases, such that the driving force for additive cation diffusion to the surface is minimized. 


\section{b. Microstructure of Oxidized Surfaces}

The phases identified by $x$-ray diffraction for the six materials are summarized in Table IX. X-ray diffraction patterns of the oxidized surfaces are shown in Fig. 34, identifying $\alpha$-cristobalite and the appropriate rare-earth disilicate to be the only major crystalline phases present. The disilicates crystallized on the surfaces into the same polymorphs as originally present as the secondary phase (compare Tables VI and IX), but here as the major phase. Also present were trace amounts of $\beta-\mathrm{Si}_{3} \mathrm{~N}_{4}$ and $\mathrm{Si}_{2} \mathrm{ON}_{2}$. The $\beta$ $\mathrm{Si}_{3} \mathrm{~N}_{4}$ peaks were smallest for those materials undergoing the greatest amount of oxidation, indicating those signals were probably from the bulk ceramic beneath the oxidized surface layer. The oxidized materials all appeared much lighter in color, changing from a dark gray to a light gray upon oxidation. Spalling of the oxide from the substrate surfaces was not observed for any material. Light microscopy of the oxidized surfaces (Fig. 35) revealed a smooth dark matrix with faceted crystals in brighter contrast growing from the surface. Close examination of these micrographs indicates the presence of two distinct types of morphologies associated with the rare-earth disilicates, a needle-like and a more equiaxed type. The $\mathrm{Y}_{2} \mathrm{Si}_{2} \mathrm{O}_{7}$ crystals also appear to have grown much larger in size than any of the other rare-earth disilicates and in a flattened elongated morphology The $\mathrm{x}$-ray diffraction pattems of the six materials indicated the disilicates crystallized in preferred orientations, with the $\left[\begin{array}{lll}0 & 0 & 1\end{array}\right]$ direction normal to the surface for those disilicates with tetragonal (Aphase) and orthorhombic ( $\delta$-phase) crystal structures, and the [lllll $\left.\begin{array}{lll}1 & 1\end{array}\right]$ direction normal to the surface for those disilicates with monoclinic ( $\beta$-phase) and triclinic ( $\alpha$-phase) structures. A similar behavior of growth of $\mathrm{Y}_{2} \mathrm{Si}_{2} \mathrm{O}_{7}$ during oxidation has been reported by Babini et al. ${ }^{88}$ with growth along the (1 110$)$ plane and aligned parallel to the oxide surface. They found texturing of the $\mathrm{Y}_{2} \mathrm{Si}_{2} \mathrm{O}_{7}$ crystals to increase with temperature.

SEM observations revealed similar microstructures of the oxidized surfaces of all six compositions. The oxidized surfaces consisted of an amorphous silicate phase, from 
which cristobalite and $\mathrm{RE}_{2} \mathrm{Si}_{2} \mathrm{O}_{7}$ grains crystallized as shown in Figs. 36 and 37. Fig. 36 was obtained using secondary electrons to gain topographical information of the oxidized surface and morphological information of the rare-earth disilicate crystals. Fig. 37 was obtained using backscattered electrons to obtain contrast differences, strongly dependent on composition. In each case the darkest phase in the background is cristobalite, the intermediate phase surrounding the cristobalite grains is the residual amorphous silicate phase, and the phase in brightest contrast growing out of the silicate phase is the rare-earth disilicate. The dark jagged lines traversing the surfaces are cracks associated with either differential thermal expansion between the bulk and oxide layers or with the volumetric change accompanying transformation of surface cristobalite from the $\beta$ - to $\alpha$-phase upon cooling.

As first observed by low-magnification light microscopy and then confirmed by SEM, the rare-earth disilicates crystallized into either a needle-like morphology or a more equiaxed and faceted morphology. The oxidized surface of the $\mathrm{Y}_{2} \mathrm{Si}_{2} \mathrm{O}_{7}-\mathrm{Si}_{3} \mathrm{~N}_{4}$ ceramic consisted exclusively of flattened and elongated $\mathrm{\beta}-\mathrm{Y}_{2} \mathrm{Si}_{2} \mathrm{O}_{7}$ crystals, while the oxidized surfaces of the $\mathrm{Sm}_{2} \mathrm{Si}_{2} \mathrm{O}_{7}-\mathrm{Si}_{3} \mathrm{~N}_{4}, \mathrm{Er}_{2} \mathrm{Si}_{2} \mathrm{O}_{7}-\mathrm{Si}_{3} \mathrm{~N}_{4}$, and $\mathrm{Yb}_{2} \mathrm{Si}_{2} \mathrm{O}_{7}-\mathrm{Si}_{3} \mathrm{~N}_{4}$ ceramics consisted exclusively of the respective disilicates in the equiaxed morphology. The oxidized surfaces of both the $\mathrm{Gd}_{2} \mathrm{Si}_{2} \mathrm{O}_{7}-\mathrm{Si}_{3} \mathrm{~N}_{4}$ and $\mathrm{Dy}_{2} \mathrm{Si}_{2} \mathrm{O}_{7}-\mathrm{Si}_{3} \mathrm{~N}_{4}$ ceramics consisted of disilicates of a needle-like morphology, but the equiaxed form still predominated. Since only the needle-like morphology was observed for disilicates having the orthorhombic structure, this growth may be dependent on crystal structure. Energy dispersive x-ray spectroscopy of the disilicates indicated the presence of $\sim 6-8$ at.\% Ca associated with crystals having a whisker morphology while no appreciable Ca was detected in the equiaxed crystals, as detailed in Table X.

Figure 38 gives higher magnification backscattered electron inages of the cristobalite and silicate phases of the oxidized surfaces of $\mathrm{Sm}_{2} \mathrm{Si}_{2} \mathrm{O}_{7}-\mathrm{Si}_{3} \mathrm{~N}_{4}, \mathrm{Y}_{2} \mathrm{Si}_{2} \mathrm{O}_{7}-$ $\mathrm{Si}_{3} \mathrm{~N}_{4}$, and $\mathrm{Er}_{2} \mathrm{Si}_{2} \mathrm{O}_{7}-\mathrm{Si}_{3} \mathrm{~N}_{4}$ ceramics. The materials undergoing the greatest oxidation 
were found to contain the lowest volume fraction of amorphous silicate and highest fraction of $\mathrm{RE}_{2} \mathrm{Si}_{2} \mathrm{O}_{7}$, as can be seen by comparing the micrographs within Figs. 37 and 38 . The cristobalite grains were found to be essentially free of impurities with less than 0.5 at. $\mathrm{Ca}$ detected in the grains of all the materials. The remaining amorphous silicate phase surrounding the cristobalite grains had very high concentrations of impurity elements ( $-3-6$ at.\% each of $\mathrm{Mg}, \mathrm{Al}$, and $\mathrm{Ca}$ ); these impurities are believed to have segregated to the grainboundary phase from the $\mathrm{Si}_{3} \mathrm{~N}_{4}$ and $\mathrm{SiO}_{2}$ powders during sintering and then migrated to the surface during oxidation. Interestingly this silicate phase was free from any but a trace amount of $\mathrm{Fe}$. The existence of $\mathrm{Fe}$ in iron silicide inclusions, as shown in Fig. 29 would minimize the accumulation of $\mathrm{Fe}$ in the surface silicate phase, although the presence of $\mathrm{Fe}$ exclusively in the form of inclusions and not as an impurity in the glassy intergranular phase is unlikely. ${ }^{89}$ The incorporation of impurities in the retained amorphous intergranular phase during processing resulted in decreased viscosity of this phase and increased diffusion rates for all cations present in the glass.

\section{Fracture Behavior}

\section{a. Flexural Strength}

Flexural strengths at room temperature and at $1300^{\circ} \mathrm{C}$ are plotted versus temperature in Fig. 39. Room-temperature strengths were generally found to be dependent on porosity levels present in the ceramics. The $\mathrm{Sm}_{2} \mathrm{Si}_{2} \mathrm{O}_{7}-\mathrm{Si}_{3} \mathrm{~N}_{4}$ material, with the lowest density of all materials at $98.0 \%$, had the lowest average strength of $533 \mathrm{MPa}$ while the $\mathrm{Yb}_{2} \mathrm{Si}_{2} \mathrm{O}_{7}-$ $\mathrm{Si}_{3} \mathrm{~N}_{4}$ material with one of the highest densities at $99.6 \%$ had the highest average strength of $623 \mathrm{MPa}$. Strengths as high as $738 \mathrm{MPa}$ were obtained of both the $\mathrm{Gd}_{2} \mathrm{Si}_{2} \mathrm{O}_{7}-\mathrm{Si}_{3} \mathrm{~N}_{4}$ and $\mathrm{Yb}_{2} \mathrm{Si}_{2} \mathrm{O}_{7}-\mathrm{Si}_{3} \mathrm{~N}_{4}$ materials at room-temperature. Although a general trend was observed, there was no explicit strength dependence on density. Standard deviation of the 
strength data for each material tested along with the average strength and Weibull modulus obtained from a Weibull analysis are given in Table XI. The values for the Weibull modulii ranged from a low of 6 for the $\mathrm{E}_{2} \mathrm{Si}_{2} \mathrm{O}_{7}-\mathrm{Si}_{3} \mathrm{~N}_{4}$ material's strength data to a high of 15 for the $\mathrm{Dy}_{2} \mathrm{Si}_{2} \mathrm{O}_{7}-\mathrm{Si}_{3} \mathrm{~N}_{4}$ material's strength data.

For the flexural strengths obtained at $1300^{\circ} \mathrm{C}$ the same general trend of strength dependence on porosity level continued with a few exceptior.ss, indicating additional failure mechanisms were operating at this elevated temperature. 'Table XII summarizes the results of flexure strength at $1300^{\circ} \mathrm{C}$. Analysis of the load vs. deflection curve produced by the chart recorder revealed linear elastic behavior from the onset of loading to failure. No load relaxation occurred during these tests, which would have been indicative of fracture by slow crack growth, and accompanied by a rapid decrease in strength.21,90-92 The absence of slow crack growth indicates the absence of gross plastic deformation by grain-boundary sliding during the short term (20-30 s) of fast-fracture testing.

Although its room-temperature strength (and density) was the lowest among the materials tested, ine $\mathrm{Sm}_{2} \mathrm{Si}_{2} \mathrm{O}_{7}-\mathrm{Si}_{3} \mathrm{~N}_{4}$ material had the highest average strength of $585 \mathrm{MPa}$ at $1300^{\circ} \mathrm{C},-10 \%$ higher than its own room-temperature strength. All other materials displayed a loss in strength at $1300^{\circ} \mathrm{C}$ of between $9 \%$ for the $\mathrm{Er}_{2} \mathrm{Si}_{2} \mathrm{O}_{7}-\mathrm{Si}_{3} \mathrm{~N}_{4}$ and $\mathrm{Yb}_{2} \mathrm{Si}_{2} \mathrm{O}_{7}-\mathrm{Si}_{3} \mathrm{~N}_{4}$ materials, to $20 \%$ for the $\mathrm{Gd}_{2} \mathrm{Si}_{2} \mathrm{O}_{7}-\mathrm{Si}_{3} \mathrm{~N}_{4}$ material. At $1300^{\circ} \mathrm{C}$, the $\mathrm{Yb}_{2} \mathrm{Si}_{2} \mathrm{O}_{7}-\mathrm{Si}_{3} \mathrm{~N}_{4}$ material had an average strength of $567 \mathrm{MPa}$, while the lowest average strength of $467 \mathrm{MPa}$ was displayed by the $\mathrm{Dy}_{2} \mathrm{Si}_{2} \mathrm{O}_{7}-\mathrm{Si}_{3} \mathrm{~N}_{4}$ material. Weibull modulii of these strength data ranged from a low of 14 for the $\mathrm{Yb}_{2} \mathrm{Si}_{2} \mathrm{O}_{7}-\mathrm{Si}_{3} \mathrm{~N}_{4}$ material to a high of 43 for the $\mathrm{Sm}_{2} \mathrm{Si}_{2} \mathrm{O}_{7}-\mathrm{Si}_{3} \mathrm{~N}_{4}$ material. These modulii, which are much higher than those obtained from the room-temperature data, indicate both the reduced dependence of failure from flaws present in these materials, as well as the effect of increased crack blunting due to plastic deformation by the softening of the thin residual amorphous film at elevated temperatures. 21 
Based on the much lower strength of the $\mathrm{im}_{2} \mathrm{Si}_{2} \mathrm{O}_{7}-\mathrm{Si}_{3} \mathrm{~N}_{4}$ material at low temperatures and its high surface porosity, healing of surface flaws through crack blunting by oxidation of the surface occuring during the brief $15 \mathrm{~min}$ exposure at $1300^{\circ} \mathrm{C}$ priol to testing may be responsible for the increased strength at the elevated temperature. ${ }^{93-94}$ This composition exhibited the greatest weight gain during oxidation and it would be expected as well that flaw healing would have the greatest effect on minimizing crack initiation from surface porosity in this material.

\section{b. Fractography}

The fracture surfaces of representative samples of each material composition, one tested at room temperature and one at $1300^{\circ} \mathrm{C}$, were examined by scanning electron microscopy. Strength limiting flaws of those materials tested at room-temperature were common processing defects such as pores, porous zones, powder agglomerates, as well as inclusions, located either at the tensile surface or just below it. Fig. 40 shows the fracture surfaces around the origin of fracture of two materials tested at room temperature. Fig. 41 illustrates two types of inclusions commonly found on the fracture surfaces of materials tested at room temperature. Inclusions commonly found in the form of spherical particles were composed of primarily $\mathrm{Si}, \mathrm{Fe}, \mathrm{Ti}$, and $\mathrm{S}$, while other particles of similar morphology were composed of primarily $\mathrm{Si}, \mathrm{Al}$, and $\mathrm{Ca}$, as the one shown in Fig. 41. Other common types of inclusions appeared to be in the form of platelets and were identified by EDS to be composed primarily of $\mathrm{Si}$ with some minor amounts of the appropriate rare-earth element. These latter inclusions are assumed to be $\mathrm{SiO}_{2}$-rich glasses or devitrification products resulting from inadequate mixing of the sintering additives during processing.

At $1300^{\circ} \mathrm{C}$ strength limiting fiaws were observed to be similar to those found in materials tested at room temperature. Fig. 42 shows the fracture surfaces of two materials tested at $1300^{\circ} \mathrm{C}$. The surfaces appear to be somewhat rougher in appearance than the 
room-temperature fractured specimens, a feature indicative of slow crack growth.91-93 In addition some fracture surfaces displayed flaws that were large inclusions of what appear to be a glassy phase or its devitrification product, attributed to incomplete powder homogenization during processing. Fig. 43 shows such an inclusions at the fracture surface of the $\mathrm{Y}_{2} \mathrm{Si}_{2} \mathrm{O}_{7}-\mathrm{Si}_{3} \mathrm{~N}_{4}$ material. At the fracture surfaces of the materials tested at $1300^{\circ} \mathrm{C}$ the glassy inclusions seem to have softened during the flexure test. Again, the composition of the glass was primarily $\mathrm{Si}$, with a trace amount of $\mathrm{Y}$. Evidence of bubble formation near the edge of the inclusion is also apparent, although this probably occurred during processing.

\section{Time-Dependent Deformation Behavior}

\section{a. Flexural Creep}

The six compositions were tested at $1400^{\circ} \mathrm{C}$ to obtain information on their hightemperature creep behavior. The load was applied and the load-point displacement monitored. The creep strain vs. time curves consisted of two characteristic regions for times up to $100 \mathrm{hr}$. The first region can be associated with what is known as the primary stage $^{95}$ consisting of a relatively high but rapidly decreasing rate of deformation. The second region can be associated with the secondary (steady-state) stage where the curve approaches linearity and the rate of deformation is constant. In the steady-state region the creep rate is given by:

$$
\mathrm{d} \varepsilon / \mathrm{dt}=\mathrm{A} \sigma^{\mathrm{n}} \exp (-\Delta \mathrm{H} / \mathrm{RT})
$$

where $A$ is a pre-exponential constant depending only on temperature and material properties, $n$ is a stress exponent which may or may not depend on stress, and $\Delta H$ is the 
activation energy of the rate-controlling process. Therefore, a log-log plot of the steadystate creep rate vs. applied stress will give a line with a slope of $n$, the stress exponent.

In this study no true steady-state stage was encountered for times up to $100 \mathrm{hr}$, instead a continuously decreasing creep rate was observed. This behavior has been reported in the literature for $\mathrm{Si}_{3} \mathrm{~N}_{4}$ ceramics tested in uniaxial tension, $96-98$ uniaxial compression,98-100 and in four-point bending,98,101,102 and has been attributed to the effects of oxidation and also to further crystallization of the grain-boundary phase occuring continuously during testing. Both processes lead to an increase in creep resistance; during oxidation, impurities migrate along and eventually out of the amorphous intergranular phase as they reach the surface oxide interface (see Section III.C.1.b.) with the net effect being a continuous increase in viscosity of the residual amorphous phase and even subsequent devitrification of the destabilized glass. Only for those samples that failed during testing was there evidence of the tertiary stage of creep behavior, characterized by a rapidly increasing rate of strain, lasting only $2-4 \mathrm{hr}$.

Because of the lack of a true steady-state regime all tests were allowed to proceed for specified length of time, at which time the slope of the creep curve was measured. In these tests the samples were allowed to deform for $70 \mathrm{hr}$ since by this time the slope of the curve had decreased to a point approaching a near steady state, and the slope was then obtained from the previous 8-10 hr. Longer times would have given lower "steady-state" creep rates, however extended test periods would have been impractical due to test fixture geometry and experimental logistics. The typical length of time for creep studies of $\mathrm{Si}_{3} \mathrm{~N}_{4}$ in the literature varies anywhere from $20 \mathrm{hr}$ to over $150 \mathrm{hr}$, depending on if and when the steady-state is achieved.

The creep strain as a function of time under an applied load of $\sim 130-145 \mathrm{MPa}$ (depending on exact specimen dimensions) for the materials, with the exception of the $\mathrm{Sm}_{2} \mathrm{Si}_{2} \mathrm{O}_{7}-\mathrm{Si}_{3} \mathrm{~N}_{4}$ material which is given for a nominal applied load of $70 \mathrm{MPa}$, is plotted in Fig. 43. The two-stage behavior displayed by these materials is evident. Total 
deformations in this plot are misleading and do not indicate the relative refractoriness of these materials, i.e., initial deformations at times are due to test rig instability, which had no effect on measurements of "steady-state" creep rates. From the slopes of these curves, and curves obtained at other applied loads, a plot of "steady-state" creep rate as a function of applied load at $1400^{\circ} \mathrm{C}$ was obtained and is given in Fig. 45. It is evident that the creep deformation behavior of all these materials is similar. The strain rates are all within an order of magnitude and the slopes of the lines fitting the data are very similar as well. The slopes, being equal to the creep stress exponent, were determined to be in the range of 1.6 to 2.0. Values for $\mathrm{n}$ within this range have been reported for $\mathrm{Si}_{3} \mathrm{~N}_{4}$ ceramics similarly tested and are expected when cavitation-induced creep is the dominant deformation mechanism, whereas creep stress exponents of 1 are expected for pure Newtonian viscous creep. $97,99,103,104$

The $\mathrm{Dy}_{2} \mathrm{Si}_{2} \mathrm{O}_{7}-\mathrm{Si}_{3} \mathrm{~N}_{4}$ and $\mathrm{Gd}_{2} \mathrm{Si}_{2} \mathrm{O}_{7}-\mathrm{Si}_{3} \mathrm{~N}_{4}$ materials displayed a surprisingly high resistance to creep based on their low retention of fast-fracture strength at $1300^{\circ} \mathrm{C}$, relative to the other materials. The $\mathrm{Sm}_{2} \mathrm{Si}_{2} \mathrm{O}_{7}-\mathrm{Si}_{3} \mathrm{~N}_{4}$ material displayed the poorest resistance to creep, while displaying the highest fast-fracture strength at $1300^{\circ} \mathrm{C}$. The creep behavior results also indicate that with the exception of the $\mathrm{Sm}_{2} \mathrm{Si}_{2} \mathrm{O}_{7}-\mathrm{Si}_{3} \mathrm{~N}_{4}$ material, all materials displayed better resistance to creep than the $\mathrm{Y}_{2} \mathrm{Si}_{2} \mathrm{O}_{7}-\mathrm{Si}_{3} \mathrm{~N}_{4}$ ceramic. For applied loads of $-100 \mathrm{MPa}$ steady-state creep rates ranged from about $2.0 \times 10^{-5}$ to $1.3 \times 10^{-4} \mathrm{hr}^{-1}$; the lower values are among the lowest reported for $\mathrm{Si}_{3} \mathrm{~N}_{4}$ in four-point bending.

\section{b. Microstructures Following Creep}

Selected materials were chosen to be examined after undergoing creep, using: transmission electron microscopy, for evidence of cavity nucleation, growth, and coalescence leading to microcrack formation, commonly reported as the rate-determining deformation mechanism in liquid-phase sintered ceramics. Three materials were chosen for 
examination: $\mathrm{Sm}_{2} \mathrm{Si}_{2} \mathrm{O}_{7}-\mathrm{Si}_{3} \mathrm{~N}_{4}$, representative of a lower creep resistant material; $\mathrm{Dy}_{2} \mathrm{Si}_{2} \mathrm{O}_{7}-\mathrm{Si}_{3} \mathrm{~N}_{4}$, representative of a higher creep resistant material; and $\mathrm{Y}_{2} \mathrm{Si}_{2} \mathrm{O}_{7}-\mathrm{Si}_{3} \mathrm{~N}_{4}$. Specimens were prepared such that the electron transparent regions were within $1 \mathrm{~mm}$ of the tensile surface of the test specimen (Fig. 6). Both Lange et al..$^{99}$ and Marion et al. ${ }^{105}$ have discussed the difficulties in discerning between cavities produced during creep and those subsequently produced during specimen preparation for TEM by ion milling. Precautions to ensure identification of cavities produced by creep included observing both pre-creep and post-creep specimens of the same materiai and comparing cavities observed in both thick and thin portions of the ion-milled regions.

Rather than being homogeneously distributed throughout the material, distinct clusters of cavities along with occasional isolated cavities were most often observed. Fig. 46 is a pair of bright-field images of the $\mathrm{Sm}_{2} \mathrm{Si}_{2} \mathrm{O}_{7}-\mathrm{Si}_{3} \mathrm{~N}_{4}$ and $\mathrm{Dy}_{2} \mathrm{Si}_{2} \mathrm{O}_{7}-\mathrm{Si}_{3} \mathrm{~N}_{4}$ materials showing the clustering of cavities in these materials. The $\mathrm{Sm}_{2} \mathrm{Si}_{2} \mathrm{O}_{7}-\mathrm{Si}_{3} \mathrm{~N}_{4}$ material contained the greatest concentration of cavities of the three materials examined, while the $\mathrm{Dy}_{2} \mathrm{Si}_{2} \mathrm{O}_{7}-\mathrm{Si}_{3} \mathrm{~N}_{4}$ material had the lowest. With the exception of the concentration of cavities, the cavitation of all three materials was very similar. A wide variety of cavity sizes and geometries was observed in these materials. Small cavities were found almost exclusively at multiple-grain junctions, with only a few observed at two-grain interfaces. The smallest cavities nucleated as circular holes and were located within three-grain junctions, as shown in Fig. 47. The nucleation of these two cavities in the two separate materials during creep is nearly certain since they were observed in a rather thick portion of the specimen where ion milling induced cavitation was unlikely to occur, although the possibility of subsequent milling of the nucleated cavity can not be ignored.

The most commonly observed cavity shape was the triangular wedge, as shown in Fig. 48, located at triple-grain junctions as reported in other investigations. ${ }^{84,96,99,104-106}$ These cavities were observed to vary in size from occupying a small part of the junction to occupying it completely. A common feature of the fully grown cavities was the presence of 
a thin film of amorphous material continuously coating the perimeter. Fig. 49 shows the residual amorphous film lining a cavity following growth. EDS analysis of the residual amorphous film indicates the presence of little Dy or other impurities in this $\mathrm{Dy}_{2} \mathrm{Si}_{2} \mathrm{O}_{7}$ $\mathrm{Si}_{3} \mathrm{~N}_{4}$ specimen, indicating the depletion of cations in the residual amorphous phase due to cation migration to the oxidized surface during testing. The presence of these amorphous films could also be attributed to damage during ion-milling as discussed by other investigators. 99,105 Since all multiple-grain junctions were found to have crystallized completely following heat treating (with the exception of a small fraction in the $\mathrm{Yb}_{2} \mathrm{Si}_{2} \mathrm{O}_{7}$ $\mathrm{Si}_{3} \mathrm{~N}_{4}$ material), it is believed that cavity nucleation occurred at the interface of $\beta-\mathrm{Si}_{3} \mathrm{~N}_{4}$ and disilicate grains where a thin amorphous film exists. Growth of these cavities probably proceeds, following the viscous flow of the vitreous phase, by a diffusive growth mechanism at the expense of the disilicate phase or possibly even $\beta-\mathrm{Si}_{3} \mathrm{~N}_{4}{ }^{84,106}$

In addition to evidence of cavitation induced creep, evidence of grain-boundary sliding in the form of "strain whorls" was observed at a few two-grain boundaries, as shown in Fig. 50. Such "strain whorls" have been previously reported 84,107 in materials examined after creep. The whorls are extinction contours resulting from a localized out-ofplane buckling of the specimen, since tiling of the specimen in the TEM caused the whorls to change shape and orientation. The extinction contours are an indication of contact stresses between the grains. The contours appear to originate from a single point, suggesting a point contact between the grains. Lange et al. ${ }^{107}$ observed that strain whorls were present only in materials that had been cooled under the applied load, with whorls occuring only on grain boundaries whose planes were parallel to the direction of grain separation. This implied that the whorls formed on those boundaries where the relative grain displacement included a component of grain-boundary sliding. Specimens in the present investigation were all cooled under applied load. 


\section{DISCUSSION}

\section{A. MICROSTRUCTURAL EVOLUTION DURING PROCESSING}

\section{Crystallization of the Intergranular Phase}

The densification of $\mathrm{Si}_{3} \mathrm{~N}_{4}$ ceramics produced by sintering in the presence of a liquid has been viewed by Kingery ${ }^{7}$ as being caused by compressive forces, arising from capillary pressure, acting between particles that are in contact. These compressive forces give rise to the higher solubility of the solid $\mathrm{Si}_{3} \mathrm{~N}_{4}$ particles at the contact positions. The diffusion of $\mathrm{Si}_{3} \mathrm{~N}_{4}$ solute in the liquid phase away from the contact positions, and therefore the approach of particle centers, leads to densification. The question of whether there is indeed intimate contact of the particles resulting in a final microstructure where $\mathrm{Si}_{3} \mathrm{~N}_{4}$ grains could be in direct contact with the expulsion of all liquid from two-grain boundaries to the multiple-grain junctions has been addressed by Lange. $108 \mathrm{By}$ applying a theory developed for plates that sandwich a liquid layer to spherical particles undergoing liquidphase siniering, it was predicted that although the liquid layer decreases with time, a finite thickness will always remain between particles when the liquid perfectly wets the solid. In fact microscopy studies have verified the existence of thin (on the order of 1-10 nm) intergranular amorphous films existing in sintered $\mathrm{Si}_{3} \mathrm{~N}_{4}$ (see for example Refs. 9-12).

Clarke ${ }^{109}$ subsequently discussed whether thin intergranular films can adopt an equilibrium thickness in polycrystalline ceramics. It was shown, based on interfacial energies and on the force balance normal to the boundary, that the origin of an equilibrium thickness was the result of two competing interactions, the balance of an ittractive van der Waals-dispersion force between the grains on either side of the boundary acting to thin the film with a repulsive force due to the structure of the liquid opposing this attraction. An equilibrium thickness on the order of $1 \mathrm{~nm}$ was proposed based on the short range $(<10$ 
$\mathrm{nm}$ ) of these interactions, but being ultimately dependent on the composition of the liquid, as well as that of the grains on either side of the liquid.

To date, crystallization of the intergranular liquid in $\mathrm{Si}_{3} \mathrm{~N}_{4}$ ceramics has always resulted in a residual amorphous phase residing at both two-grain junctions as thin films and at multiple-grain junctions, typically segregated at the nodes as shown in Figs. 13 and 14. It has been shown based on thermodynamical considerations that complete crystallization of the amorphous phase segregated in grain boundaries in polyphase ceramics is more difficult to achieve than crystallization of the same phase in bulk.31,66 The liquid constrained in the grain boundaries may support hydrostatic stresses and any volume changes occuring during phase transformation, therefore, will give rise to strain energy which will oppose devitrification. No crystallization will occur if the pocket size is less than half the critical radius (a function of geometry, interfacial energies and change in free energy of the crystallized glass). 66

Other factors complicating complete crystallization of the intergranular phase include inhomogeneous glass composition and the presence of impurities which segregate to the glass from the $\mathrm{Si}_{3} \mathrm{~N}_{4}$ powder during the solution-reprecipitation process. The presence of compositional heterogeneities in the intergranular glass, as shown in Fig. 27, can lead to regions with enhanced glass stability, resulting in only partial devitrification of multiple-grain junctions in these regions (Figs. 25 and 26). The enhanced stability of amorphous phases and their subsequent resistance to devitrification has also been attributed to the presence of impurities. $29,59,101,110$ The presence of $\mathrm{Al}$ in stabilizing glasses has been introduced in Section I.D. and this stabilization by other glass-network formers is well known. The stabilization of vitreous materials by the addition of multiple dissolved impurities is a common practice in the industry. In general cations having high valence, high single-bond strength, and forming coordination polyhedra are considered network formers and aid in vitrification. ${ }^{110}$ In order to achieve maximum crystallization of the intergranular phase of $\mathrm{Si}_{3} \mathrm{~N}_{4}$ ceramics and obtain optimum high-temperature behavior, 
higher quality starting powders having improved purities are essential to eliminate the presence of trace impurity elements.

\section{Crystallization of $\mathrm{RE}_{2} \mathrm{Si}_{2} \mathrm{O}_{7}$ as a Secondary Phase}

The crystallization behavior of $\mathrm{RE}_{2} \mathrm{Si}_{2} \mathrm{O}_{7}$ at the multiple-grain junctions of these $\mathrm{Si}_{3} \mathrm{~N}_{4}$ compositions consists of large scale crystal growth exceeding the single multiplegrain junction where nucleation occurred. The growth of the single crystal has been shown (for example, Fig. 11) to span several micrometers. Work in crystallizing other $\mathrm{Si}_{3} \mathrm{~N}_{4}$ compositions also resulted in a similar secondary phase morphology. 26,28,57,58,75 While Bonnell et al. 26 observed the crystallization behavior of yttrium aluminum garnet $\left(\mathrm{Y}_{3} \mathrm{Al}_{5} \mathrm{O}_{12}\right)$ in sialon ceramics to proceed via large scale growth of single crystals, crystallization of cordierite $\left(\mathrm{Mg}_{2} \mathrm{Al}_{4} \mathrm{Si}_{5} \mathrm{O}_{14}\right)$ resulted in a fine-grained structure with each multiple-grain junction composed of individual crystals. The crystallization behavior resulting in the differing secondary-phase morphologies is likely to be a function of the relative ease of nucleation and growth of the crystals. For the crystallization of a phase where nucleation is limited, growth proceeds from fewer nuclei resulting in a secondary phase consisting of fewer but larger grains. The crystallization of a phase undergoing frequent nucleation events, results in a secondary phase consisting of many fine grained crystals.

The processing of the materials in the present study entailed a drop from the sintering temperature directly to the temperature where crystallization was obtained. The absence of a nucleation period at a temperature just above the softening point of the glass decreases or even may eliminate the nucleation rate since at the higher temperatures the solubility in the melt is maximized. 59 Whereas, by incorporating a two-stage heat treatment, maximum rates of nucleation and growth may be realized, resulting in finer grained microstructure with improved fracture strength but reduced creep resistance. ${ }^{111}$ An 
alternative method to obtain a finer dispersion of secondary-phase grains would be to incorporate chemically inert particles (such as $\mathrm{Z}_{2}$ ) as nucleating agents into the sintering additives. ${ }^{29}$ The type of secondary-phase morphology required is dependent on the material properties desired. The observation that all materials in this study exhibited similar secondary-phase crystallization behavior was expected from previous work on the formation of the rare-earth disilicates in bulk.36,38

\section{B. MICROSTRUCTURAL EVOLUTION DURING OXIDATION}

\section{Mechanism of Silicon Nitride Oxidation}

The parabolic oxidation kinetics exhibited by sintered silicon nitride ceramics were originally assumed to be the result of a protective surface layer of $\mathrm{SiO}_{2}$, as in the case of pure $\mathrm{Si}_{3} \mathrm{~N}_{4}$. The work of Singhal ${ }^{67}$ and Cubicciotti et al. ${ }^{68,69}$ dispelled this notion of the oxide layer forming a passivating layer through which the diffusion of oxygen was the ratelimiting step. Singhal found that there was no effect of varying oxygen partial-pressure on the weight gain of $\mathrm{MgO}$-sintered $\mathrm{Si}_{3} \mathrm{~N}_{4}$ and concluded that the diffusion of oxygen through

the scale was not rate limiting. Cubicciotti et al. found that the reoxidation of previously oxidized $\mathrm{MgO}$ - and $\mathrm{Y}_{2} \mathrm{O}_{3}$-sintered $\mathrm{Si}_{3} \mathrm{~N}_{4}$ specimens from which a portion of the oxide scale had been removed yielded kinetic data which followed the original parabolic curves, i.e., the change in weight was independent of the removal of the oxide scale for both materials. It was then shown that the outward diffusion of additive cations $\left(\mathrm{Mg}^{2+}\right.$ or $\mathrm{Y}^{3+}$, as well as impurities of $\mathrm{Al}^{3+}, \mathrm{Ca}^{2+}$, and $\mathrm{Fe}^{3+}$ ) and nitrogen, produced by the amorphous intergranular-phase/oxide-layer diffusion couple, and the inward diffusion of oxygen resulted in a compositional gradient beneath the oxide layer.

Since the compositional gradient is produced by diffusion, its extent within the bulk is governed by a parabolic rate law. This outward diffusion of additive and impurity 
cations decreases the volume fraction of the glass phase. Since the decrease in glass content is governed by the same parabolic oxidation kinetics that governs the compositional change, the flux of inward diffusing $\mathrm{O}^{2}$ - decreases with parabolic kinetics. Therefore, the parabolic oxidation kinetics exhibited by sintered $\mathrm{Si}_{3} \mathrm{~N}_{4}$ ceramics is produced, not by a protective surface oxide layer, but by a sublayer compositional gradient.

In the present study, the aim was to produce $\mathrm{Si}_{3} \mathrm{~N}_{4}$ ceramics a with crystalline secondary phase of $\mathrm{RE}_{2} \mathrm{Si}_{2} \mathrm{O}_{7}$. In addition to $\mathrm{RE}_{2} \mathrm{Si}_{2} \mathrm{O}_{7}$, a thin residual amorphous film was observed to exist at the grain boundaries (Figs. 13 and 14). Also, incomplete crystallization of the multi-grain junctions was observed in an isolated region of the $\mathrm{Yb}_{2} \mathrm{Si}_{2} \mathrm{O}_{7}-\mathrm{Si}_{3} \mathrm{~N}_{4}$ material prepared for transmission electron microscopy (Figs. 25 and 26). The presence of residual amorphous grain-boundary phases, which are never in equilibrium with $\mathrm{SiO}_{2}$ (the oxidation product of $\mathrm{Si}_{3} \mathrm{~N}_{4}$ ), result in the $c_{2}$ zation of a driving force for additive and impurity cation diffusion to the $\mathrm{Si}_{3} \mathrm{~N}_{4}$-bulk/oxide-layer interface. Although undetectable due to difficulties in analyzing the very thin amorphous grainboundary films by microanalysis in these materials, impurities such as $\mathrm{Mg}, \mathrm{Al}, \mathrm{Ca}$, and $\mathrm{Fe}$ are known to segregate to the amorphous intergranular phase during liquid-phase sintering. The presence of these impurities in addition to the additive cations $\left(\mathrm{RE}^{3+}\right)$ determine to a great extent the properties of the amorphous phase. Whereas the substitution of rare-earth oxides for magnesia as sintering aids for $\mathrm{Si}_{3} \mathrm{~N}_{4}$ was made to increase the refractoriness of the amorphous grain-boundary phase by increasing its viscosity, the unintentional incorporation of transition metal impurities into the glassy phase results in a reduction in viscosity.

The stability of the secondary phases toward oxidation and the refractoriness of residual amorphous films, therefore primarily determine the oxidation behavior of the $\mathrm{Si}_{3} \mathrm{~N}_{4}$ ceramic. In the materials studied, the secondary phases obtained are stable toward oxidation, therefore, the oxidation behavior was dependent solely on the amorphous intergranular-phase composition and the diffusion of its components to the bulk/oxide 
interface. The impurity content of the oxidized surfaces (Table X) of all six materials was very similar, implying that the differences obtained in oxidation behavior can be attributed to the effect of the additive cation on amorphous-phase viscosity. The differences observed in the six materials based on specific weight gain (Fig. 32) support the dependence of oxidation behavior on the specific additive cation. The ranking of these materials by oxidation resistance is directly proportional to the eutectic temperatures of the respective $\mathrm{RE}_{2} \mathrm{O}_{3}-\mathrm{SiO}_{2}$ binary systems (Table II and Fig. 3); i.e., in the binary systems with the highest eutectic temperatures, the materials based on these additives have shown the lowest weight gains. For these chemically similar grain-boundary phises, the viscosities are, therefore, assumed to be related to the eutectic temperatures. Although the amorphous phase contains $\mathrm{N}$ (which is estimated to lower the eutectic temperature of the $\mathrm{Y}_{2} \mathrm{O}_{3}-\mathrm{SiO}_{2}$ system by $\sim 140^{\circ} \mathrm{C}$, however raise its viscosity 52 ), as well as the impurities mentioned, the effect of these constituents should be similar for all materials based on their similar compositions.

The one material which displayed greatly differing oxidation behavior was the $\mathrm{Sm}_{2} \mathrm{Si}_{2} \mathrm{O}_{7}-\mathrm{Si}_{3} \mathrm{~N}_{4}$ material. Whereas all other materials displayed, for the most part, parabolic oxidation kinetics, the $\mathrm{Sm}_{2} \mathrm{Si}_{2} \mathrm{O}_{7}-\mathrm{Si}_{3} \mathrm{~N}_{4}$ material deviated from this behavior and exhibited twice the weight gain as the other materials after $192 \mathrm{hr}$. Mieskowski and Sanders ${ }^{72}$ also reported nearly twice the weight gain of a $\mathrm{Sm}_{2} \mathrm{O}_{3}$-sintered $\mathrm{Si}_{3} \mathrm{~N}_{4}$ material as that of a $\mathrm{Y}_{2} \mathrm{O}_{3}$-sintered $\mathrm{Si}_{3} \mathrm{~N}_{4}$ after $200 \mathrm{hr}$ at $1370^{\circ} \mathrm{C}$, however, they also reported parabolic oxidation kinetics for both materials. Both materials were characterized as having completely amorphous grain-boundary phases.

The rate of weight gain of the $\mathrm{Sm}_{2} \mathrm{Si}_{2} \mathrm{O}_{7}-\mathrm{Si}_{3} \mathrm{~N}_{4}$ material in the present study was very high at first and then decreased to a rate similar to that of the other five materials. The apparent departure of the oxidation behavior from that of parabolic may involve a reduction in surface area as oxidation progresses by the sealing of open porosity by the oxidation product, with the net effect being a steady increase in specific weight (assuming a constant 
surface area). The $\mathrm{Sm}_{2} \mathrm{Si}_{2} \mathrm{O}_{7}-\mathrm{Si}_{3} \mathrm{~N}_{4}$ material had achieved the lowest percentage of theoretical density (98\%) and therefore the existence of open porosity is likely. The increased surface area provided by porosity open to the surface initially would produce artificially high oxidation rates by assuming surface area based on specimen dimensions alone. As oxidation proceeded and the pores were closed by oxidation product, this additional surface where reaction initially occurred would no longer be a source of reactant and the measured specific weight gain would approach the true weight gain per unit surface area as given by the specimen dimensions. Hence, following an initial period of oxidation where available surface area is continuously decreasing, the surface area becomes constant and parabolic oxidation kinetics are observed, as can be seen in Fig. 33.

The much higher apparent diffusivity of $\mathrm{Sm}$ cations through the grain-boundary phase than that of the other rare-earth cations can not be explained on the basis of differences in eutectic temperatures of the systems alone. Although, the high specific weight gains initially occuring may be due to inaccurate estimates of surface area due to the presence of purosity, an alternative explanation for the high rate of oxidation throughout the test may reside in the fact that $\mathrm{Sm}$ can exist in both the divalent and trivalent states. ${ }^{112}$ Cerium can also exist in more than just the trivalent oxidation state. In $\mathrm{CeO}_{2}$-sintered $\mathrm{Si}_{3} \mathrm{~N}_{4}$ ceramics, $\mathrm{CeO}_{2}$ is known to reduce to $\mathrm{Ce}_{2} \mathrm{O}_{3}$ during sintering under inert conditions according to the reaction 62,113

$$
12 \mathrm{CeO}_{2}+\mathrm{Si}_{3} \mathrm{~N}_{4}=6 \mathrm{Ce}_{2} \mathrm{O}_{3}+3 \mathrm{SiO}_{2}+2 \mathrm{~N}_{2}
$$

During the oxidation of $\mathrm{CeO}_{2}$-sintered $\mathrm{Si}_{3} \mathrm{~N}_{4}$ ceramics, the mechanism proposed ${ }^{71}$ involves the migration of $\mathrm{Ce}^{3+}$ cations from the grain-boundary phase to the bulk/oxide interface and subsequent dissolution in the amorphous surface silicate phase up to the equilibrium saturation, with excess $\mathrm{Ce}^{3+}$ being oxidized to $\mathrm{Ce}^{4+}$ by oxygen dissolved in 
the silicate resulting in the exolution of $\mathrm{CeO}_{2}$ crystals. $\mathrm{S}_{33} \mathrm{~N}_{4}$ then dissolves in the silicate phase and reacts with the dissolved oxygen forming $\mathrm{SiO}_{2}$ and the evolution of $\mathrm{N}_{2}$.

A similar reduction/oxidation reaction is proposed for $\mathrm{Sm}$ in $\mathrm{Sm}_{2} \mathrm{Si}_{2} \mathrm{O}_{7}-\mathrm{Si}_{2} \mathrm{~N}_{4}$ ceramics. Although the trivalent state is the characteristic one for all lanthanides and they can all exist in the divalent state under unusual conditions, only Sm, Eu, and $\mathrm{Yb}$ have significant "normal" chemistry in the divalent state. ${ }^{112}$ Atypical oxidation states are most prevalent for lanthanides when the ion can attain empty, half-filled, or filled $f$-shells. Even though $\mathrm{Sm}, \mathrm{Eu}$, and $\mathrm{Yb}$ are known to exist in the divalent state, the trivalent state is the most stable oxidation state. Analogous to the reaction involving the reduction of $\mathrm{CeO}_{2}$ to $\mathrm{Ce}_{2} \mathrm{O}_{3}$, samarium could exist as $\mathrm{Sm}^{2+}$ after rusuction by dissolved nitrogen in the residual amorphous grain-boundary phase, which is known to be an oxynitride glass. The diffusion rate of divalent $\mathrm{Sm}$ is expected to be much greater than that of trivalent $\mathrm{Sm},{ }^{112}$ which would account for the much greater weight gain upon oxidation of this material as compared with the weight gain of the other five materials. Upon reaching the bulk/oxide interface $\mathrm{Sm}^{2+}$ dissolves in the surface silicate phase and is subsequently oxidized to $\mathrm{Sm}^{3+}$, reacts with dissolved $\mathrm{SiO}_{2}$, and precipitates out of solution as $\mathrm{Sm}_{2} \mathrm{Si}_{2} \mathrm{O}_{7}$. A problem with this hypothesis is that $\mathrm{Yb}$ can also exist in the divalent state; based on the observed oxidation kinetics of the $\mathrm{Yb}_{2} \mathrm{Si}_{2} \mathrm{O}_{7}-\mathrm{Si}_{3} \mathrm{~N}_{4}$ material, whch are similar to that of the other four materials, there is no reason to suspect the reduction of $\mathrm{Yb}^{3+}$ to $\mathrm{Yb}^{2+}$.

\section{Morphology of Oxidized Surfaces}

During the oxidation of sintered $\mathrm{Si}_{3} \mathrm{~N}_{4}$ materials, the surface silica produced as the oxidation product of $\mathrm{Si}_{3} \mathrm{~N}_{4}$ is brought to chemical equilibriurn with thcse intergranular phases not already existing in equilibrium with $\mathrm{SiO}_{2}$ (amorphous phase and incompatible crystalline phases) by the outward diffusion of additive and impurity cations. The equilibrium condition changes as oxidation proceeds and the grain-boundary phase 
becomes depleted of these cations. Precipitation of crystalline $\mathrm{RE}_{2} \mathrm{Si}_{2} \mathrm{O}_{7}$ and $\mathrm{SiO}_{2}$ from the surface silicate melt maintains chemical equilibrium with the changing grain-boundary phase composition. The growth of crystals in preferred directions can be explained in terms of relative entropy changes $(\Delta S)$ associated with growth. ${ }^{110} \mathrm{~A}$ large $\Delta S$ results in the growth of faceted crystals due to anisotropic growth rates. A small $\Delta S$ results in the growth of isotropic crystals due to low growth-rate anisotropy. A large $\Delta S$ is expected for the growth of most inorganic compounds from the vapor phase or dilute solutions, including silicates from melts; whereas, a small $\Delta S$ accoinpanies the growth of most metals and $\mathrm{SiO}_{2}$ from melts. ${ }^{110}$ Figs. 36-38 indicate the isotropic growth of $\mathrm{SiO}_{2}$ and the faceted growth of the disilicates as predicted by differences in changes in entropy of crystal growth.

Previous investigations ${ }^{72,88}$ have reported the growth of $\mathrm{RE}_{2} \mathrm{Si}_{2} \mathrm{O}_{7}$ crystals on the surface of the oxidized samples to be primarily in the form of needles and platelets. Babini et al. ${ }^{88}$ have studied the effects of relative amounts of impurities in $\mathrm{Y}_{2} \mathrm{O}_{3} / \mathrm{SiO}_{2}$-sintered $\mathrm{Si}_{3} \mathrm{~N}_{4}$ on the evolution of the morphology of the oxidized surfaces. They concluded that viscosity of the surface silicate phase, ionic mobility and degree of oversaturation of the diffusing cations in the surface silicate were closely related to the rate of oxidation, and that the morphology of the $\mathrm{Y}_{2} \mathrm{Si}_{2} \mathrm{O}_{7}$ crystallized in the oxidized surface was dependent on oxidation temperature, quenching rate, and relative amount of impurities to $\mathrm{Y}^{3+}$ in the surface silicate. In general, at lower oxidation temperatures $\left(1000-1300^{\circ} \mathrm{C}\right)$ the ratio of impurity cations to $\mathrm{RE}^{3+}$ in the surface silicate is higher due to the higher diffusion coefficients of the impurities. The high viscosity of the surface silicate and low degree of oversaturation of $\mathrm{RE}^{3+}$ and low mobility lead to the formation of $\mathrm{RE}_{2} \mathrm{Si}_{2} \mathrm{O}_{7}$ occuring along the most energetically favored directions. At higher temperatures $\left(>1300^{\circ} \mathrm{C}\right)$ the ratio of impuni:-s to $\mathrm{RE}^{3+}$ is reduced and due to the resulting high degree of oversaturation of $\mathrm{RE}^{3+}$ and its inc-ased mobility $\mathrm{RE}_{2} \mathrm{Si}_{2} \mathrm{O}_{7}$ crystallizes closer to equilibrium, minimizing surface energy and growing in more equiaxed morphoiogy. 
All materials in the present investigation were oxidized under the same conditions $\left(1400^{\circ} \mathrm{C}\right.$ for $-200 \mathrm{hr}$ ) and according to the results of $\mathrm{x}$-ray microanalysis presented in Section III.C.1.b. impurity concentrations in the oxidized surface layers of all six materials were about the same. The surfaces of all materials with the exception of the $\mathrm{Y}_{2} \mathrm{Si}_{2} \mathrm{O}_{7}$ $\mathrm{Si}_{3} \mathrm{~N}_{4}$ material contained $\mathrm{RE}_{2} \mathrm{Si}_{2} \mathrm{O}_{7}$ crystals of equiaxed morphology, with that of $\mathrm{Y}_{2} \mathrm{Si}_{2} \mathrm{O}_{7}$ being elongated and plate-like. Only the $\mathrm{Gd}_{2} \mathrm{Si}_{2} \mathrm{O}_{7}-\mathrm{Si}_{3} \mathrm{~N}_{4}$ and $\mathrm{Dy}_{2} \mathrm{Si}_{2} \mathrm{O}_{7}-\mathrm{Si}_{3} \mathrm{~N}_{4}$ materials contained disilicates of the needle-like morphology and in both cases the needles contained -6 at.\% $\mathrm{Ca}$, while the same disilicates in the equiaxed morphology did not. It is highly likely that $\mathrm{Ca}$ acts to catalyze the growth of these crystals along preferred planes, forming high aspect ratios resulting from highly anisotropic growth rates. By sintering $\mathrm{Si}_{3} \mathrm{~N}_{4}$ with the addition of a small amount of a dopant such as $\mathrm{CaO}$, highly elongated $\beta-\mathrm{Si}_{3} \mathrm{~N}_{4}$ grains have been known to be catalyzed, 114 resulting in a microstructure that exhibits improved fracture toughness. Such a mechanism may be responsible for the formation of the needlelike $\delta-\mathrm{Gd}_{2} \mathrm{Si}_{2} \mathrm{O}_{7}$ and $\delta-\mathrm{Dy}_{2} \mathrm{Si}_{2} \mathrm{O}_{7}$ grains in the presence of high $\mathrm{Ca}$ concentrations.

The needle-like morphology was only assumed by the disilicates having an orthorhombic crystal structure. The $\beta-\mathrm{Er}_{2} \mathrm{Si}_{2} \mathrm{O}_{7}$ and $\beta-\mathrm{Yb}_{2} \mathrm{Si}_{2} \mathrm{O}_{7}$ forming the equiaxed, granular-like crystals are monoclinic as is $\mathrm{Y}_{2} \mathrm{Si}_{2} \mathrm{O}_{7}$ forming the flattened elongated crystals. The polymorphs of $\mathrm{RE}_{2} \mathrm{Si}_{2} \mathrm{O}_{7}$ observed by others ${ }^{72,88}$ to grow into needle-like crystals were not identified, however the oxidation temperatures of $-1300-1400^{\circ} \mathrm{C}$ suggest the same polymorphs to be present as identified in the present study. The tetragonal structure of $A$ $\mathrm{Sm}_{2} \mathrm{Si}_{2} \mathrm{O}_{7}$ resulted in highly faceted crystals, not unlike those of the orthorhombic $\delta$ $\mathrm{Gd}_{2} \mathrm{Si}_{2} \mathrm{O}_{7}$ and $\delta-\mathrm{Dy}_{2} \mathrm{Si}_{2} \mathrm{O}_{7}$. 


\section{INFLUENCE OF MICROSTRUCTURE ON MECHANICAL BEHAVIOR}

\section{Dependence of Strength on Inhomogeneities}

The strength of all materials is limited by defects. This limitation is even more pronounced in ceramics where defects lead to stress concentrations, crack initiation, and failure due to their unforgiving (brittle) nature. Defects are introduced during either fabrication or surface preparation. These flaws include surface cracks, large voids or clusters of voids, inclusions, and large grains resulting from abnormal grain growth. Surface crack and large-grain-induced fractures are primarily a consequence of residual stresses, void-related failures are generally due to stress concentrations, and inclusioninitiated failure involves a combination of residual stresses and stress concentrations. ${ }^{115}$

In $\mathrm{Si}_{3} \mathrm{~N}_{4}$ ceramics, at temperatures below $\sim 800^{\circ} \mathrm{C}$, fracture is elastic and the strength is generally invariant with temperature. Fracture in this temperature range usually occurs from pre-existing flaws or from the coalescence of stress-induced microcracks. In specimens tested in flexure the largest tensile stresses are imposed on the surface; therefore, fractures generally originate from surface flaws and flexural strengths generally reflect the surface flaw population. Fracture at temperatures above $-800^{\circ} \mathrm{C}$ is often characterized by a prior nonlinear deformation and strength decreases with increasing temperature and decreasing strain rate. Fracture now depends critically on the nature and composition of the secondary and grain-boundary phases, and involves the formation and coalescence of cavities associated with either diffusive transport of matter from the growing cavity or viscous hole growth within an amorphous cavity. 116

The microstructures of all materials fabricated in this study were essentially identical with respect to grain size and morphology and crystalline nature of the secondary phase. Room-temperature strengths were directly related to the density of these materials, 
indicating that strengths were probably related to surface flaw population. At the elevated temperature all materials with the exception of the $\mathrm{Sm}_{2} \mathrm{Si}_{2} \mathrm{O}_{7}-\mathrm{Si}_{3} \mathrm{~N}_{4}$ material showed a decrease in strength of $9-20 \%$. The high-temperature strengths followed the same relation to density as those at room-temperature, with a lack of nonlinear deformation preceding fracture indicative of the refractoriness of these materials. The retentions in strength of these materials could be roughly correlated with the $\mathrm{RE}_{2} \mathrm{O}_{3}-\mathrm{SiO}_{2}$ binary eutectic temperatures, which give a relative approximation of the refractoriness of the residual amorphous phases present in each material. The strength at $1300^{\circ} \mathrm{C}$, however, is as much dependent on flaws present in these materials as on the refractoriness of the grain-boundary phases. This point is exemplified in the behavior of the $\mathrm{Sm}_{2} \mathrm{Si}_{2} \mathrm{O}_{7}-\mathrm{Si}_{3} \mathrm{~N}_{4}$ material at the elevated temperature. The results of oxidation and creep tests suggest that the refractoriness of the $\mathrm{Sm}_{2} \mathrm{Si}_{2} \mathrm{O}_{7}-\mathrm{Si}_{3} \mathrm{~N}_{4}$ material is somewhat less than that of the other five materials. However, the strength obtained at $1300^{\circ} \mathrm{C}$ of the $\mathrm{Sm}_{2} \mathrm{Si}_{2} \mathrm{O}_{7}-\mathrm{Si}_{3} \mathrm{~N}_{4}$ material was the highest, $10 \%$ higher than its room-temperature strength which was the lowest of all materials tested. The low room-temperature strength is believed to be attributed to the low bulk density and therefore high flaw population in this material. An increase in strength at $1300^{\circ} \mathrm{C}$ seems to indicate a healing of surface flaws during the $15 \mathrm{~min}$ exposure during testing by crack ip blunting, thereby reducing stress concentrations. 93.94

Govila 91,92 has reported a moderate strength increase (10\%) at temperatures where the onset of amorphous grain-boundary softening is thought to occur. This increase in strength was attributed to increased plasticity of the grain-boundary phase resulting in absorption of energy from the propagating crack via crack blunting, similar in effect to the plastic zone in metals. As the temperature increases further, strength decreases dramatically due to viscous flow of the glassy phase, leading to grain-boundary sliding. A similar mechanism is not likely to be responsible for the increase in strength of the $\mathrm{Sm}_{2} \mathrm{Si}_{2} \mathrm{O}_{7}$ $\mathrm{Si}_{3} \mathrm{~N}_{4}$ material, since the more refractory materials tested had decreases in strengths at 
$1300^{\circ} \mathrm{C}$, rather than maintaining their room-temperature strengths, indicating $1300^{\circ} \mathrm{C}$ is well past the onset of grain-boundary softening.

Some plastically induced fracture resistance was evidenced at $1300^{\circ} \mathrm{C}$ based on the much higher Weibull modulii of the high-temperature strength data than those obtained of the room-temperature data, indicating the effect of increased crack blunting due to plastic deformation by the softening of the thin residual amorphous film at elevated temperatures. However, softening of the amorphous phase beyond the point of reducing crack energy by plastic deformation to where fracture of these materials is enhanced was still below that necessary for large-scale grain-boundary sliding and nonlinear deformation prior to failure.

\section{Mechanism of Time-Dependent Creep}

Time-dependent creep of silicon nitride ceramics is a direct result of deformation and failure of a grain-boundary amorphous or crystalline secondary phase. Evans and Sharp ${ }^{117}$ have indicated that dislocation motion is not observed in $\beta-\mathrm{Si}_{3} \mathrm{~N}_{4}$ and that it is not likely to occur at temperatures below $1700^{\circ} \mathrm{C}$. Kossowsky 118 also noted that even if dislocation motion was occuring at a temperature of $\sim 1400^{\circ} \mathrm{C}$, the contribution to total strain would be $\sim 10^{-5}$, whereas creep strains observed in the present study, and in others in the literature, are on the order of $10^{-2}$. Observations of materials tested in creep also did not reveal any indication of deformation occuring in the $\mathrm{B}-\mathrm{Si}_{3} \mathrm{~N}_{4}$ grains themselves, rather creep can be attributed to activity occuring within the grain-boundaries and multiple-grain junctions containing the disilicate secondary phase (Figs. 46-50). In liquid-phase sintered ceramics, creep damage in the form of cavitation nucleation and growth at the multiplegrain junctions has been shown to dominate creep life. 84,97,99,104-106 Various approaches have been taken to minimize this process by either reducing the cavitation nucleation rate or reducing the cavity growth rate by varying the grain size and grain morphology, varying 
the type and amount of sintering additives, thereby changing the grain-boundary phase, or by crystallizing the grain-boundary phase.

The creep of $\mathrm{Si}_{3} \mathrm{~N}_{4}$ ceramics containing an amorphous intergranular phase has beeil shown 99,105 to proceed by a combination of diffusional creep and cavitational creep. Diffusional creep is presumed to occur by the redistribution of matter through the viscous grain-boundary phase. Solution of $\mathrm{Si}_{3} \mathrm{~N}_{4}$ into the viscous phase and subsequent reprecipitation is driven by differential chemical potentials that arise from localized stresses. 99 Cavitational creep relies on grain-boundary sliding for the nucleation and growth of cavities to occur. ${ }^{119,120}$ Once the cavity is nucleated, pocket depletion proceeds by viscous flow of the amorphous phase into the neighboring two-grain channels until the pocket is fully depleted. Pocket depletion is then followed by linkage with other depleted junctions in the formation of a facet cavity.

In $\mathrm{Si}_{3} \mathrm{~N}_{4}$ with crystalline secondary phases, cavitational creep proceeds by a combination of cavity nucleation at the thin residual amorphous phase followed by diffusive cavitation growth at the expense of the secondary phase or even neighboring $\mathrm{Si}_{3} \mathrm{~N}_{4}$ grains. ${ }^{106}$ Since after crystallization there is a thin residual amorphous film remaining due to the difficulties in obtaining complete crystallization as discussed in Section IV.A.1., these sites are extremely small and therefore the cavity density of these materials has been showin to be much less than that of materials consisting of a completely amorphous secondary phase. ${ }^{106}$ Subsequent stages of failure are then expected to involve the coalescence of cavities to form discrete microcracks. Crack advance then proceeds by the nucleation and growth of cavities in the concentrated stress field ahead of the crack and the subsequent extension of the crack to a critical dimension.

Observations of cavitation nucleation and growth in the present study indicate the nucleation of grains occuring at multiple-grain junctions at the interface of $\mathrm{Si}_{3} \mathrm{~N}_{4}-\mathrm{Si}_{3} \mathrm{~N}_{4}$ grains and the interface of $\mathrm{Si}_{3} \mathrm{~N}_{4}-\mathrm{RE}_{2} \mathrm{Si}_{2} \mathrm{O}_{7}$ grains where the thin amorphous film exists. Following nucleation and depletion of the residual amorphous phase, growth proceeds by 
diffusion of the crystalline phases. Observations of cavity growth suggest that diffusional growth proceeds primarily at the expense of the rare-earth disilicates. $\mathrm{RE}_{2} \mathrm{Si}_{2} \mathrm{O}_{7}$ also begins to deform at these elevated temperatures since it is an ionically bonded compound that is stressed well above half its melting temperature (see Table II). The coalescence of cavities was observed (Fig. 46), however, the formation of microcracks from these cavinies between the $\beta-\mathrm{Si}_{3} \mathrm{~N}_{4}$ grains was rarely observed. The low strains $(\sim 1 \%)$ exhibited by the materials examined by TEM may have been inadequate for the formation of a high density of microctacks since cavitation density was low.

\section{Oxidation Effects on Creep Behavior}

The materials tested in creep in this study all displayed a continuing decrease in strain-rate with time. This behavior has been reported previously in the literature and has been atrributed to both devitrification of the grain-boundary phase and oxidation effects occuring throughout the duration of the test.84,96-102 The present materials were all believed to have crystallized to the fullest extent, i.e., complete crystallization of the multiple-grain junctions with a thin residual amorphous film remaining at the two-grain boundaries. Therefore devitrification effects are not believed to be the main reason for the continued decrease in strain-rate. Oxidation of these materials, however, is thought to lead to an increase in the refractoriness of the ceramics by purifying the amorphous grainboundary phase due to outward diffusion of impurity cations (see Section IV.B.), thereby increasing its viscosity. As the concentration of glass-forming impurities decreases during oxidation the stability of the glass phase decreases as well, accelerating crystallization of this residual amorphous phase. ${ }^{101}$

The apparent conflicting results of the high-temperature strength tests and those of creep may be explained on the basis of the differences in defects present in the various materials and the refractoriness of the residual amorphous phases before and after 
oxidation. Defects play a greater role in determining the high-temperature strength of these materials than in determining the creep behavior. Alternatively, the composition of the grain-boundary phase has a stronger effect on creep behavior than it does on strength, when the materials are as refractory as the $\mathrm{RE}_{2} \mathrm{Si}_{2} \mathrm{O}_{7}-\mathrm{Si}_{3} \mathrm{~N}_{4}$ ceramics have shown to be.

The relative retention in room-temperature strengths of these materials at $1300^{\circ} \mathrm{C}$ can be correlated exactly with their oxidation resistances, with the notable exception of the behavior exhibited by the $\mathrm{Sm}_{2} \mathrm{Si}_{2} \mathrm{O}_{7}-\mathrm{Si}_{3} \mathrm{~N}_{4}$ material. When first comparing the results of strength retention and oxidation resistance with those of the creep tests no relation appears to exist that would indicate strength retention, oxidation resistance, and creep resistance depend on the same material properties, i.e., grain-boundary phase composition. However, if oxidation which occurs during creep testing is considered, it can be shown that not only is the creep behavior dependent on the state of the secondary and grainboundary phases at commencement of the creep test but it is also dependent on the effects of oxidation on the state of the intergranular phase during the test. Comparing the specific weight gains during oxidation of these materials with the "steady-state" creep strains, those materials having the highest weight gains had among the highest creep strains. It is proposed that while the initial composition of the residual grain-boundary phase dictates high-temperature fast-fracture strength and oxidation resistance, the effect of oxidation on this phase during creep, which includes out-diffusion of impurity cations to increase the viscosity and accelerate subsequent devitrification must be considered when discussing the creep resistance of these materials.

From the results of energy-dispersive x-ray spectroscopy of the oxidized surfaces, and given the same additives (same specified purities) were used for each material the impurity levels present in these materials were essentially the same, these materials can be compared directly based on the secondary-phase composition. For example, $\mathrm{Yb}_{2} \mathrm{Si}_{2} \mathrm{O}_{7}-$ $\mathrm{Si}_{3} \mathrm{~N}_{4}$ displayed among the highest strengths at both $25^{\circ} \mathrm{C}$ and $1300^{\circ} \mathrm{C}$ and a high retention in strength of $91 \%$. However, its resistance to creep was found to be greater than only that 
of $\mathrm{Sm}_{2} \mathrm{Si}_{2} \mathrm{O}_{7}-\mathrm{Si}_{3} \mathrm{~N}_{4}$ and $\mathrm{Y}_{2} \mathrm{Si}_{2} \mathrm{O}_{7}-\mathrm{Si}_{3} \mathrm{~N}_{4}$. The specific weight gain after oxidation was the lowest after that of $\mathrm{E}_{2} \mathrm{Si}_{2} \mathrm{O}_{7}-\mathrm{Si}_{3} \mathrm{~N}_{4}$.

Another example is the behavior of $\mathrm{Gd}_{2} \mathrm{Si}_{2} \mathrm{O}_{7}-\mathrm{Si}_{3} \mathrm{~N}_{4}$ at high temperatures. $\mathrm{Gd}_{2} \mathrm{Si}_{2} \mathrm{O}_{7}-\mathrm{Si}_{3} \mathrm{~N}_{4}$ also gave one of the highest room-temperature strengths, however, retained only $80 \%$ of that strength at $1300^{\circ} \mathrm{C}$, the lowest of the six materials studied. Its resistance to creep was the greatest, next to that of $\mathrm{Dy}_{2} \mathrm{Si}_{2} \mathrm{O}_{7}-\mathrm{Si}_{3} \mathrm{~N}_{4}$, and it exhibited the greatest specific-weight gain during oxidation, excluding that of $\mathrm{Sm}_{2} \mathrm{Si}_{2} \mathrm{O}_{7}-\mathrm{Si}_{3} \mathrm{~N}_{4}$. The high oxidation rate of this material is believed to be responsible for the enhanced refractoriness of this material resulting from the out-diffusion of impurity cations, thereby creating a more refractory residual amorphous phase.

$\mathrm{Sm}_{2} \mathrm{Si}_{2} \mathrm{O}_{7}-\mathrm{Si}_{3} \mathrm{~N}_{4}$ had by a factor of two the greatest specific-weight gain upon oxidation of the six materials. The actual increase in strength at $1300^{\circ} \mathrm{C}$ was explained based the relatively lower oxidation resistance of this material. The foregoing argument would lead to the reasoning that $\mathrm{Sm}_{2} \mathrm{Si}_{2} \mathrm{O}_{7}-\mathrm{Si}_{3} \mathrm{~N}_{4}$ should show the greatest resistance to creep of the six materials based on its rapid oxidation behavior and higher $1300^{\circ} \mathrm{C}$ strength. However, this material actually undergoes by far the greatest deformation in the group. The low refractoriness of the residual amorphous grain-boundary phase present in this material is believed to be so much lower than the refractoriness of the amorphous phases in the other materials that the effects of oxidation are insufficient to increase the refractoriness of this low-viscosity grain-boundary phase to that of the glass in the other five materials.

\section{ALTERNATIVE SECONDARY PHASES}

The understanding that the secondary phases in silicon nitride ceramics are primarily responsible for their high-temperature properties has led to the well accepted practice of heat treating to devitrify grain-boundary amorphous phases. However, at present there are few suitable secondary phases that can be obtained through crystallization 
of grain-boundary glasses that meet the chemical and mechanical properties required at temperatures up to $1400^{\circ} \mathrm{C}$. Of the possible phases known at present it will be shown that the $\mathrm{RE}_{2} \mathrm{Si}_{2} \mathrm{O}_{7}$ compounds provide for $\mathrm{Si}_{3} \mathrm{~N}_{4}$ ceramics with the best high-temperature properties.

As discussed earlier the substitution of $\mathrm{Y}_{2} \mathrm{O}_{3}$ or $\mathrm{Y}_{2} \mathrm{O}_{3}$ and $\mathrm{Al}_{2} \mathrm{O}_{3}$ was one of the first attempts at improving the viscosity of the amorphous phases and also at obtaining a glass that can subsequently be devitrified without concurrent phase separation. 38,40 It must be remembered that in processing $\mathrm{Si}_{3} \mathrm{~N}_{4}, \mathrm{SiO}_{2}$ must always be considered as a component due to its present on the surface of all $\mathrm{Si}_{3} \mathrm{~N}_{4}$ powders. In the $\mathrm{Y}-\mathrm{Si}-\mathrm{Al}-\mathrm{O}-\mathrm{N}$ system a number of possible crystalline phases exist, however, as discussed in Sections I.C. and II.A. the oxynitrides must be discounted due to the potential catastrophic failure of the ceramic that can occur resulting from volume changes associated with the oxidation of the oxynitrides to silicates and silica, with concurrent evolution of nitrogen. The only remaining phases which could be devitrified include yttrium aluminum garnet (YAG, $\left.\mathrm{Y}_{3} \mathrm{Al}_{5} \mathrm{O}_{12}\right)$, mullite $\left(\mathrm{Si}_{2} \mathrm{Al}_{6} \mathrm{O}_{13}\right)$, yttrium orthosilicate $\left(\mathrm{Y}_{2} \mathrm{SiO}_{5}\right)$, and yttrium disilicate.

YAG has been studied as a secondary phase by several investigators $26,55,106,111$ with the main advantage being the lower eutectic temperature of $\left(-1300^{\circ} \mathrm{C}\right)^{111}$ in this system which facilitates complete densification. The principal disadvantages to YAG$\mathrm{Si}_{3} \mathrm{~N}_{4}$ are that above $-1300^{\circ} \mathrm{C}$, these materials suffer from severe oxidation, since $\mathrm{Y}_{3} \mathrm{Al}_{5} \mathrm{O}_{12}$ is not in equilibrium with $\mathrm{SiO}_{2}$ at these temperatures ${ }^{121}$ and that upon devitrification any residual amorphous phases will contain $\mathrm{Al}$, thus resulting in low viscosity phases, which are detrimental to the high-temperature mechanical properties. Although mullite is in equilibrium with $\mathrm{SiO}_{2}$, it is not in equilibrium with $\mathrm{Si}_{3} \mathrm{~N}_{4}$, and would therefore not be stable as a secondary phase. The crystallization of $\mathrm{Y}_{2} \mathrm{SiO}_{5}$ results in a phase that is neither in equilibrium with $\mathrm{Si}_{3} \mathrm{~N}_{4}$ or $\mathrm{SiO}_{2}$ and will therefore transform to $\mathrm{Y}_{2} \mathrm{Si}_{2} \mathrm{O}_{7}$ during high-temperature exposure. ${ }^{41} \quad \mathrm{Y}_{2} \mathrm{Si}_{2} \mathrm{O}_{7}$ is the best alternative for a secondary phase in this system since it is in equilibrium with $\mathrm{Si}_{3} \mathrm{~N}_{4}$ and $\mathrm{SiO}_{2},{ }^{41}$ and during 
processing $\mathrm{Al}_{2} \mathrm{O}_{3}$ and $\mathrm{AlN}$ can be eliminated to obtain high refractory residual amorphous phases. Also, any of the lanthanides can be substituted for $Y$ to obtain a refractory secondary phase, as has been demonstrated in the present study.

Thompson ${ }^{111}$ has also suggested other possible crystalline secondary phases that do not incorporate $\mathrm{Al}$, among them $\mathrm{LiSiON}, \mathrm{Li}_{2} \mathrm{SiO}_{3}, \mathrm{Li}_{2} \mathrm{Si}_{2} \mathrm{O}_{5}$, and $\mathrm{Zr}_{2} \mathrm{SiO}_{4}$. Of the $\mathrm{Li}$ containing compounds, the oxynitride decomposes at $-1200^{\circ} \mathrm{C}$ and the silicates melt below this temperature. In the $\mathrm{Zr}$-Si-O-N system, $\mathrm{Zr}_{2} \mathrm{SiO}_{4}$ is the only possible phase but the liquid phase does not cross the $\mathrm{Si}_{3} \mathrm{~N}_{4}-\mathrm{Z}_{2} \mathrm{SiO}_{4}$ tie-line, prohibiting extensive liquid-phase sintering. Also, $\mathrm{Zr}_{2} \mathrm{SiO}_{4}$ has been shown to oxidize $\mathrm{Si}_{3} \mathrm{~N}_{4}$ to $\mathrm{Si}_{2} \mathrm{ON}_{2}$.

Solid solutions of $\mathrm{Si}_{3} \mathrm{~N}_{4}$ incorporating $\mathrm{Al}$ and $\mathrm{O}$ or $\mathrm{Be}$ and $\mathrm{O}$ have also been investigated as a means of producing dense single-phase ceramics of $\mathrm{Si}_{6-\mathrm{x}} \mathrm{Al}_{\mathbf{x}} \mathrm{O}_{\mathbf{x}} \mathrm{N}_{8-\mathrm{x}}{ }^{1}$ or $\mathrm{Si}_{6-\mathrm{x}} \mathrm{B}: \mathrm{x}_{\mathrm{x}} \mathrm{O}_{\mathrm{x}} \mathrm{N}_{8-\mathrm{x}},{ }^{122}$ in an effort to eliminate secondary phases entirely, however the incomplete substitution of $\mathrm{Al}$ or $\mathrm{Be}$ into $\mathrm{Si}_{3} \mathrm{~N}_{4}$ results in a residual $\mathrm{Al}$ - or $\mathrm{Be}$-rich grainboundary glassy phase deleterious to high-temperature properties. In addition, the well known toxicity of $\mathrm{BeO}$ has deterred development of these ceramics. 


\section{v. CONCLUSIONS}

The processing-microstructure-property relations of silicon nitride ceramics sintered with rare-earth oxide additives have been investigated with the aim of improving the hightemperature behavior. The additions of the oxides of $\mathrm{Sm}, \mathrm{Gd}, \mathrm{Dy}, \mathrm{Er}$, and $\mathrm{Yb}$, having high melting points and behaving similarly to $\mathrm{Y}_{2} \mathrm{O}_{3}$, were compositionally controlled to tailor a microstructure consisting of a $\beta-\mathrm{Si}_{3} \mathrm{~N}_{4}$ discontinuous matrix phase and a crystalline secondary phase of $\mathrm{RE}_{2} \mathrm{Si}_{2} \mathrm{O}_{7}$. Microstructural observations by scanning and transmission electron microscopy were correlated with high-temperature mechanical properties to obtain an understanding of the effect of the various rare-earth-oxide additives on high-temperature performance. Based on the results obtained in this investigation the following conclusions can be made:

1. Microstructurally designed silicon nitride ceramics incorporating a crystalline secondary phase of $\mathrm{RE}_{2} \mathrm{Si}_{2} \mathrm{O}_{7}$ have been successfully produced with excellent high-temperature properties. The lanthanide oxides studied in this investigation as sintering additives for silicon nitride have been shown to be as effective as $\mathrm{Y}_{2} \mathrm{O}_{3}$ in densifying $\mathrm{Si}_{3} \mathrm{~N}_{4}$ by sintering without the aid of an applied stress (i.e., hot-pressing). Densities of $99 \%$ theoretical density were achieved with a 2:1 ratio of $\mathrm{SiO}_{2}-\mathrm{RE}_{2} \mathrm{O}_{3}$ additives. The $\mathrm{Sm}_{2} \mathrm{Si}_{2} \mathrm{O}_{7}-\mathrm{Si}_{3} \mathrm{~N}_{4}$ material contained the highest fraction of porosity of the six materials that were fabricated.

2. The morphologies of the microstructures of the six compositions were identical with high aspect ratio $\beta-\mathrm{Si}_{3} \mathrm{~N}_{4}$ grains as the primary phase and a secondary phase consisting of large grained $\mathrm{RE}_{2} \mathrm{Si}_{2} \mathrm{O}_{7}$. The crystallization behavior of all six disilicates was similar, characterized by a limited nucleation and rapid growth mechanism resulting in large single crystals as the secondary 
phase. Complete crystallization of the intergranular phase was obtained with the exception of a thin (on the order of 1-10 nm) residual amorphous film, which was observed at interfaces and believed to be rich in impurities that were initially present in the $\mathrm{Si}_{3} \mathrm{~N}_{4}$ and $\mathrm{SiO}_{2}$ starting powders, thereby inhibiting complete devitrification. The $\mathrm{Yb}_{2} \mathrm{Si}_{2} \mathrm{O}_{7}-\mathrm{Si}_{3} \mathrm{~N}_{4}$ material contained isolated regions of incompletely crystallized multiple grain junctions, due to compositional heterogeneities in the milled $\mathrm{Si}_{3} \mathrm{~N}_{4}-\mathrm{SiO}_{2}-\mathrm{Yb}_{2} \mathrm{O}_{3}$ powder. No impurities were detected in these amorphous regions or at the two-grain interfaces.

3. The resistance to oxidation of these materials was nearly an order of magnitude better than that of other sintered $\mathrm{Si}_{3} \mathrm{~N}_{4}$ found in the literature. The low oxidation rate is attributed to the minimization of amorphous phases via devitrification to disilicates that are compatible with $\mathrm{SiO}_{2}$, the oxidation product of $\mathrm{Si}_{3} \mathrm{~N}_{4}$. The relative rates of oxidation where found to be roughly inversely related to eutectic temperature of the $\mathrm{SiO}_{2}-\mathrm{RE}_{2} \mathrm{O}_{3}$ system, indicating a lower viscosity residual amorphous phase results in a higher rate of oxidation since the rate-limiting step is diffusion of additive and impurity cations through this amorphous phase to the oxidized surface. The oxidation behavior displayed by these materials was parabolic, which is consistent with previous studies that indicated parabolic kinetics prevail during the oxidation of $\mathrm{Si}_{3} \mathrm{~N}_{4}$ ceramics.

4. The oxidation of $\mathrm{Sm}_{2} \mathrm{Si}_{2} \mathrm{O}_{7}-\mathrm{Si}_{3} \mathrm{~N}_{4}$ and $\mathrm{Dy}_{2} \mathrm{Si}_{2} \mathrm{O}_{7}-\mathrm{Si}_{3} \mathrm{~N}_{4}$ was not found to display parabolic oxidation kinetics until only after a certain exposure time. It is believed that the initially higher specific weight gains were obtained due to the presence of open porosity that was eventually sealed, leading subsequently to oxidation kinetics that were parabolic. The much higher oxidation rate of $\mathrm{Sm}_{2} \mathrm{Si}_{2} \mathrm{O}_{7}-\mathrm{Si}_{3} \mathrm{~N}_{4}$, even after sealing of porosity, could be due 
to the divalent nature of $\mathrm{Sm}$ in certain reducing etrvironments, which would lead to enthanced transport to the oxidized surface.

5. Enhanced oxidation of sintered silicon nitride proceeds by dissolution of $\mathrm{Si}_{3} \mathrm{~N}_{4}$ in a high viscosity surface silicate. To maintain equilibrium as the concentration of cations in the liquid increases $\mathrm{SiO}_{2}$ and $\mathrm{RE}_{2} \mathrm{Si}_{2} \mathrm{O}_{7}$ are expelled and crystallize on the surface. $\mathrm{RE}_{2} \mathrm{Si}_{2} \mathrm{O}_{7}$ grew out of the surface silicate in preferred orientations that were dictated by crystal structure. The morphology of the microstructure of the oxidized surfaces was shown to be partially dependent on the concentration of impurities; the presence of $\mathrm{Ca}$ was found to coincide with the preferred growth of $\mathrm{Gd}_{2} \mathrm{Si}_{2} \mathrm{O}_{7}$ and $\mathrm{Dy}_{2} \mathrm{Si}_{2} \mathrm{O}_{7}$ into needle-like whiskers.

6. The retention in room-temperature strength displayed by these ceramics at $1300^{\circ} \mathrm{C}$ is among the highest reported to date, with that of $\mathrm{E}_{2} \mathrm{Si}_{2} \mathrm{O}_{7}$ $\mathrm{Si}_{3} \mathrm{~N}_{4}$ and $\mathrm{Yb}_{2} \mathrm{Si}_{2} \mathrm{O}_{7}-\mathrm{Si}_{3} \mathrm{~N}_{4}$ reaching $91 \%$. $\mathrm{Sm}_{2} \mathrm{Si}_{2} \mathrm{O}_{7}-\mathrm{Si}_{3} \mathrm{~N}_{4}$ was found to actually increase in strength at the higher temperature by $10 \%$. This has been attributed to surface flaw healing by oxidation of the surface occuring prior to testing. Fracture surfaces were found to contain metallic as well as nonmetallic inclusions. Failure initiation most often occurred at the tensile surface. Even at $1300^{\circ} \mathrm{C}$ there was no evidence of inelastic deformation preceding failure, indicative of the high refractoriness of these materials.

7. The "steady-state" creep rates, at $1400^{\circ} \mathrm{C}$ in flexural mode, displayed by the most refractory materials are among the lowest reported. The creep behavior was found to be strongly dependent on residual amorphous phase viscosity as well as on the oxidation behavior of these materials, as evidenced by the nonsteady-state creep rates of all materials. As oxidation proceeds there is a purifying effect on the residual amorphous phases due to impurity diffusion to the surface. This purification results in higher viscosity glasses and 
destabilized glasses that may further devitrify. All of the rare-earth oxide sintered materials, with the exception of $\mathrm{Sm}_{2} \mathrm{Si}_{2} \mathrm{O}_{7}-\mathrm{Si}_{3} \mathrm{~N}_{4}$, had lower creep strains than the $\mathrm{Y}_{2} \mathrm{Si}_{2} \mathrm{O}_{7}-\mathrm{Si}_{3} \mathrm{~N}_{4}$ material.

8. Exa dination of materials that were tested in creep indicates that deformation proceeds by grain-boundary cavitation. Cavities nucleate at the thin amorphous film between $\mathrm{RE}_{2} \mathrm{Si}_{2} \mathrm{O}_{7}-\mathrm{Si}_{3} \mathrm{~N}_{4}$ and $\mathrm{Si}_{3} \mathrm{~N}_{4}-\mathrm{Si}_{3} \mathrm{~N}_{4}$ grains. A diffusive mass transport mechanism results in cavity growth at the expense of $\mathrm{RE}_{2} \mathrm{Si}_{2} \mathrm{O}$. Under the stresses applied to these materials at $1400^{\circ} \mathrm{C}$, coalescence of cavities was frequently observed, however not to the degree associated with that necessary for microcrack formation.

Presented in this study is an initial attempt to microstructurally design $\mathrm{Si}_{3} \mathrm{~N}_{4}$ ceramics with a secondary phase, intended to improve the high-temperature properties of these materials. No attempt has been made to optimize or even refine the processing of these materials. Optimization of these materials should begin by reducing the rather high fraction of sintering additives used in this study. However, to remain on the $\mathrm{Si}_{3} \mathrm{~N}_{4}$ $\mathrm{RE}_{2} \mathrm{Si}_{2} \mathrm{O}_{7}$ tie-line a minimum amount of $\mathrm{RE}_{2} \mathrm{O}_{3}$ is required, as dictated by the everpresence of oxide on the surface of $\mathrm{Si}_{3} \mathrm{~N}_{4}$ powders. By reducing the amount of additives, alternative processing techniques may become necessary, including high-temperature gaspressure sintering or hot isostatic pressing to achieve components of near-net shape and full density.

An additional heat treatment in air, following the devitrification heat treatment conducted under nitrogen, prior to high-temperature mechanical testing should result in improved high-temperature properties. By exposing these materials to an additional heat treatment in air prior to testing, an enhancement in residual amorphous phase viscosity should result by the outward diffusion of impurities to the oxide surface. The fraction of amorphous phase should also be reduced by subsequent devitrification. Additionally, 
powders of improved purity and cleaner processing equipment are needed. More careful processing techniques must be employed to minimize contamination, which is undoubtedly a primary cause of incomplete grain-boundary phase crystallization. A more detailed microstructural analysis of the grain-boundary phase is also necessary, with emphasis on the characterization of the residual amorphous film by high-resolution electron microscopy and high-resolution elemental microanalysis. 


\section{APPENDIX}

\section{Analysis of Stresses and Strains in Flexural Creep}

Creep experiments on ceramic materials are often performed in bending to avoid problems of gripping and the difficulties of specimen preparation associated with tensile tests. Although experimentally easy to perform, exact calculations of strains from measured deflections and stresses from applied loads are not straight forward, and simplifying assumptions are usually made.

The steady-state thermal creep behavior relating creep strain rate to applied stress can be described by Norton's law in the form $d \varepsilon / d t=A \sigma^{n} \exp (-\Delta H / R T)$, where $A$ is a pre-exponential constant depending only on temperature and material properties, $\mathrm{n}$ is a stress exponent which may or may not depend on stress, and $\Delta H$ is the activation energy of the rate-controlling process.

The following summary of strains and stresses in four-point bending creep tests is based on the analysis of Hollenberg et al. 80 In the limit of small beam deflections $(<0.02$ outer fiber strain) an analysis of stresses and strains in four-point bending results in a general equation which relates the load-point deflection, applied load, creep exponent (n), and geometrical parameters of the loading system. The elastic equation relating the loadpoint deflection to the outer fiber strain is strictly valid for viscous creep $(n=1)$ and approximately valid for nonviscous creep $(n>1)$ if the ratio of the distances between support points to load points is not very large $(\leq 2)$.

Fig. 51 is a schematic diagram of a beam in four-point bending. The analysis of strains were based on deflections measured at the inner load points and in terms of creep compliance $\mathrm{J}(\mathrm{t})$. In non-linear mechanics, the constitutive law of a material can be assumed to be of the form 


$$
\varepsilon(t, \sigma)=\sigma^{n J}(t)
$$

For creep under steady-state conditions, $J(t)$ and $\partial J(t) / \partial t$ are of the form

$$
\begin{aligned}
& J(t)=C_{1} t+C_{2} \\
& \partial J(t) / \partial t=C_{1}
\end{aligned}
$$

where $\mathrm{C}_{\mathrm{i}}$ is a constant.

It is assumed that the neutral axis remains at the center of the beam throughout the test. The strain at a distance $\mathrm{z}$ from the neutral axis is

$$
\varepsilon=z / p
$$

For a rectangular beam of width $b$ and height $h$, the bending moment is defined as

$$
M=\int_{+2}^{a / 2} z \sigma b d z
$$

Substitution of Eqqs. A1 and A3 into Eq. A4 and a subsequent integration gives

here

$$
\begin{aligned}
& M=I_{n} /(J(t) \rho)^{1 / n} \\
& I_{n}=\frac{2 b(h / 2)^{(2 n+1) / n}}{(2 n+1) / n}
\end{aligned}
$$


Solving Eq. A5 in terms of $\rho$ and setting $z=h / 2$ (distance from neutral axis to outer fiber), the maximum stress, which is in the outer is fiber, is

$$
\sigma_{\max }=\left[3(L-a) P / b h^{2}\right][(2 n+1) / 3 n]
$$

To determine the relation between load-point deflection and outer fiber strain, the radius of curvature must be determined in terms of the beam deflection. For small deflections, it can be assumed that

$$
1 / p=d^{2} y / d x^{2}
$$

where $y$ is a deflection at a position $x$ along the beam. Substitution of Eq. A7 into Eq. A5 gives

$$
d^{2} y / d x^{2}=J(t)\left[M / I_{n}\right]^{n}
$$

The solution of Eq. A8 is a mixed boundary-value problem with the following conditions:

$$
\begin{aligned}
& M=P(L-a) / 2 \text { for }(L-a) / 2<x<(L+a) / 2 \\
& M=P x \text { for } 0<x<(L-a) / 2 \text { and }(L+a) / 2<x<L \\
& d y / d x=0 \text { at } x=L / 2 \text { and } y=0 \text { at } x=0
\end{aligned}
$$

On integration and evaluation at the boundary' conditions, the solution of Eq. A8 for $y_{L}$ is

$$
y L=-J(t)\left[P / I_{n}\right]^{n}[(L-a) / 2]^{n+1}[L+a(n+1)] / 2(n+2)
$$

or

$$
\log d y / d t=n \log P+C_{3}
$$


The creep compliance when expressed in terms of the strain in the outer fiber and maximum stress is

$$
\mathrm{J}(\mathrm{t})=\varepsilon_{\max } / \sigma_{\max } \mathrm{n}
$$

Substituting Eqs. A6 and A9 into A10 and solving for $\varepsilon_{\max }$ gives the final relation between strain in the outer fiber and the load-point deflection

$$
\varepsilon_{\max }=[2 h(n+2)][(L-a)(L+a(n+1))] y L
$$

One of the major limitations of this analysis is that associated with the assumption that the neutral axis remains at the center of the beam. This assumption implies that creep properties in tension and compression are similar. Finnie ${ }^{81}$ first discussed an analysis of data generated by bending beams of trapezoidal cross-section, taking into account pronounced differences between tensile and compressive creep $\left(A_{t} \neq A_{c}\right)$ for the case when $n_{1}=n_{c}=1$. Talty and Dirks ${ }^{82}$ extended the analysis of the same trapezoidal beam to a general case of $N\left(n_{t}=n_{c}=N\right)$. Chuang 83 extended this work further to a completely general case of unequal tension and compression power-law creep behaviors where $n_{\mathfrak{l}} \neq n_{\mathcal{C}}$ and $A_{t} \neq A_{c}$, resulting in two coupled non-linear algebraic equations requiring computer models to be matched with the empirical data. A second limitation of this analysis is that it is limited to small beam deflections. In the present study the assumption of small beam deflections $(-1 \%)$ is valid. 


\section{REFERENCES}

1. K.H. Jack, "Review: Sialons and Related Nitrogen Ceramics," J. Mater. Sci., 11 $1135-58$ (1976).

2. J. Weiss, "Silicon Nitride Ceramics: Composition, Fabrication Parameters, and Properties," Ann. Rev. Mater. Sci., 11 381-99 (1981).

3. G. Ziegler, J. Heinrich, and G. Wötting, "Review: Relationship Between Processing, Mictostructure and Properties of Dense and Reaction-Bonded Silicon Nitride," J. Mater. Sci., 22 3041-86 (1987).

4. M. Taguchi, "Applications of High-Technology Ceramics in Japanese Automobiles," Adv. Ceram. Mater., 2 [4] 754-62 (1987).

5. D.W. Richerson, "Evolution in the U.S. of Ceramic Technology for Turbine Engines," Am. Ceram. Soc. Bull., 64 [2] 282-86 (1985).

6. K. Kijima and S. Shirasaki, "Nitrogen Self-Diffusion in Silicon Nitride," J. Chem. Phys., 65 [7] 2668-71 (1976).

7. W.D. Kingery, "Densification During Sintering in the Presence of a Liquid Phase, I: Theory," J. Appl. Phys., 30 [3] 301-06 (1959).

8. P. Drew and M.H. Lewis, "Microstructures of Silicon Nitride Ceramics During HotPressing Transformations," J. Mater. Sci., 9 261-69 (1974).

9. D.R. Clarke and G. Thomas, "Grain Boundary Phases in a Hot-Pressed MgO Fluxed Silicon Nitride,” J. Am. Ceram. Soc., 60 [11-12] 491-95 (1977).

10. D.R. Clarke and G. Thomas, "Microstructure of $\mathrm{Y}_{2} \mathrm{O}_{3}$ Fluxed Hot-Pressed Silicon Nitride," J. Am. Ceram. Soc., 61 [3-4] 114-18 (1978).

11. L.K.V. Lou, T.E. Mitchell, and A.H. Heuer, "Impurity Phases in Hot-Pressed $\mathrm{Si}_{3} \mathrm{~N}_{4}$," J. Am. Ceram. Soc., 61 [9-10] 392-96 (1978).

12. O.L. Krivanek, T.M. Shaw, and G. Thomas, "The Microstructure and Distribution of Impurities in Hot-Pressed and Sintered Silicon Nitrides," J. Am. Ceram. Soc., 62 [11-12] 585-590 (1979).

13. J.L. Iskoe, F.F. Lange, and E.S. Diaz, "Effect of Selected Impurities on the HighTemperature Mechanical Properties of Hot-Pressed Silicon Nitride," J. Mater. Sci. 11 908-12 (1976).

14. G.E. Gazza, "Hot-Pressed $\mathrm{Si}_{3} \mathrm{~N}_{4}$," J. Am. Ceram. Soc., 56 [12] 662 (1973).

15. I.C. Huseby and G. Petzow, "Influence of Various Densifying Additives on HotPressed Si3 N4," Powder Metall. Int., 6 [1] 17-19 (1974). 
16. A. Tsuge, $\mathrm{H}$. Kudo, and $\mathrm{K}$. Komeya, "Reaction of $\mathrm{Si}_{3} \mathrm{~N}_{4}$ and $\mathrm{Y}_{2} \mathrm{O}_{3}$ in HotPressing," J. Am. Ceram. Soc., 57 [6] 269-70 (1974).

17. G.E. Gazza, "Effect of Ytria Additions on Hot-Pressed $\mathrm{Si}_{3} \mathrm{~N}_{4}$," Am. Ceram. Soc. Bull., 54 [9] 778-81 (1975).

18. G.Q. Weaver and J.W. Lucek, "Optimization of Hot-Pressed $\mathrm{Si}_{3} \mathrm{~N}_{4}-\mathrm{Y}_{2} \mathrm{O}_{3}$ Materials," Am. Ceram. Soc. Bull., 57 [12] 1131-34,36 (1978).

19. A. Arias, "Pressureless Sintered SiAlON with Low Amounts of Sintering Aid,"J. Mater. Sci., 14 1353-60 (1979).

20. R.E. Loehman and D.J. Rowcliffe, "Sintering of $\mathrm{Si}_{3} \mathrm{~N}_{4}-\mathrm{Y}_{2} \mathrm{O}_{3}-\mathrm{Al}_{2} \mathrm{O}_{3}$," J. Am. Ceram. Soc., 63 [3-4] 144-48 (1980).

21. J.T. Smith and C.L. Quackenbush, "Phase Effects in $\mathrm{Si}_{3} \mathrm{~N}_{4}$ Containing $\mathrm{Y}_{2} \mathrm{O}_{3}$ or $\mathrm{CeO}_{2}$ : I, Strength," Am. Ceram. Soc. Bull., 59 [5] 529-32, 537 (1980).

22. A. Tsuge, K. Nishida, and M. Komatsu, "Effect of Crystallizing the Grain-Boundary Phase on the High-Temperature Strength of Hot-Pressed $\mathrm{Si}_{3} \mathrm{~N}_{4}$ Ceramics," J. Am. Ceram. Soc., 58 [7-8] 323-26 (1975).

23. J.E. Weston, P.L. Pratt, and B.C.H. Steele, "Crystallization of Grain-Boundary Phases in Hot-Pressed Silicon Nitride," J. Mater. Sci., 13 2137-56 (1978).

24. D.R. Clarke, F.F. Lange, and G.D. Schnittgrund, "Strengthening of a Sintered Silicon Nitride by a Post-Fabrication Heat Treatment," J. Am. Ceram. Soc., 65 [4] C-51-52 (1982).

25. L.A. Pierce, D.M. Mieskowski, and W.A. Sanders, "Effect of Grain-Boundary Crystallization on the High-Temperature Strength of Silicon Nitride," J. Mater. Sci., 21 1345-48 (1986).

26. D.A. Bonnell, T.-Y. Tien, and M. Rühle, "Controlled Crystallization of the Amorphous Phase in Silicon Nitride Ceramics, J. Am. Ceram. Soc., 70 [7] 460-65 (1987).

27. L.L. Falk. and G.L. Dunlop, "Crystallization of the Glassy Phase in an $\mathrm{Si}_{3} \mathrm{~N}_{4}$ Material by Post-Sintering Heat Treatments," J. Mater. Sci., 22 4369-76 (1987).

28. W.E. Lee, C.H. Drummond III, G.E. Hilmas, J.D. Kiser, and W.A. Sanders, "Microstructural Evolution on Crystallizing the Glassy Phase in a $6 \mathrm{wt} \% \mathrm{Y}_{2} \mathrm{O}_{3}$. $\mathrm{Si}_{3} \mathrm{~N}_{4}$ Ceramic," Ceram. Eng. Sci. Proc., 9 [9-10] 1355-66 (1988).

29. W. Braue, G. Wötting, and G. Ziegler, "The Impact of Compositional Variations and Processing Conditions on Secondary Phase Characteristics in Sintered Silicon Nitride Materials," pp. 883-96 in Ceramic Microstructures '86: Role of Interfaces, Edited by J.A. Pask and A.G. Evans, Plenum Press, New York, 1987.

30. C. Greskovich and J.H. Rosolowski, "Sintering of Covalent Solids," J. Am. Ceram. Soc., 59 [7-8] 336-43 (1976).

31. R.Raj, "Morphology and Stability of the Glass Phase in Glass-Ceramic Systems," J. Am. Ceram. Soc., 64 [5] 245-48 (1981). 
32. K. Negita, "Effective Sintering Aids for $\mathrm{Si}_{3} \mathrm{~N}_{4}$ Ceramics," J. Mater. Sci. Lett., 4 755-58 (1985).

33. H.D. Batha and E.D. Whitney, "Kinetics and Mechanism of the Thermal Decomposition of $\mathrm{Si}_{3} \mathrm{~N}_{4}$," J. Am. Ceram. Soc., 56 [7] 365-69 (1973).

34. C. Greskovich and S. Prochazka, "Stability of $\mathrm{Si}_{3} \mathrm{~N}_{4}$ and Liquid Phase(s) During Sintering," J. Am. Ceram. Soc., 64 [7] C-96-97 (1981).

35. F.F. Lange, "Volatilization Associated with the Sintering of Polyphase $\mathrm{Si}_{3} \mathrm{~N}_{4}$ Materials," J. Am. Ceram. Soc., 65 [8] C-120-21 (1982).

36. J. Felsche, "Polymorphism and Crystal Data of the Rare-Earth Disilicates of the Type $\mathrm{RE}_{2} \mathrm{Si}_{2} \mathrm{O}_{7}$," J. Less-Common Metals, 21 1-14 (1970).

37. J.E. Shelby and J.T. Kohli, "Rare-Earth Aluminosilicate Glasses," J. Am. Ceram. Soc., 73 [1] 39-42 (1990).

38. J. Ito and H. Johnson, "Synthesis and Study of Yttrialite," Am. Minerologist, 53 1940-52 (1968).

39. R.R. Wills, R.W. Stewar, J.A. Cunningham, and J.M. Wimmer, "The Silicon Lanthanide Oxynitrides," J. Mater. Sci., 11 749-59 (1976).

40. E. Hamp and M.J. Hoffmann, unpublished work.

41. F.F. Lange, S.C. Singhal, and R.C. Kuznicki, "Phase Relations and Stability Studies in the $\mathrm{Si}_{3} \mathrm{~N}_{4}-\mathrm{SiO}_{2}-\mathrm{Y}_{2} \mathrm{O}_{3}$ Pseudoternary System," J. Am. Ceram. Soc., 60 [5-6] 249-52 (1977).

42. C.L. Quakenbush and J.T. Smith, "Phase Effects in $\mathrm{Si}_{3} \mathrm{~N}_{4}$ Containing $\mathrm{Y}_{2} \mathrm{O}_{3}$ or $\mathrm{CeO}_{2}$ : II, Oxidation," Am. Ceram. Soc. Bull., 59 [5] 533-37 (1980).

43. Phase Diagrams for Ceramists, 1969 Supplement, Edited by E.M. Levin, C.R. Robbins, and H.F. McMurdie, American Ceramic Society, Westerville, OH, 1969.

44. K. Liddell and D.P. Thompson, "X-ray Diffraction Data for Ytuium Silicates," Br. Ceram. Trans. J., 85 17-22 (1986).

45. T.M. Shaw, "The Crystallization Of Glasses in the Mg-Si-O-N System," Ph.D. Dissertation, University of California at Berkeley (1980).

46. G. Thomas, C. Ahn, and J. Weiss, "Characterization and Crystallization of Y-Si-AlO-N Glass," J. Am. Ceram. Soc., 65 [11] C-185-88 (1982).

47. T.M. Shaw, G. Thomas, and R.E. Loehman, "Formation and Microstructure of MgSi-O-N Glasses," J. Am. Ceram. Soc., 67 [10] 643-47 (1984).

48. T.R. Dinger, "Microstructural Development During Crystallization in Y-Si-Al-O-N Glass-Ceramics," Ph.D. Dissertation, University of California at Berkeley (1985).

49. T.R. Dinger, R.S. Rai, and G. Thomas, "Crystallization Behavior of a Glass in the $\mathrm{Y}_{2} \mathrm{O}_{3}-\mathrm{SiO}_{2}$-AIN System," J. Am. Ceram. Soc., 71 [4] 236-44 (1988). 
50. H. Qayum and G. Thomas, "Crystallization of Glasses and the High-Temperature Phases in the Y-Si-Al-O-N System," submitted to J. Am. Ceram. Soc. (1990).

51. R.E. Loehman, "Preparation and Properties of Ytrium-Silicon-Aluminum Oxynitride Glasses," J. Am.Ceram. Soc., 62 [9-10] 491-94 (1979).

52. R.A.L. Drew, S. Hampshire, and K.H. Jack, "Nitrogen Glasses," Proc. Br. Ceram. Soc., 31 119-32 (1981).

53. D.R. Messier, "Preparation and Properties of Si-Y-Al-O-N Glasses," Ceram. Eng. Sci. Proc., 3 [9-10] 565-76 (1982).

54. G. Leng-Ward and M.H. Lewis, "Crystallization in Y-Si-Al-O-N Glasses," Mater. Sci. Eng., 71 101-11 (1985).

55. M.H. Lewis, A.R. Bhatti, R.J. Lumby, and B. North, "The Microstructure of Sintered Si-Al-O-N Ceramics," J. Mater. Sci., 15 103-13 (1980).

56. G. Thomas, S.M. Johnson, and T.R. Dinger, "Method of Producing a Dense Refractory Silicon Nitride Compact with One or More Crystalline Phases," U.S. Patent No. 4830 800, May 1989.

57. M.K. Cinibulk, "Processing of Silicon Nitride Ceramics for Improved HighTemperature Performance," M.S. Thesis, University of California at Berkeley, May 1989.

58. M.K. Cinibulk, G. Thomas, and S.M. Johnson, "Grain-Boundary-Phase Crystallization and Strength of Silicon Nitride Sintered with a YSiAlON Glass," J. Am. Ceram. Soc., 73 [6] 1606-12 (1990).

59. P.W. MacMillan, Glass-Ceramics, Academic Press, New York,1964.

60. K.S. Mazdiyasni and C.M. Cooke, "Consolidation, Microstructure, and Mechanical Properties of $\mathrm{Si}_{3} \mathrm{~N}_{4}$ Doped with Rare-Earth Oxides," J. Am. Ceram. Soc., 57 [12] 536-37 (1974).

61. H.F. Priest, G.L. Priest, and G.E. Gazza, “Sintering of $\mathrm{Si}_{3} \mathrm{~N}_{4}$ under High Nitrogen Pressure," J. Am. Ceram. Soc., 60 [1-2] 81 (1977).

62. F.F. Lange, " $\mathrm{Si}_{3} \mathrm{~N}_{4}-\mathrm{Ce}_{2} \mathrm{O}_{3}-\mathrm{SiO}_{2}$ Materials: Phase Relations and Strength," Am. Ceram. Soc. Bull., 59 [2] 239-40, 49 (1980).

63. W.A. Sanders and D.M. Mieskowski, "Strength and Microstructure of Sintered $\mathrm{Si}_{3} \mathrm{~N}_{4}$ with Rare-Earth-Oxide Additions," J. Am. Ceram. Soc., 64 [2] 304-09 (1985).

64. E. Tani, S. Umebayashi, K. Kishi, K. Kobayashi, and M. Nishijima, "Gas-Pressure Sintering of $\mathrm{Si}_{3} \mathrm{~N}_{4}$ with Concurrent Addition of $\mathrm{Al}_{2} \mathrm{O}_{3}$ and $5 \mathrm{wt} \%$ Rare Earth Oxide: High Fracture Toughness $\mathrm{Si}_{3} \mathrm{~N}_{4}$ with Fiber-Like Structure," Am. Ceram. Soc. Bull., 65 [9] 1311-15 (1986).

65. N. Hirosaki, A. Okada, and K. Matoba, "Sintering of $\mathrm{Si}_{3} \mathrm{~N}_{4}$ with the Addition of Rare-Earth Oxides," J. Am. Ceram. Soc., 71 [3] C-144-47 (1988). 
66. R. Raj and F.F. Lange, "Crystallization of Small Quantities of Glass (or a Liquid) Segregated in Grain Boundaries," Acta. Metall., 29 1993-2000 (1981).

67. S.C. Singhal, "Thermodynamics and Kinetics of Oxidation of Hot-Pressed Silicon Nitride," J. Mater. Sci., 11 500-09 (1976).

68. D. Cubicciotti, K.H. Lau, and R.L. Jones, "Rate-Controlling Process in the Oxidation of Hot-Pressed Silicon Nitride," J. Electrochem. Soc., 124 [12] 1955-56 (1977).

69. D. Cubicciotri and K.H. Lau, "Kinetics of Oxidation of Hot-Pressed Silicon Nitride Containing Magnesia," J. Am. Ceram. Soc., 61 [11-12] 512-17 (1978).

70. D. Cubicciotti and K.H. Lau, "Kinetics of Oxidation of Yuria Hot-Pressed Silicon Nitride," J. Electrochem. Soc., 126 [10] 1723-28 (1979).

71. G.N. Babini, A. Bellosi, and P. Vincenzini, "Oxidation of Silicon Nitride HotPressed with Ceria," J. Am. Ceram. Soc., 64 [10] 578-84 (1981).

72. D.M. Mieskowski and W.A. Sanders, "Oxidation of Silicon Nitride Sintered with Rare-Earth Oxide Additions," J. Am. Ceram. Soc., 68 [7] C-160-63 (1985).

73. M.H. Lewis, C.J. Reed, and N.D. Butler, "Pressureless-Sintered Ceramics Based on the Compound $\mathrm{Si}_{2} \mathrm{~N}_{2} \mathrm{O}$," Mater. Sci. Eng., 71 87-94 (1985)

74. M. Ohashi, S. Kanzaki, and H. Tabata, "Processing, Mechanical Properties, and Oxidation Behavior of Silicon Oxynitride Ceramics," J. Am. Ceram. Soc., 74 [1] 109-14 (1991).

75. M.K. Cinibulk, "Mictostructure and Microanalysis of Silicon Nitride Sintered in the Y-Si-Al-O-N and Y-Si-O-N Systems," pp. 1072-73 in Proc. XIIth ICEM Vol. 4: Materials Sciences, Edited by L.D. Peachey and D.B. Williams, San Francisco Press, San Francisco, 1990.

76. Powder Diffraction File, JCPDS-Intemational Centre for Diffraction Data, Swarthmore, PA, 1989.

77. MIL-STD-1942A, "Flexural Strength of High Performance Ceramics at Ambient Temperature," U.S. Army Materials Technology Laboratory, Watertown, MA, 1990.

78. W. Weibull, "Statistical Distribution Function of Wide Applicability," J. Appl. Mech., 18 [3] 293-97 (1951).

79. N.A. Weil and I.M. Daniel, "Analysis of Fracture Probabilities in Nonuniformly Stressed Brittle Materials," J. Am. Ceram. Soc., 47 [6] 268-74 (1964).

80. G.W. Hollenberg, G.R. Terwilliger, and R.S. Gorden, "Calculation of Stresses and Strains in Four-Point Bending Creep Tests," J. Am. Ceram. Soc., 54 [4] 196-99 (1971).

81. I. Finnie, "Method for Predicting Creep in Tension and Compression from Bending Tests," J. Am. Ceram. Soc., 49 [4] 218-20 (1966). 
82. P.K. Talty and R.A. Dirks, "Determination of Tensile and Compressive Creep Behavior of Ceramic Materials From Bend Tests," J. Mater. Sci., 13 580-86 (1978).

83. T.-J. Chuang, "Estimation of Power-Law Creep Parameters From Bend Test Data," J. Mater. Sci., 21 165-75 (1986).

84. G.D. Quinn and W.R. Braue, "Secondary Phase Devitrification Effects upon the Static Fatigue Resistance of Sintered Silicon Nitride," Ceram. Eng. Sci. Proc., 11 [7-8] 616-32 (1990).

85. M.M. Chadwick and T.F. Malis, "AEM Characterization of Sintered Silicon Nitride with Yturia and Alumina Additions," Ultramicroscopy, 31 205-16 (1989).

86. K.M. Krishnan and C.J. Echer, "Determination of UTW KXSi Factors for LowAtomic-Number Microanalysis: A Systematic Approach," pp. 99-102 in Analytical Electron Microscopy-1987, Edited by D.C. Joy, San Francisco Press, San Francisco, 1987.

87. F.F. Lange, B.I. Davis, and H.C. Graham, "Compressive Creep and Oxidation Resistance of an $\mathrm{Si}_{3} \mathrm{~N}_{4}$ Material Fabricated in the System $\mathrm{Si}_{3} \mathrm{~N}_{4}-\mathrm{Si}_{2} \mathrm{ON}_{2}-\mathrm{Y}_{2} \mathrm{Si}_{2} \mathrm{O}_{7}$," J. Am. Ceram. Soc., 66 [6] C-98-99 (1983).

88. G.N. Babini, A. Bellosi, and P. Vincenzini, "Factors Influencing Structural Evolution in the Oxide of Hot-Pressed $\mathrm{Si}_{3} \mathrm{~N}_{4}-\mathrm{Y}_{2} \mathrm{O}_{3}-\mathrm{SiO}_{2}$ Materials," J. Mater. Sci., 19 3487-97 (1984).

89. C.C. Ahn and G. Thomas, "Microstructure and Grain Boundary Composition of Hot-Pressed Silicon Nitride with Yttria and Alumina," J. Am. Ceram. Soc., 66 [1] 14-17 (1983).

90. N.J. Tighe, "The Structure of Slow Crack Interfaces in Silicon Nitride," J. Mater. Sci., 13 1455-63 (1978).

91. R.K Govila, "Strength Characterization of Yturia-Doped Sintered Silicon Nitride," J. Mater. Sci., 204345 (1985).

92. R.K. Govila, "Fracture Phenomenology of a Sintered Silicon Nitride Containing Oxide Additives," J. Mater. Sci., 23 1141-50 (1988).

93. D.W. Richerson, Modem Ceramic Engineering, Marcel Dekker, Inc., New York, 1982.

94. L. Chuck, S.M. Goodrich, N.L. Hecht, and D.E. McCullum, "High-Temperature Tensile Strength and Stress Rupture Behavior of Norton/TRW NT-154 Silicon Nitride," Ceram. Eng. Sci. Proc., 11 [7-8] 1007-27 (1990).

95. W.R. Cannon and T.G. Langdon, "Review: Creep of Ceramics, Par 1: Mechanical Characteristics," J. Mater. Sci., 18 1-50 (1983).

96. R.M. Arons and J.K. Tien, "Creep and Strain Recovery in Hot-Pressed Silicon Nitride," J. Mater. Sci., 15 2046-58 (1980).

97. R. Kossowsky, D.G. Miller, and E.S. Diaz, "Tensile and Creep Strength of HotPressed Si3N4," J. Mater. Sci., 10 983-97 (1975). 
98. M.K. Ferber, M.G. Jenkins, and V.J. Tennery, "Comparison of Tension, Compression, and Flexure Creep for Alumina and Silicon Nitride Ceramics," Ceram. Eng. Sci. Proc., 11 [7-8] 1028-45 (1990).

99. F.F. Lange, B.I. Davis, and D.R. Clarke, "Compressive Creep of $\mathrm{Si}_{3} \mathrm{~N}_{4} / \mathrm{MgO}$ Alloys: Part 1, Effect of Composition," J. Mater. Sci., 15 601-10 (1980).

100. F.F. Lange, B.I. Davis, and D.R. Clarke, "Compressive Creep of $\mathrm{Si}_{3} \mathrm{~N}_{4} / \mathrm{MgO}$ Alloys: Part 3, Effects of Oxidation Induced Compositional Change," J. Mater. Sci., 15 616-18 (1980).

101. B.S.B. Karunaratne and M.H. Lewis, "High-Temperature Fracture and Diffusional Deformation Mechanisms in Si-Al-O-N Ceramics," J. Mater. Sci., 15 449-62 (1980).

102. S.M. Wiederhorn and N.J. Tighe, "Structural Reliability of Ytria-Doped HotPressed Silicon Nitride at Elevated Temperatures," J. Am. Ceram. Soc., 66 [12] 884-89 (1983).

103. R. Morrell and K.H.G. Ashbee, "High-Temperature Creep of Lithium Zinc Silicate Glass Ceramics," J. Mater. Sci., 8 [9] 1253-70 (1973).

104. S.U. Din and P.S. Nicholson, "Creep of Hot-Pressed Silicon Nitride," J. Mater. Sci., 10 1375-80 (1975).

105. J.E. Marion, A.G. Evans, M.D. Drory, and D.R. Clarke, "High Temperature Failure Initiation in Liquid Phase Sintered Materials," Acta. Metall., 31 [10] 1445-57 (1983).

106. C.-F. Chen and T.-Y. Tien, "High Temperature Mechanical Properties of SiAlON Ceramics: Microstructural Effects," Ceram. Eng. Sci. Proc., 8 [7-8] 778-95 (1987).

107. F.F. Lange, D.R. Clarke, and B.I. Davis, "Compressive Creep of $\mathrm{Si}_{3} \mathrm{~N}_{4} / \mathrm{MgO}$ Alloys, Part 2: Source of Viscoelastic Effect,"J. Mater. Sci., 1561 1-15 (1980).

108. F.F. Lange, "Liquid-Phase Sintering: Are Liquids Squeezed Out From Between Compressed Particles?," J. Am. Ceram. Soc., 65 [2] C-23 (1982).

109. D.R. Clarke, "On the Equilibrium Thickness of Intergranular Glass Phases in Ceramic Materials," J. Am. Ceram. Soc., 70 [1] 15-22 (1987).

110. W.D. Kingery, H.K. Bowen, and U.R. Uhlmann, Introduction to Ceramics, 2nd edition, Wiley-Interscience, New York, 1976.

111. D.P. Thompson, "Altemative Grain-Boundary Phases For Heat-Treated $\mathrm{Si}_{3} \mathrm{~N}_{4}$ and $\beta^{\prime}$-Sialon Ceramics," Proc. Br. Ceram. Soc., 45 1-13 (1990).

112. F.A. Cotton and G. Wilkinson, Advanced Inorganic Chemistry, 5th edition, WileyInterscience, New York, 1988.

113. J. Felsche and W. Hersiger, "Polymorphs of the Rare-Earth Pyrosilicates $\mathrm{RE}_{2} \mathrm{Si}_{2} \mathrm{O}_{7}$ [RE: La, Ce, Pr, Nd, Sm]," J. Less-Common Metals, 18 [2] 131-37 (1969). 
114. A.J. Pyzik and D.R. Beamon, "Processing, Microstructure, and Properties of SelfReinforced Silicon Nitride," presenied at 92nd Ann. Meeting Am. Ceram. Soc., Dallas, TX, April 22-26, 1990.

115. A.G. Evans, "Structural Reliability: A Processing-Dependent Phenomenon," J. Am. Ceram. Soc., 65 [3] 127-37 (1982).

116. A.G. Evans and A. Rana, "High Temperature Failure Mechanisms in Ceramics," Acta. Metall., 28 129-41 (1980).

117. A.G. Evans and J.V. Sharp, "Microstructural Studies on Silicon Nitride," J. Mater. Sci., 6 1292-1302 (1971).

118. R. Kossowsky, "Cyclic Fatigue of Hot-Pressed Silicon-Nitride," J. Am. Ceram. Soc., 56 [9] 531-35 (1973).

119. A.G. Evans and S.M. Wiederhom, "Crack Propagation and Failure Prediction in Silicon Nitride at Elevated Temperatures," J. Mater. Sci., $9270-78$ (1974).

120. R.L. Tsai and R. Raj, "The Role of Grain-Boundary Sliding in Fracture of HotPressed $\mathrm{Si}_{3} \mathrm{~N}_{4}$ at High-Temperatures," J. Am. Ceram. Soc., 63 [9-10] 513-17 (1980).

121. I.K. Naik and T.-Y. Tien, "Subsolidus Phase Relations in Part of the System $\mathrm{Si}, \mathrm{Al}, \mathrm{Y} / \mathrm{N}, \mathrm{O}$, , J. Am. Ceram. Soc., 62 [11-12] 642-43 (1979).

122. I.C. Huseby, H.L. Lukas, and G. Petzow, "Phase Equilibria in the System $\mathrm{Si}_{3} \mathrm{~N}_{4}$ $\mathrm{SiO}_{2}-\mathrm{BeO}-\mathrm{Be}_{3} \mathrm{~N}_{2}$," J. Am. Ceram. Soc., 58 [7-8] 377-80 (1975). 


\section{TABLES}

Table I. Properties of Silicon Nitride at $25^{\circ} \mathrm{C}$

\begin{tabular}{llc}
\hline Lattice Parameters: & $\begin{array}{l}\alpha \text {-phase (hexagonal) } \\
\beta \text {-phase (hexagonal) }\end{array}$ & $a=7.75-7.77 \AA, c=5.16-5.69 \AA$ \\
Theoretical Density: & $\alpha$-phase & $a=7.59-7.61 \AA, c=2.71-2.92 \AA$ \\
& $\beta$-phise & $3.17-3.19 \mathrm{~g} / \mathrm{cm}^{3}$ \\
Thermal Expansion Coefficient & $3.19-3.20 \mathrm{~g} / \mathrm{cm}^{3}$ \\
Thermal Conductivity & $2.9-3.4 \times 10^{-6} / \mathrm{C}$ \\
Thermal Diffusivity & $15-50 \mathrm{~W} / \mathrm{m}^{\circ} \mathrm{C}$ \\
Specific Heat & $0.08-0.30 \mathrm{~cm} 2 / \mathrm{s}$ \\
Hardness (Vickers) & $700 \mathrm{~J} / \mathrm{kg}-{ }^{\circ} \mathrm{C}$ \\
Young's Modilus & $1600-2200 \mathrm{MPa}$ \\
Flexural Strength & $300-330 \mathrm{GPa}$ \\
Fracture Toughness & $500-1200 \mathrm{MPa}$ \\
\end{tabular}


Table II. Melting and Eutectic Temperatures of $\mathrm{RE}_{2} \mathrm{O}_{3}-\mathrm{SiO}_{2}$

Disilicate $\quad$ Melting Temperature $\left({ }^{\circ} \mathrm{C}\right) \quad$ Lowest Eutectic $\left({ }^{\circ} \mathrm{C}\right)$ in System

\begin{tabular}{lll}
\hline $\mathrm{Y}_{2} \mathrm{Si}_{2} \mathrm{O}_{7}$ & 1775 & 1660 \\
$\mathrm{Sm}_{2} \mathrm{Si}_{2} \mathrm{O}_{7}$ & 1775 & 1650 \\
$\mathrm{Gd}_{2} \mathrm{Si}_{2} \mathrm{O}_{7}$ & 1725 & 1645 \\
$\mathrm{Dy}_{2} \mathrm{Si}_{2} \mathrm{O}_{7}$ & 1720 & 1640 \\
$\mathrm{Er}_{2} \mathrm{Si}_{2} \mathrm{O}_{7}$ & 1800 & 1680 \\
$\mathrm{Yb}_{2} \mathrm{Si}_{2} \mathrm{O}_{7}$ & 1850 & 1650
\end{tabular}


Table III. Ube SN E-10 SizN 4 Powder Specifications

\begin{tabular}{cc}
\hline Avg. Particle Size & $-0.3 \mu \mathrm{m}$ \\
Specific Surface Area & $11.6 \mathrm{~m}^{2} / \mathrm{g}$ \\
$\alpha(\alpha+\beta)$ by weight & $>0.95$ \\
Impurities & \\
$\mathrm{O}$ & $1.39 \mathrm{wt} \%$ \\
$\mathrm{Cl}$ & $<100 \mathrm{ppm}$ \\
$\mathrm{Fe}$ & $<100 \mathrm{ppm}$ \\
$\mathrm{Ca}$ & $<50 \mathrm{ppm}$ \\
$\mathrm{Al}$ & $<50 \mathrm{ppm}$
\end{tabular}

Table IV. Semi-Quantitative Analyses of $\mathrm{Si}_{3} \mathrm{~N}_{4}$ and $\mathrm{SiO}_{2}$

Powder $\quad \mathrm{Mg} \quad \mathrm{Al} \quad \underset{(\text { at.\%) }}{\mathrm{Ca}} \quad \mathrm{Ti} \quad \mathrm{Fe}$

$\begin{array}{llllll}\mathrm{Si}_{3} \mathrm{~N}_{4} & 0.001 & 0.001 & 0.0002 & & 0.003 \\ & & & & & \\ \mathrm{SiO}_{2} & 0.02 & 0.13 & 0.002 & 0.0006 & 0.005\end{array}$


Table V. Compositions of $\mathrm{Si}_{3} \mathrm{~N}_{4}$ Ceramics

\begin{tabular}{cccc} 
Material & \multicolumn{3}{c}{ Composition (mol\%) } \\
& $\mathrm{RE}_{2} \mathrm{O}_{3}$ & $\mathrm{SiO}_{2}$ & $\mathrm{Si}_{3} \mathrm{~N}_{4}$ \\
& & & \\
\hline $\mathrm{Y}_{2} \mathrm{Si}_{2} \mathrm{O}_{7}-\mathrm{Si}_{3} \mathrm{~N}_{4}$ & 5.89 & 11.78 & 82.33 \\
$\mathrm{Sm}_{2} \mathrm{Si}_{2} \mathrm{O}_{7}-\mathrm{Si}_{3} \mathrm{~N}_{4}$ & 6.08 & 12.16 & 81.76 \\
$\mathrm{Gd}_{2} \mathrm{Si}_{2} \mathrm{O}_{7}-\mathrm{Si}_{3} \mathrm{~N}_{4}$ & 5.74 & 11.47 & 82.79 \\
$\mathrm{Dy}_{2} \mathrm{Si}_{2} \mathrm{O}_{7}-\mathrm{Si}_{3} \mathrm{~N}_{4}$ & 5.88 & 11.77 & 82.25 \\
$\mathrm{Er}_{2} \mathrm{Si}_{2} \mathrm{O}_{7}-\mathrm{Si}_{3} \mathrm{~N}_{4}$ & 5.82 & 11.64 & 82.54 \\
$\mathrm{Yb}_{2} \mathrm{Si}_{2} \mathrm{O}_{7}-\mathrm{Si}_{3} \mathrm{~N}_{4}$ & 5.91 & 11.82 & 82.27
\end{tabular}




\section{Table VI. Processing Results}

\begin{tabular}{ccc} 
Rare-Earth Oxide Additive & Density $\left(\mathrm{g} / \mathrm{cm}^{3}\right)$ & Density (\%) \\
\hline $\mathrm{Y}_{2} \mathrm{O}_{3}$ & 3.28 & 99.5 \\
$\mathrm{Sm}_{2} \mathrm{O}_{3}$ & 3.48 & 98.0 \\
$\mathrm{Gd}_{2} \mathrm{O}_{3}$ & 3.51 & 99.8 \\
$\mathrm{Dy}_{2} \mathrm{O}_{3}$ & 3.52 & 99.2 \\
$\mathrm{Er}_{2} \mathrm{O}_{3}$ & 3.52 & 98.5 \\
$\mathrm{Yb}_{2} \mathrm{O}_{3}$ & 3.59 & 99.6
\end{tabular}


Table VII. X-ray Diffraction of Bulk Ceramics

\begin{tabular}{clll} 
Rare-Earth Oxude Additive & Primary Phase & Secondary Phase & Minor Phase \\
\hline $\mathrm{Y}_{2} \mathrm{O}_{3}$ & $\beta-\mathrm{Si}_{3} \mathrm{~N}_{4}$ & $\beta-\mathrm{Y}_{2} \mathrm{Si}_{2} \mathrm{O}_{7}$ & $\mathrm{Si}_{2} \mathrm{ON}_{2}$ \\
$\mathrm{Sm}_{2} \mathrm{O}_{3}$ & $\beta-\mathrm{Si}_{3} \mathrm{~N}_{4}$ & $\mathrm{~A}-\mathrm{Sm}_{2} \mathrm{Si}_{2} \mathrm{O}_{7}$ & $\mathrm{Si}_{2} \mathrm{ON}_{2}$ \\
$\mathrm{Gd}_{2} \mathrm{O}_{3}$ & $\beta-\mathrm{Si}_{3} \mathrm{~N}_{4}$ & $\delta-\mathrm{Gd}_{2} \mathrm{Si}_{2} \mathrm{O}_{7}$ & $\mathrm{Si}_{2} \mathrm{ON}_{2}$ \\
$\mathrm{Dy}_{2} \mathrm{O}_{3}$ & $\beta-\mathrm{Si}_{3} \mathrm{~N}_{4}$ & $\alpha-\delta-\mathrm{Dy}_{2} \mathrm{Si}_{2} \mathrm{O}_{7}$ & $\mathrm{Si}_{2} \mathrm{ON}_{2}$ \\
$\mathrm{Er}_{2} \mathrm{O}_{3}$ & $\beta-\mathrm{Si}_{3} \mathrm{~N}_{4}$ & $\beta-\mathrm{Er}_{2} \mathrm{Si}_{2} \mathrm{O}_{7}$ & $\mathrm{Si}_{2} \mathrm{ON}_{7}$ \\
$\mathrm{Yb}_{2} \mathrm{O}_{3}$ & $\beta-\mathrm{Si}_{3} \mathrm{~N}_{4}$ & $\beta-\mathrm{Yl}_{2} \mathrm{Si}_{2} \mathrm{O}_{7}$ & $\mathrm{Si}_{2} \mathrm{ON}_{2}$
\end{tabular}




\section{Table VIII. Oxidation Kinetics}

Rate Constant $\left(\mathrm{mg}^{2} / \mathrm{cm}^{4} \mathrm{hr}\right) \quad$ Total Specific Wt. Gain $\left(\mathrm{mg} / \mathrm{cm}^{2}\right)$

$\begin{array}{ccc}\mathrm{Sm}_{2} \mathrm{Si}_{2} \mathrm{O}_{7}-\mathrm{Si}_{3} \mathrm{~N}_{4} & 14.0 \times 10^{-4} & 0.644 \\ \mathrm{Gd}_{2} \mathrm{Si}_{2} \mathrm{O}_{7}-\mathrm{Si}_{3} \mathrm{~N}_{4} & 6.1 \times 10^{-4} & 0.346 \\ \mathrm{Y}_{2} \mathrm{Si}_{2} \mathrm{O}_{7}-\mathrm{Si}_{3} \mathrm{~N}_{4} & 5.1 \times 10^{-4} & 0.313 \\ \mathrm{Dy}_{2} \mathrm{Si}_{2} \mathrm{O}_{7}-\mathrm{Si}_{3} \mathrm{~N}_{4} & 5.0 \times 10^{-4} & 0.314 \\ \mathrm{Yb}_{2} \mathrm{Si}_{2} \mathrm{O}_{7}-\mathrm{Si}_{3} \mathrm{~N}_{4} & 3.7 \times 10^{-4} & 0.268 \\ \mathrm{Er}_{2} \mathrm{Si}_{2} \mathrm{O}_{7}-\mathrm{Si}_{3} \mathrm{~N}_{4} & 3.3 \times 10^{-4} & 0.252\end{array}$

* Determined for the period 72-192 hr (parabolic hehavior) 


\section{Table IX. X-ray Diffraction of Oxidized Surfaces}

Material

Major Phases

$\mathrm{\beta}-\mathrm{Y}_{2} \mathrm{Si}_{2} \mathrm{O}_{7}, \mathrm{SiO}_{2} *$

$A-\mathrm{Sm}_{2} \mathrm{Si}_{2} \mathrm{O}_{7}, \mathrm{SiO}_{2}$

$\delta-\mathrm{Gd}_{2} \mathrm{Si}_{2} \mathrm{O}_{7}, \mathrm{SiO}_{2}$

$\mathrm{Dy}_{2} \mathrm{Si}_{2} \mathrm{O}_{7}-\mathrm{Si}_{3} \mathrm{~N}_{4}$

$\mathrm{Er}_{2} \mathrm{Si}_{2} \mathrm{O}_{7}-\mathrm{Si}_{3} \mathrm{~N}_{4}$

$\mathrm{Yb}_{2} \mathrm{Si}_{2} \mathrm{O}_{7}-\mathrm{Si}_{3} \mathrm{~N}_{4}$

* as $\alpha$-cristobalite

$\delta-\mathrm{Dy}_{2} \mathrm{Si}_{2} \mathrm{O}_{7}, \mathrm{SiO}_{2}$

$\beta-\mathrm{Er}_{2} \mathrm{Si}_{2} \mathrm{O}_{7}, \mathrm{SiO}_{2}$

$\beta-\mathrm{Yb}_{2} \mathrm{Si}_{2} \mathrm{O}_{7}, \mathrm{SiO}_{2}$
Minor Phases

$\mathrm{Si}_{2} \mathrm{ON}_{2}, \beta-\mathrm{Si}_{3} \mathrm{~N}_{4}$

$\mathrm{Si}_{2} \mathrm{ON}_{2}, \beta-\mathrm{Si}_{3} \mathrm{~N}_{4}$

$\mathrm{Si}_{2} \mathrm{ON}_{2}, \beta-\mathrm{Si}_{3} \mathrm{~N}_{4}$

$\alpha-\mathrm{Dy}_{2} \mathrm{Si}_{2} \mathrm{O}_{7}, \mathrm{Si}_{2} \mathrm{ON}_{2}, \beta-\mathrm{Si}_{3} \mathrm{~N}_{4}$

$\mathrm{Si}_{2} \mathrm{ON}_{2}, \beta-\mathrm{Si}_{3} \mathrm{~N}_{4}$

$\mathrm{Si}_{2} \mathrm{ON}_{2}, \beta-\mathrm{Si}_{3} \mathrm{~N}_{4}$ 


\title{
Table X. Semi-Quantitative Microanalysis of Oxidized Surfaces
}

\author{
Material Phase Elemental Composition (at.\%)
}

$\begin{array}{llllll}\mathrm{Mg} & \mathrm{Al} & \mathrm{Si} & \mathrm{Ca} & \mathrm{Fe} & \mathrm{RE}\end{array}$

\begin{tabular}{|c|c|c|c|c|c|c|c|}
\hline \multirow[t]{2}{*}{$\mathrm{Y}_{2} \mathrm{Si}_{2} \mathrm{O}_{7}-\mathrm{Si}_{3} \mathrm{~N}_{4}$} & $\beta-\mathrm{Y}_{2} \mathrm{Si}_{2} \mathrm{O}_{7}$ & 0.0 & 0.0 & 48.8 & $<0.2$ & $<0.2$ & 51.0 \\
\hline & Amorph. Silicate & 4.2 & 1.7 & 78.3 & 6.2 & $<0.2$ & 9.5 \\
\hline \multirow[t]{2}{*}{$\mathrm{Sm}_{2} \mathrm{Si}_{2} \mathrm{O}_{7}-\mathrm{Si}_{3} \mathrm{~N}_{4}$} & $\mathrm{~A}-\mathrm{Sm}_{2} \mathrm{Si}_{2} \mathrm{O}_{7}$ (equiaxed) & 0.0 & 0.0 & 49.4 & 0.0 & 0.2 & 50.4 \\
\hline & Amorph. Silicate & 0.5 & 2.6 & 93.5 & $<0.2$ & $<0.2$ & 3.2 \\
\hline \multirow[t]{3}{*}{$\mathrm{Gd}_{2} \mathrm{Si}_{2} \mathrm{O}_{7}-\mathrm{Si}_{3} \mathrm{~N}_{4}$} & $\delta-\mathrm{Gd}_{2} \mathrm{Si}_{2} \mathrm{O}$ (equiaxed) & $0.0^{*}$ & 0.0 & 54.3 & 0.0 & $<0.2$ & 45.6 \\
\hline & $\delta-\mathrm{Gd}_{2} \mathrm{Si}_{2} \mathrm{O}_{7}$ (needle) & $0.0^{*}$ & 0.0 & 48.6 & 6.1 & $<0.2$ & 45.2 \\
\hline & Amorph. Silicate & $6.0^{*}$ & 5.7 & 81.2 & 1.1 & $<0.2$ & 5.9 \\
\hline \multirow[t]{3}{*}{$\mathrm{Dy}_{2} \mathrm{Si}_{2} \mathrm{O}_{7}-\mathrm{Si}_{3} \mathrm{~N}_{4}$} & $\delta-\mathrm{Dy}_{2} \mathrm{Si}_{2} \mathrm{O}_{7}$ (equiaxed) & 0.0 & 0.0 & 47.9 & 0.0 & $<0.2$ & 52.0 \\
\hline & $\delta-\mathrm{Dy}_{2} \mathrm{Si}_{2} \mathrm{O}_{7}$ (needle) & 0.0 & 0.0 & 30.6 & 7.5 & $<0.2$ & 61.8 \\
\hline & Amorph. Silicate & 3.6 & 2.8 & 85.0 & 1.4 & $<0.2$ & 7.2 \\
\hline \multirow[t]{2}{*}{$\mathrm{Er}_{2} \mathrm{Si}_{2} \mathrm{O}_{7}-\mathrm{Si}_{3} \mathrm{~N}_{4}$} & $\beta-\mathrm{Er}_{2} \mathrm{Si}_{2} \mathrm{O}_{7}$ (equiaxed) & 0.0 & 0.0 & 61.7 & 0.0 & $<0.2$ & 38.2 \\
\hline & Amorph. Silicate & 3.5 & 6.3 & 80.0 & 4.1 & 0.5 & 5.6 \\
\hline \multirow[t]{2}{*}{$\mathrm{Yb}_{2} \mathrm{Si}_{2} \mathrm{O}_{7}-\mathrm{Si}_{3} \mathrm{~N}_{4}$} & $\beta-\mathrm{Yb}_{2} \mathrm{Si}_{2} \mathrm{O}$ (equiaxed) & $0.0^{\dagger}$ & 0.0 & 32.5 & $<0.2$ & $<0.2$ & 67.2 \\
\hline & Amorph. Silicate & $3.5^{\dagger}$ & 6.0 & 81.6 & 5.4 & $<0.2$ & 3.4 \\
\hline
\end{tabular}


'rable XI. Flexural Strength Results at $25^{\circ} \mathrm{C}$

Material Strength* (MPa) Std. Dev. (MPa) Weibull Modulus

$\begin{array}{lccc}\mathrm{Y}_{2} \mathrm{Si}_{2} \mathrm{O}_{7}-\mathrm{Si}_{3} \mathrm{~N}_{4} & 599 & 69 & 10 \\ \mathrm{Sm}_{2} \mathrm{Si}_{2} \mathrm{O}_{7}-\mathrm{Si}_{3} \mathrm{~N}_{4} & 533 & 56 & 11 \\ \mathrm{Gd}_{2} \mathrm{Si}_{2} \mathrm{O}_{7}-\mathrm{Si}_{3} \mathrm{~N}_{4} & 615 & 68 & 10 \\ \mathrm{Dy}_{2} \mathrm{Si}_{2} \mathrm{O}_{7}-\mathrm{Si}_{3} \mathrm{~N}_{4} & 540 & 42 & 15 \\ \mathrm{Er}_{2} \mathrm{Si}_{2} \mathrm{O}_{7}-\mathrm{Si}_{3} \mathrm{~N}_{4} & 550 & 112 & 6 \\ \mathrm{Yb}_{2} \mathrm{Si}_{2} \mathrm{O}_{7}-\mathrm{Si}_{3} \mathrm{~N}_{4} & 623 & 93 & 8 \\ { }^{*} \text { Mean strength of six test specimens } & & \end{array}$

Table XII. Flexural Strength Results at $1300^{\circ} \mathrm{C}$

Material Strength* (MPa) Std. Dev. (MPa) Weibull Modulus

$\begin{array}{llll}\mathrm{Y}_{2} \mathrm{Si}_{2} \mathrm{O}_{7}-\mathrm{Si}_{3} \mathrm{~N}_{4} & 523 & 37 & 17 \\ \mathrm{Sm}_{2} \mathrm{Si}_{2} \mathrm{O}_{7}-\mathrm{Si}_{3} \mathrm{~N}_{4} & 585 & 17 & 43 \\ \mathrm{Gd}_{2} \mathrm{Si}_{2} \mathrm{O}_{7}-\mathrm{Si}_{3} \mathrm{~N}_{4} & 490 & 26 & 23 \\ \mathrm{Dy}_{2} \mathrm{Si}_{2} \mathrm{O}_{7}-\mathrm{Si}_{3} \mathrm{~N}_{4} & 467 & 31 & 18 \\ \mathrm{Er}_{2} \mathrm{Si}_{2} \mathrm{O}_{7}-\mathrm{Si}_{3} \mathrm{~N}_{4} & 502 & 21 & 29 \\ \mathrm{Yb}_{2} \mathrm{Si}_{2} \mathrm{O}_{7}-\mathrm{Si}_{3} \mathrm{~N}_{4} & 567 & 49 & 14 \\ \text { * Mean strength of six test specimens } & \end{array}$




\section{FIGURES}

Figure 1. (top) Dark-field transmission electron micrograph of $\mathrm{Si}_{3} \mathrm{~N}_{4}$ sintered with $\mathrm{Y}_{2} \mathrm{O}_{3}$ and $\mathrm{Al}_{2} \mathrm{O}_{3}$ additives. Image obtained using electrons incoherently scattered by the amorphous grain-boundary phase, which is in bright contrast. (bottom) Plot of flexural strength vs. temperature for above material. Loss in strength at high temperatures is typical for conventionally materials.

Figure 2. Phase relations in the $\mathrm{Si}_{3} \mathrm{~N}_{4}-\mathrm{SiO}_{2}-\mathrm{Y}_{2} \mathrm{O}_{3}$ s s ystem (after Lange et al. ${ }^{41}$ ).

Figure 3. Phase diagrams of systems $\mathrm{SiO}_{2}-\mathrm{RE}_{2} \mathrm{O}_{3} \cdot{ }^{43}$

Figure 4. Polymorphism of the rare-earth disilicates, after Ito and Johnson 38 and Felsche. ${ }^{36}$

Figure 5. Schematic of sample configurition in sintering furnace.

Figure 6. Schematic of flexure specimen showing location were specimens were obtained for TEM. Shaded region indicates $3 \mathrm{~mm}$ specimen.

Figure 7. Schematic of furnace and the configuration used for flexural strength and creep testing.

Figure 8. Light micrographs of the six materials, sectioned, showing levels of porosity present internally.

Figure 9. $\mathrm{X}$-ray diffrarion patterns of the six $\mathrm{RE}_{2} \mathrm{O}_{3}$-sintered materials following heat treatment.

Figure 10. Transmission electron micrographs of the six $\mathrm{RE}_{2} \mathrm{Si}_{2} \mathrm{O}_{7}-\mathrm{Si}_{3} \mathrm{~N}_{4}$ materials showing the similarity in morphology of the microstructures.

Figure 11. Transmission electron mictographs of $\mathrm{Y}_{2} \mathrm{Si}_{2} \mathrm{O}_{7}-\mathrm{Si}_{3} \mathrm{~N}_{4}$ in (top) bright-field and (bottom) dark-field, obtained using diffracted electrons from the [ [ $\left.\begin{array}{lll}1 & 3 & 2\end{array}\right]$ 
diffraction partern of $\beta-\mathrm{Y}_{2} \mathrm{Si}_{2} \mathrm{O}_{7}$ shown inset, therefore regions in bright contrast are of the same disilicate crystal.

Figure 12. Transmission electron micrographs of $\mathrm{Y}_{2} \mathrm{Si}_{2} \mathrm{O}_{7}-\mathrm{Si}_{3} \mathrm{~N}_{4}$ in (top) bright-field and (bottom) dark-field, obtained using diffracted electrons from the $\left[\begin{array}{lll}0 & 0 & 2\end{array}\right]$ diffraction pattem of $\beta-\mathrm{Y}_{2} \mathrm{Si}_{2} \mathrm{O}$, shown inset.

Figure 13. Transmission electron micrographs of $\mathrm{Y}_{2} \mathrm{Si}_{2} \mathrm{O}_{7}-\mathrm{Si}_{3} \mathrm{~N}_{4}$ in (top) bright-field and (bottom) dark-field, obtained using electrons incoherently scattered from the amorphous phase, therefore regions in bright contrast are amorphous.

Figure 14. Transmission electron micrographs of $\mathrm{Y}_{2} \mathrm{Si}_{2} \mathrm{O}_{7}-\mathrm{Si}_{3} \mathrm{~N}_{4}$ in (top) bright-field and (bottom) dark-field, obtained using electrons incoherently scattered from the amorphous phase. Bottom dark-field image is blurred due to specimen motion during the long exposure $(-60 \mathrm{~min})$ required to obtain this image.

Figure 15. Transmission electron micrographs of $\mathrm{Sm}_{2} \mathrm{Si}_{2} \mathrm{O}_{7}-\mathrm{Si}_{3} \mathrm{~N}_{4}$ in (top) bright-field and (bottom) dark-field, obtained using diffracted electrons from the [ [ 12120$]$ diffraction pattern of $\mathrm{A}-\mathrm{Sm}_{2} \mathrm{Si}_{2} \mathrm{O}_{7}$ shown inset.

Figure 16. Transmission electron micrographs of $\mathrm{Sm}_{2} \mathrm{Si}_{2} \mathrm{O}_{7}-\mathrm{Si}_{3} \mathrm{~N}_{4}$ in (top) bright-field and (bottom) dark-field, obtained using diffracted electrons from the [ [ $\left.\begin{array}{lll}12 & 12 & 0\end{array}\right]$ diffraction pattem of $\mathrm{A}-\mathrm{Sm}_{2} \mathrm{Si}_{2} \mathrm{O}_{7}$ shown inset. Dark secondary phase crystal in the dark-field image is also crystalline but in a different orientation.

Figure 17. Transmission electron micrographs of $\mathrm{Gd}_{2} \mathrm{Si}_{2} \mathrm{O}_{7}-\mathrm{Si}_{3} \mathrm{~N}_{4}$ in (top) bright-field and (bottom) dark-field, obtained using diffracted electrons from the [ [ $\left.\begin{array}{lll}1 & 1 & 0\end{array}\right]$ ] diffraction pattern of $\delta-\mathrm{Gd}_{2} \mathrm{Si}_{4} \mathrm{O}_{7}$ shown inset.

Figure 18. Transmission electron micrographs of $\mathrm{Gd}_{2} \mathrm{Si}_{2} \mathrm{O}_{7}-\mathrm{Si}_{3} \mathrm{~N}_{4}$ in (top) bright-field and (bottom) dark-field, obtained using diffracted electrons from the $\left[\begin{array}{lll}2 & 0 & 0\end{array}\right]$ diffraction pattem of $\delta-\mathrm{Gd}_{2} \mathrm{Si}_{2} \mathrm{O}_{7}-\mathrm{Si}_{3} \mathrm{~N}_{4}$ shown inset.

Figure 19. Transmission electron mictographs of $\mathrm{Dy}_{2} \mathrm{Si}_{2} \mathrm{O}_{7}-\mathrm{Si}_{3} \mathrm{~N}_{4}$ in (tnn) bright-field and (bottom) dark-field, obtained using diffracted electrons from the $\left[\begin{array}{lll}0 & 0 & 2\end{array}\right]$ diffraction pattem of $\delta-\mathrm{Dy}_{2} \mathrm{Si}_{2} \mathrm{O}_{7}$ shown inset. 
Figure 20. Transmission electron micrographs of $\mathrm{Dy}_{2} \mathrm{Si}_{2} \mathrm{O}_{7}-\mathrm{Si}_{3} \mathrm{~N}_{4}$ in (top) bright-field and (bottom) dark-field, obtained using diffracted electrons from the [0 20$]$ diffraction pattern of $\delta-\mathrm{Dy}_{2} \mathrm{Si}_{2} \mathrm{O}_{7}$ shown inset.

Figure 21. Transmission electron micrographs of $\mathrm{E}_{2} \mathrm{Si}_{2} \mathrm{O}_{7}-\mathrm{Si}_{3} \mathrm{~N}_{4}$ in (top) bright-field and (bottom) dark-field, obtained using diffracted electrons from the [0 20$]$ diffraction pattern of $\beta-\mathrm{E}_{2} \mathrm{Si}_{2} \mathrm{O}$ shown inset.

Figure 22. Transmission electron micrographs of $\mathrm{Er}_{2} \mathrm{Si}_{2} \mathrm{O}_{7}-\mathrm{Si}_{3} \mathrm{~N}_{4}$ in (top) bright-field and (bottom) dark-field, obtained using diffracted electrons from the [ $\left[\begin{array}{ll}0 & 0\end{array}\right]$ diffraction pattern of $\beta-\mathrm{Er}_{2} \mathrm{Si}_{2} \mathrm{O}$, shown inset.

Figure 23. Transmission electron micrographs of $\mathrm{Yb}_{2} \mathrm{Si}_{2} \mathrm{O}_{7}-\mathrm{Si}_{3} \mathrm{~N}_{4}$ in (top) bright-field and (bottom) dark-field, obtained using diffracted electrons from the [ll 112$]$ diffraction pattern of $\beta-\mathrm{Yb}_{2} \mathrm{Si}_{2} \mathrm{O}_{7}$ shown inset.

Figure 24. Transmission electron micrographs of $\mathrm{Yb}_{2} \mathrm{Si}_{2} \mathrm{O}_{7}-\mathrm{Si}_{3} \mathrm{~N}_{4}$ in (top) bright-field and (bottom) dark-field, obtained using diffracted electrons from the [ [1 12 2] diffraction pattem of $\beta-\mathrm{Yb}_{2} \mathrm{Si}_{2} \mathrm{O}_{7}$ shown inset.

Figure 25. Transmission electron micrographs of $\mathrm{Yb}_{2} \mathrm{Si}_{2} \mathrm{O}_{7}-\mathrm{Si}_{3} \mathrm{~N}_{4}$ in (top) bright-field and (bottom) dark-field, obtained using diffracted electrons from the [1 112 ] diffraction pattem of $\beta-\mathrm{Yb}_{2} \mathrm{Si}_{2} \mathrm{O}_{7}$ shown top inset. Lower inset is the diffraction pattem obtained from the amorphous $\mathrm{region}$ labeled $A$. Note similar contrast of amorphous pocket in both images.

Figure 26. Transmission electron micrographs of $\mathrm{Yb}_{2} \mathrm{Si}_{2} \mathrm{O}_{7}-\mathrm{Si}_{3} \mathrm{~N}_{4}$ in (top) bright-field and (bottom) dark-field, obtained using electrons incoherently scattered from the amorphous regions. Some amorphous phase is also covering crystalline $\mathrm{Yb}_{2} \mathrm{Si}_{2} \mathrm{O}_{7}$

Figure 27. EDS spectra of (top) $\mathrm{\beta}-\mathrm{Yb}_{2} \mathrm{Si}_{2} \mathrm{O}_{7}$ and (bottom) amorphous region. Note relative heights of $S_{1} K_{\alpha}$ and $\mathrm{Yb}_{\alpha} \mathrm{M}_{\alpha}$ peaks, indicating high Si-concentration of amorphous region. Presence of $\mathrm{N}$ in spectrum of amorphous phase suggests that it is an oxynitride. 
Figure 28. EDS spectrum of $\beta-\mathrm{Si}_{3} \mathrm{~N}_{4}$ in $\mathrm{Yb}_{2} \mathrm{Si}_{2} \mathrm{O}_{7}-\mathrm{Si}_{3} \mathrm{~N}_{4}$ material showing no evidence of solubility of the lanthanides.

Figure 29. Transmission electron mictographs of Fe-rich inclusions in $\mathrm{Y}_{2} \mathrm{Si}_{2} \mathrm{O}_{7}-\mathrm{Si}_{3} \mathrm{~N}_{4}$.

Figure 30. EDS spectrum of inclusion in center of grain shown in Fig. 29 (top).

Figure 31. EDS spectra of the disilicate phases crystallized in the six compositions. Note no evidence of impurites present in these phases. Presence of Ar, Mo, and $\mathrm{Cu}$ are artifacts introduced during thin-foil specimen preparation.

Figure 32. Plot of specific weight gains due to oxidation as a function of time at $1400^{\circ} \mathrm{C}$.

Figure 33. (top) Parabolic plot of specific weight gains (squared) as a function of time. (bottom) Expansion of the parabolic plot.

Figure 34. X-ray diffraction patterns of the oxidized surfaces of the six materials, showing preferential orientation of $\mathrm{RE}_{2} \mathrm{Si}_{2} \mathrm{O}_{7}$. Indexed peaks identify planes of the disilicates lying parallel to the surface.

Figure 35. Light micrographs of the oxidized surfaces of the six materials. Biightcontrast phase in each image is $\mathrm{RE}_{2} \mathrm{Si}_{2} \mathrm{O}_{7}$.

Figure 36. Scanning electron micrographs of the oxidized surfaces of the six materials imaged using secondary electrons, showing surface topography and morphology and preference in direction of growth of the disilicates.

Figure 37. Scanning electron micrographs of the oxidized surfaces of the six materials imaged using backscattered electrons to obtain contrast based on average atomic weight. Darkest-contrast phase is cristobalite, medium-contrast phase is residual silicate, and brightest-contrast phase is the disilicate in each image.

Figure 38. Scanning electron mictographs of the oxidized surfaces of three materials imaged using backscattered electrons, showing cristobalite and residual 
intergranular silicate phase. Note increasing volume fraction of silicate for materials displaying increased resistance to oxidation.

Figure 39. Plot of flexural strengths at $25^{\circ} \mathrm{C}$ and $1300^{\circ} \mathrm{C}$. Error bars have been omitted for clarity. Standard deviations were $\sim 10 \%$ and $\sim 5 \%$ of mean strengths at $25^{\circ} \mathrm{C}$ and $1300^{\circ} \mathrm{C}$, respectively.

Figure 40. Scanning electron micrographs of room-temperature fracture surfaces imaged using secondary electrons of (top) $\mathrm{Sm}_{2} \mathrm{Si}_{2} \mathrm{O}_{7}-\mathrm{Si}_{3} \mathrm{~N}_{4}$ and (bottom) $\mathrm{Gd}_{2} \mathrm{Si}_{2} \mathrm{O}_{7}$ $\mathrm{Si}_{3} \mathrm{~N}_{4}$.

Figure 41. Scanning electron micrographs of room-temperature fracture surfaces imaged using secondary electrons of inclusions in $\mathrm{Gd}_{2} \mathrm{Si}_{2} \mathrm{O}_{7}-\mathrm{Si}_{3} \mathrm{~N}_{4}$. (Top) $\mathrm{Al}$ and $\mathrm{Ca}$-rich inclusion and (bottom) Si-rich inclusion.

Figure 42. Scanning electron micrographs of high-temperature fracture surfaces imaged using secondary electron of (top) $\mathrm{Sm}_{2} \mathrm{Si}_{2} \mathrm{O}_{7}-\mathrm{Si}_{3} \mathrm{~N}_{4}$ and (bottom) $\mathrm{Gd}_{2} \mathrm{Si}_{2} \mathrm{O}_{7}-$ $\mathrm{Si}_{3} \mathrm{~N}_{4}$.

Figure 43. Scanning electron micrograph of high-temperature fracture surface imaged using secondary electron of $3 \mathrm{i}$-rich glassy inclusion in $\mathrm{Y}_{2} \mathrm{Si}_{2} \mathrm{O}_{7}-\mathrm{Si}_{3} \mathrm{~N}_{4}$.

Figure 44. Plot of total creep strains as a function of time at $1400^{\circ} \mathrm{C}$ under nominal stresses of $\sim 130-145 \mathrm{MPa}$. Exact stresses depend on specific dimensions of each specimen.

Figure 45. Plot of "steady-stere" creep strain rates as a function of applied stress at $1400^{\circ} \mathrm{C}$. Creep stress exponents are given inset.

Figure 46. Transmission electron micrographs of (top) $\mathrm{Sm}_{2} \mathrm{Si}_{2} \mathrm{O}_{7}-\mathrm{Si}_{3} \mathrm{~N}_{4}$ and (bottom) $\mathrm{Dy}_{2} \mathrm{Si}_{2} \mathrm{O}_{7}-\mathrm{Si}_{3} \mathrm{~N}_{4}$ showing clustering of cavities and relative cavitation density following creep at $1400^{\circ} \mathrm{C}$ for $70 \mathrm{hr}$ under $\sim 130 \mathrm{MPa}$ nominal stress.

Figure 47. Transmission electron micrographs showing cavity nucleation in (top) $\mathrm{Y}_{2} \mathrm{Si}_{2} \mathrm{O}_{7}-\mathrm{Si}_{3} \mathrm{~N}_{4}$ and (bottom) $\mathrm{Sm}_{2} \mathrm{Si}_{2} \mathrm{O}_{7}-\mathrm{Si}_{3} \mathrm{~N}_{4}$ at triple-junctions. 
Figure 48. Transmission electron micrographs showing triangular wedge-shaped cavities in (top) $\mathrm{Sm}_{2} \mathrm{Si}_{2} \mathrm{O}_{7}-\mathrm{Si}_{3} \mathrm{~N}_{4}$ and (bottom) $\mathrm{Dy}_{2} \mathrm{Si}_{2} \mathrm{O}_{7}-\mathrm{Si}_{3} \mathrm{~N}_{4}$.

Figure 49. Transmission electron micrographs of $\mathrm{Dy}_{2} \mathrm{Si}_{2} \mathrm{O}_{7}-\mathrm{Si}_{3} \mathrm{~N}_{4}$ showing residual amorphous phase surrounding perimeter of cavity imaged in (top) bright-field and (bottom) dark-field using inccherently scattered electrons from this amorphous film.

Figure 50. Transmission electron micrographs of strain whorls in $\mathrm{Y}_{2} \mathrm{Si}_{2} \mathrm{O}_{7}-\mathrm{Si}_{3} \mathrm{~N}_{4}$ indicating grain-boundary sliding. Extinction contours seem to center on points of contact.

Figure 51. Schematic of a beam in partly circular bending. 80 

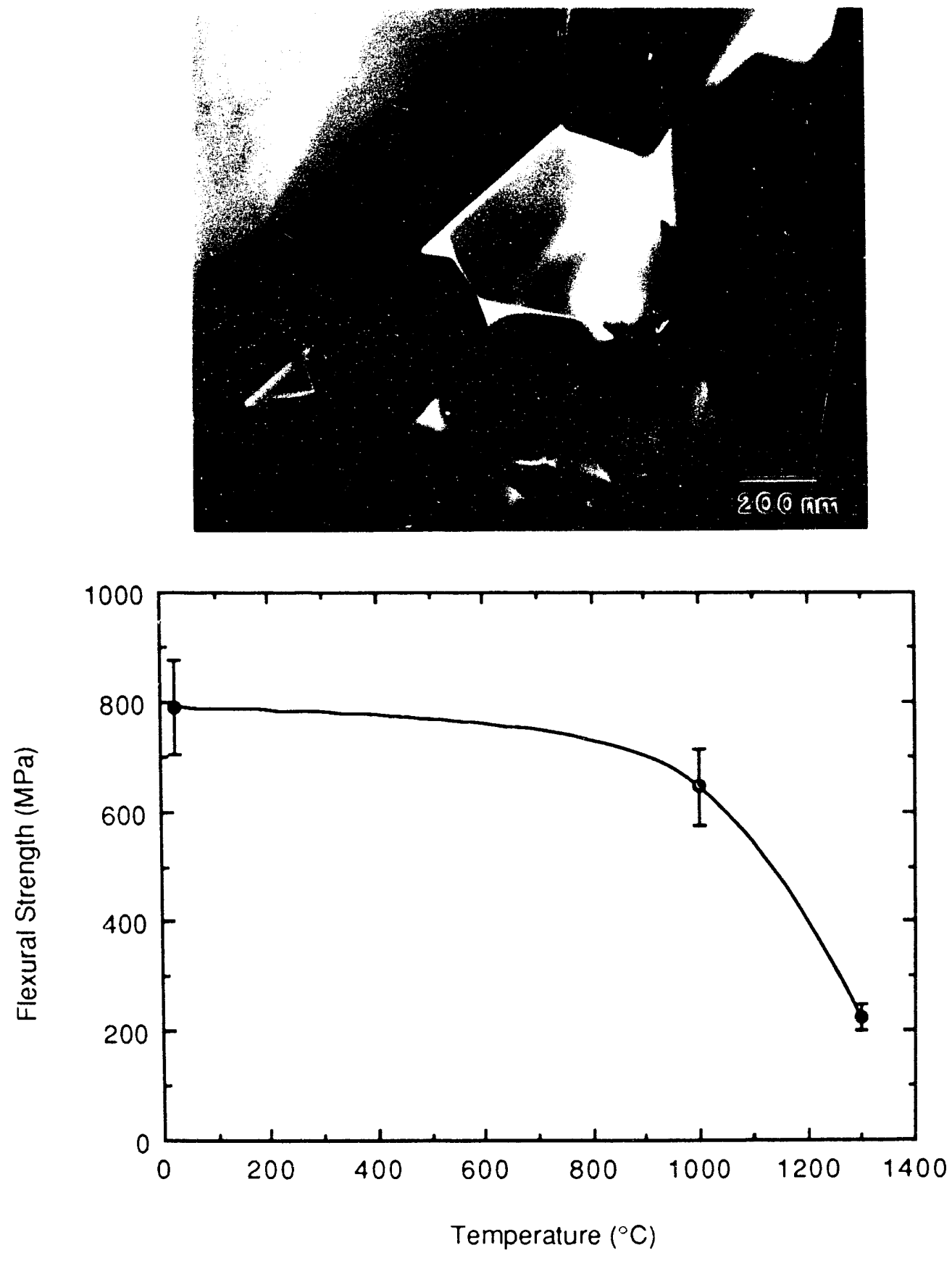

Figure 1 


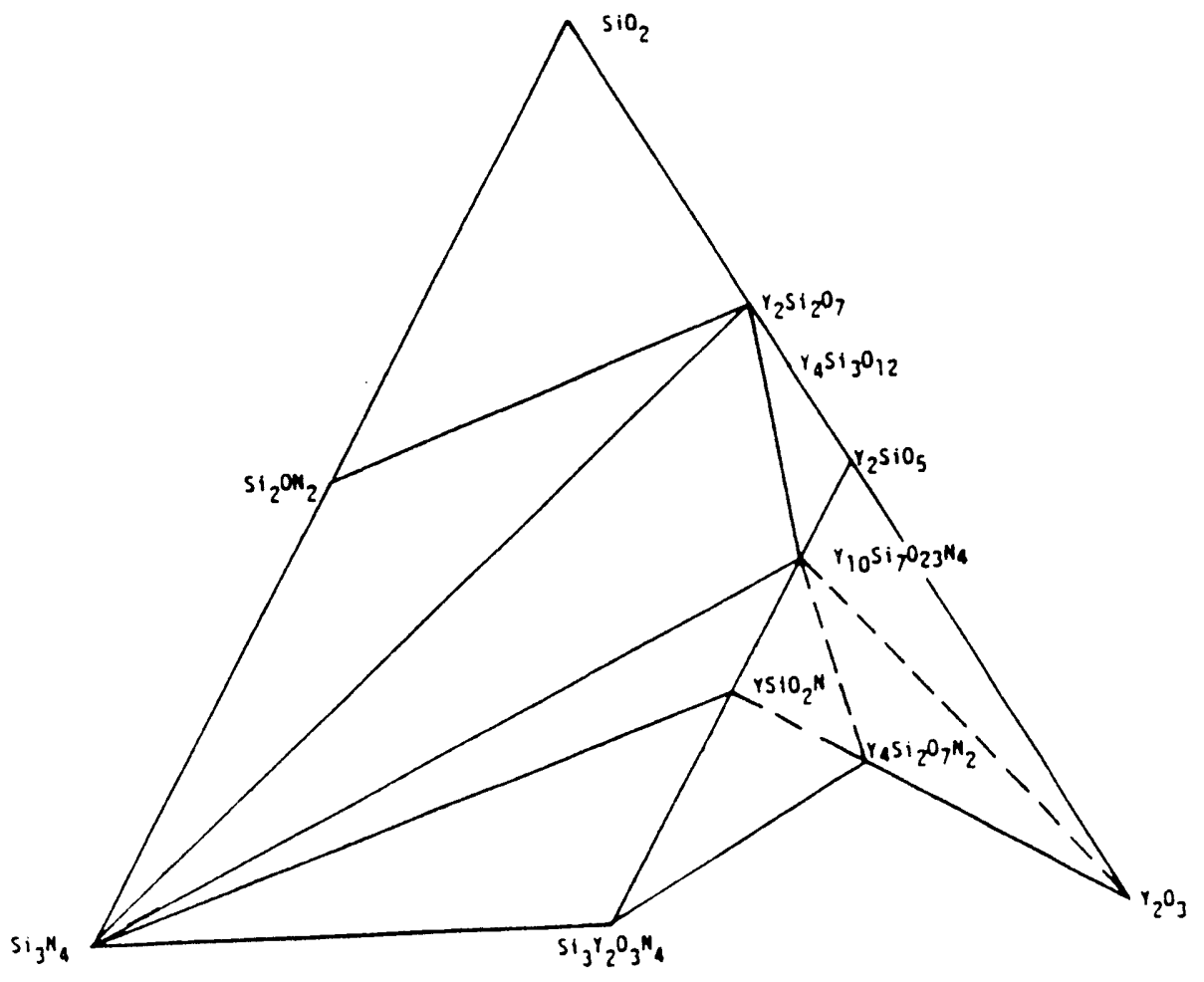

XEL $917-1588$

Figure 2 

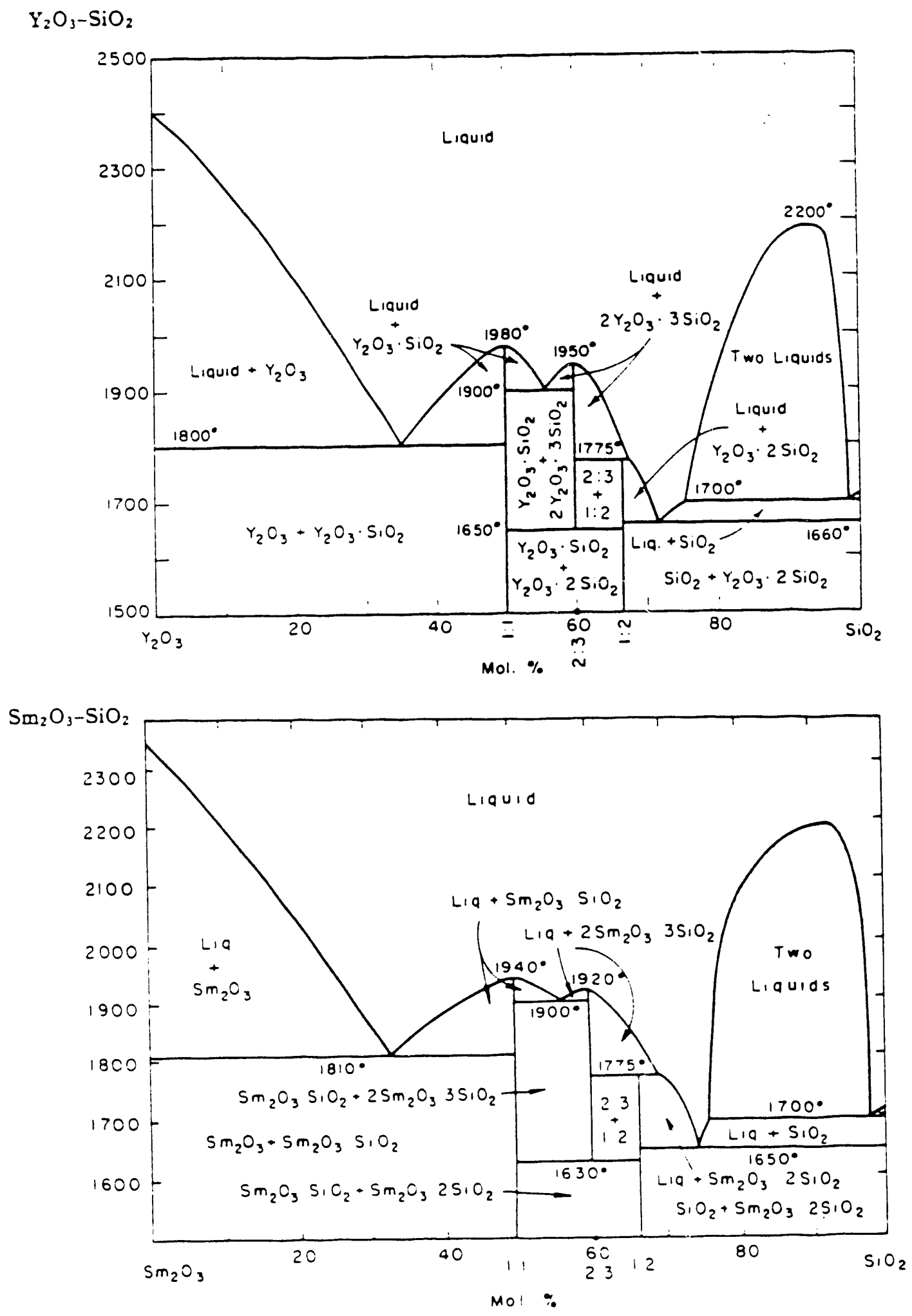

XBL $917-1589$

Figure 3 
$\mathrm{Gd}_{2} \mathrm{O}_{3}-\mathrm{SiO}_{2}$

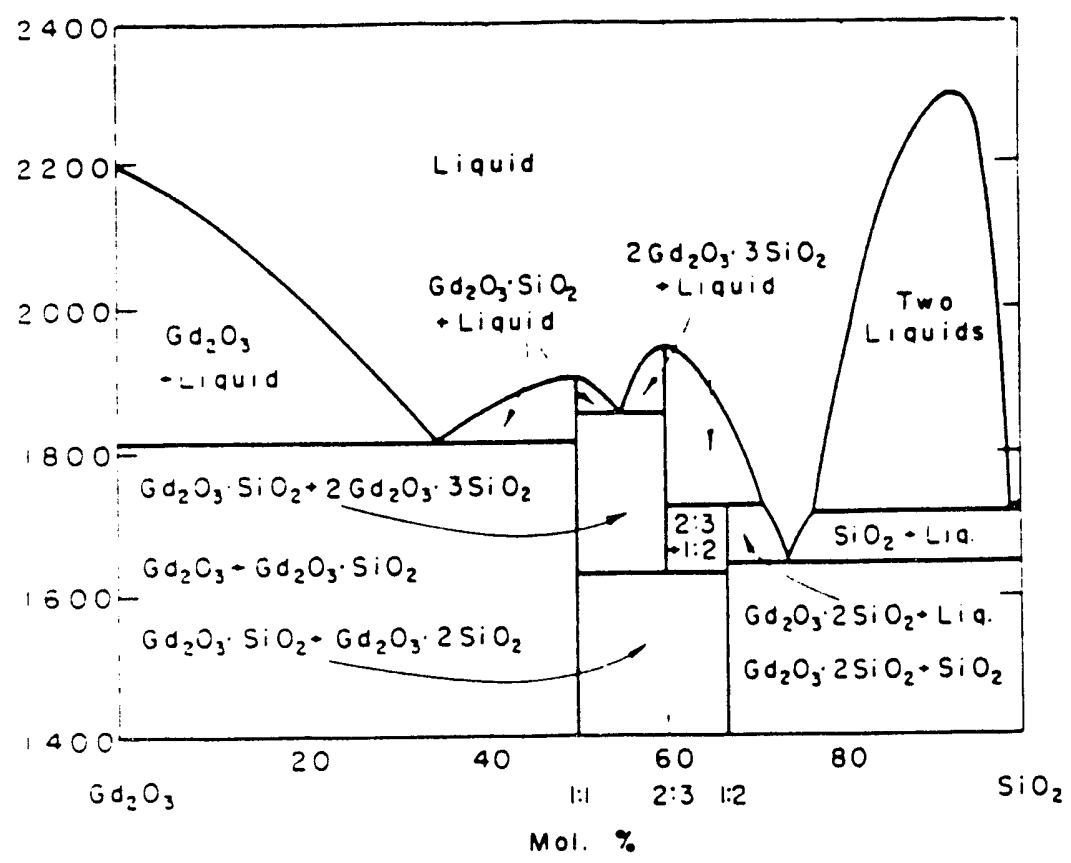

$\mathrm{Dy}_{2} \mathrm{O}_{3}-\mathrm{SiO}_{2}$

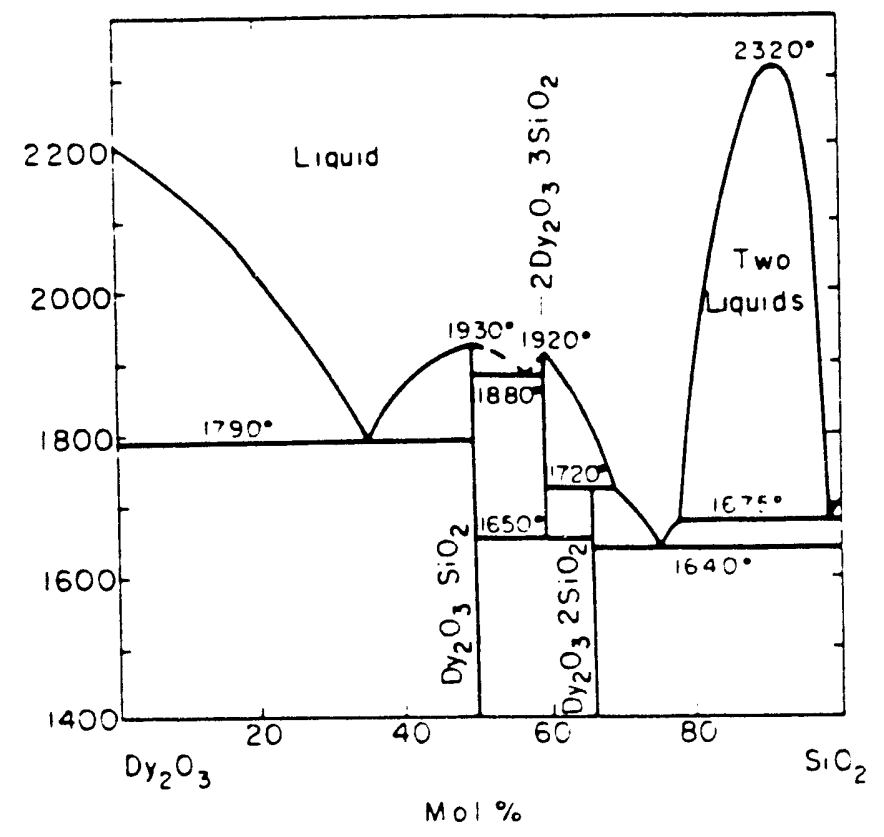

$x=19: 7 \cdot 1530$

Figure 3

(cont.) 

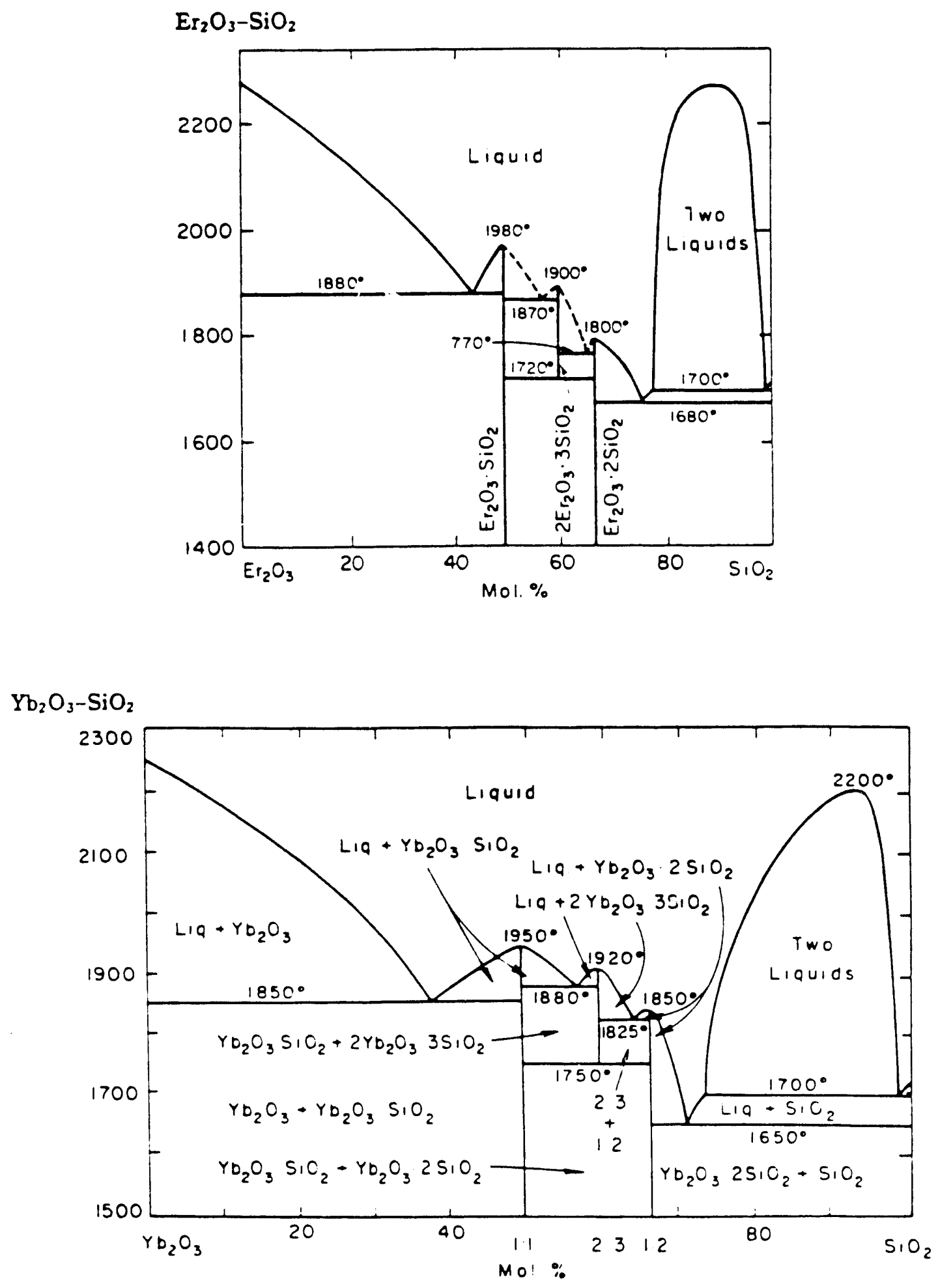

1E: 917-1591

Figure 3

(cont.) 


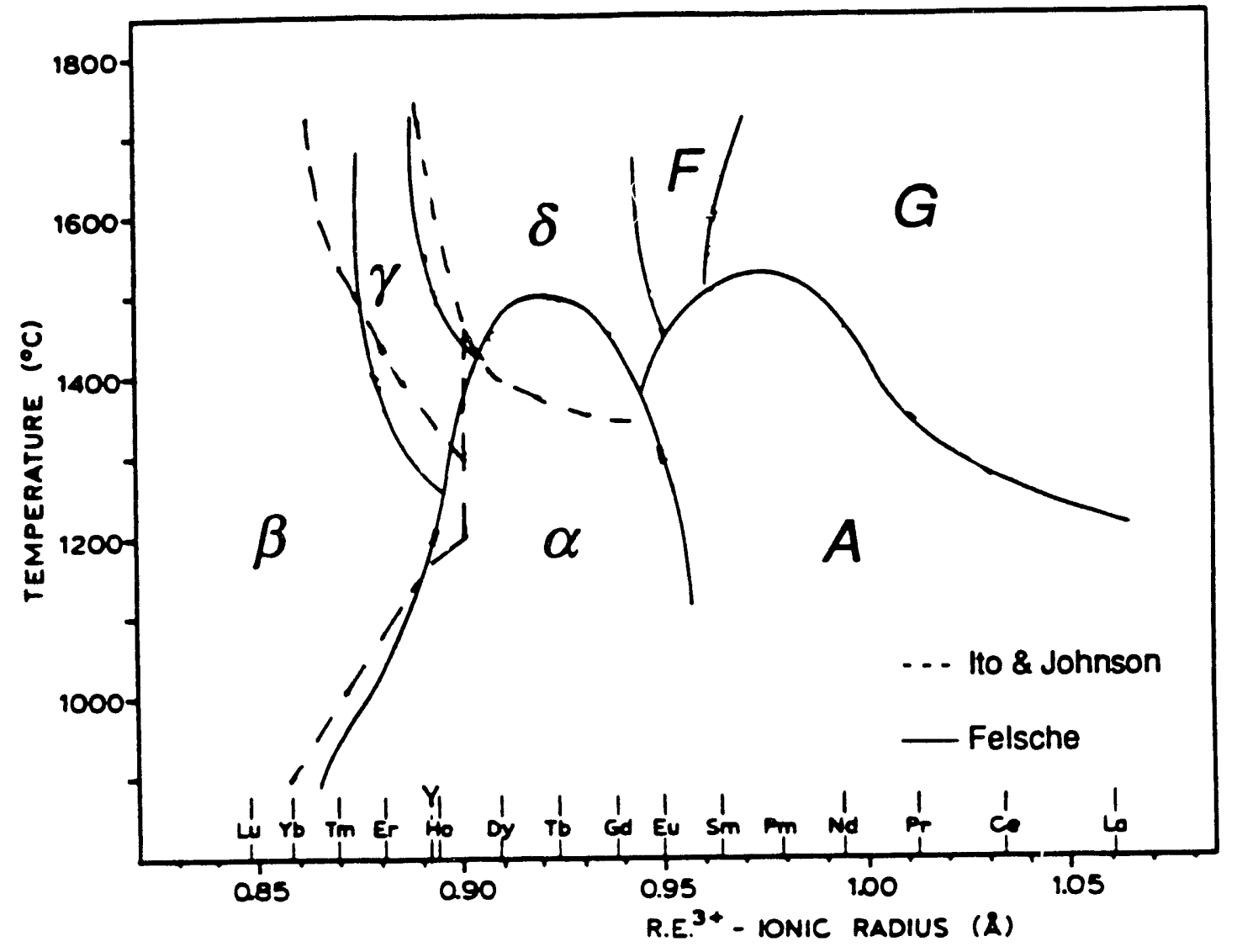

Y.9L $917-1592$

Figure 4 


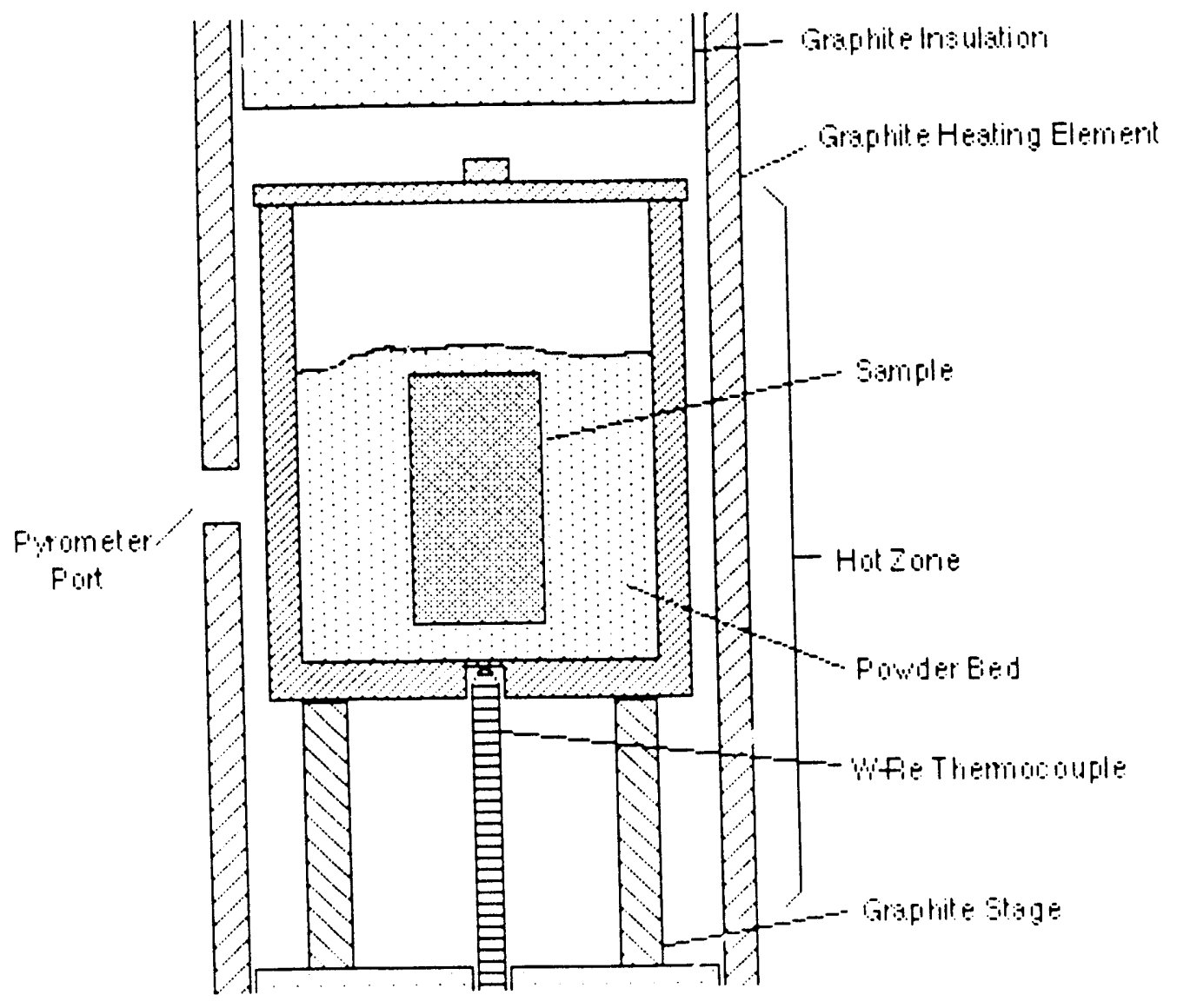

$1 \div \quad \div \quad \div \square$

Figure 5 


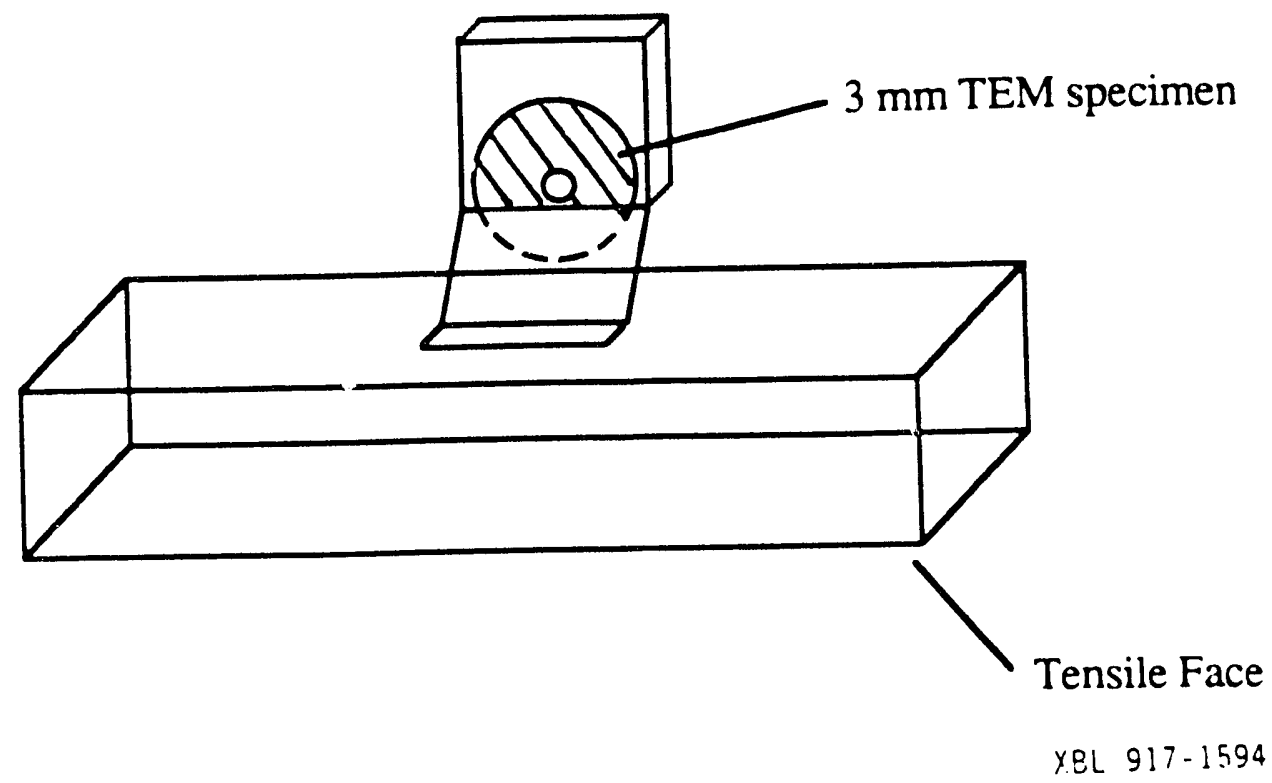

Figure 6 


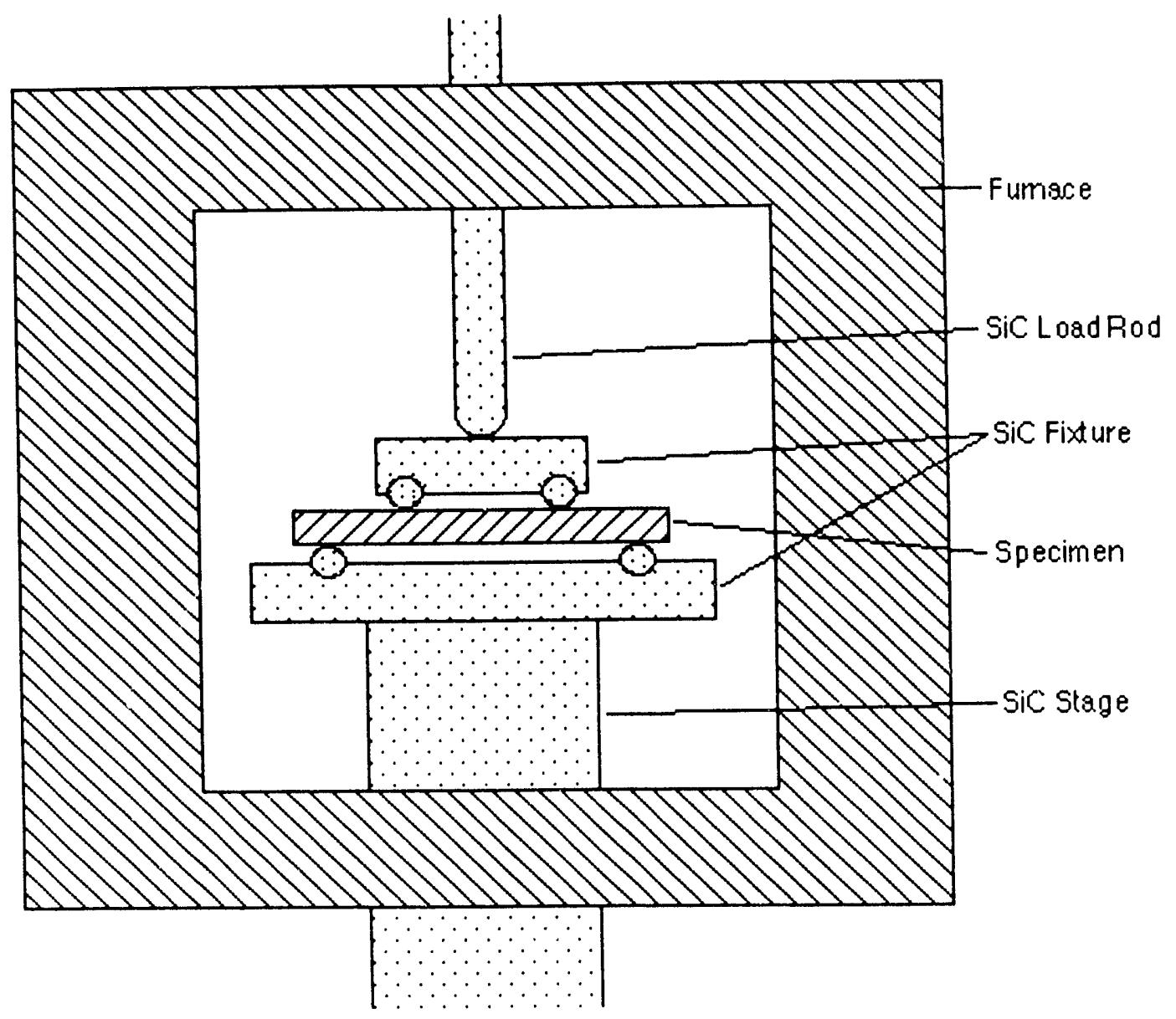

XBL 917-1595

Figure 7 

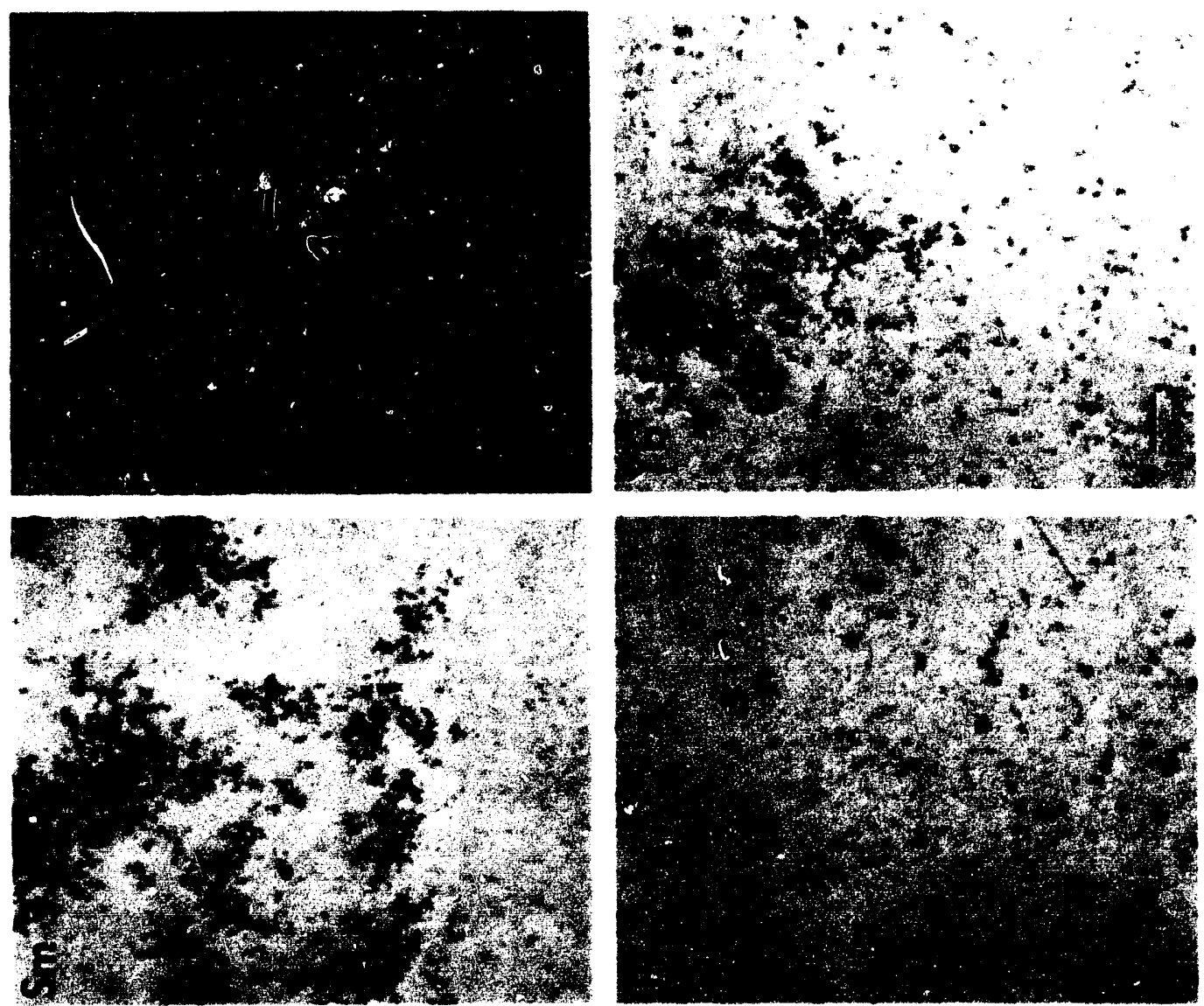

点
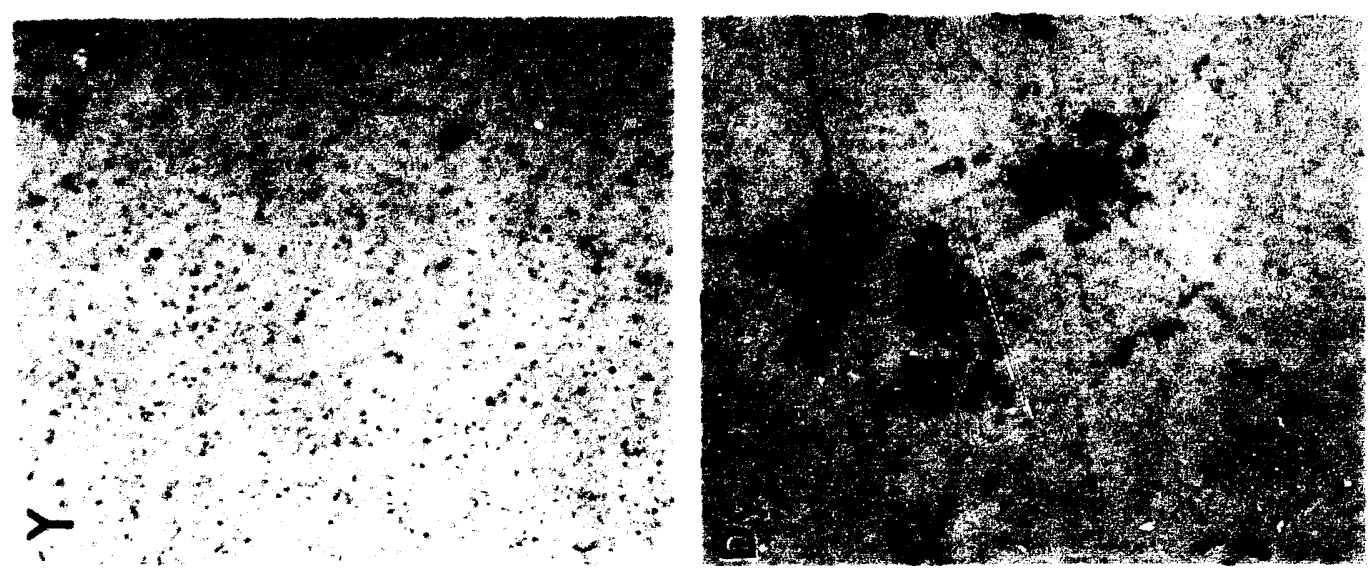

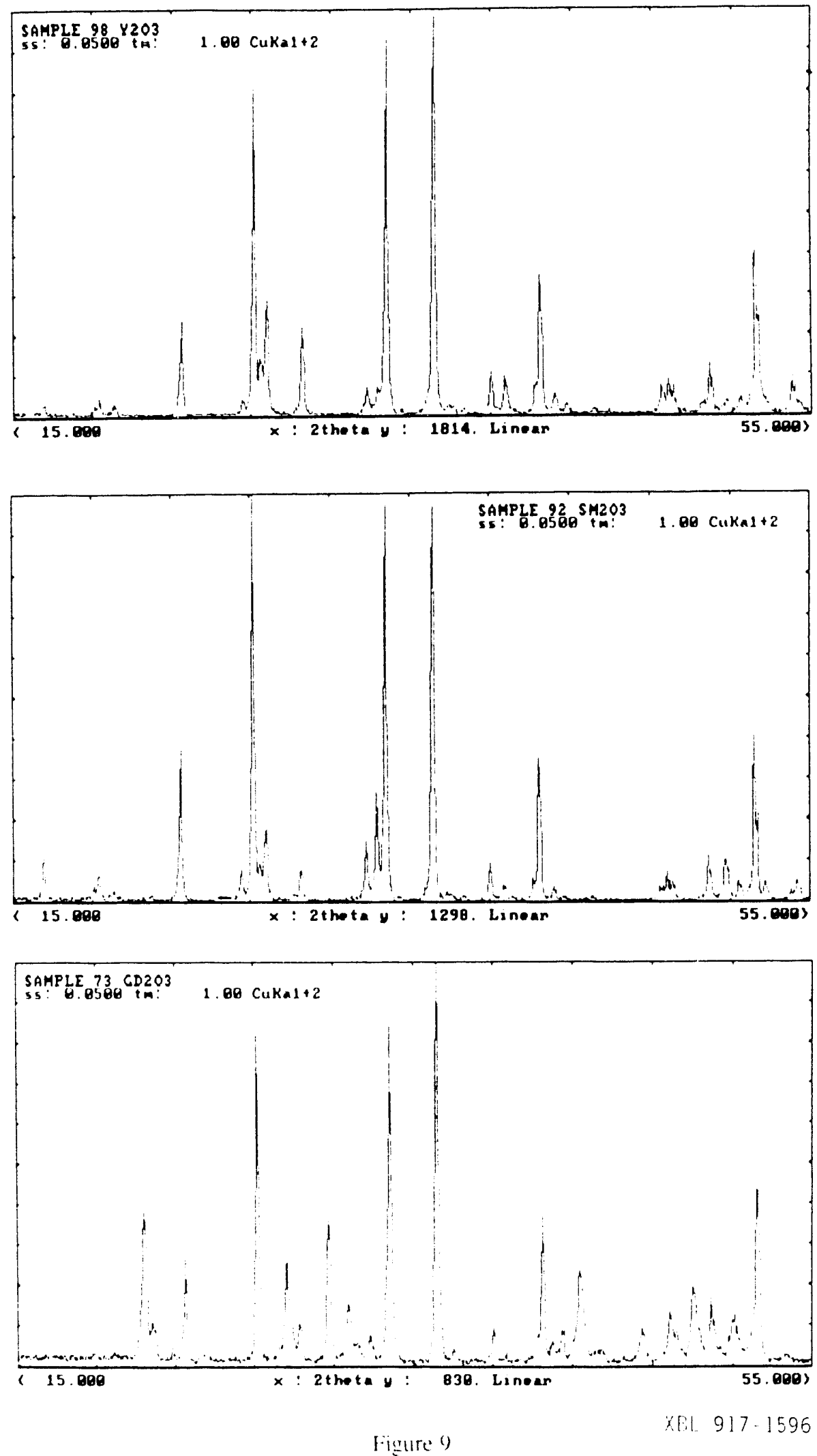

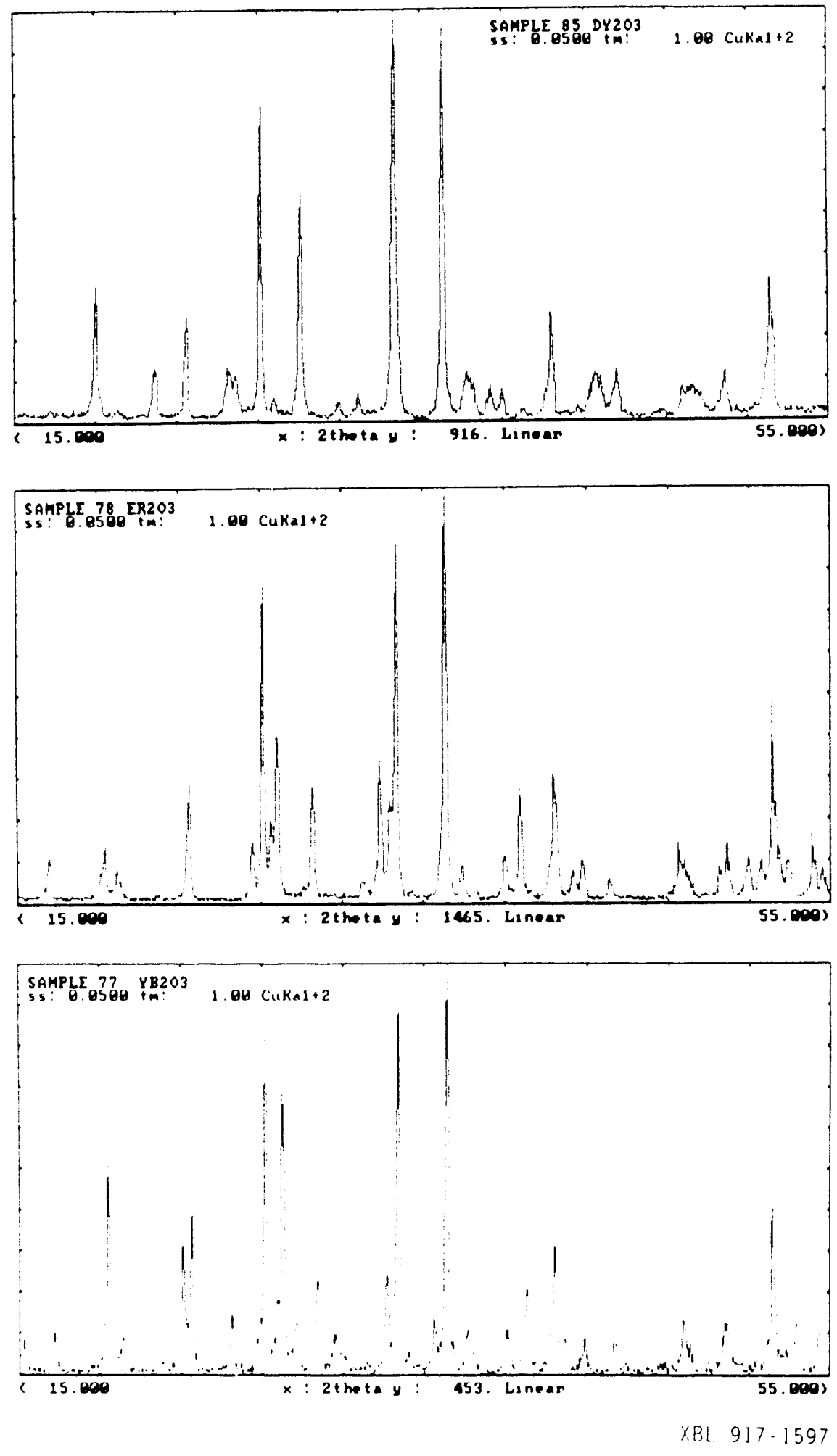

Figure9

(cont.) 

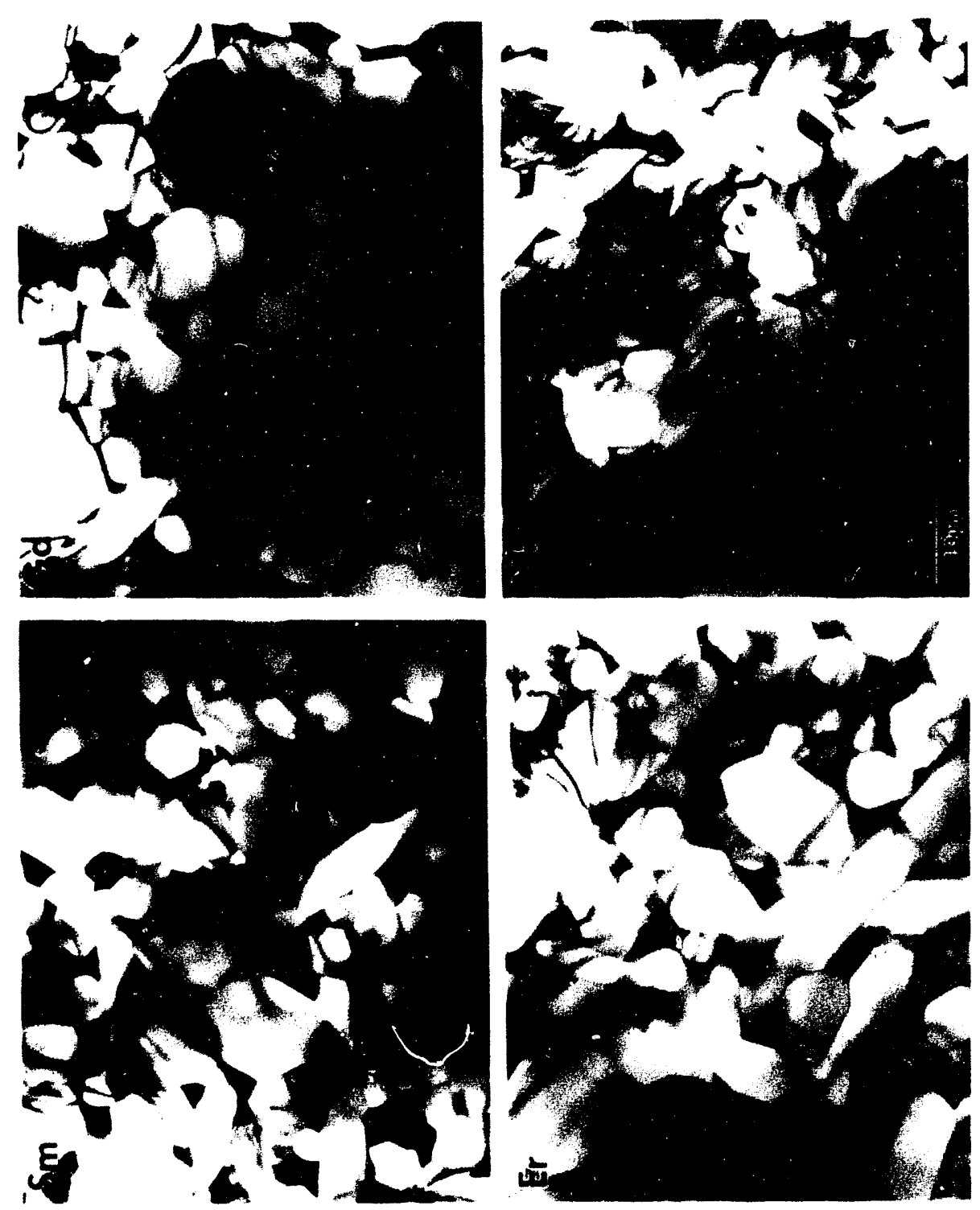

을

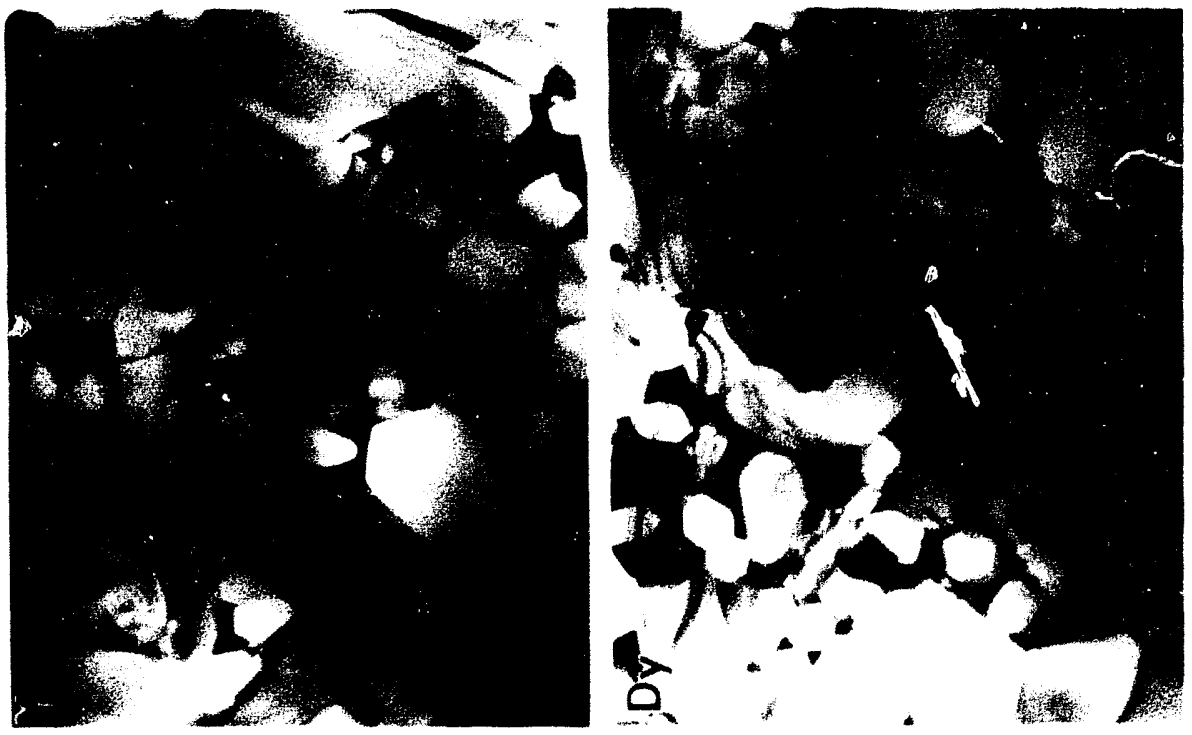




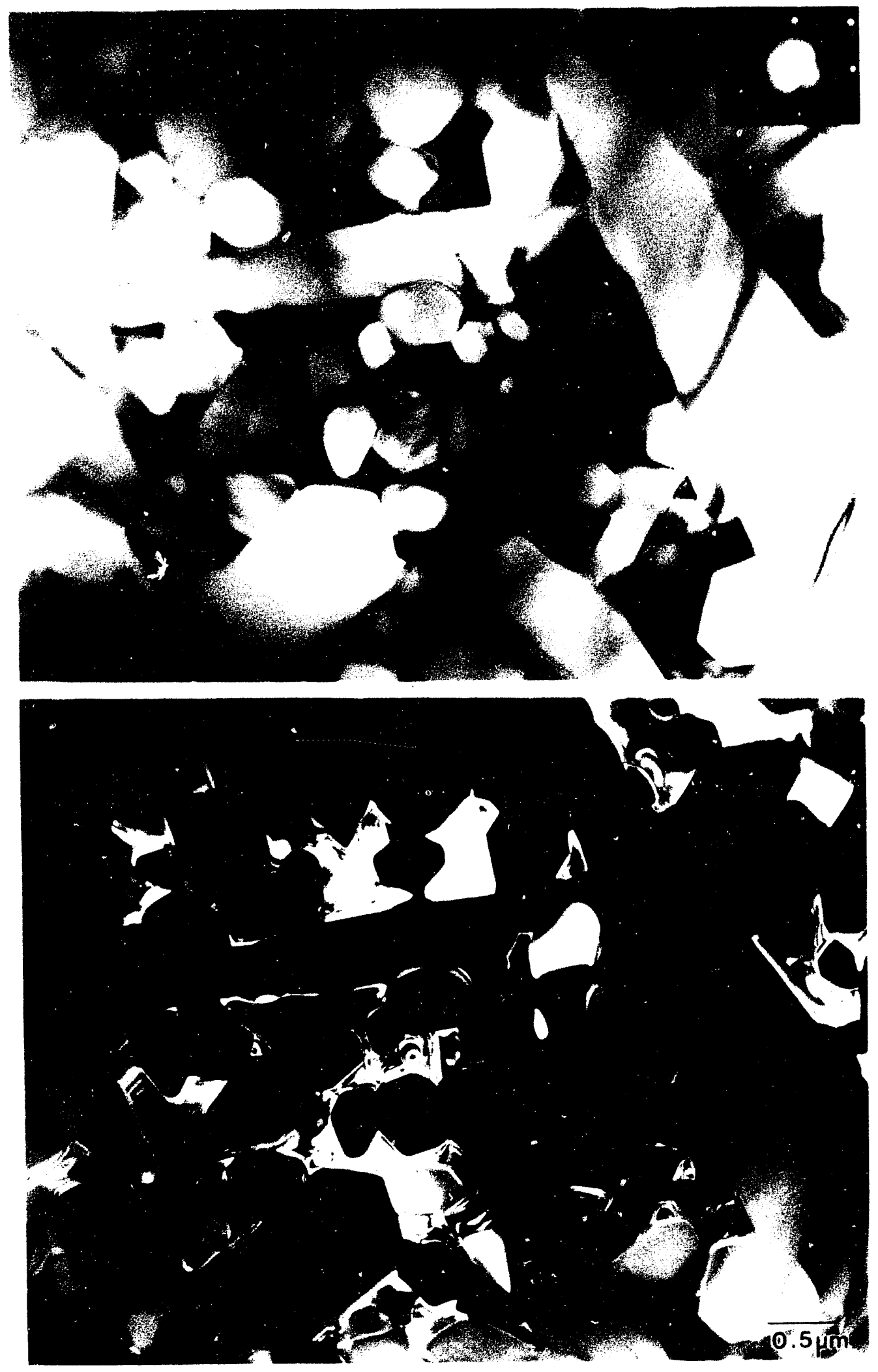

Figure 11 


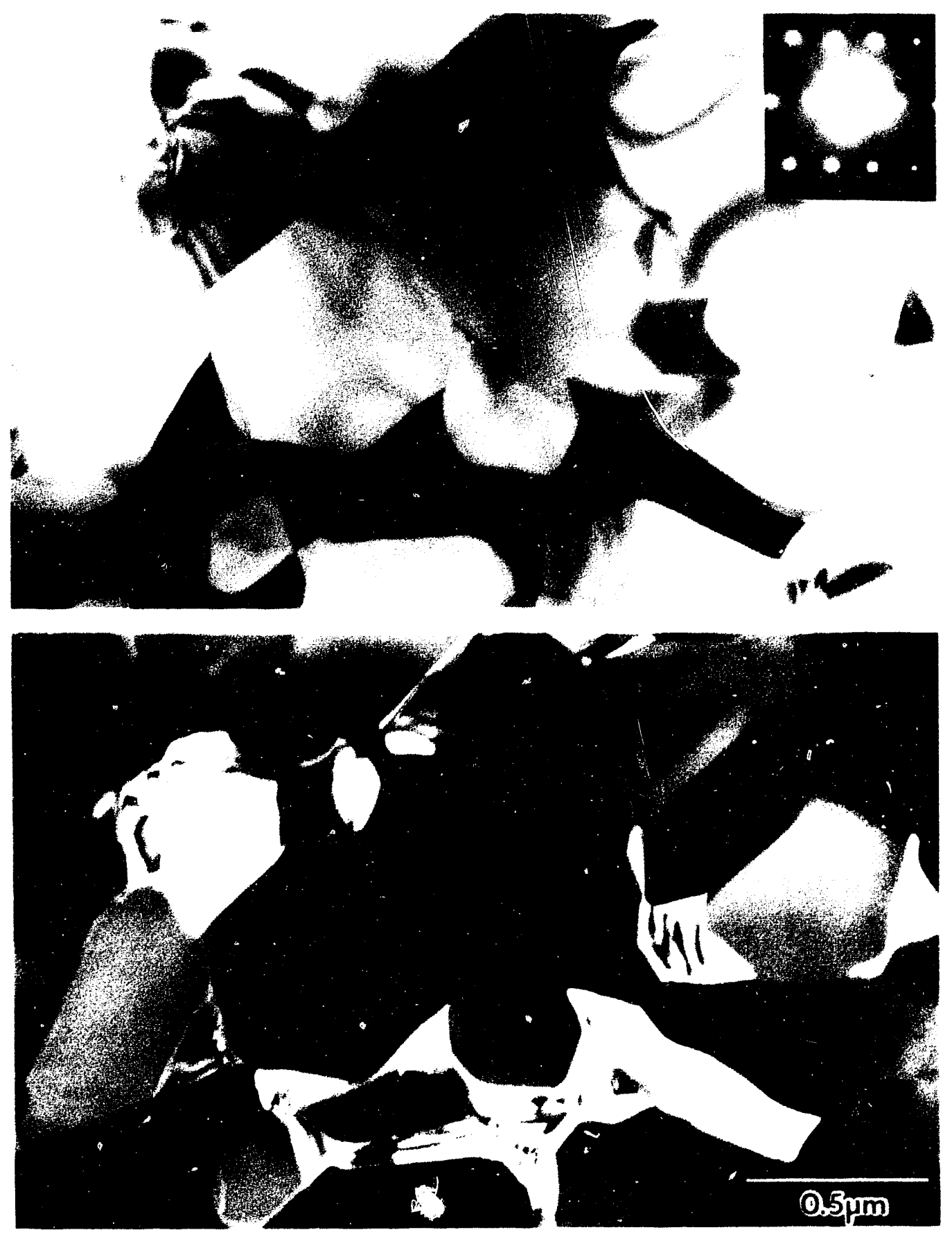

Figure 12 


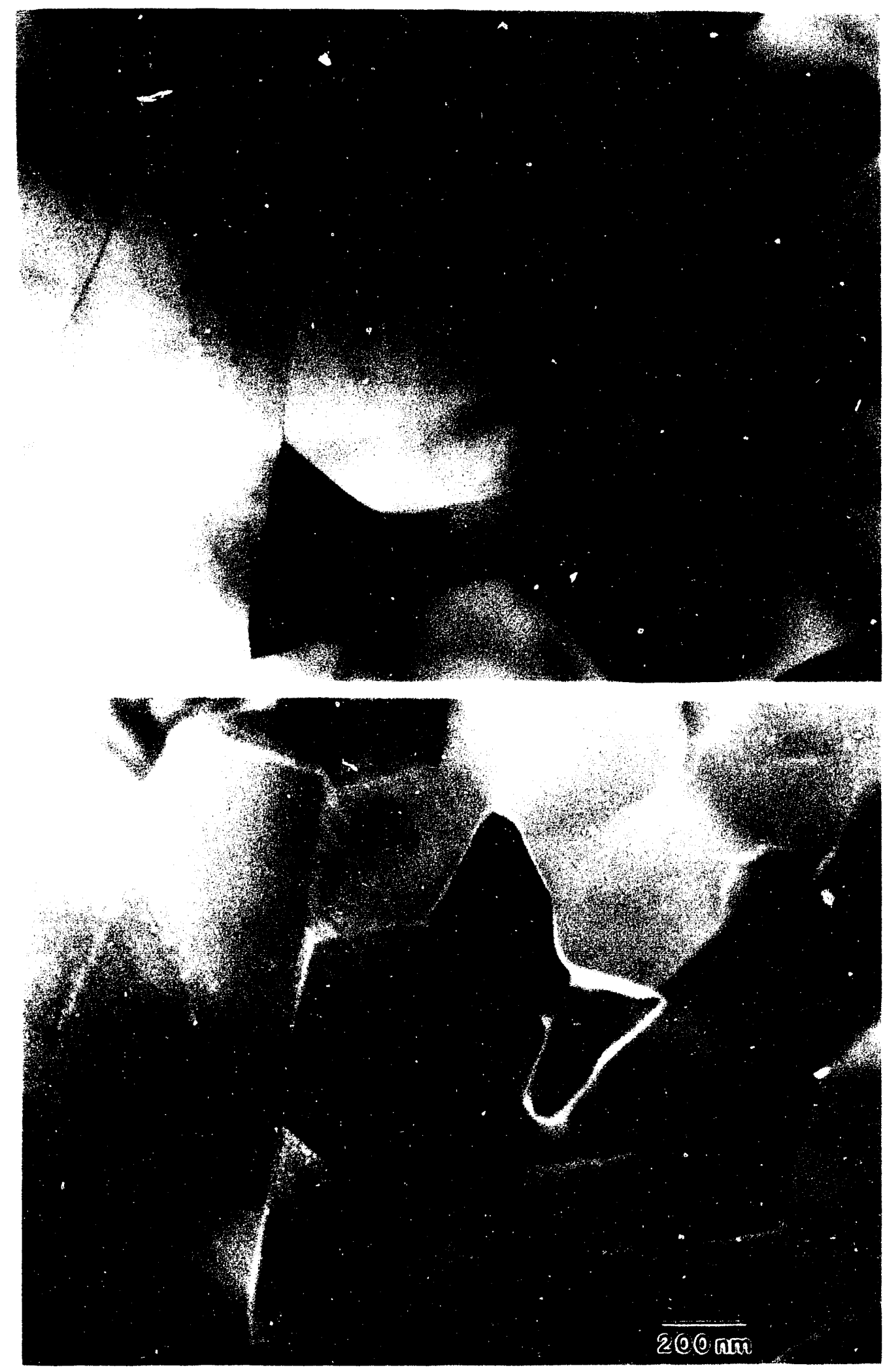

Figure 13 


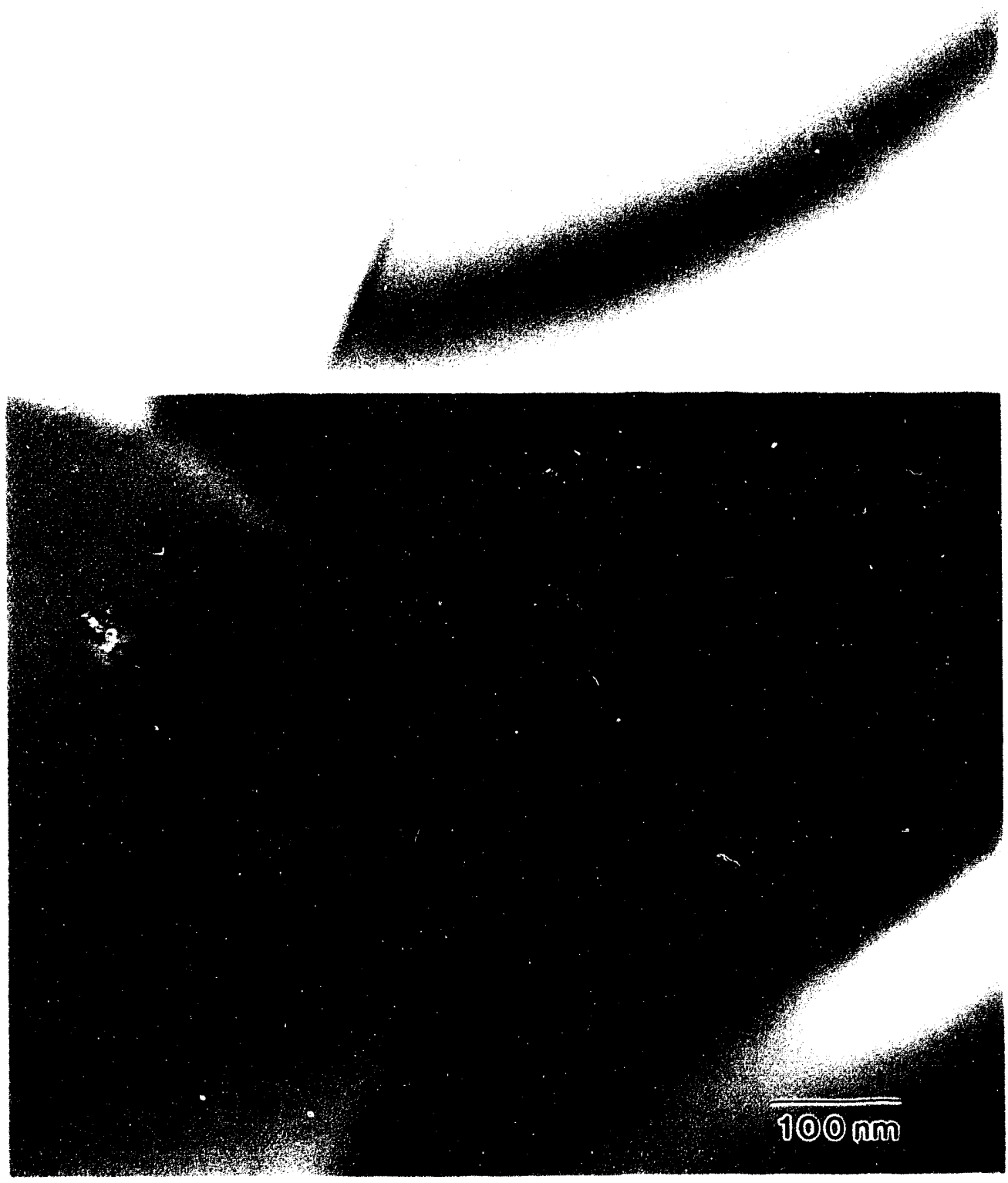

Figure 14 

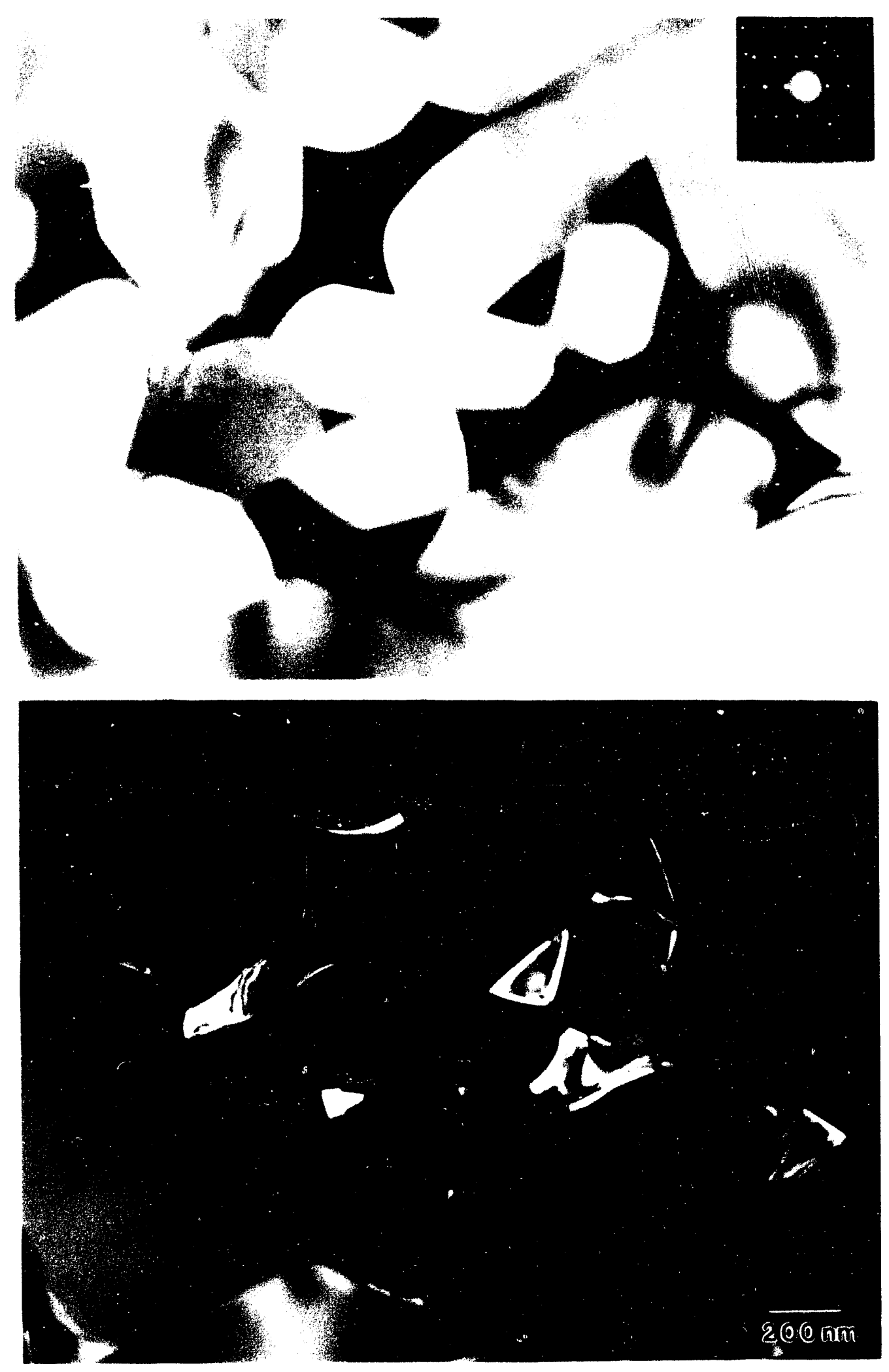

Figure 15 


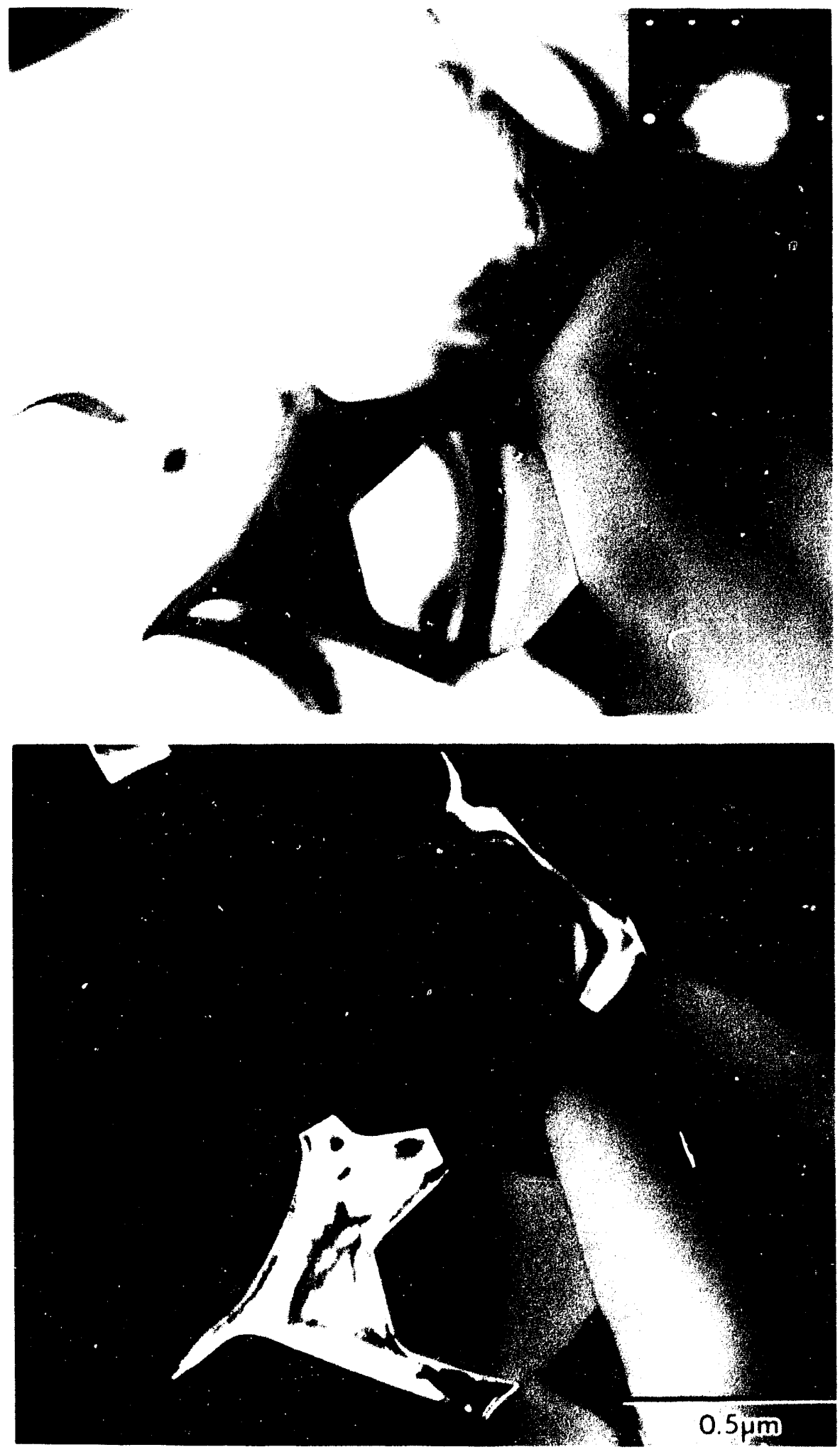

Figure 16 

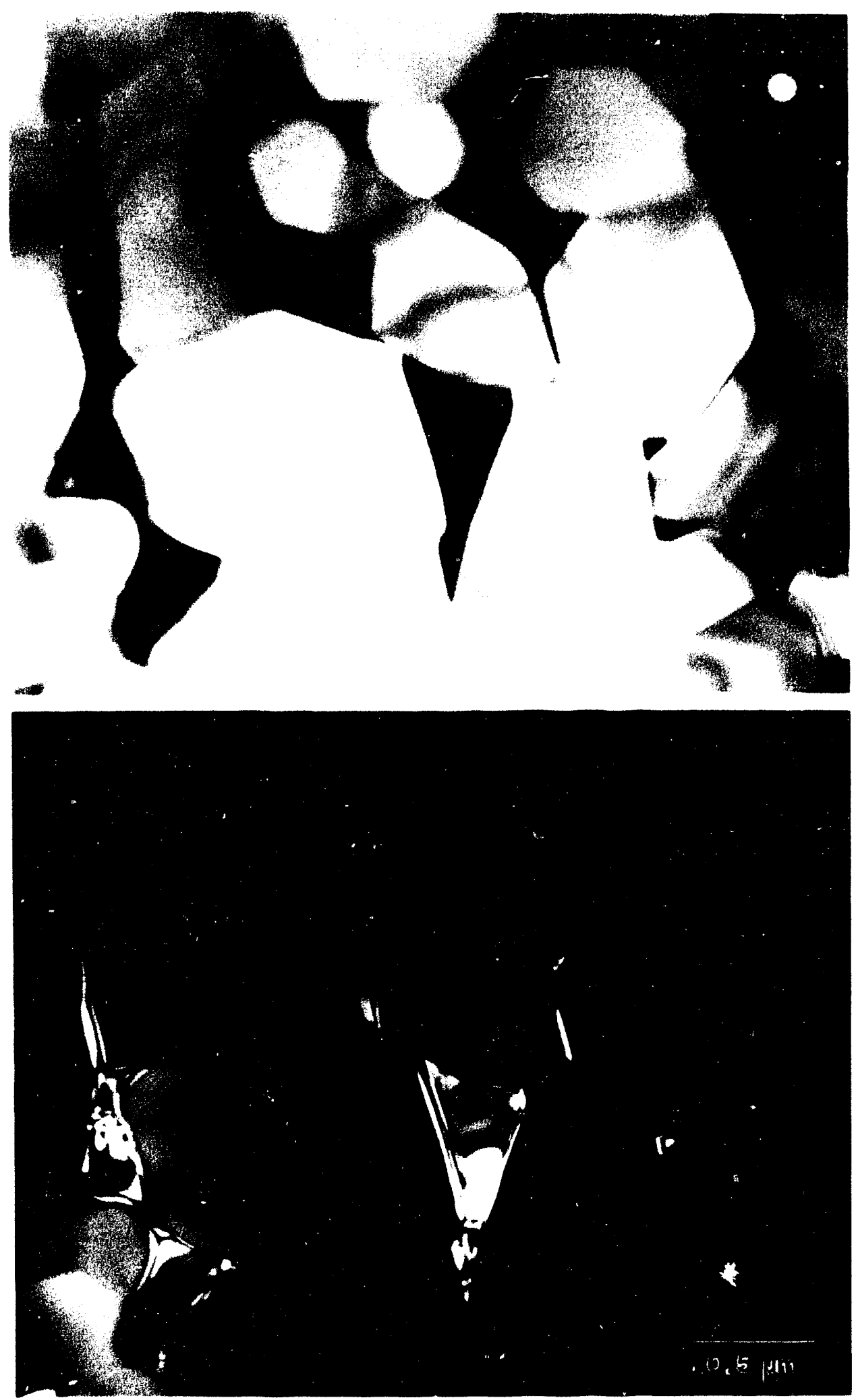

Figure 17 

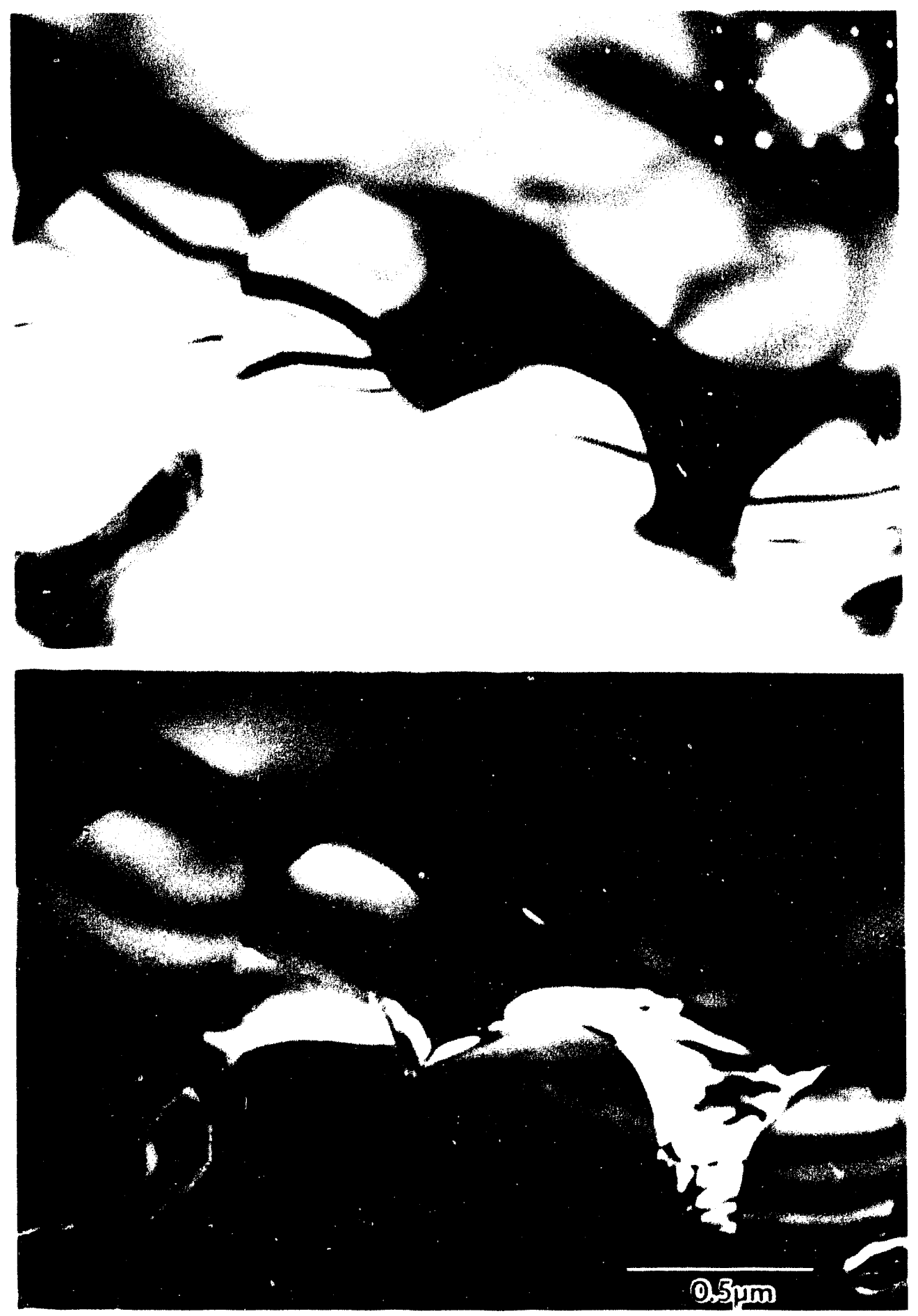

Figure 18 

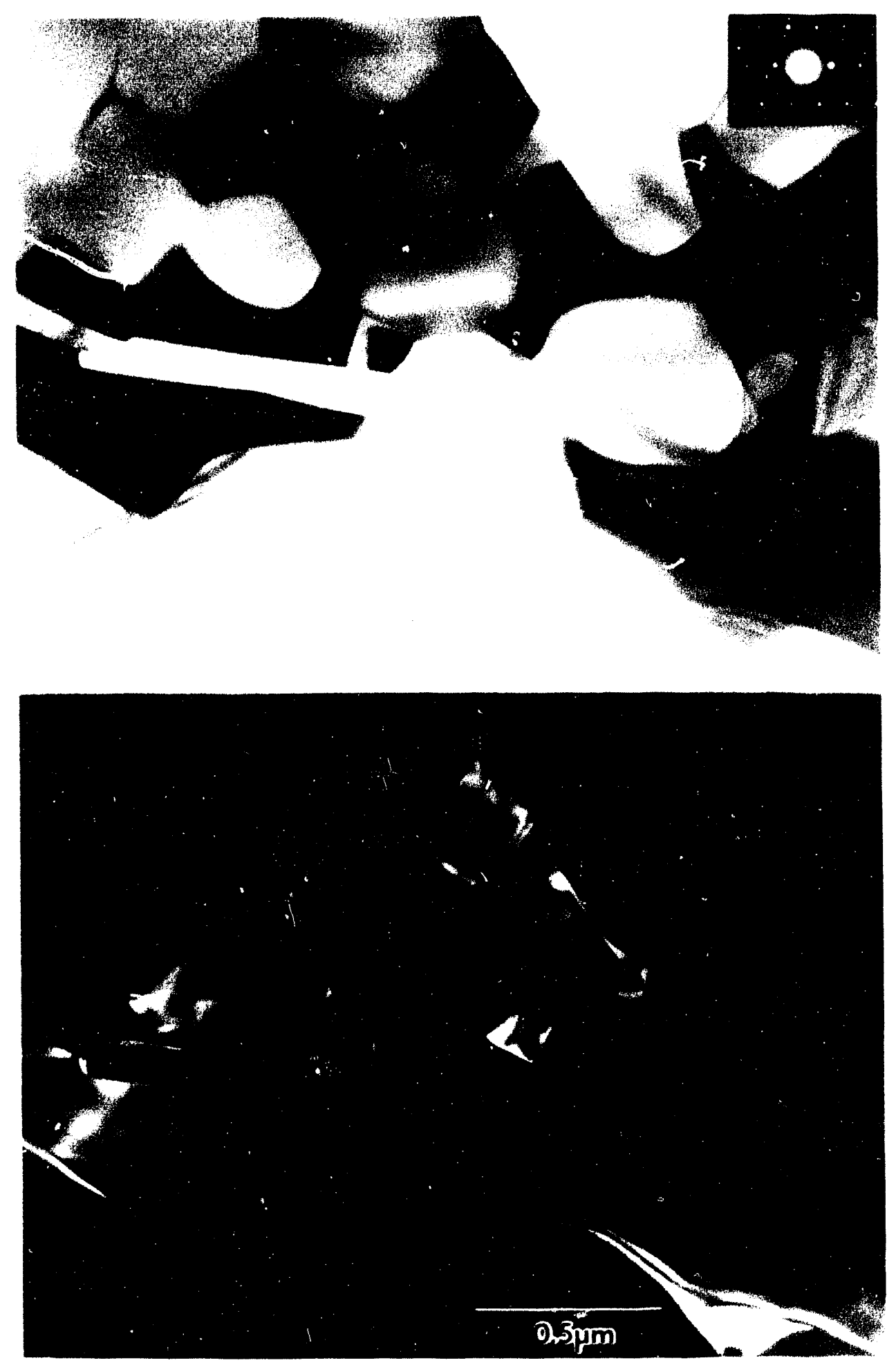

Figure 19 

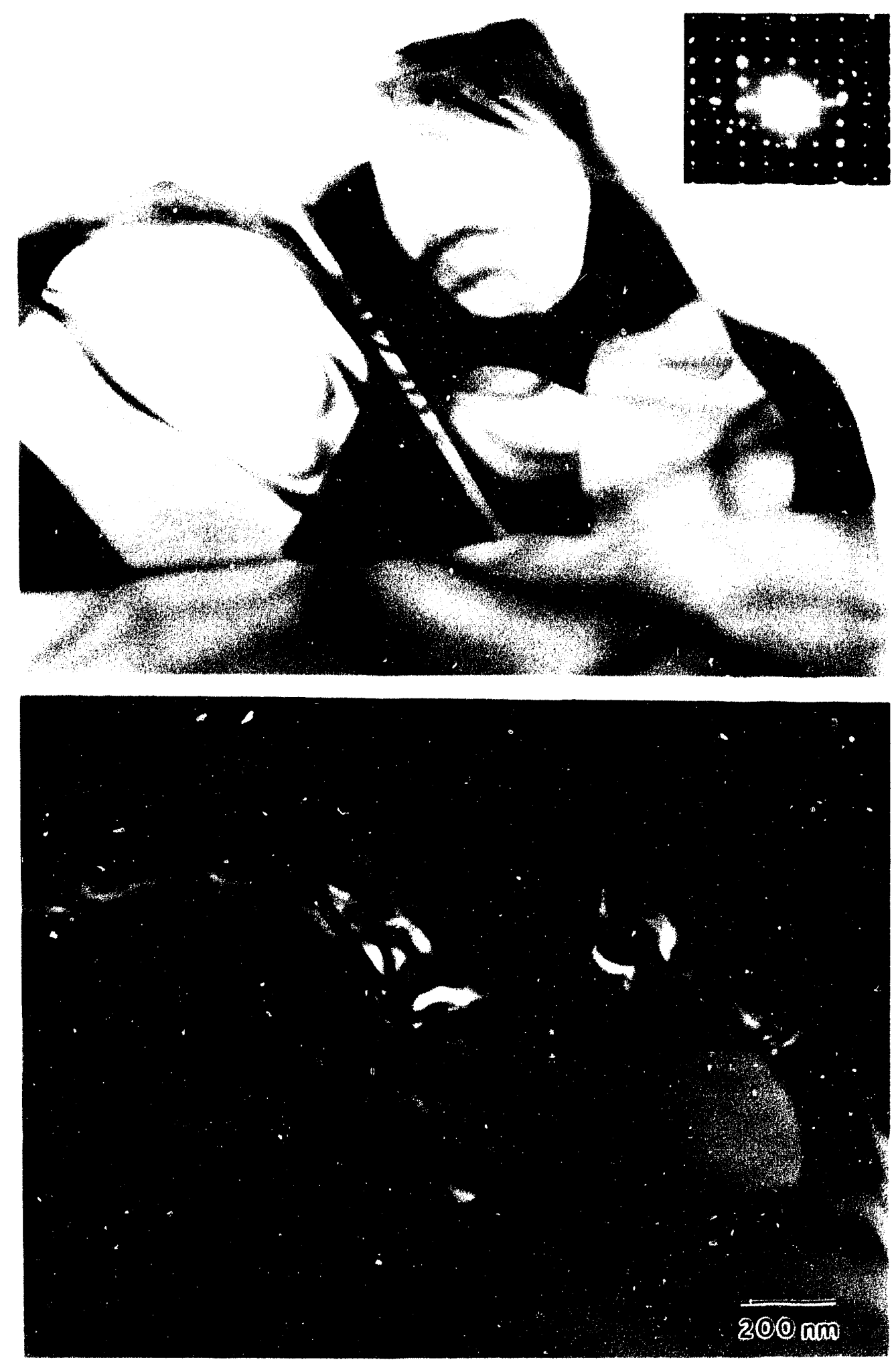

Figure 20 


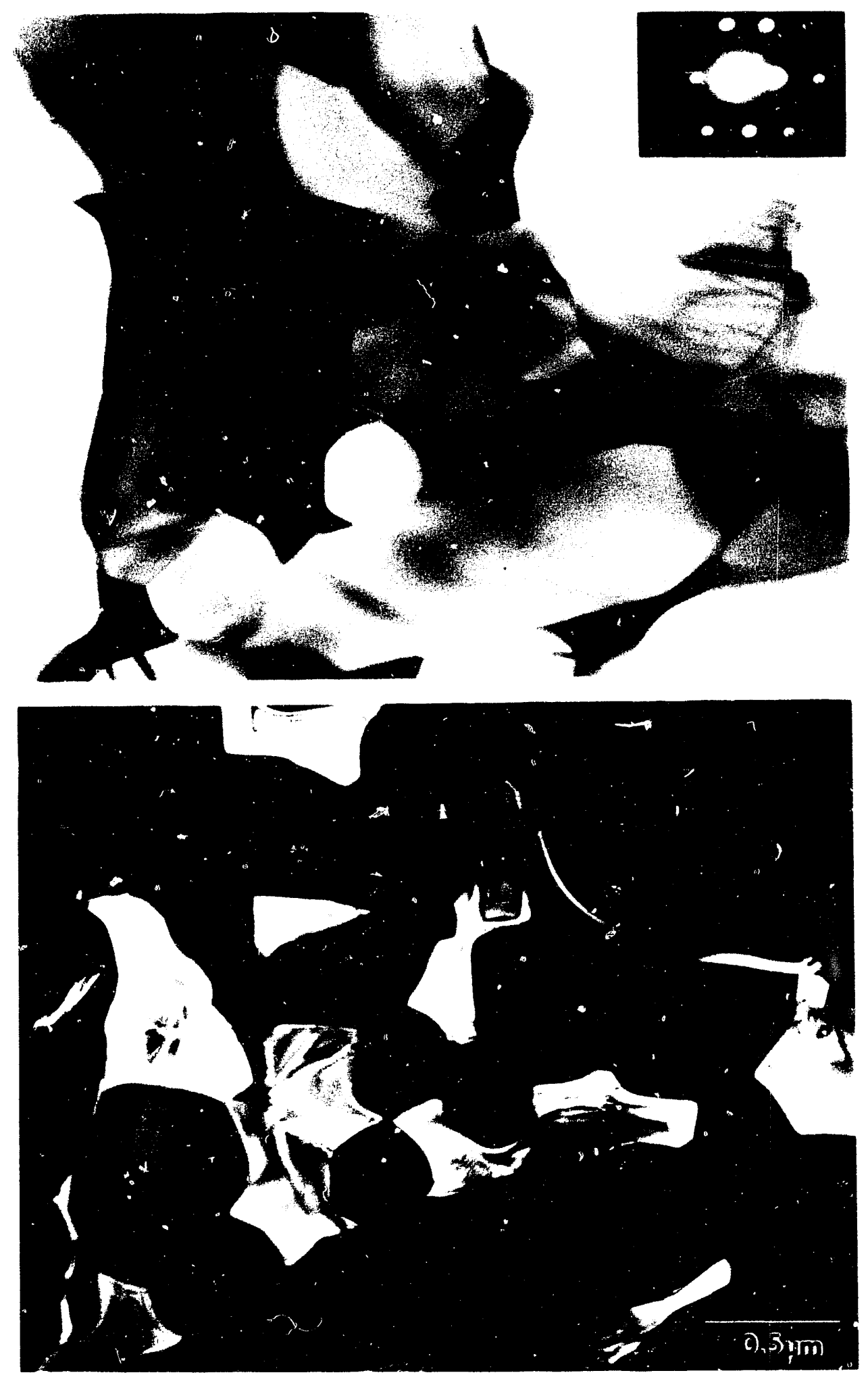

Fïgure 21 

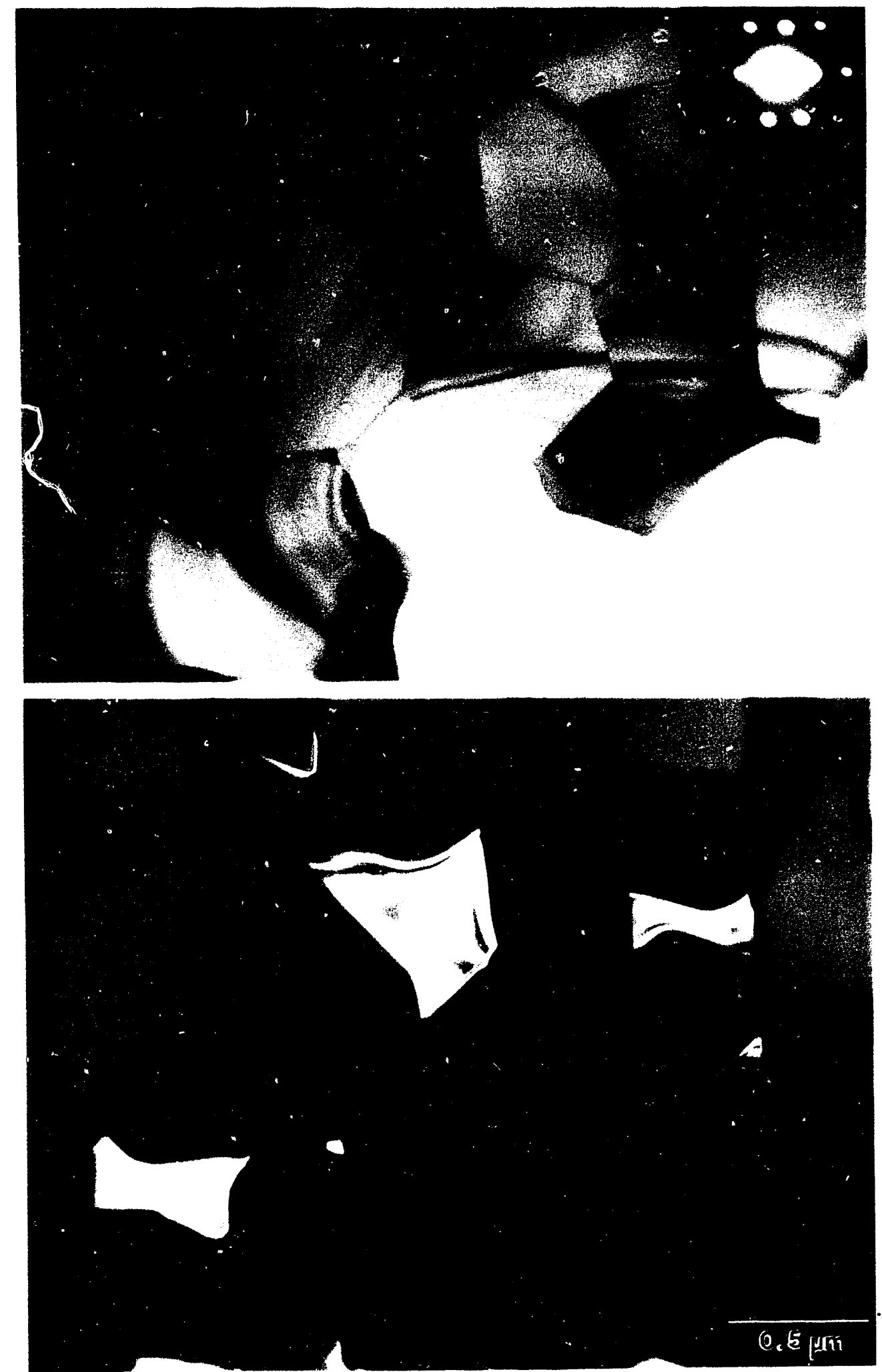

Figure 22 

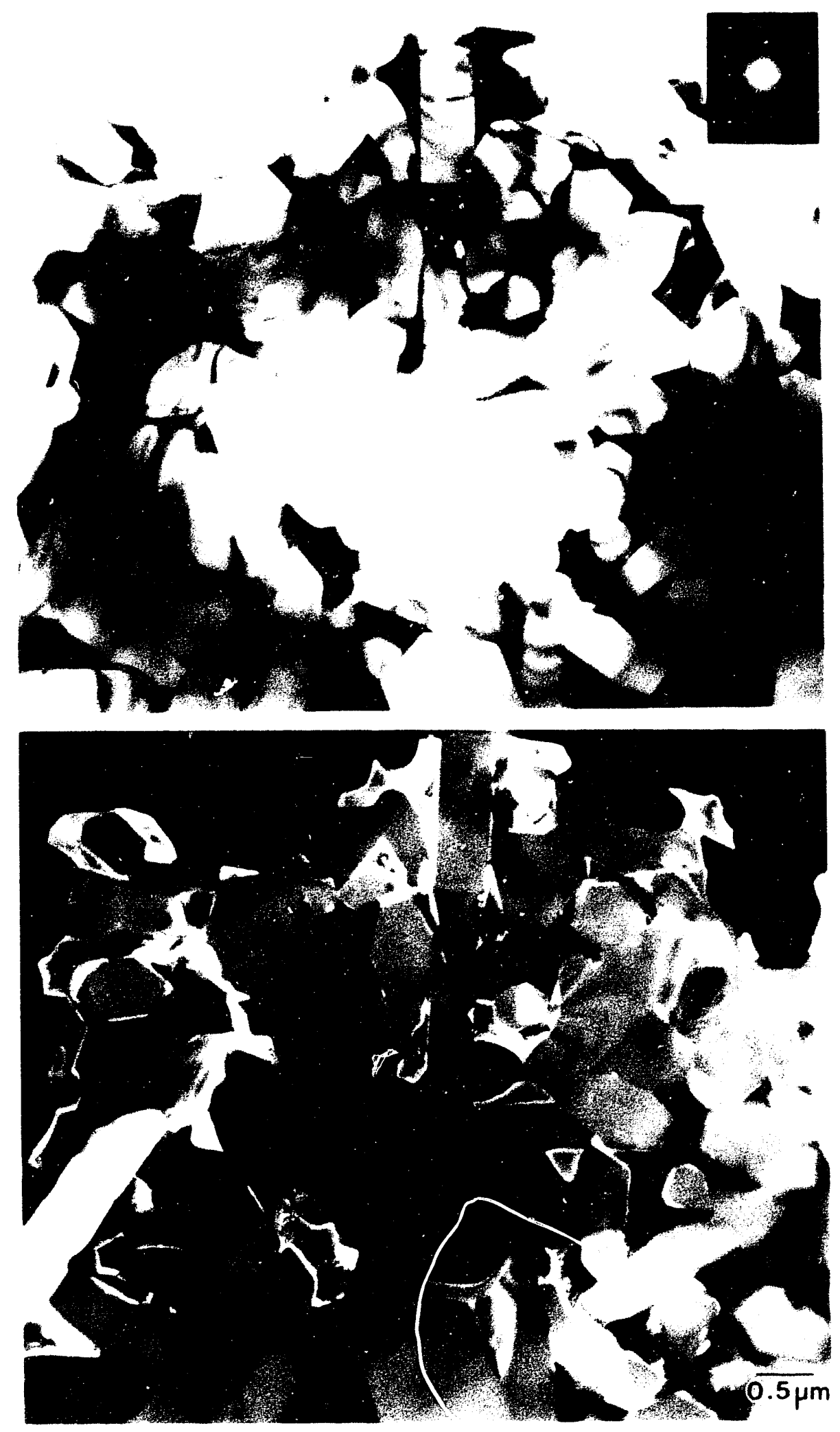

Figure 23 

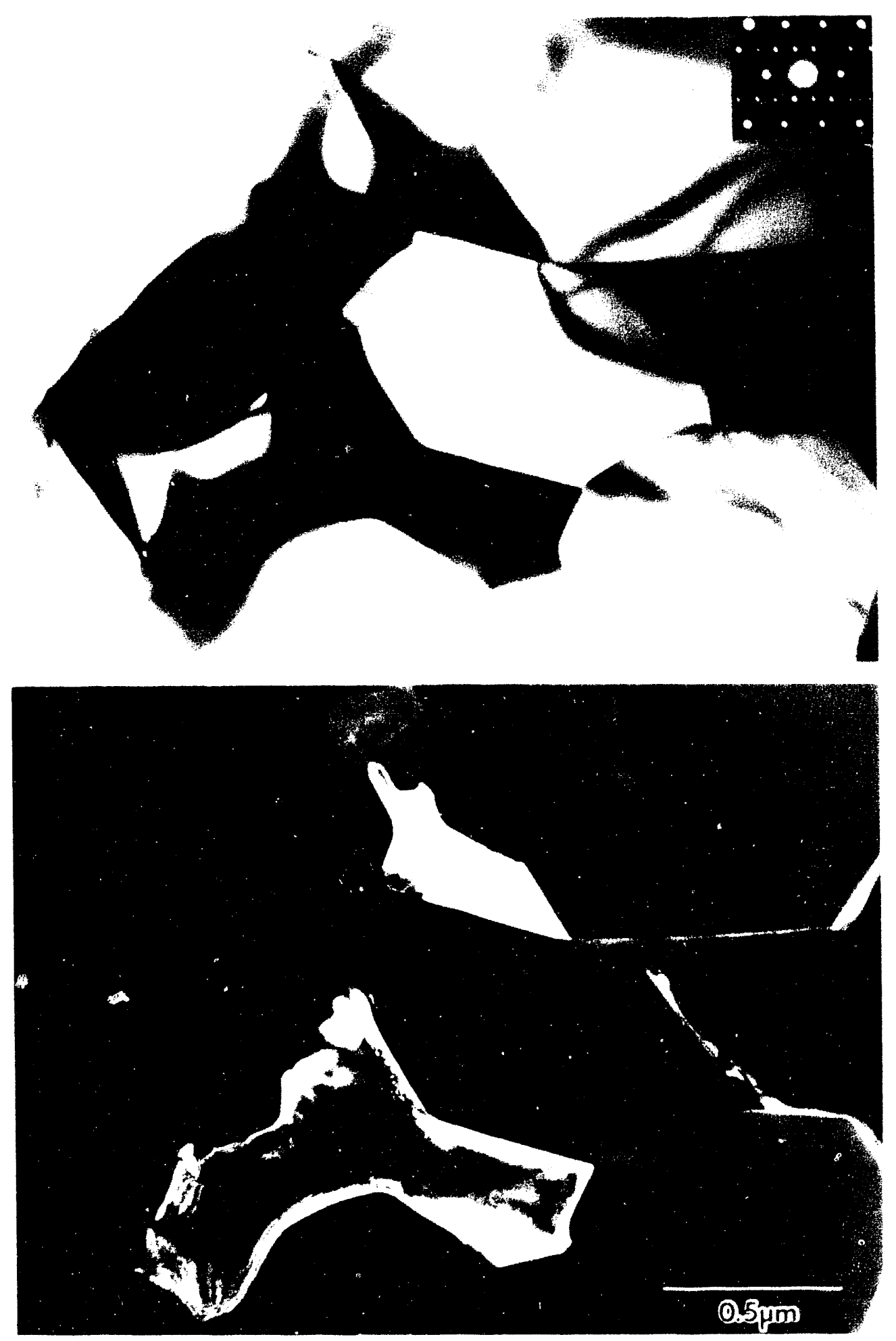

Figure 24 

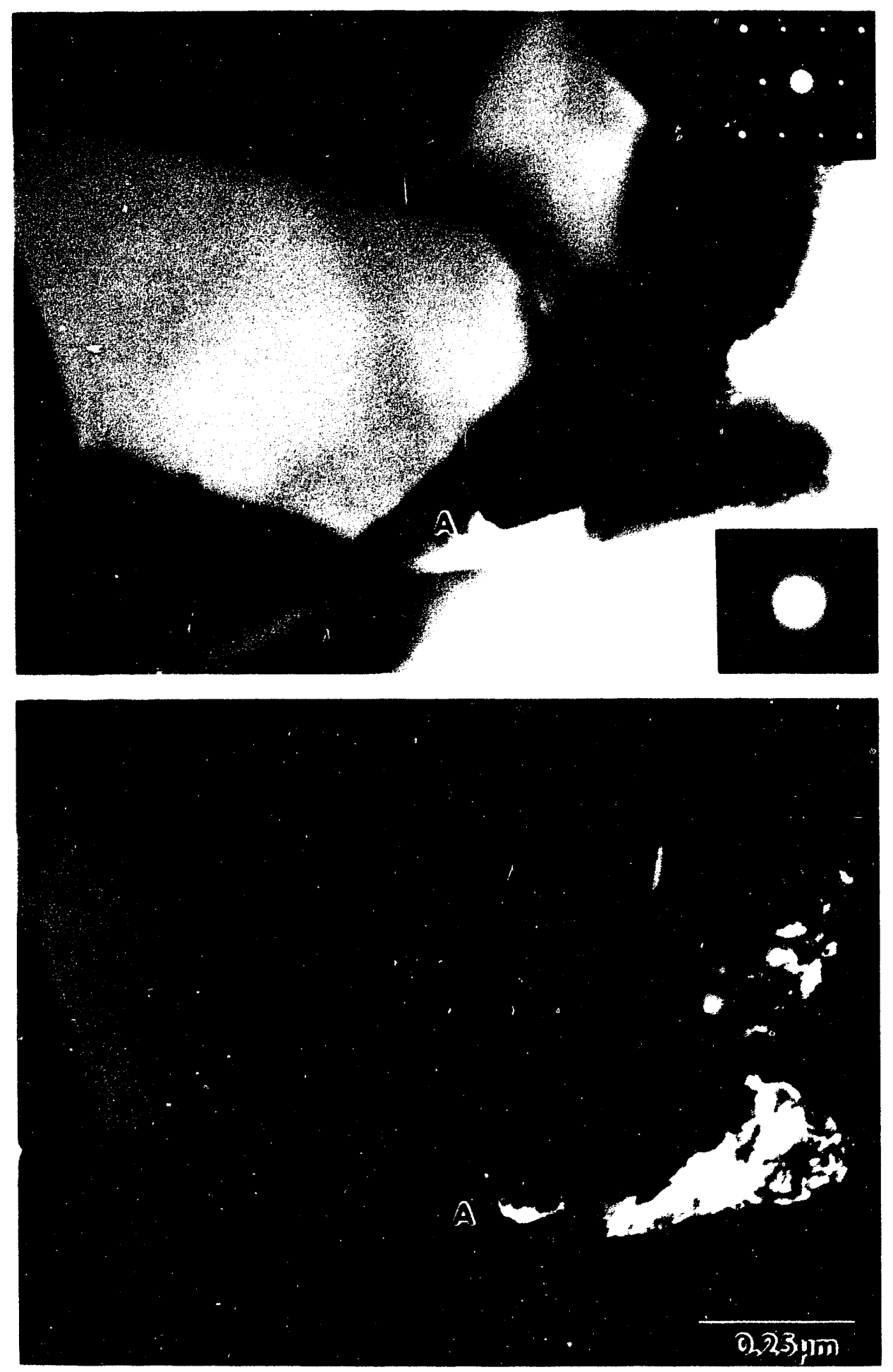

Figure 25 

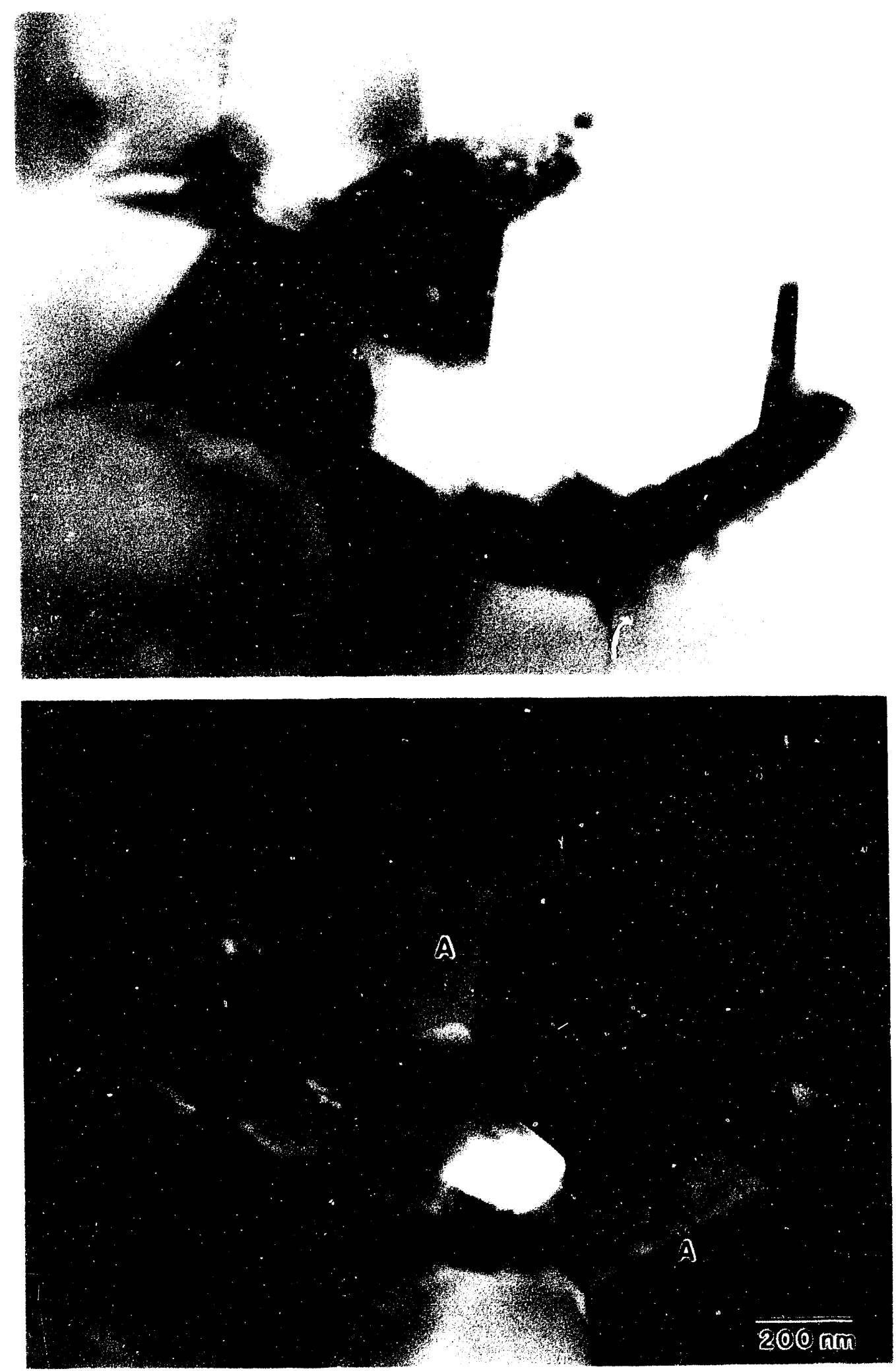

Figure 26 

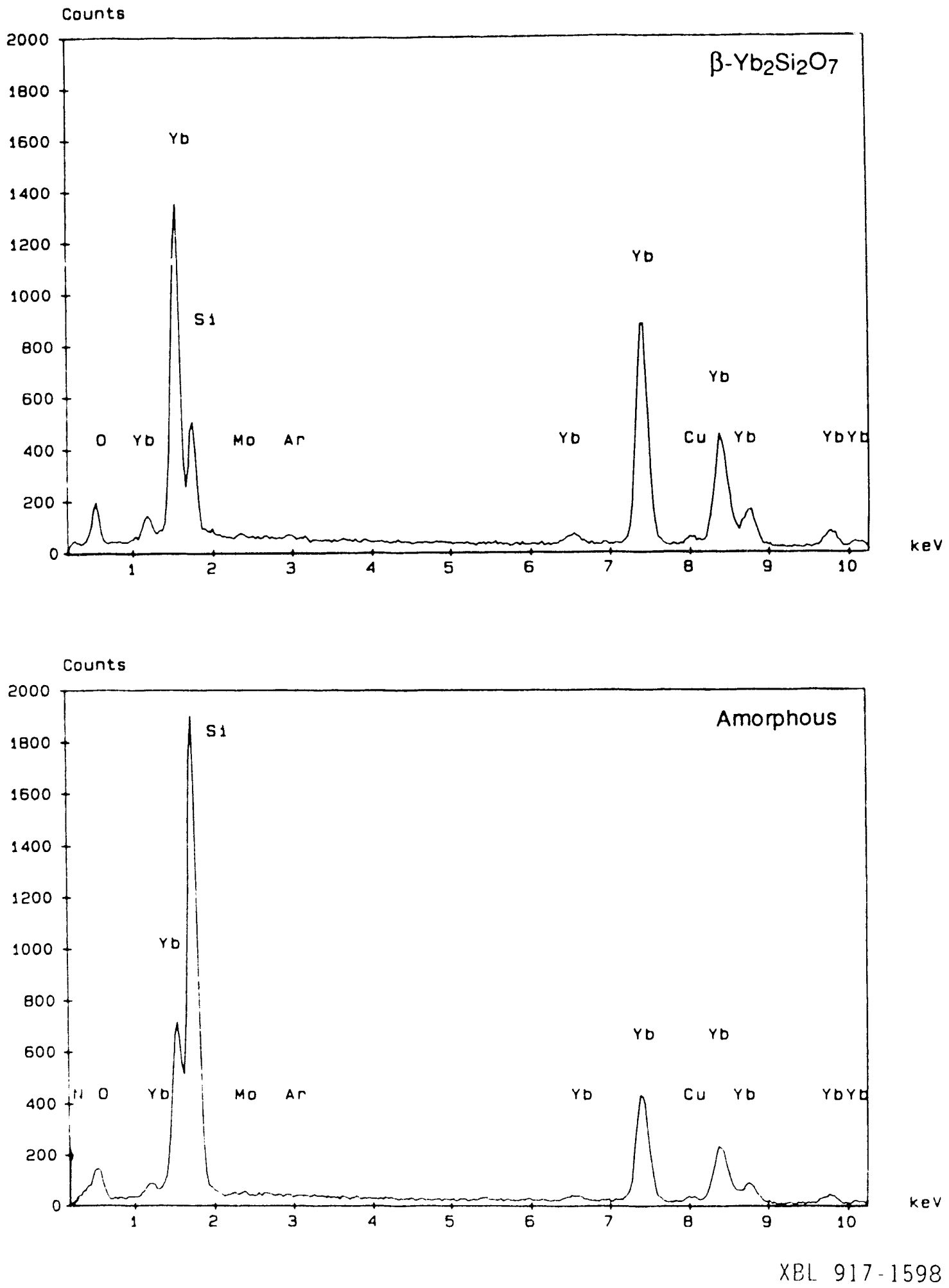

Figure 27 


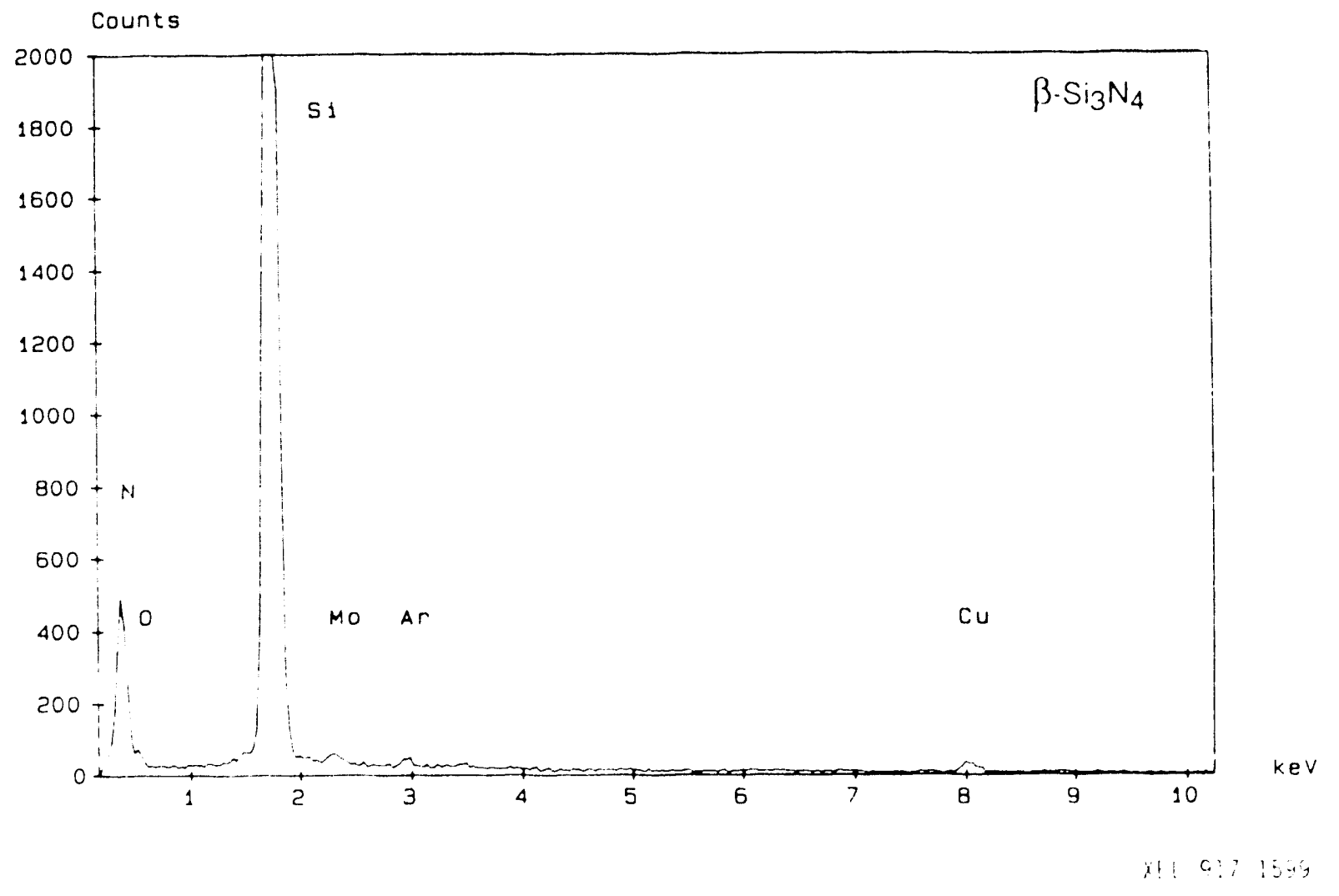

Figure 28 

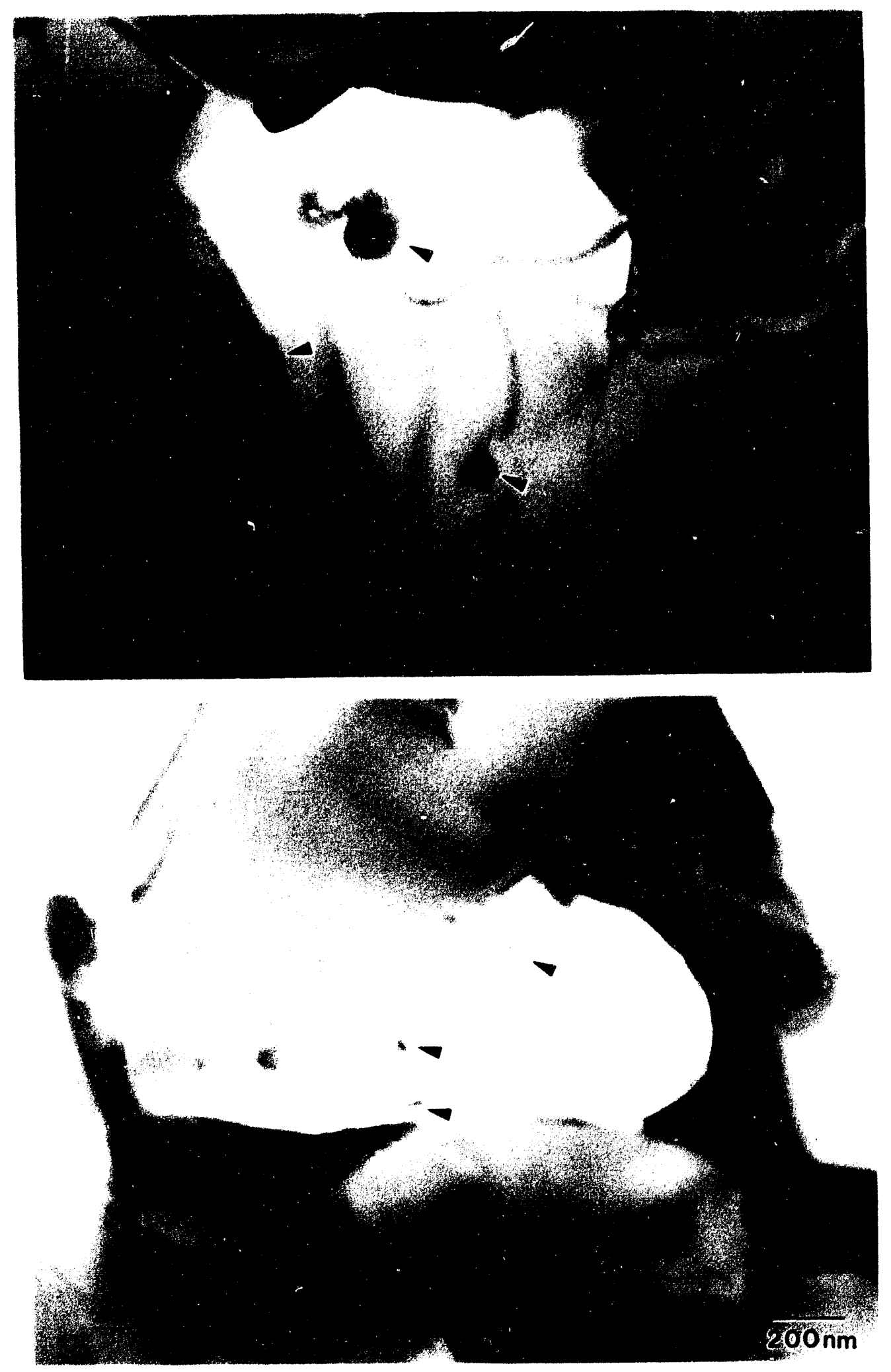

Figure 29 


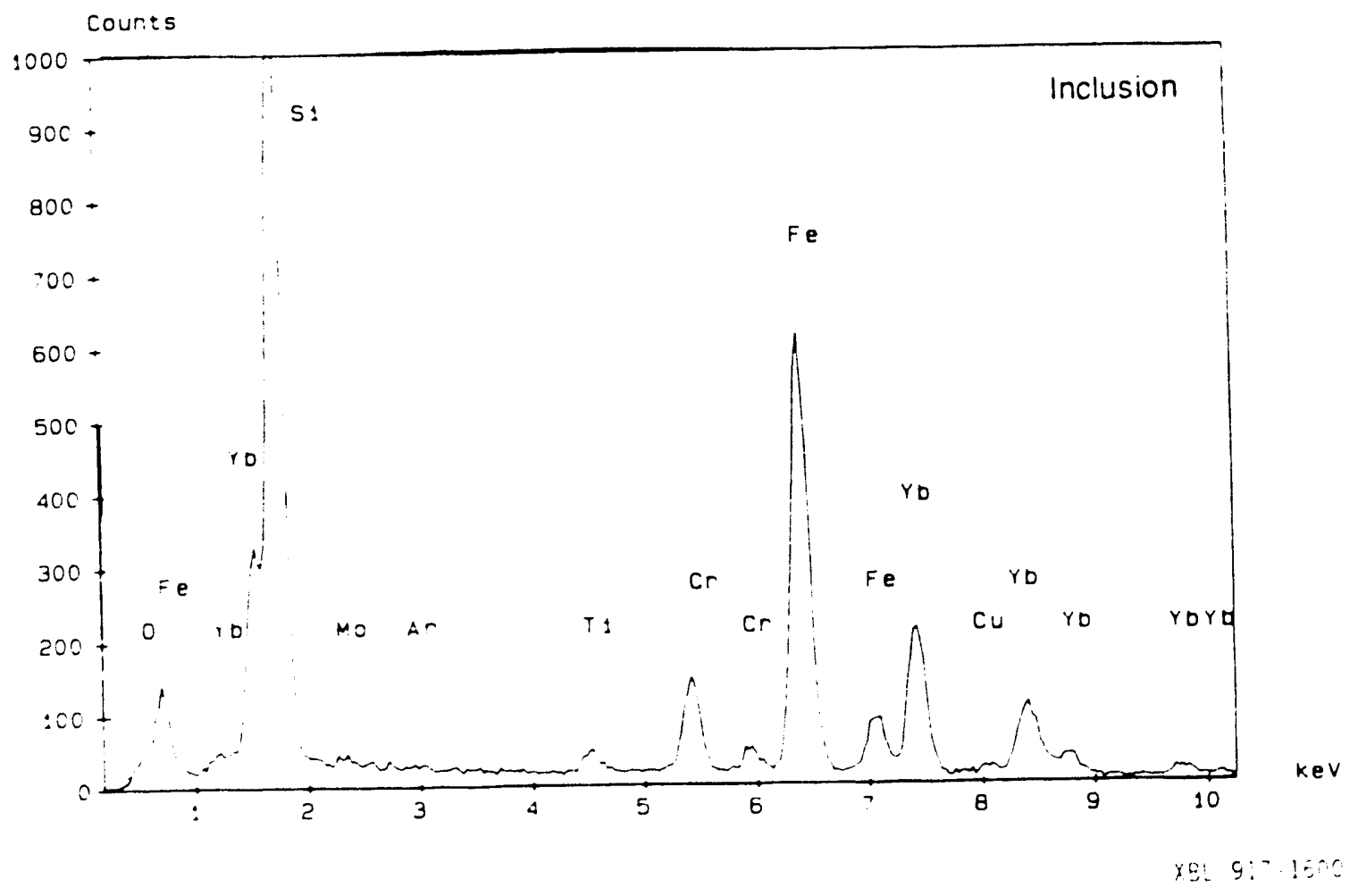

Figure 3() 

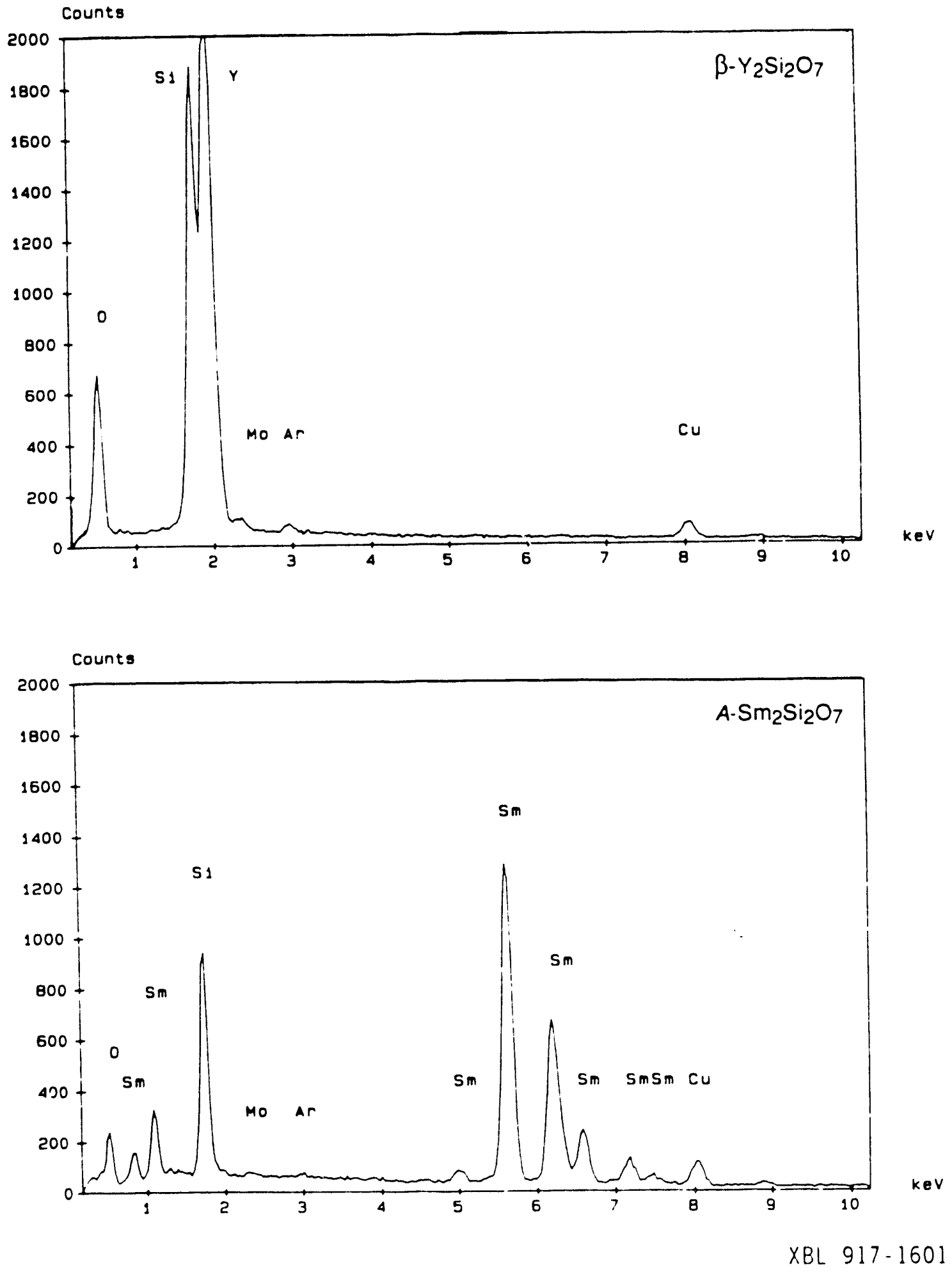

Figure 31 

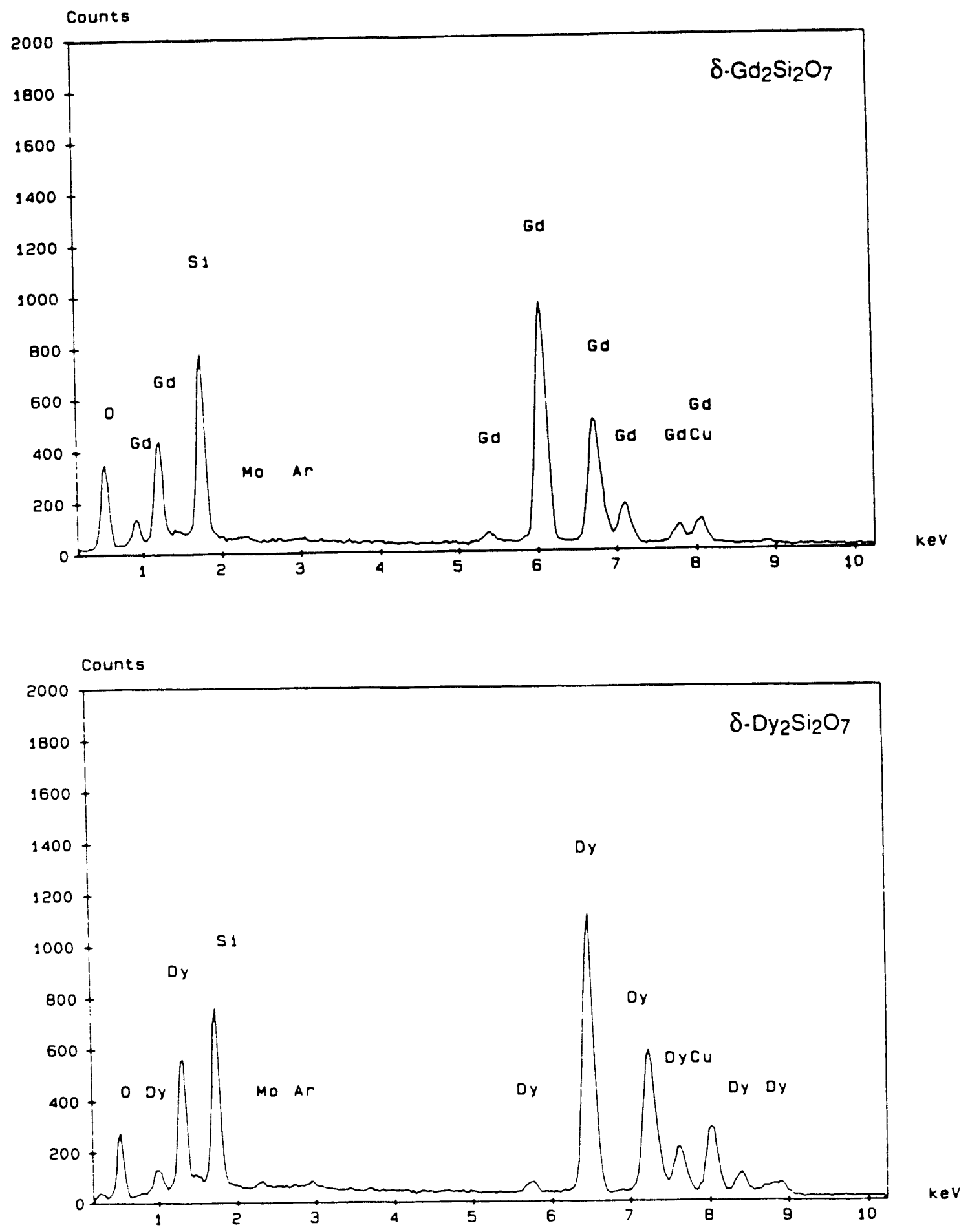

Figure 31

XBL 917-1602

(cont.) 

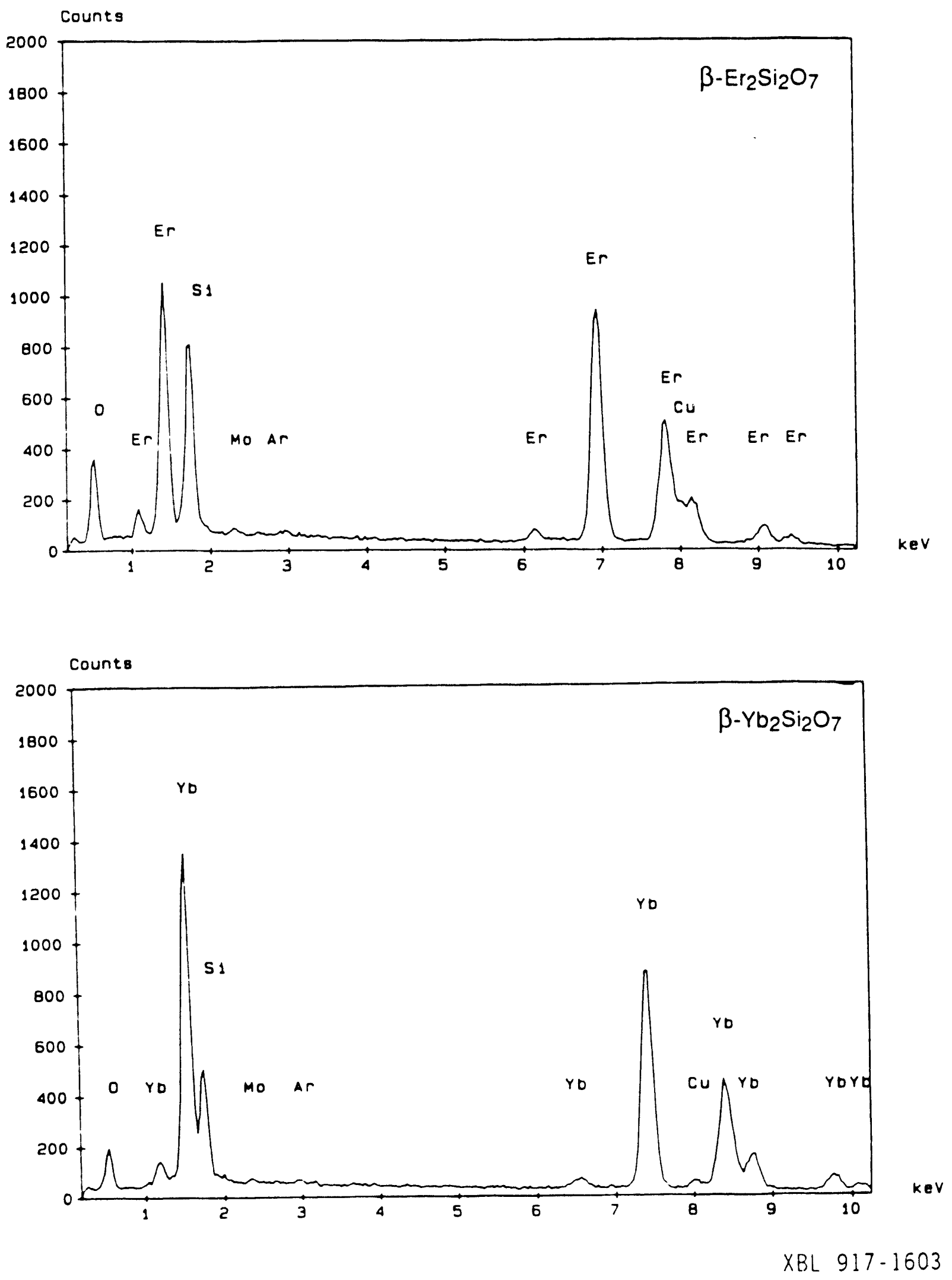

Figure 31

(cont.) 


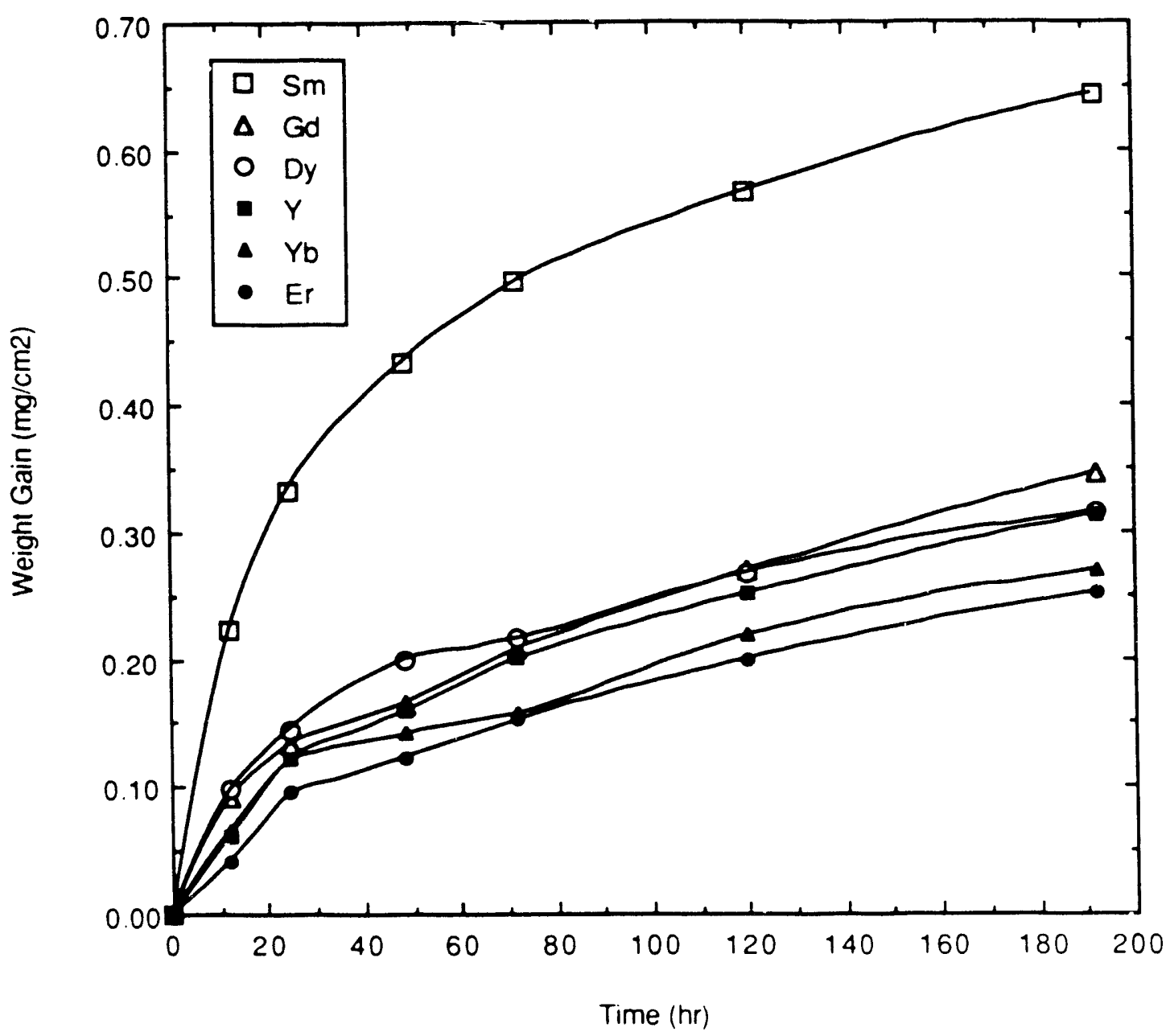

XBL $9 ! 6 \cdot 1287$

Figure 32 

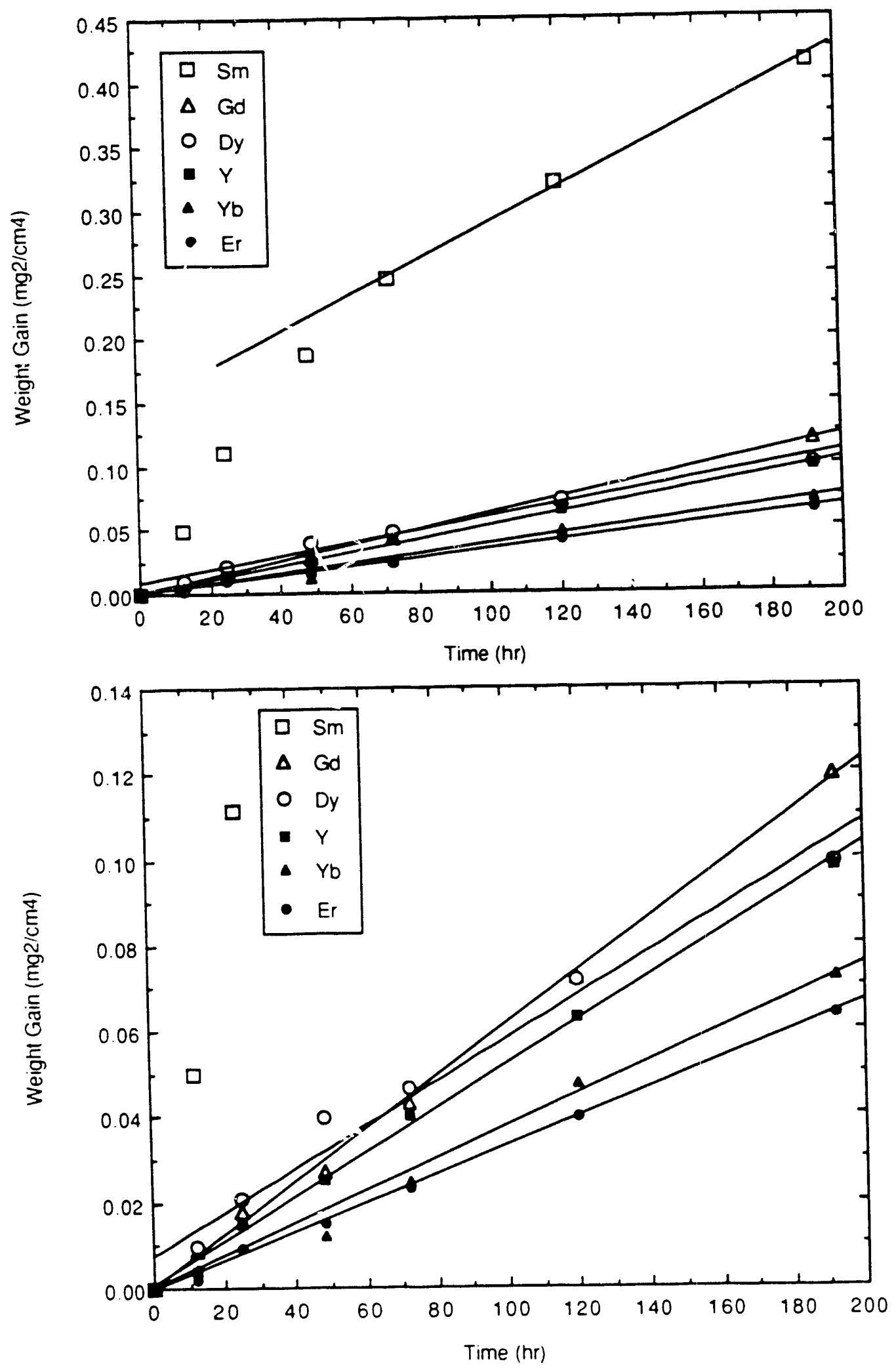

Figure 33

X'BL $917-1608$ 

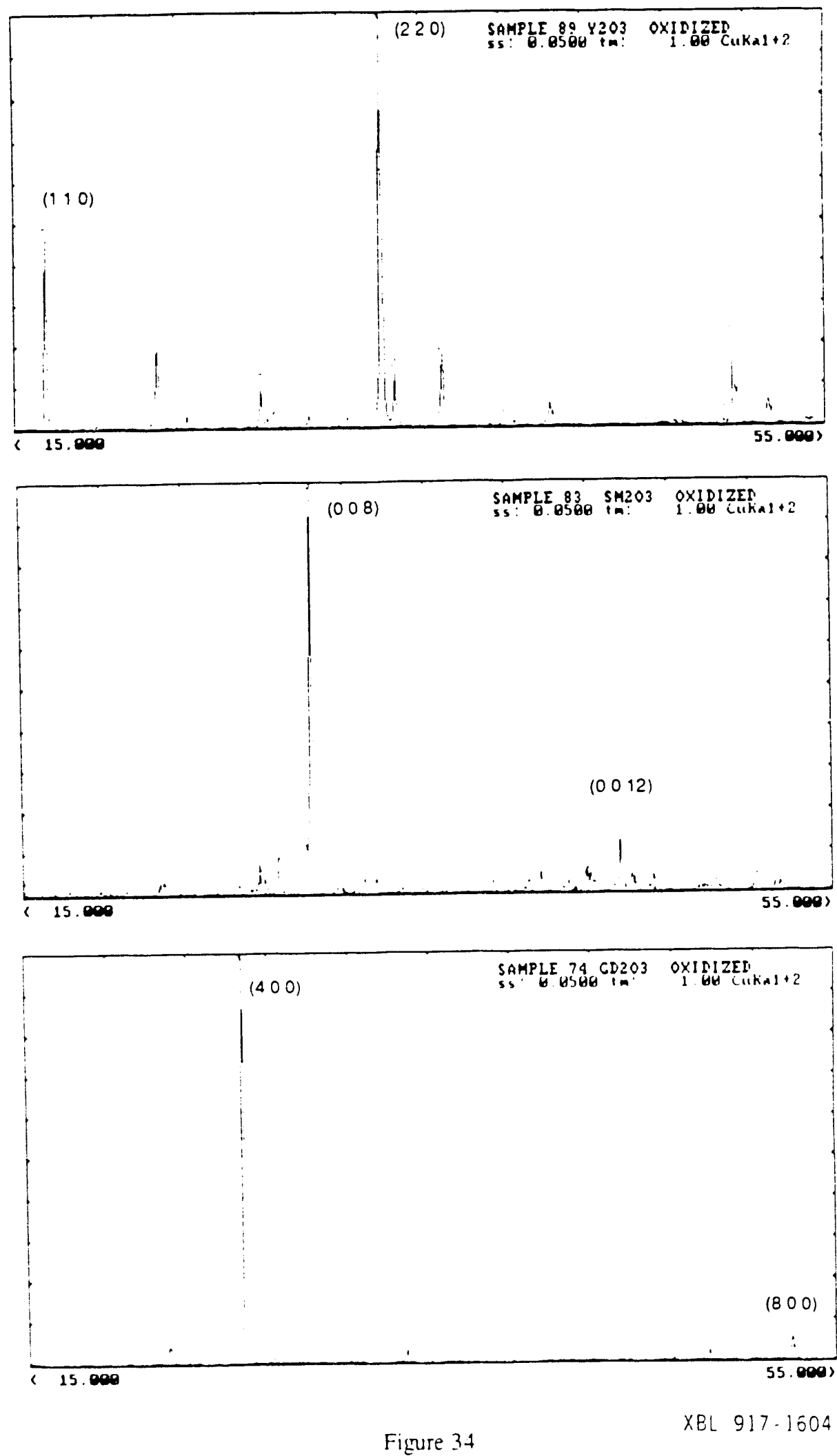

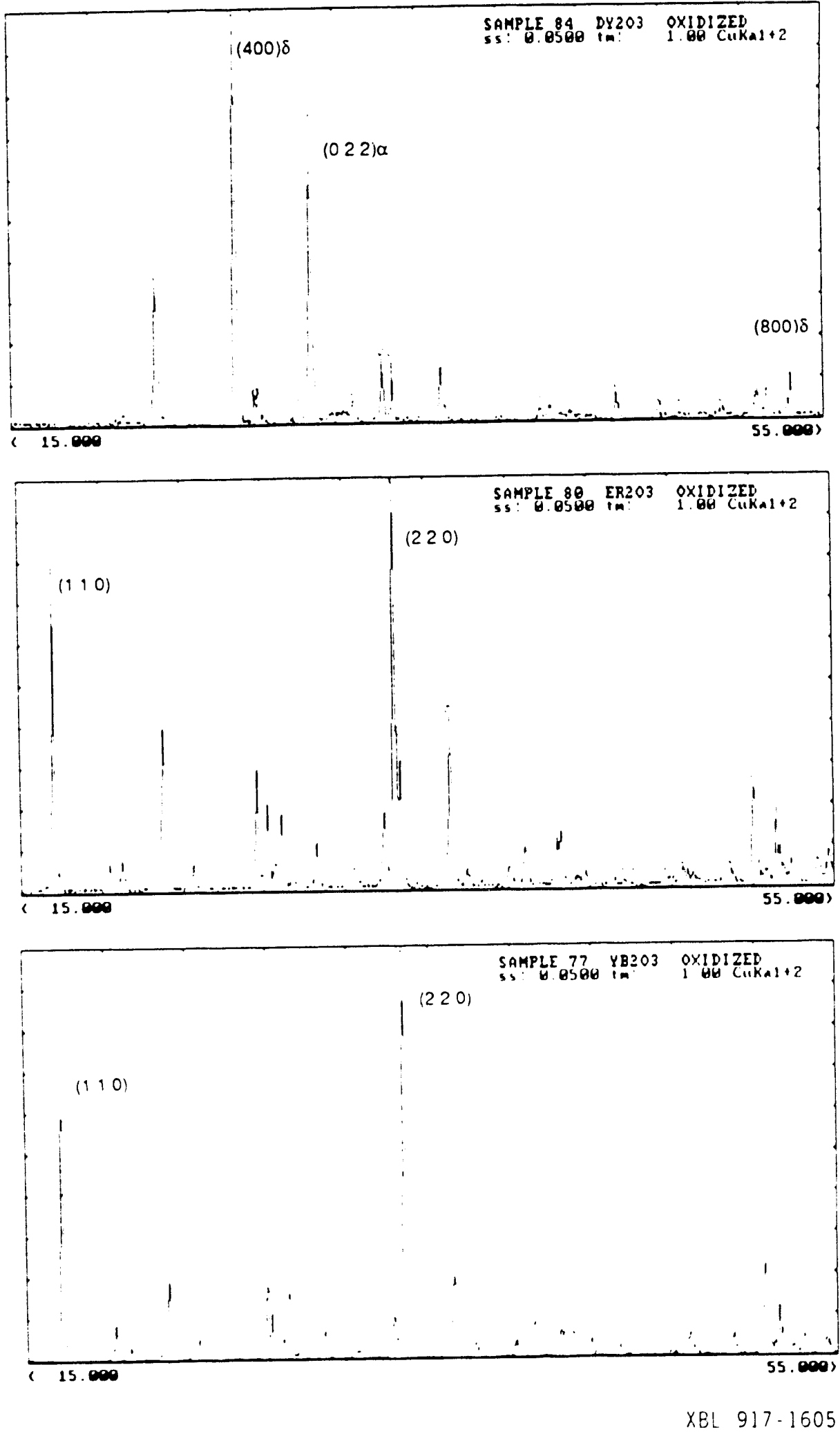

Figure 34

(cont.) 

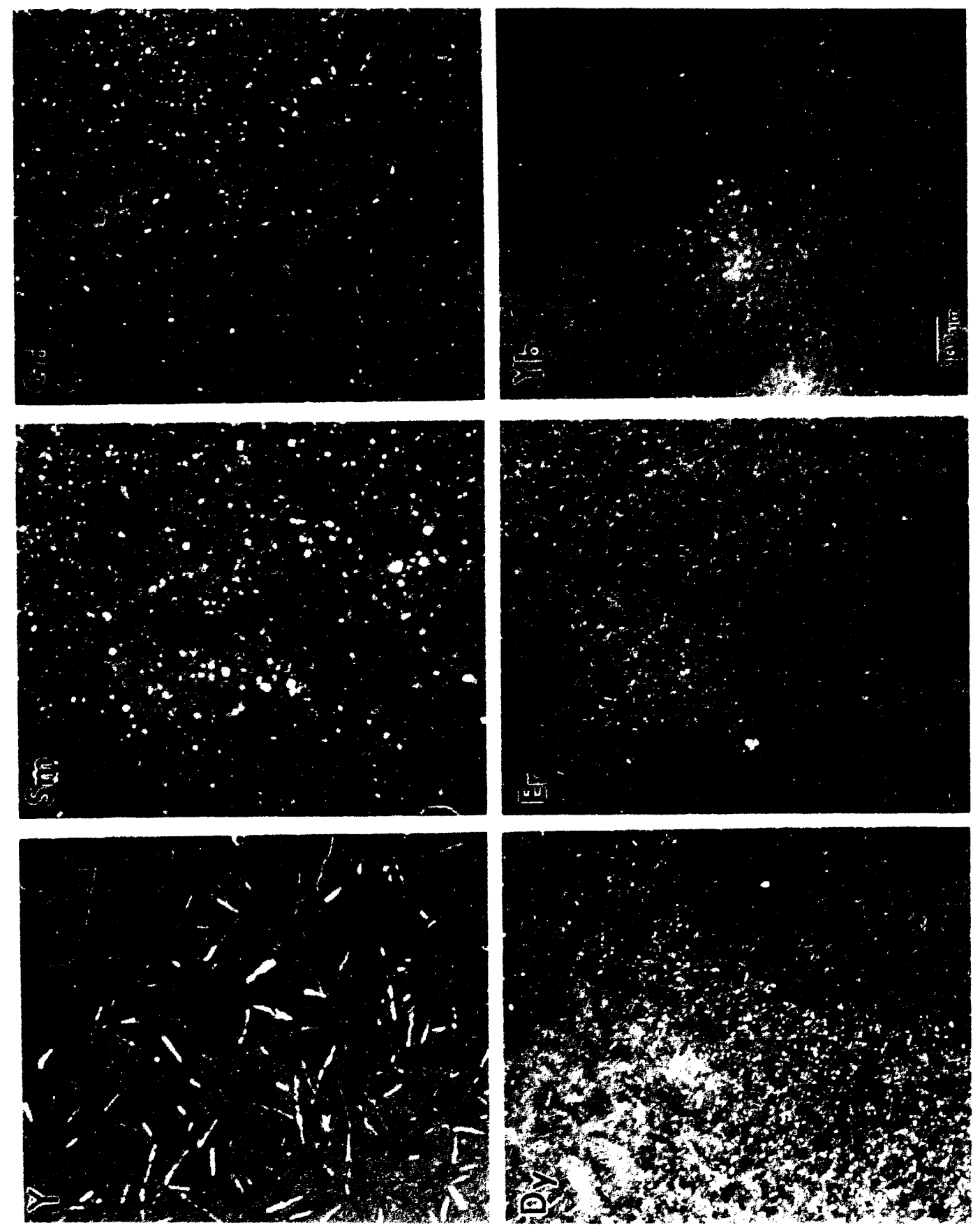

$\stackrel{\sim}{\curvearrowleft}$ 


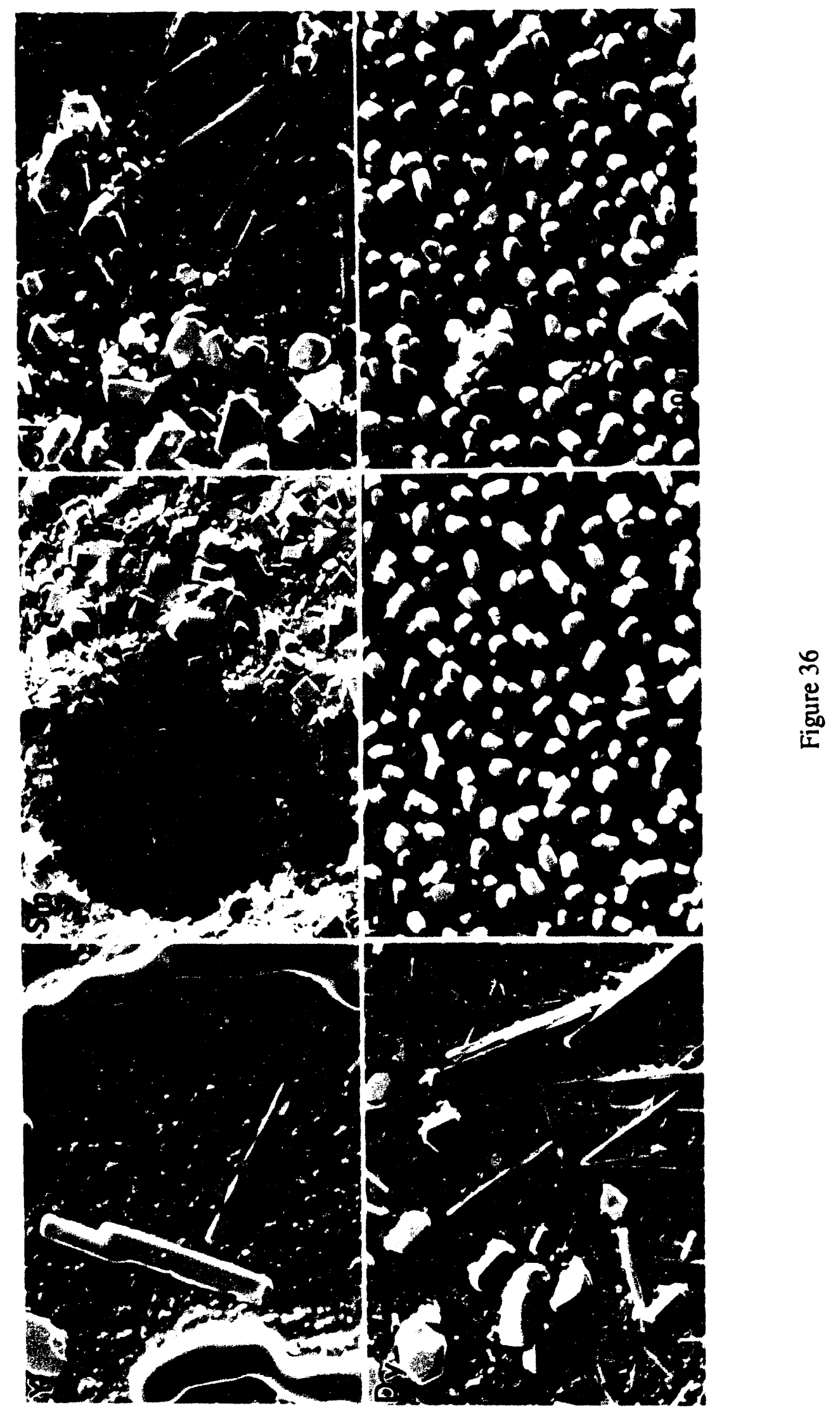




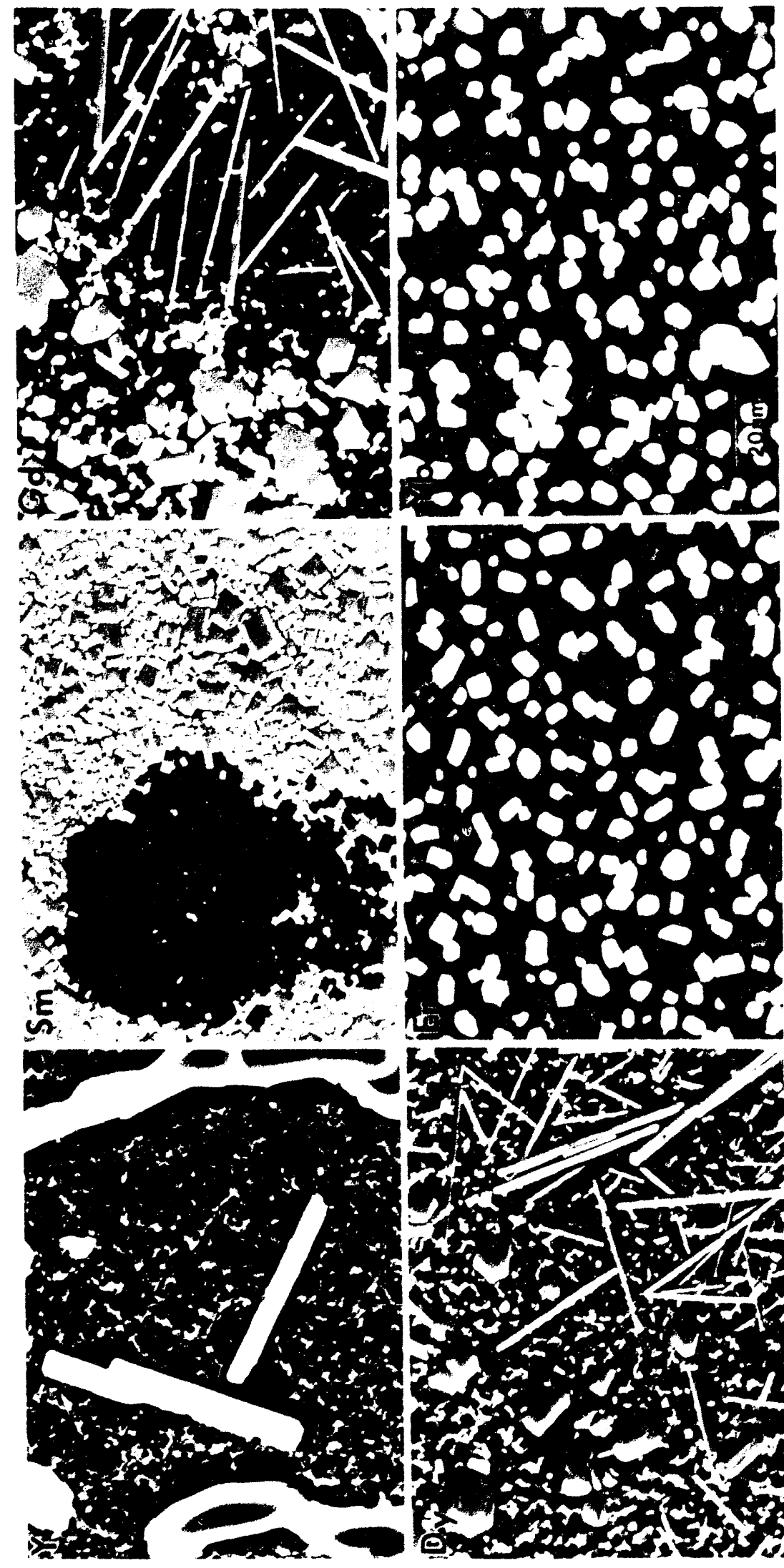

辤 


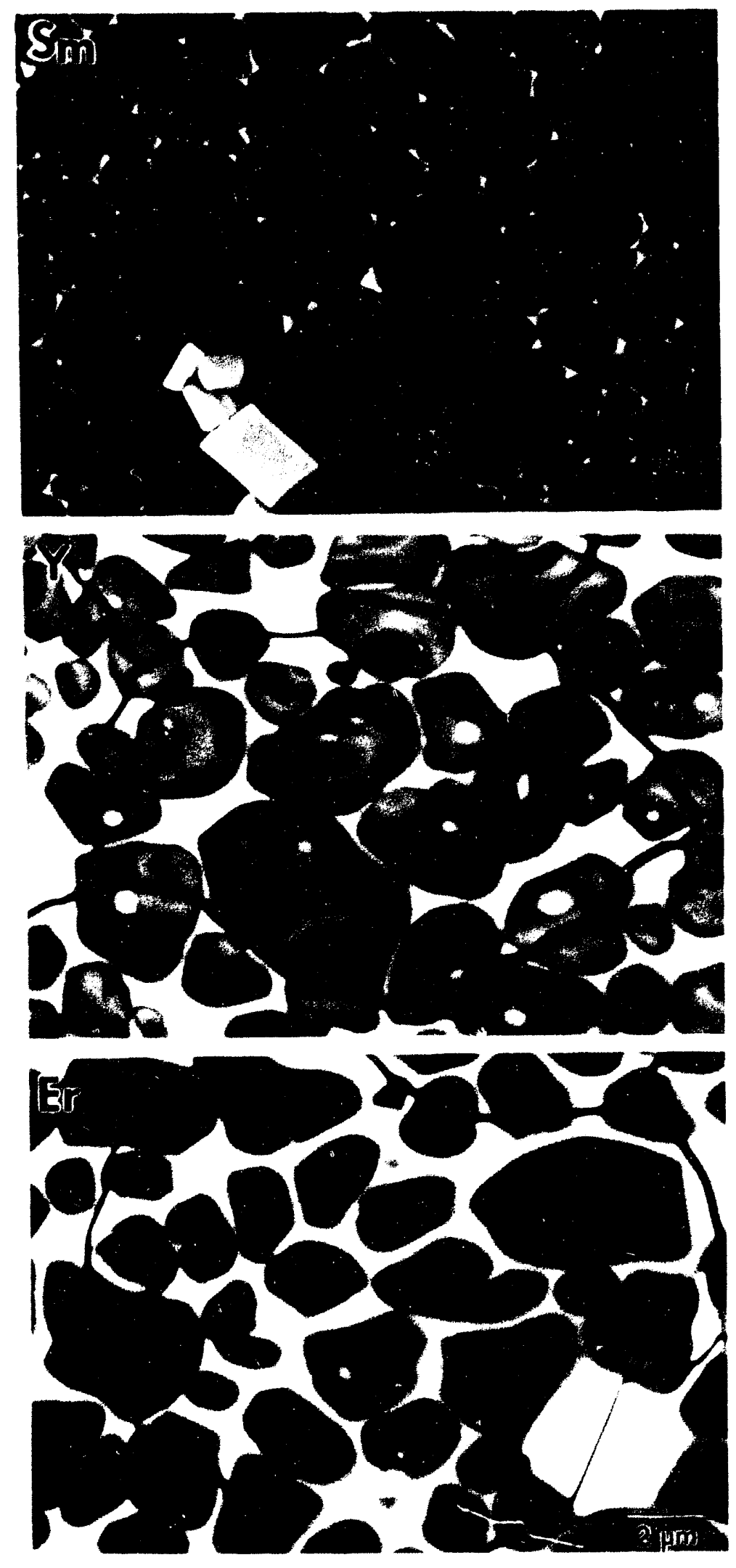

Figure 38 


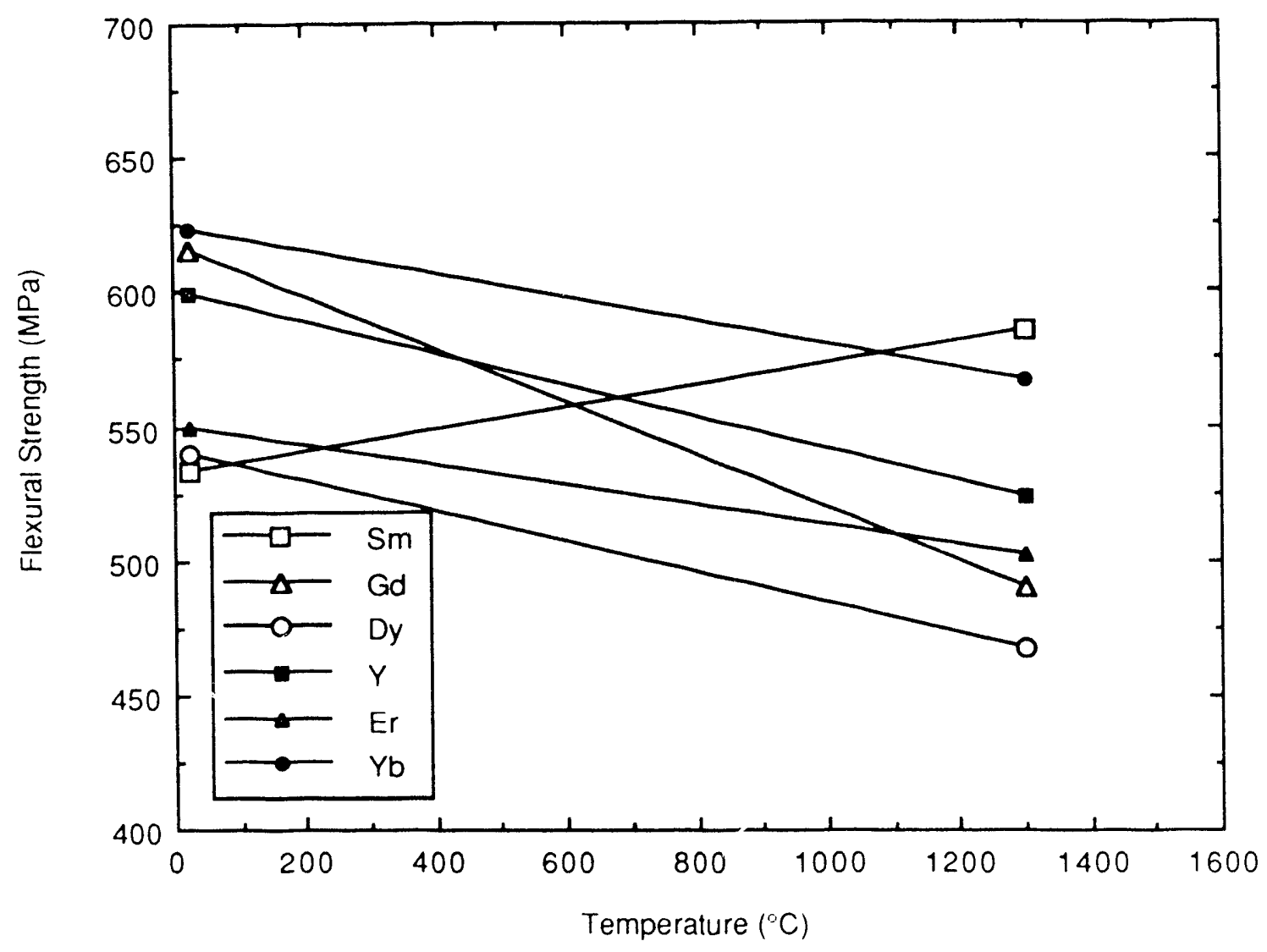

XB1 $916 \cdot 1288$

Figure 39 

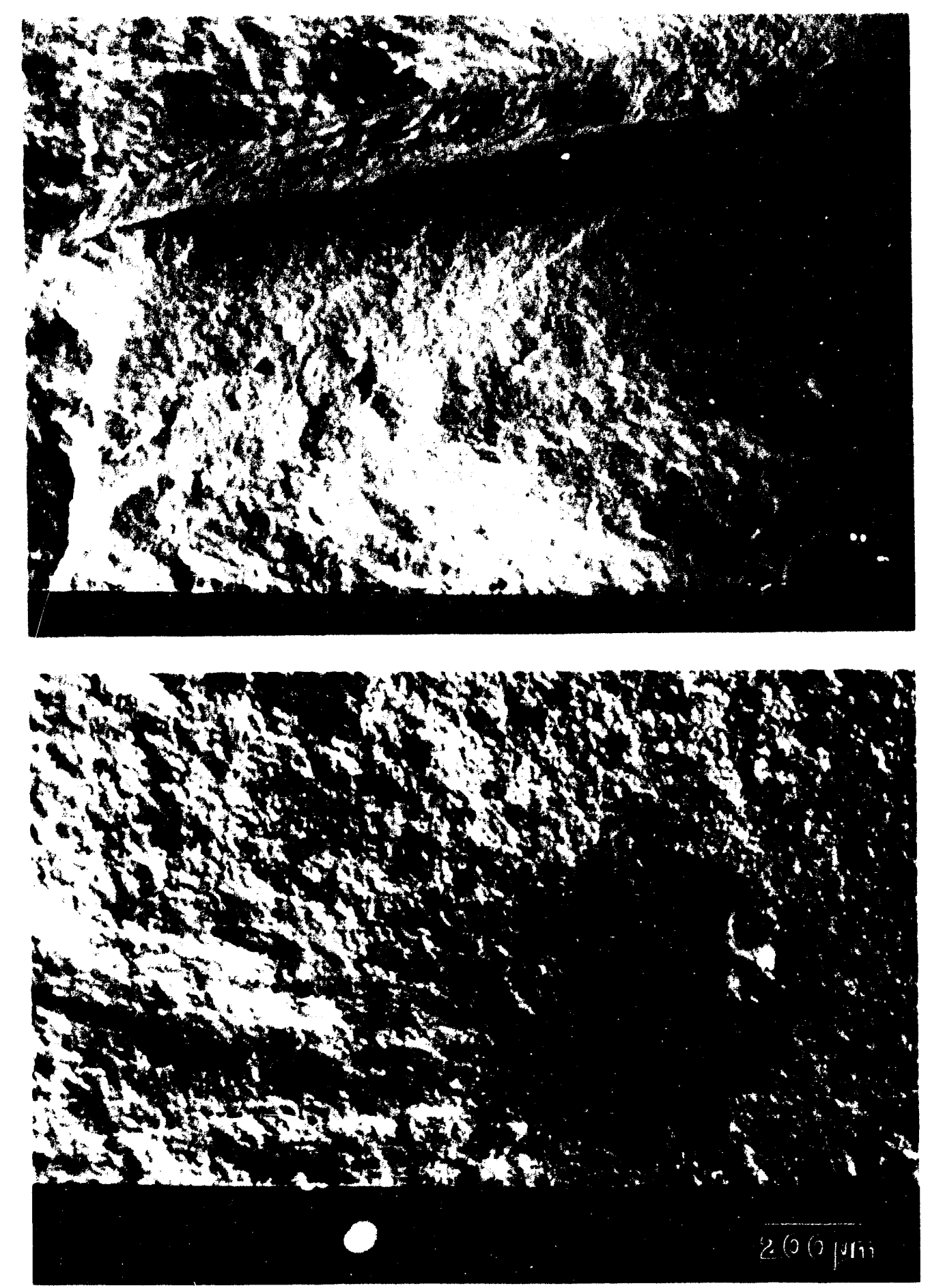

Figure 40 


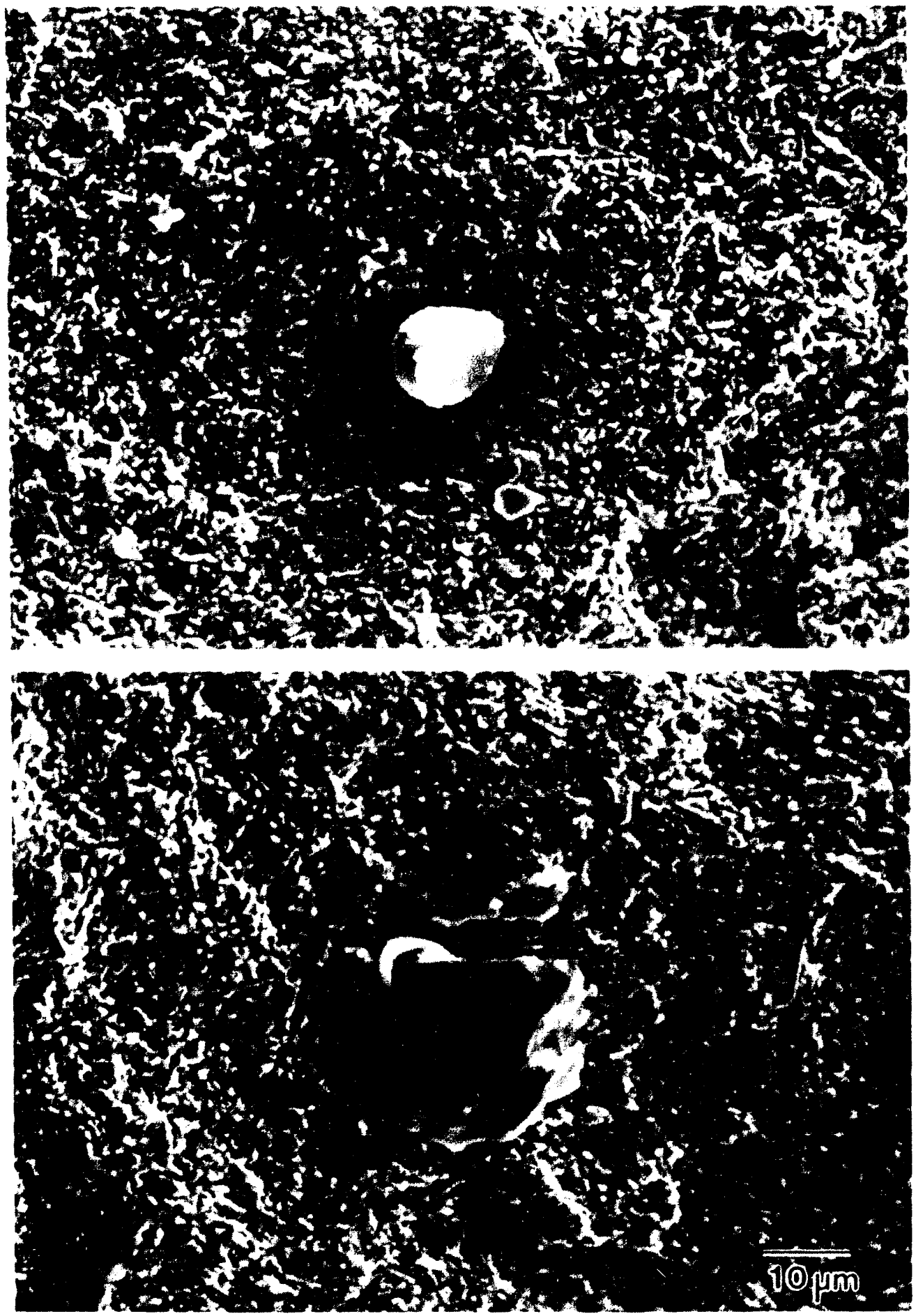

Figure 41 

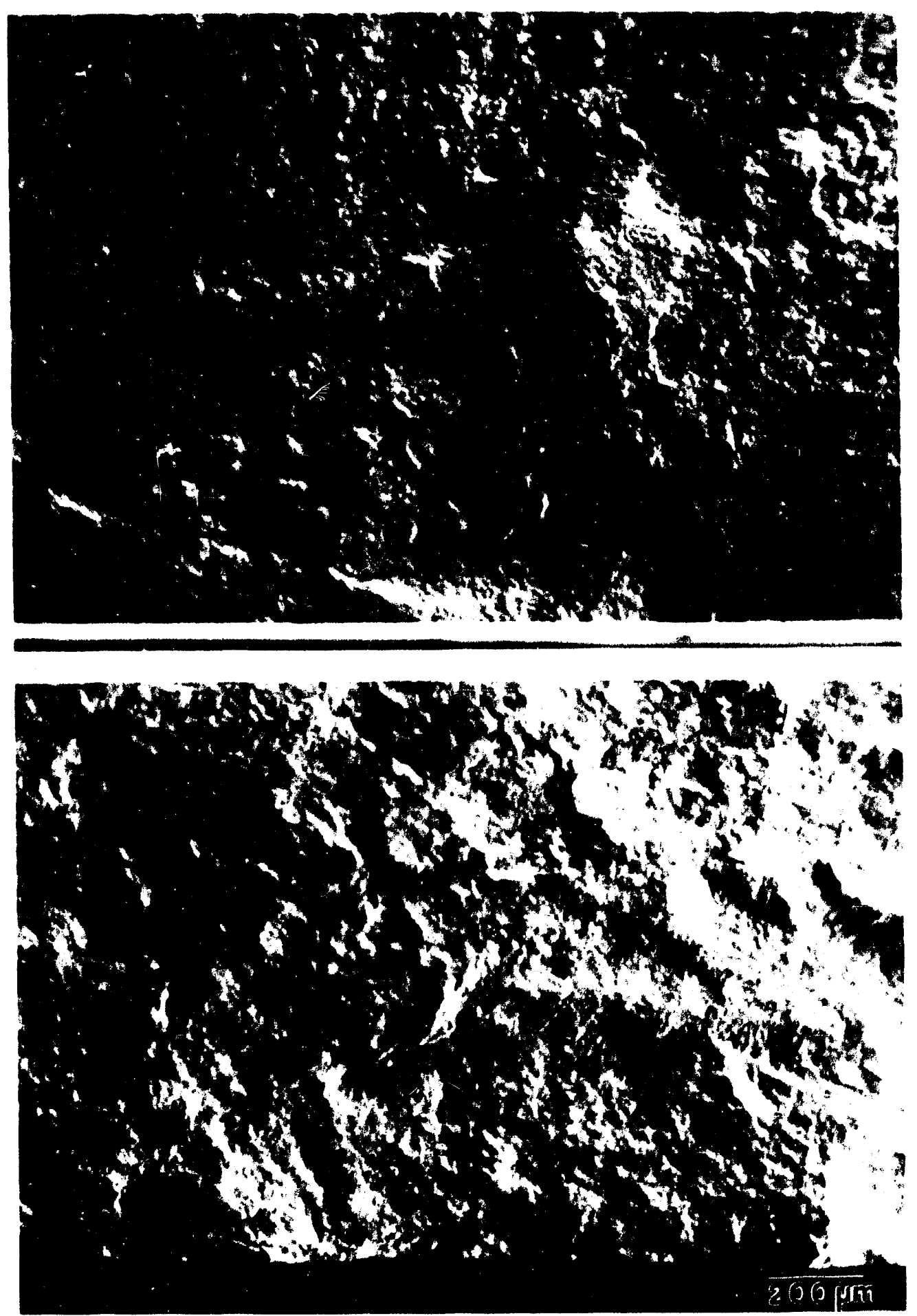

Figure 42 


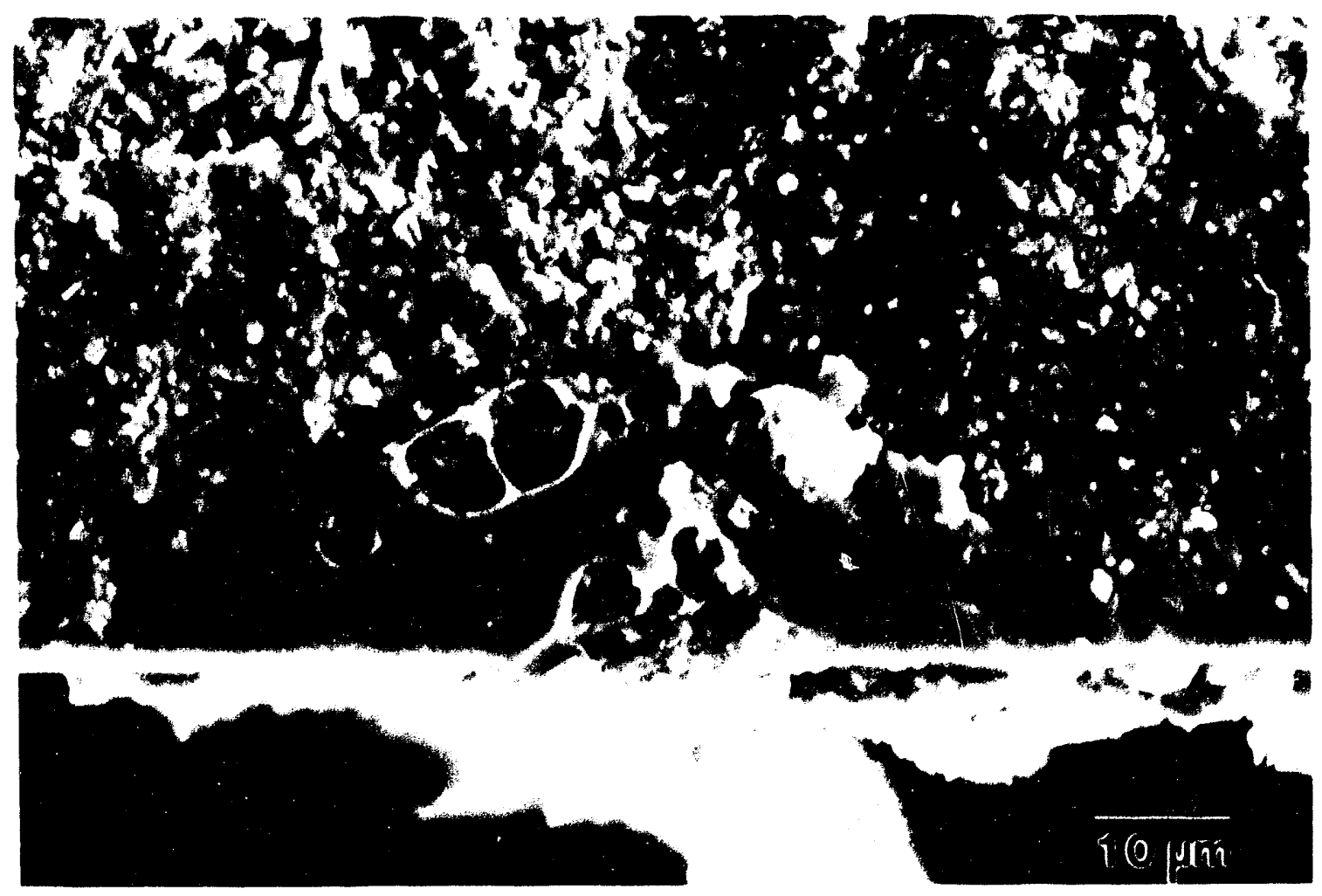

Figure 43 


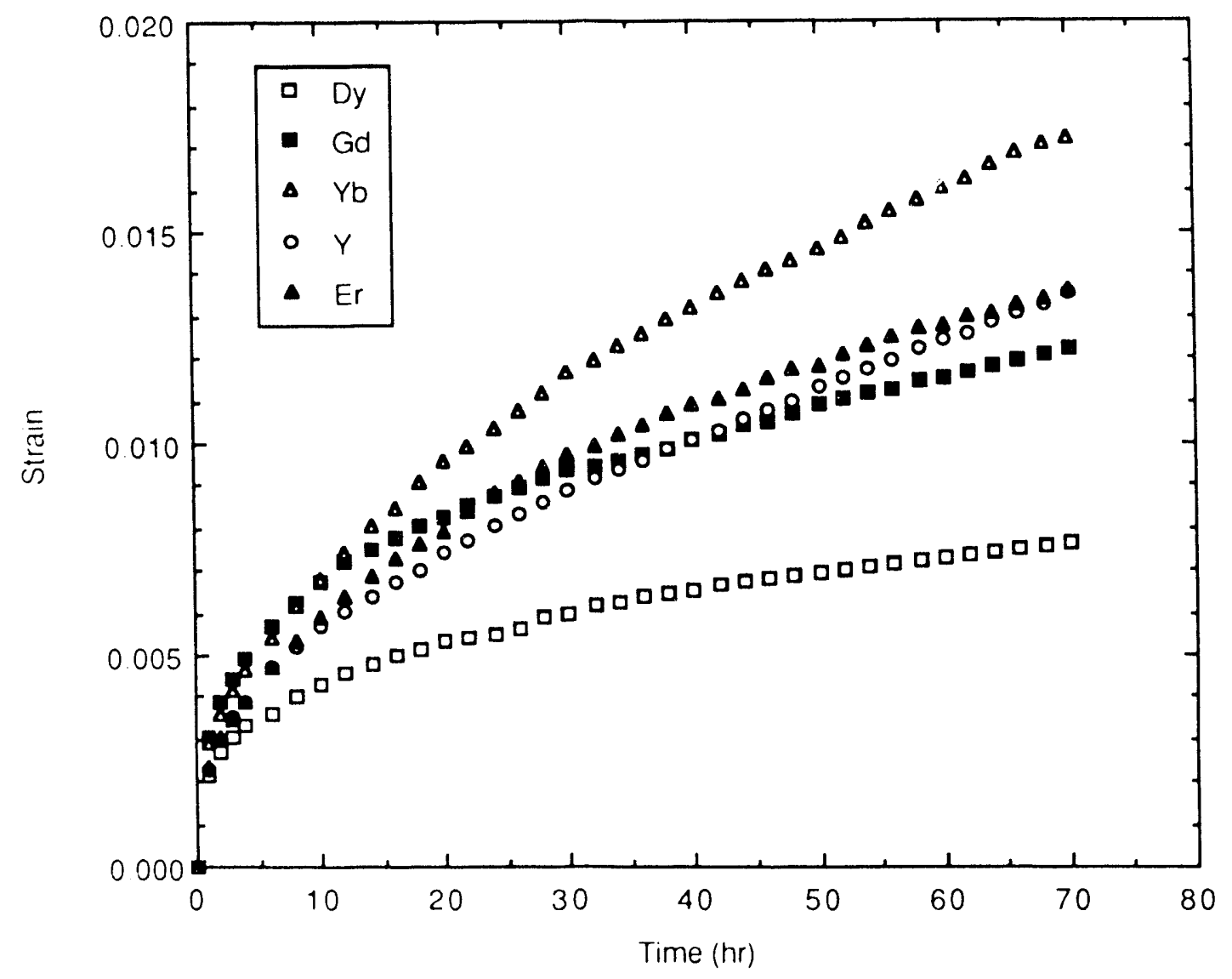

$\dddot{x}: 91^{+} \cdot 150$

Figure 44 


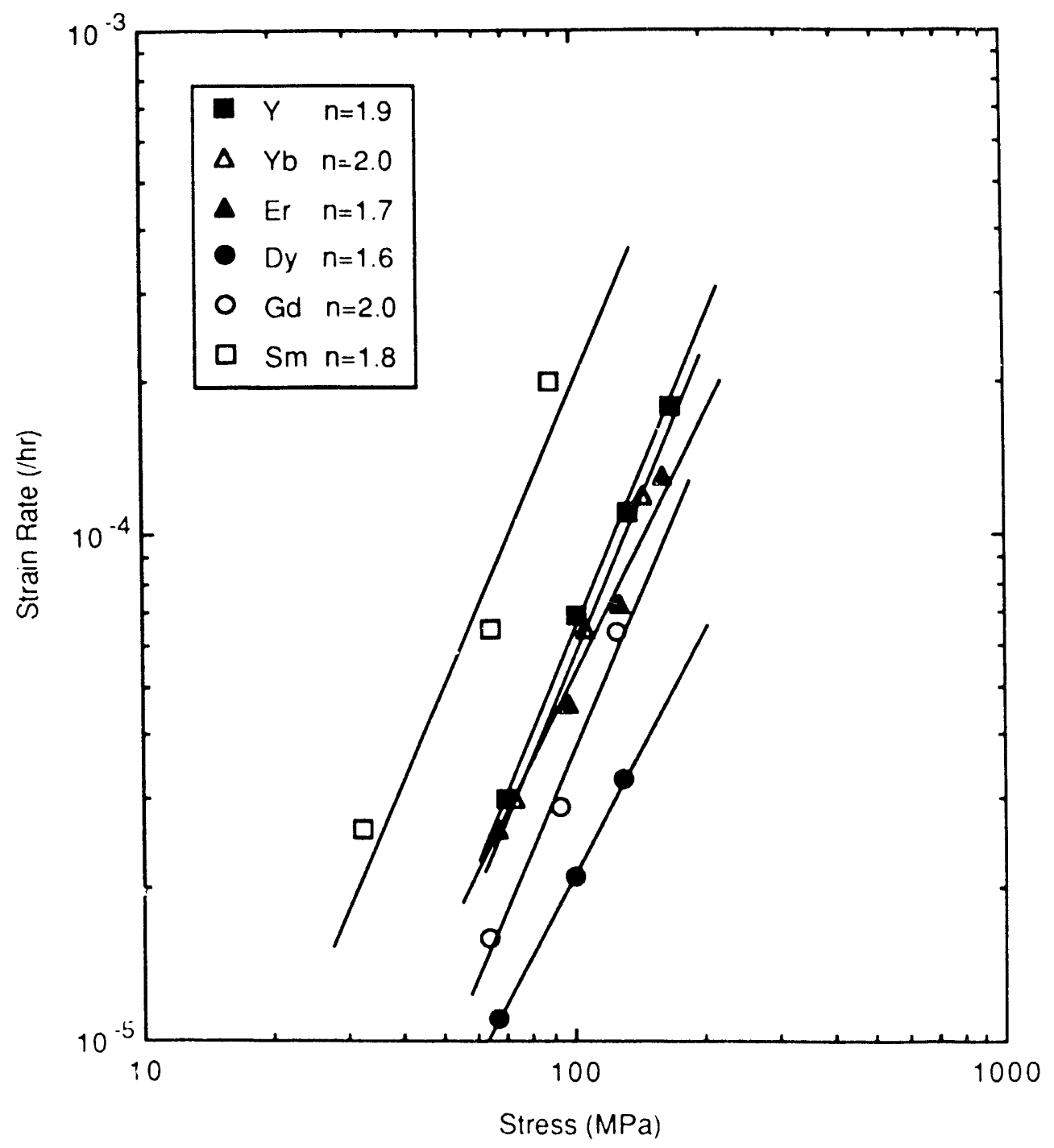

XB1 916.1289

Figure 45 

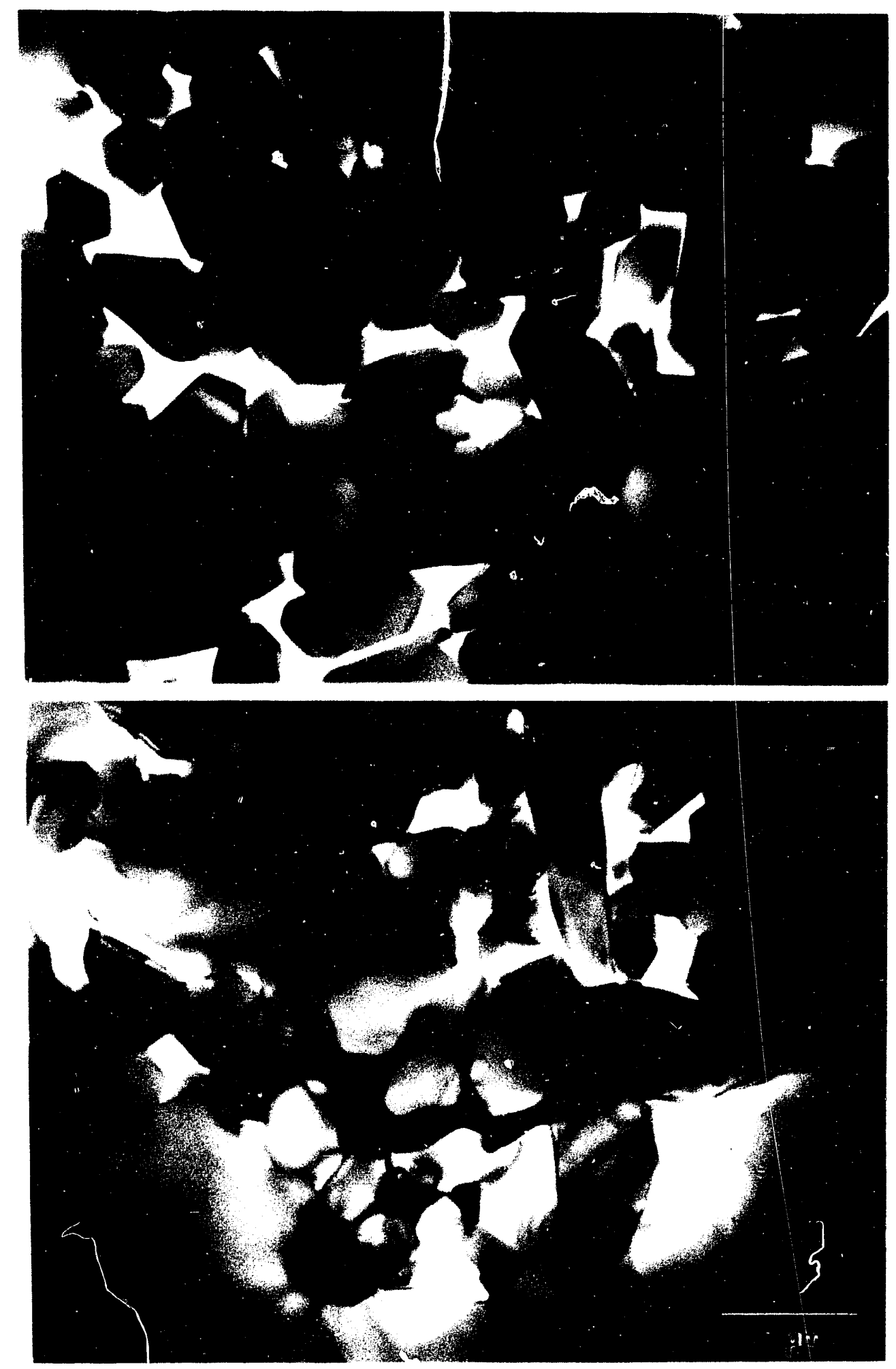

Figure 46 

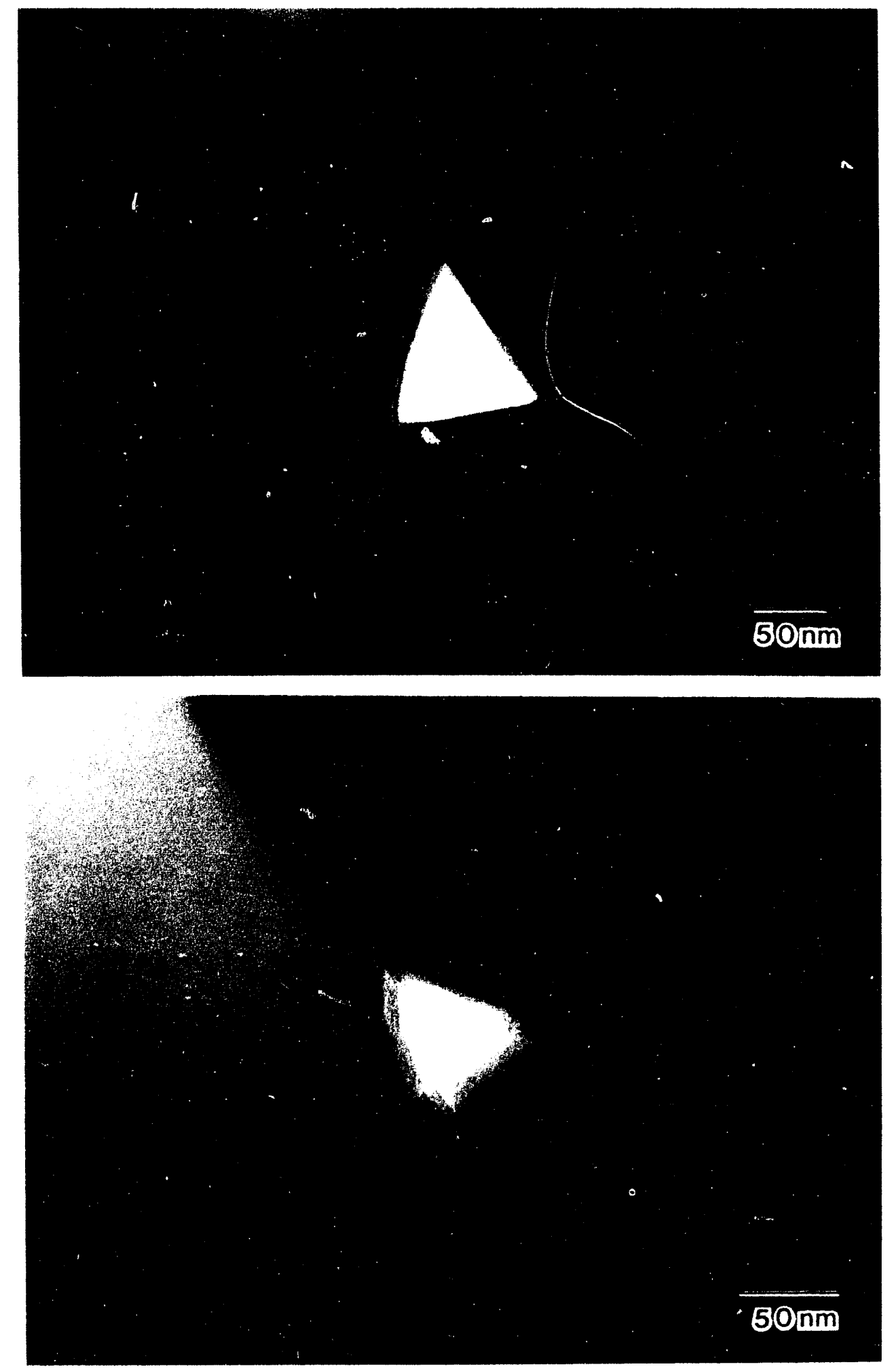

Figure 47 


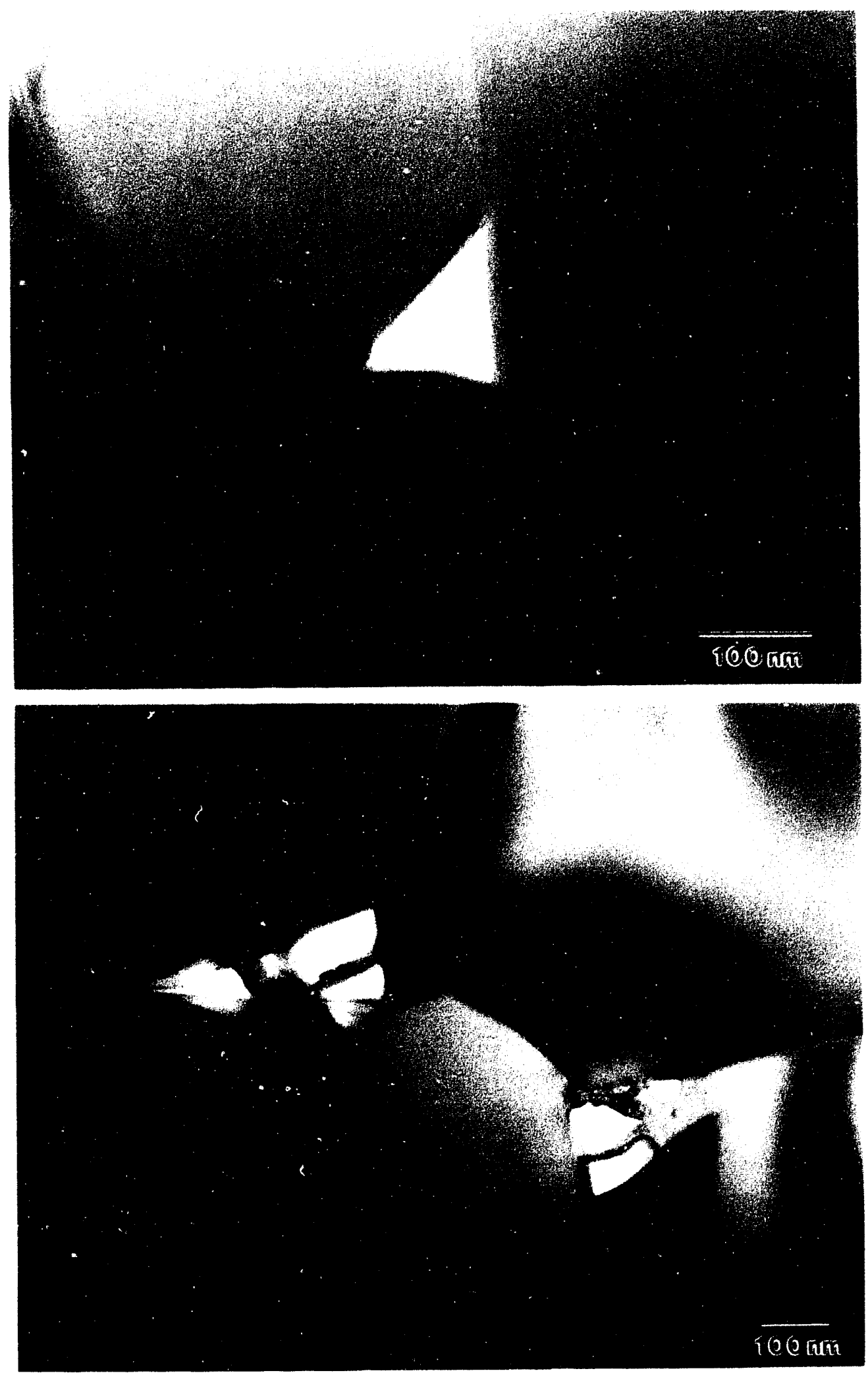

Figuirc 48 

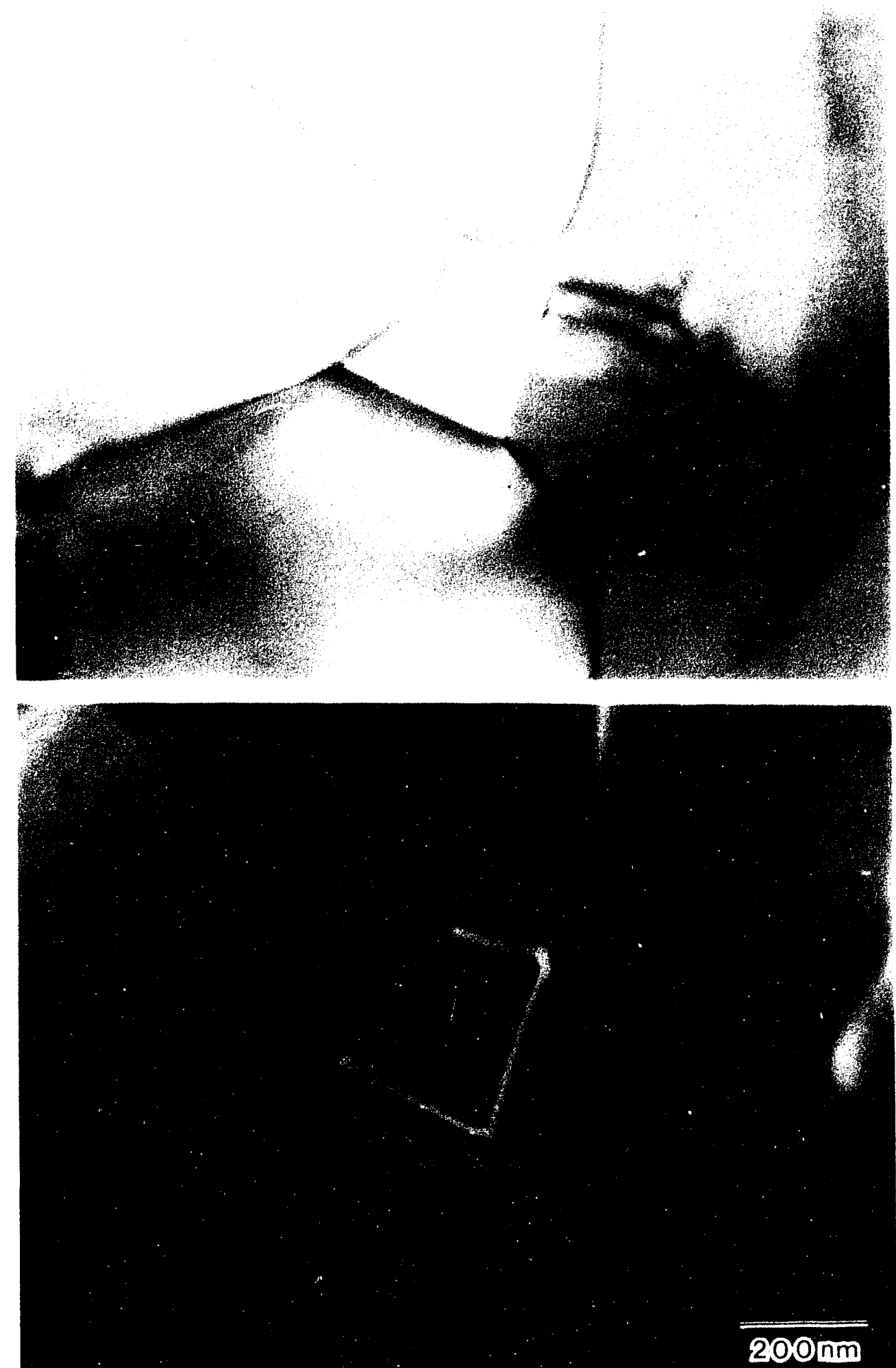

Figure 49 

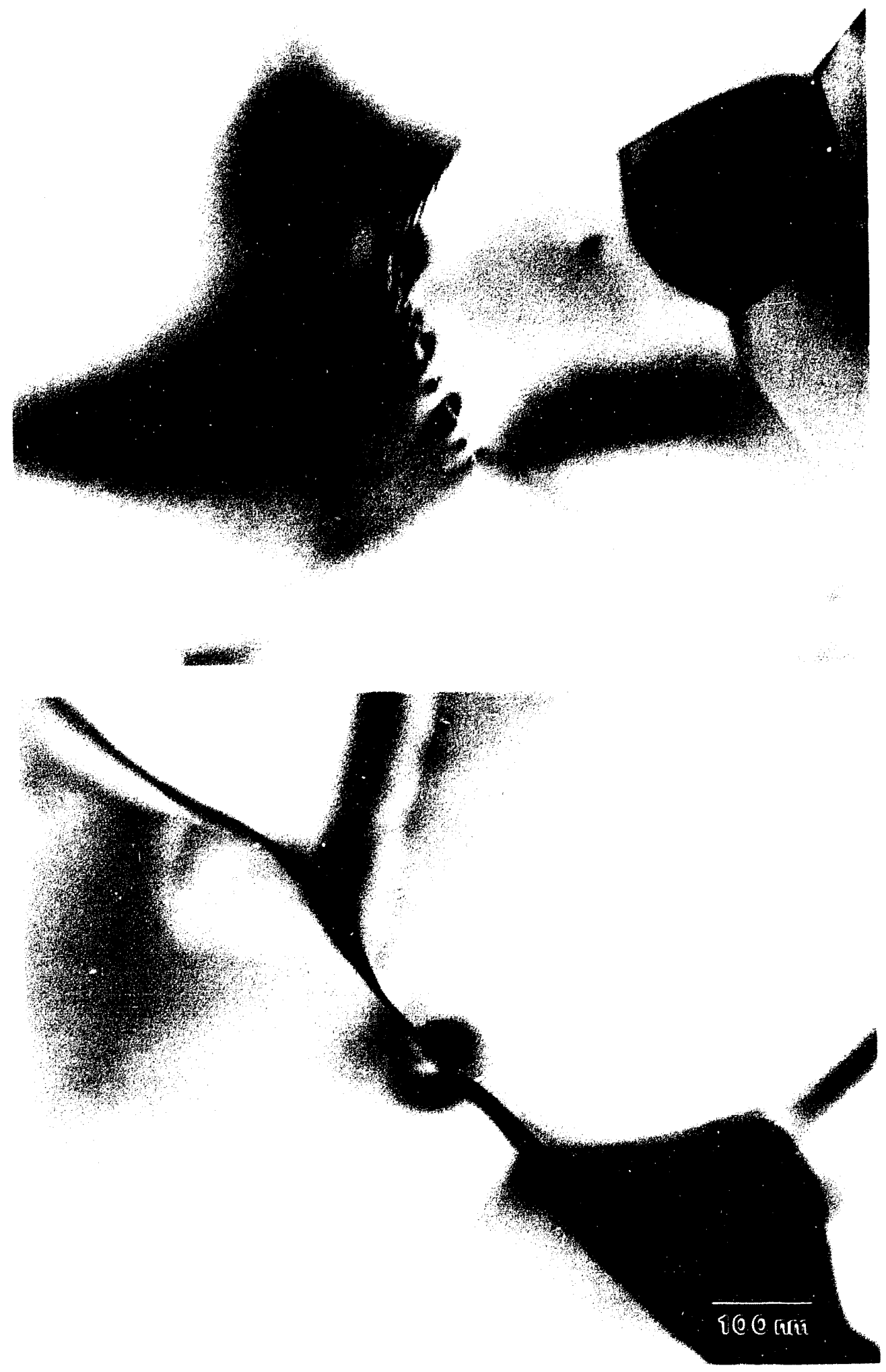

Figure 50 


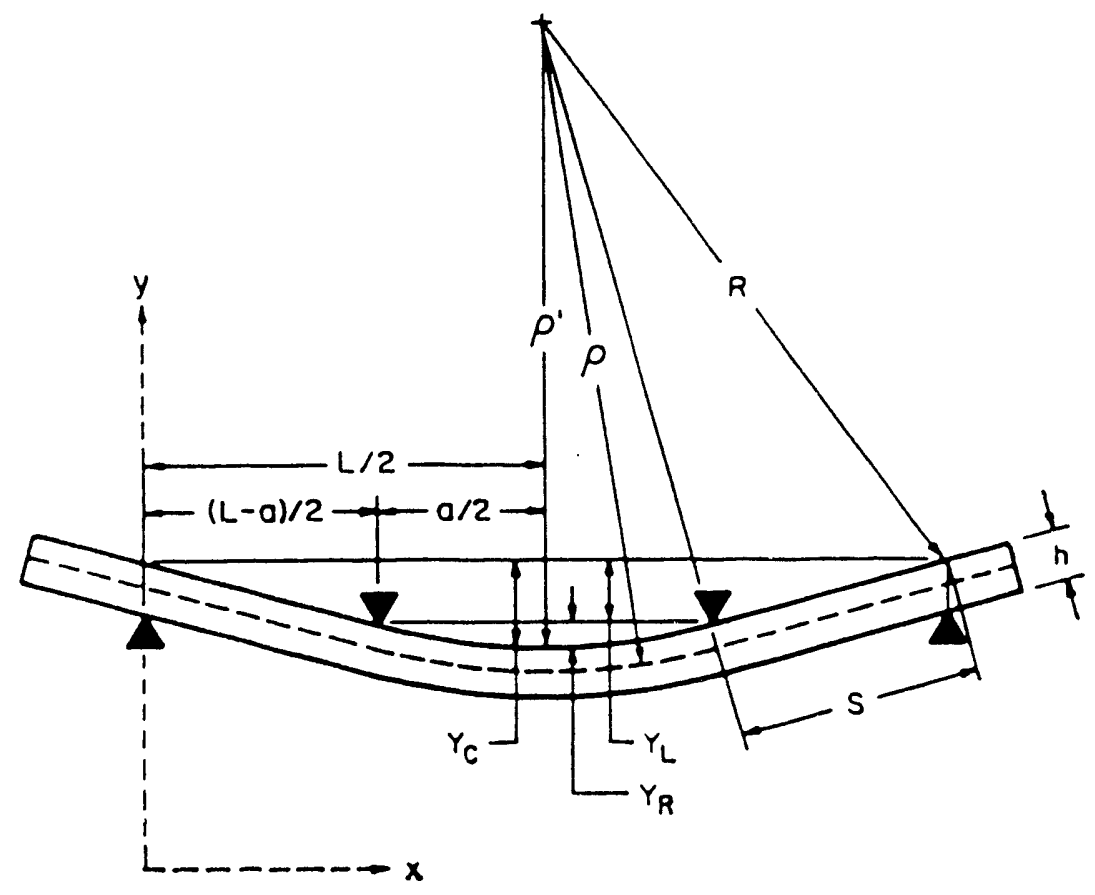

X.BL $\quad 917 \cdot 1607$

Figure 51 

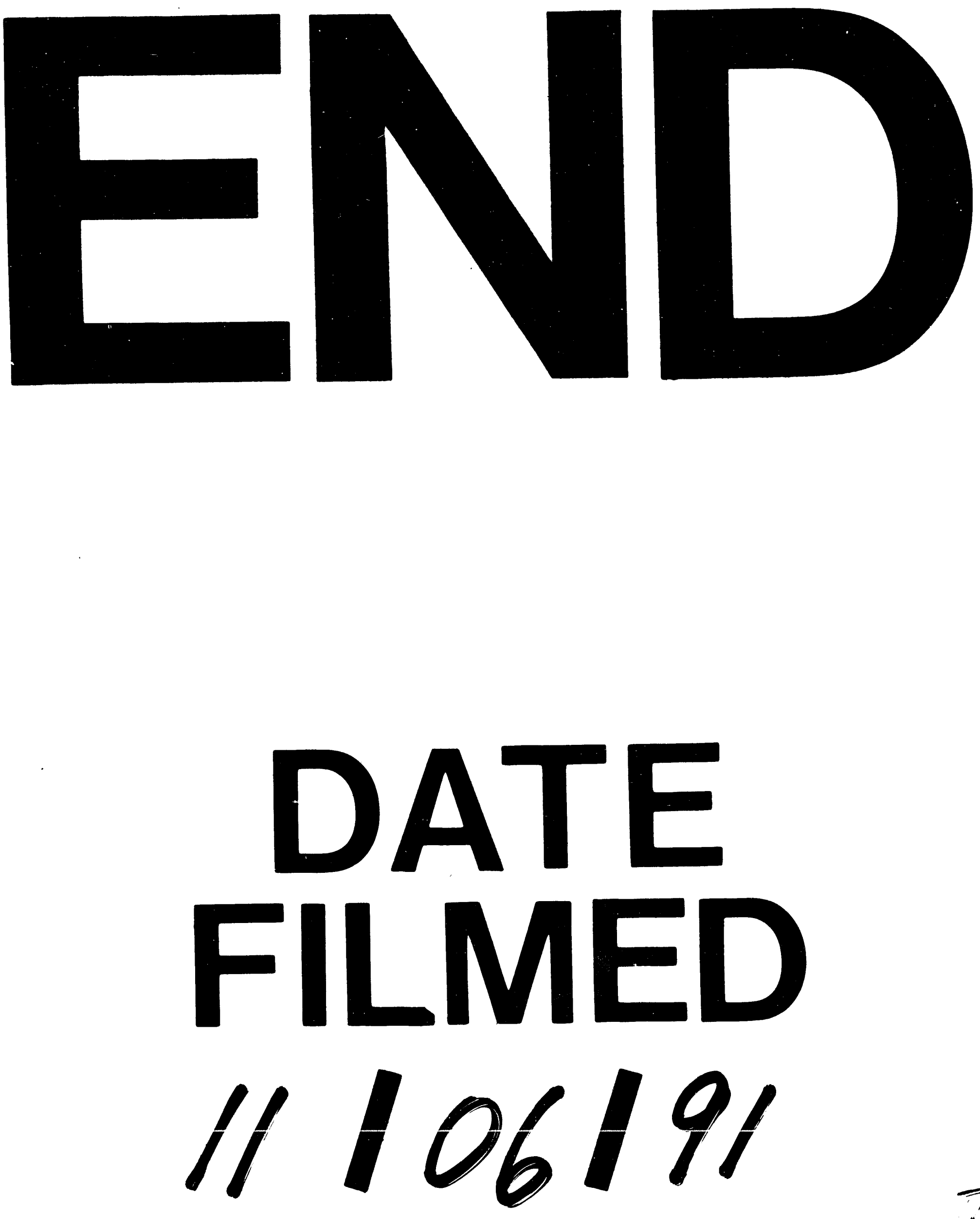

I 
